\title{
Triple oxygen isotope study on the Earth-Moon system
}

\author{
Dissertation \\ zur Erlangung des mathematisch-naturwissenschaftlichen Doktorgrades \\ "Doctor rerum naturalium" \\ der Georg-August-Universität Göttingen \\ im Promotionsprogramm Geoscience \\ der Georg-August University School of Science (GAUSS)
}

\author{
vorgelegt von \\ Meike Fischer \\ aus Hann. Münden
}

Göttingen, 2021 
Betreuungsausschuss

Prof. Dr. Andreas Pack

Abt. Geochemie und Isotopengeologie, GZG, Georg-August-Universität Göttingen

Dr. Paul Hartogh

Max-Planck-Institut für Sonnensystemforschung, Göttingen

Dr. Stefan Peters

Institute of Earth Sciences, University of Iceland, Háskóli Íslands, Island

Mitglieder der Prüfungskommission

Referent: Prof. Dr. Andreas Pack

Abt. Geochemie und Isotopengeologie, GZG, Georg-August-Universität Göttingen

Korreferent: Dr. Paul Hartogh

Max-Planck-Institut für Sonnensystemforschung, Göttingen

Weitere Mitglieder der Prüfungskommission:

Dr. Stefan Peters

Institute of Earth Sciences, University of Iceland, Háskóli Íslands, Island

Prof. Dr. Matthias Willbold

Abt. Geochemie und Isotopengeologie, GZG, Georg-August-Universität Göttingen

Dr. Daniel Herwartz

Institut für Geologie und Mineralogie, Universität zu Köln

Dr. Burkhard Schmidt

Abt. Mineralogie, GZG, Georg-August-Universität Göttingen

Tag der mündlichen Prüfung: 26.04.2021 


\section{Abstract}

Triple oxygen isotope systematics $\left(\Delta^{\prime 17} \mathrm{O}\right)$ are an established tool to trace and classify extraterrestrial material. This tool is used in the field of cosmochemistry to study the genetic link between different Solar System bodies (accretion/planet formation processes) as well as the material flux in the Solar System in the past and at present. To decipher the accretion history of the Earth-Moon system it is crucial to gather information on the nature and provenance of formerly impacted bodies. Triple oxygen isotope systematics can be used to identify the chemical trace of an impacted projectile (impactor signature) in the created impact rock. This approach was so far only applied to constrain the giant impactor, which initiated the Moon formation. A few studies compared the $\Delta^{\prime 17} \mathrm{O}$ of silicate Earth and Moon for this purpose with contrasting results. It is also not yet proven, if the same approach can be applied to late accreted smaller impacts on e.g. the lunar surface. The reconstruction of impactor material based on the $\Delta^{\prime 17} \mathrm{O}$ is challenging. The effect of the impactor material on the $\Delta^{\prime 17} \mathrm{O}$ of the produced impact rock is usually very small, hence it requires high-precision measurements. The definition of a representative $\Delta^{\prime 17} \mathrm{O}$ of the Earth and the Moon is complicated by possible isotopic heterogeneities associated with different Earth mantle materials and lunar lithologies.

This dissertation combines three experimental studies, which aim at (I) setting up a measurement protocol, (II) assessing the possibility of a triple oxygen isotope anomaly affecting the results of feldspar-bearing rocks, constraining the triple oxygen isotope composition of the Earth (III) and the Moon (IV) as well as evaluating if triple oxygen isotopes can be used to reconstruct the impactor material which accreted to the terrestrial mantle (V) and the lunar crust (VI). We are interested in studying the Moon-forming impactor as well as the material delivered during the late accretion (after the Moon formation). If this material was volatile-rich, then it might have been a crucial contribution to the water content of the Earth.

In the first study, we investigated the oxygen isotope fractionation in terrestrial feldsparbearing rocks as a conceptual model of common lunar feldspar-rich lithologies (highland rocks). We characterised their petrography, chemistry and performed oxygen isotope measurements on mineral separates. We studied the equilibrium fractionation behaviour between anorthite-rich plagioclase and other co-genetic minerals. The study revealed that there is no direct indication for an oxygen isotope anomaly connected to plagioclase, which would lead to a systematically lower $\Delta^{\prime 17} \mathrm{O}$ in feldspar-bearing terrestrial or lunar rocks. We evaluated different approaches to accurately analyse feldspar using the laser fluorination technique and we discussed alternative explanations for the low $\Delta^{\prime 17} \mathrm{O}$ values of lunar feldspar-rich rocks as reported in the literature.

In the second study, we reassessed the triple oxygen isotope composition of the Earth's post-Archean mantle, and the Archean mantle prior to the late accretion. We deter- 
mined the $\Delta^{\prime 17} \mathrm{O}$ of the post-Archean mantle with improved precision based on a comprehensive sample set of subcontinental and suboceanic lithospheric mantle peridotites: $-51.6 \pm 1.1 \mathrm{ppm}\left(1 \sigma, \lambda=0.528\right.$, relative to San Carlos olivine: $\left.\Delta^{\prime 17} \mathrm{O}=-51.8 \mathrm{ppm}\right)$. We compared this value with the $\Delta^{\prime 17} \mathrm{O}$ of ultramafic rocks from the Eoarchean Itsaq Gneiss Complex (IGC) and the Mesoarchean Fiskefjord region in southwest Greenland, whose mantle source did not incorporate the full amount of Earth's late accreted material based on ruthenium $(\mathrm{Ru})$ isotope data. We found no significant $\Delta^{\prime 17} \mathrm{O}$ offset between the post-Archean and the Archean pre-late accretion mantle. This restricts the late accretion contribution to the terrestrial mantle to $\leq 0.12 \%$ of Earth's mass assuming material similar to most carbonaceous chondrites (CM, CV, CO, CK, CR, CH, CB, excluding CI), to $\leq 0.11 \%$ of Earth's mass assuming CM-like material, or to $\leq 1.2 \%$ of Earth's mass assuming CI-like material. A CI-like late accretion is the only option which is in agreement with a larger late accretion contribution, because CI chondrites resemble the Earth in $\Delta^{\prime 17} \mathrm{O}$.

In the third study, we reassessed the triple oxygen isotope composition of the Moon. We determined the $\Delta^{\prime 17} \mathrm{O}$ of the pristine Moon with improved precision based on feldsparrich highland rocks, mare basalts and pyroclastic glass: $-51.2 \pm 0.5 \mathrm{ppm}(1 \sigma, \lambda=0.528$, relative to San Carlos olivine: $\Delta^{\prime 17} \mathrm{O}=-51.8 \mathrm{ppm}$ ). We found that Earth and Moon are identical within $1 \mathrm{ppm}$ in their $\Delta^{\prime 17} \mathrm{O}$. We studied various lunar rock types and found no indication for the discussed lithology-dependent $\Delta^{\prime 17} \mathrm{O}$ variations (e.g. no systematically lower $\Delta^{\prime 17} \mathrm{O}$ values of the highland rocks). However, the $\Delta^{\prime 17} \mathrm{O}$ of impact-influenced lunar rocks (soils, impact melt rocks and breccias) deviates from the pristine lunar $\Delta^{\prime 17} \mathrm{O}$. We conclude that impactor signatures can be traced using triple oxygen isotope systematics. The oxygen isotope data of Apollo 16 and Apollo 17 impact rocks is resolvable with a carbonaceous chondrite (CC, exception $\mathrm{CI}$ )-like or primitive chondrite-like late accretion contribution to the lunar crust.

Our studies reveal no trace of the Moon-forming impactor by means of triple oxygen isotopes, which implicates either a similar isotopic composition of the impactor and the proto-Earth, or particular impact conditions that suppressed an initial heterogeneity (e.g. high-energy impact). We found no indication for lithology-dependent $\Delta^{\prime 17} \mathrm{O}$ variations in lunar rocks, which would affect this conclusion (e.g. a feldspar-specific isotope anomaly). Our findings concerning late accreted material to the terrestrial mantle and the lunar crust support the concept of a heterogeneous accretion of the Earth and a late delivery of volatile-rich material. We resolved, for the first time, impactor signatures in the triple oxygen isotope composition of lunar impact rocks. 


\section{Kurzfassung}

Die Sauerstoffisotopen Systematik $\left(\Delta^{\prime 17} \mathrm{O}\right)$ ist eine etablierte Technik zum Aufspüren und Klassifizieren von extraterrestrischem Material. In der Kosmochemie wird diese Technik genutzt, um die Entstehung unterschiedlicher Körper (Akkretions- und Planetenbildungsprozesse), sowie den Materiefluss im Sonnensystem in Vergangenheit und Gegenwart zu studieren. Um die Akkretionsgeschichte des Erde-Mond Systems zu verstehen, müssen wir Informationen über die Natur und Herkunft von ehemalig akkretierenden Körpern sammeln. Mit Hilfe der Sauerstoffisotopen Systematik kann die chemische Spur eines einschlagenden Projektils (Impaktorsignatur) im erzeugten Impaktgestein identifiziert werden. Bisher wurde dieses Verfahren nur genutzt, um den riesigen Einschlagsköper näher zu bestimmen, der die Mondbildung einleitete. Einige Studien haben den $\Delta^{\prime 17} \mathrm{O}-$ Wert der silikatischen Erde und des silikatischen Mondes für diesen Zweck verglichen mit unterschiedlichem Ergebnis. Es wurde ebenfalls noch nicht bewiesen, ob dieses Verfahren auch auf spätere, kleinere Einschläge in die Mondoberfläche angewendet werden kann. Die Rekonstruktion des Impaktormaterials mittels des $\Delta^{\prime 17} \mathrm{O}$-Werts ist anspruchsvoll. Die Auswirkung des exogenen Materials auf den $\Delta^{\prime 17} \mathrm{O}$-Wert des erzeugten Impaktgesteins sind überlicherweise sehr klein und daher sind Hochpräzisionsmessungen nötig. Die Ermittlung eines repräsentativen $\Delta^{\prime 17} \mathrm{O}$-Werts der Erde und des Mondes wird erschwert durch mögliche $\Delta^{\prime 17} \mathrm{O}$-Heterogenitäten in verschiedenen Erdmantel- und Mondgesteinen.

Diese Dissertation umfasst drei experimentelle Studien, die darauf abzielen (I) ein Messprotokoll zu erstellen, (II) die Möglichkeit einer Sauerstoffisotopenanomalie einzuschätzen, die die Ergebnisse Feldspat führender Gesteine beeinflusst, (III) die Sauerstoffisotopenzusammensetzung der Erde und (IV) des Mondes zu bestimmen, sowie zu ermitteln, ob die Sauerstoffisotopen Systematik zur Rekonstruktion des Impaktormaterials verwendet werden kann, das dem Erdmantel und der Mondkruste hinzugefügt wurde. Wir interessieren uns für den Mond-bildenden Einschlagskörper, sowie für das Material, das während der späten Akkretion geliefert wurde (die Phase nach der Mondbildung). Wenn dieses Material reich an volatilen Elementen war, könnte es einen wesentlichen Beitrag zum Wassergehalt der Erde dargestellt haben.

In der ersten Studie, untersuchten wir die Sauerstoffisotopen-Fraktionierung in terrestrischen, Feldspat führenden Gesteinen als konzeptuelles Modell für die weitverbreiteten Feldspat-reichen Mondgesteine (Hochlandgesteine). Wir charakterisierten ihre Petrographie, Chemie und führten Sauerstoffisotopen Messungen an Mineralseparaten durch. Wir untersuchten die Gleichgewichtsfraktionierung zwischen Anorthit-reichem Plagioklas und den kogenetischen mafischen Mineralen. Die Studie zeigte, dass es keinen direkten Hinweis darauf gibt, dass Plagioklas eine Sauerstoffisotopenanomalie aufweist, die zu systematisch niedrigeren $\Delta^{\prime 17} \mathrm{O}$-Werten von Feldspat-reichen Erd- und Mondgesteinen 
führen würden. Wir untersuchten unterschiedliche Verfahren zur akkuraten Analyse von Feldspat mit der Methode der Laser Fluorinierung und diskutierten alternative Erklärungen für die in the Literatur aufgeführten niedrigen $\Delta^{\prime 17} \mathrm{O}$-Werte von Feldspat führenden Mondgesteinen.

In der zweiten Studie, bestimmten wir die Sauerstoffisotopenzusammensetzung des post-Archaischen Erdmantels und des Archaischen Mantels vor der späten Akkretion. Wir bestimmten den $\Delta^{\prime 17} \mathrm{O}$-Wert des post-Archaischen Mantels mit verbesserter Präzision, basierend auf einem umfangreichen Probensatz aus subkontinentalen und subozeanischen, lithosphärischen Mantelperidotiten: $-51.6 \pm 1.1 \mathrm{ppm}(1 \sigma, \lambda=0.528$, relativ zu San Carlos Olivin: $\left.\Delta^{\prime 17} \mathrm{O}=-51.8 \mathrm{ppm}\right)$. Wir verglichen diesen Wert mit dem $\Delta^{\prime 17} \mathrm{O}$ von ultramafischen Gesteinen aus dem Eoarchaischen Itsaq Gneiss Komplex (IGC) und der Mesoarchaischen Fiskefjord Region im Südwesten Grönlands, deren Mantelquellen nicht die volle Menge des spät-akkretierten Materials enthielten basierend auf Ruthenium $(\mathrm{Ru})$ Isotopen Daten. Wir fanden keinen signifikanten Unterschied zwischen dem postArchaischen und dem Archaischen Mantel vor der späten Akkretion. Dies begrenzt den Anteil der späten Akkretion auf $\leq 0.12 \%$ der Erdmasse, wenn angenommen wird, dass das Material den meisten kohligen Chondriten ähnelte (CM, CV, CO, CK, CR, CH, CB außer CI), auf $\leq 0.11 \%$ der Erdmasse berücksichtig man nur CM-ähnliches Material, oder auf $\leq 1.2 \%$ der Erdmasse berücksichtig man nur CI-ähnliches Material. Nur eine Akkretionskomponente dominiert durch CI Chondriten erlaubt einen höheren Anteil, weil CI Chondrite der Erde im $\Delta^{\prime 17} \mathrm{O}$ gleichen.

In der dritten Studie, untersuchten wir die Sauerstoffisotopenzusammensetzung des Mondes. Wir bestimmten den $\Delta^{\prime 17} \mathrm{O}$ des ursprünglichen Mondes mit verbesserter Präzision basierend auf Feldspat-reichen Hochlandgesteinen, Mare Basalten und pyroklastischen Gläsern: $-51.2 \pm 0.5 \mathrm{ppm}\left(1 \sigma, \lambda=0.528\right.$, relativ zu San Carlos Olivin: $\Delta^{\prime 17} \mathrm{O}=$ $-51.8 \mathrm{ppm}$ ). Wir fanden, dass Erde und Mond innerhalb eines $1 \mathrm{ppm}$ identisch sind im $\Delta^{\prime 17} \mathrm{O}$. Wir untersuchten unterschiedliche Gesteinstypen des Mondes und fanden keinen Hinweis für die diskutierten Lithologie-abhängigen $\Delta^{\prime 17} \mathrm{O}$-Variationen. Jedoch weicht der $\Delta^{\prime 17} \mathrm{O}$-Wert von Impaktgesteinen (Böden, Impakt-schmelzgesteine und -breckzien) vom ursprünglichen $\Delta^{\prime 17} \mathrm{O}$ des Mondes ab. Wir schlussfolgern, dass Impaktorsignaturen tatsächlich mit Hilfe der Sauerstoffisotopen Systematik aufgelöst werden können. Unsere Daten von Apollo 16 und 17 Impaktgesteinen sind vereinbar mit einer späten Akkretionskomponente zur Mondkruste, die kohligen Chondriten ähnelt (Außnahme: CI) oder primitiven Achondriten.

Während unserer Studien fanden wir keine auflösbare Spur des Mond-bildenen Einschlagskörpers mittels Sauerstoffisotopen Systematik. Dies impliziert entweder eine gleiche Isotopenzusammensetzung des Einschlagkörpers und der Proto-Erde, oder spezielle Einschlagsbedingungen, die die anfänglichen Heterogenitäten auflösten (z.B. durch einen hoch-energetischen Einschlag). Wir fanden keinen Hinweis für Lithologie-abhängige $\Delta^{\prime 17} \mathrm{O}$-Variationen, die diese Schlussfolgerungen erschweren würden (z.B. eine Feldspatspezifische Sauerstoffisotopenanomalie). Unsere Befunde bezüglich des spät-akkretierten Materials zum Erdmantel und der Mondkruste unterstützen das Konzept der heterogenen Akkretion der Erde und der späten Ankunft volatil-reichen Materials. Wir wiesen zum ersten mal Impaktorsignaturen mit Hilfe der Sauerstofffisotopen in Mond-Impaktgesteinen nach. 


\section{Contents}

Abstract

Kurzfassung iii

$\begin{array}{ll}\text { List of abbreviations ix } & \text { ix }\end{array}$

List of figures $\quad$ xiv

List of tables $\quad$ xvi

1 Introduction $\quad 1$

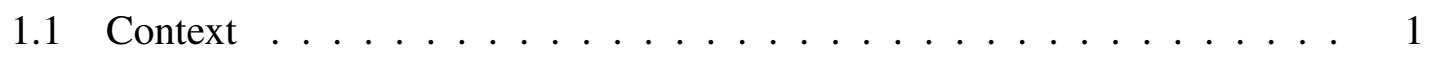

1.2 The Earth-Moon system - a history of accretion and impacts . . . . . 2

1.2.1 Proto-Earth formation . . . . . . . . . . . . 2

1.2.2 Moon formation ................ 3

1.2.3 Late accretion to the Earth-Moon system . . . . . . . . . 5

1.3 Oxygen isotope systematics . . . . . . . . . . . . . . . 7

1.3.1 Basic definitions . . . . . . . . . . . . . . 7

1.3.2 Mass-dependent isotope fractionation . . . . . . . . . . . 8

1.3.3 Mass-independent isotope fractionation . . . . . . . . . . . 9

1.4 Triple oxygen isotopes as a tool for the reconstruction of the material flux in the Solar System . . . . . . . . . . . . . . . . . . 12

1.4.1 Oxygen in the Solar System . . . . . . . . . . . . . . . 12

1.4.2 Triple oxygen isotope variations in the Solar System . . . . . . . 12

1.4.3 Oxygen isotopes as tracer of impactor signatures . . . . . . . 16

1.5 Aim of the dissertation . . . . . . . . . . . . . . . 18

2 Material 19

2.1 Terrestrial feldspar-rich rocks . . . . . . . . . . . . . . . . . . 19

2.2 Terrestrial mantle rocks . . . . . . . . . . . . . . . . 20

2.3 Lunar rocks . . . . . . . . . . . . . . . . . . . 22

3 High-precision triple oxygen isotope measurements of silicates 25

3.1 Laser fluorination technique . . . . . . . . . . . . . . . . . 25

3.2 Stable isotope ratio mass spectrometry . . . . . . . . . . . . . . . . 28

3.3 Standard normalisation . . . . . . . . . . . . . . . . . . . . 29

3.4 Corrections . . . . . . . . . . . . . . . . . . . . . . 29 
3.5 Analytical precision . . . . . . . . . . . . . . 30

4 Triple oxygen isotope fractionation in feldspar-rich rocks 31

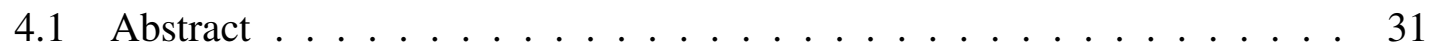

4.2 Introduction . . . . . . . . . . . . . . . 31

4.3 Samples and methods . . . . . . . . . . . . . . . . 32

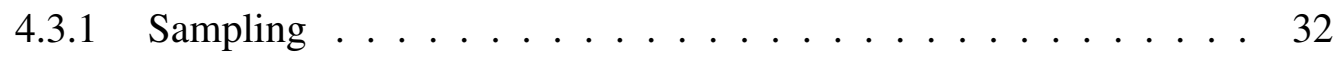

4.3.2 Petrographic examination ..................... 34

4.3.3 Electron probe micro analyses (EPMA) . . . . . . . . . . . 34

4.3 .4 Oxygen isotope analyses . . . . . . . . . . . . . . . 34

4.4 Results . . . . . . . . . . . . . . . . . . . . 34

4.4.1 Petrography ........................ 34

4.4 .2 Mineral chemistry . . . . . . . . . . . . . . . . . . . . 37

4.4 .3 Stable isotopes . . . . . . . . . . . . . 41

4.5 Discussion . . . . . . . . . . . . . . . . . 41

4.5.1 Methodical aspects concerning the laser fluorination of feldspar . 41

4.5.2 Triple oxygen isotope fractionation between feldspar and associated minerals . . . . . . . . . . . . . . . . . 44

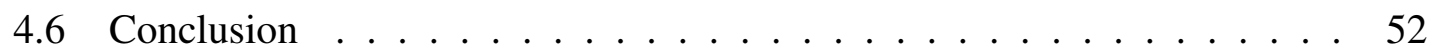

5 Tight bounds on missing late veneer in early Archean peridotite from triple oxygen isotopes $\quad 53$

5.1 Abstract ............................. 53

5.2 Introduction . . . . . . . . . . . . . . . . 54

5.2.1 Missing late veneer in early Archean mantle domains . . . . . . . 54

5.2.2 Potential of studying triple oxygen isotope ratios . . . . . . . . 54

5.3 Samples and methods . . . . . . . . . . . . . . . . 55

5.4 Results . . . . . . . . . . . . . . . . . . . . . 55

5.5 Discussion and conclusion $\ldots \ldots \ldots \ldots \ldots$

5.5 .1 Effects of fluid-rock reactions . . . . . . . . . . . 57

5.5.2 Implications for missing late veneer . . . . . . . . . . . . 57

6 Tracing impactor signatures in lunar rocks using triple oxygen isotope systematics

6.1 Abstract ............................. 61

6.2 Introduction . . . . . . . . . . . . . . . . . . 61

6.3 Samples and methods . . . . . . . . . . . . . . . . . 62

6.4 Results . . . . . . . . . . . . . . . . . 63

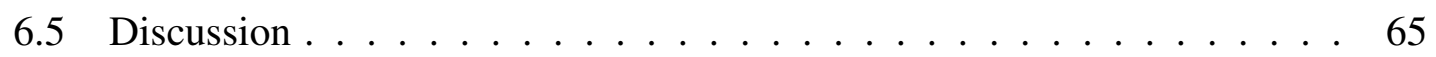

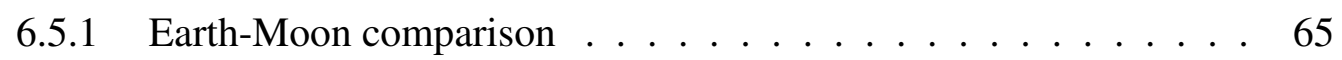

6.5.2 The Moon formation . . . . . . . . . . . . . . . 65

6.5.3 Impact-dependent $\Delta^{\prime 17} \mathrm{O}$ variations . . . . . . . . . . . 66

6.5.4 Impactor reconstruction (mixing model) . . . . . . . . . . 67

6.6 Conclusion . . . . . . . . . . . . . . . . . . . 69 
7 Reconstructing the provenance of Solar System bodies accreted to the Earth$\begin{array}{ll}\text { Moon system by means of oxygen isotope systematics } & 71\end{array}$

7.1 The Moon-forming impactor . . . . . . . . . . . . . . . . . 71

7.2 The late accretion contribution to the Earth-Moon system . . . . . . . . . 74

8 Summary, conclusions and outlook $\quad 77$

8.1 Summary and conclusions . . . . . . . . . . . . . . . 77

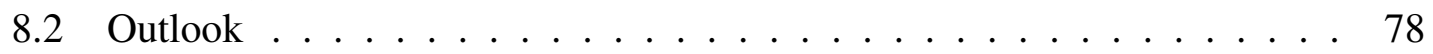

$\begin{array}{ll}\text { Bibliography } & 81\end{array}$

A Supplementary information: High-precision triple oxygen isotope measure$\begin{array}{lr}\text { ments of silicates } & 101\end{array}$

A.1 Additional figures . . . . . . . . . . . . . . . . . . . . . . 101

A.2 Additional tables . . . . . . . . . . . . . . . . 105

B Supplementary information: Triple oxygen isotope fractionation in feldspar$\begin{array}{lr}\text { rich rocks } & 109\end{array}$

B.1 Analytical methods . . . . . . . . . . . . . . . . . . . . . . 109

B.2 Additional figures . . . . . . . . . . . . . . . . . . . . 111

B.3 Additional tables . . . . . . . . . . . . . . . . . . 130

C Supplementary information: Tight bounds on missing late veneer in early Archean peridotite from triple oxygen isotopes 139

C.1 Sample suite . . . . . . . . . . . . . . . . . . . . . . . . 139

C.2 Analytical methods . . . . . . . . . . . . . . . . . . . . . 140

C.3 Determining the bulk silicate Earth $\Delta^{\prime 17} \mathrm{O}$ value . . . . . . . . . . . . 141

C.4 Mass balance calculations for missing late veneer . . . . . . . . . . . . 142

C.5 Additional tables . . . . . . . . . . . . . . . . . . . . . 143

D Supplementary information: Tracing impactor signatures in lunar rocks us$\begin{array}{lr}\text { ing triple oxygen isotopes } & 147\end{array}$

D.1 Sample suite . . . . . . . . . . . . . . . . . . . . . . . . . 147

D.2 Analytical methods . . . . . . . . . . . . . . . . . 151

D.3 Analysis of rock fractions . . . . . . . . . . . . . . . . . 152

D.3.1 Pyroclastic green glass . . . . . . . . . . . . . . . 152

D.3.2 Impact rocks . . . . . . . . . . . . . . . . 153

D.4 Determining the $\Delta^{\prime 17} \mathrm{O}$ of the bulk silicate Moon . . . . . . . . . . 155

D.4.1 Lithology-dependent $\Delta^{\prime 17} \mathrm{O}$ variations $\ldots \ldots \ldots \ldots$

D.4.2 Earth-Moon comparison . . . . . . . . . . . . 157

D.5 The late accretion to the lunar crust . . . . . . . . . . . . . 158

D.5.1 Soils . . . . . . . . . . . . . . . . 158

D.5.2 Impact rocks . . . . . . . . . . . . . . . . . . . . . . . . . . . . . . . . . . . . .

D.6 Additional figures . . . . . . . . . . . . . . . . . . . . . . 162

D.7 Additional tables . . . . . . . . . . . . . . . . . 165

$\begin{array}{ll}\text { Acknowledgements } & 175\end{array}$ 
Publications 


\section{List of abbreviations}

$$
\begin{aligned}
& \delta^{*} \mathrm{O} \\
& \delta^{*} \mathrm{O} \\
& \Delta^{\prime * *} \mathrm{O} \\
& { }^{*} R_{s m p} \\
& { }^{*} R_{s t d} \\
& { }^{*} R_{A} \\
& { }^{*} R_{B} \\
& { }^{*} \alpha_{A-B} \\
& \theta \\
& R L \\
& \lambda \\
& \gamma \\
& m \\
& i
\end{aligned}
$$

\section{VSMOW}

$h v$

M

SD

SEM

$N$

Wt.

calc

meas

WR

F
Delta value (\%o) of the heavy isotope ${ }^{*} \mathrm{O}$ Linearised delta value $(\% \circ)$ of the heavy isotope * $\mathrm{O}$ Cap delta value $(\mathrm{ppm})$ of the rare isotope ${ }^{* *} \mathrm{O}$ Isotopic ratio of a sample Isotopic ratio of a reference (standard) material Isotopic ratio of phase $A$ Isotopic ratio of phase $B$ Fractionation factor between phase $A$ and $B$ Triple oxygen isotope fractionation exponent

Reference line Slope of a reference line Intercept of a reference line Slope of a line Intercept of a line Vienna Standard Mean Ocean Water Energy state of light: $h=$ Planck's constant, $v=$ frequency of the light $\mathrm{M}$ represents for instance molecular nitrogen, oxygen or carbon dioxide Standard deviation; in tables: SD or $\pm 1 \sigma$ SD Standard error of the mean; in tables $\pm 1 \sigma$ or $\pm 1 \sigma$ SEM Number Weighted Calculated Measured Whole rock Rock fragments Electron microprobe 
BSE

IRMS

conv.

prem.

GC

TCD

MS-Q

$X_{\text {extr. }}$

T

$p$

I

TFL

CCAM

CAI

AOA

OC

EC

$\mathrm{CC}$

Carb.

$\mathrm{C}^{*}$

NC

$\mathrm{R}$

K

Aca

Lod

Aca, Lod

Win

Bra

Ang

Aub

How

Euc

Dio
Backscattered electron image

Isotope ratio mass spectrometer Conventional laser fluorintation system

Pre-melted

Gas chromatograph

Thermal conductivity detector

Quadrupole mass spectrometer

Excess of components in the extracted sample gas

Temperature

Pressure

Intensity

Terrestrial fractionation line

Carbonaceous chondrite anhydrous mixing line

Calcium, aluminium-rich inclusion

Amoeboid olivine aggregates

Ordinary chondrites

Enstatite chondrites

Carbonaceous chondrites

Carbonaceous

$\mathrm{CB}, \mathrm{CK}, \mathrm{CO}, \mathrm{CR}, \mathrm{CV}, \mathrm{CH}$

Non-carbonaceous

Rumuruti chondrites

Kankangari chondrites

Acapulcoites

Lodranites

Acapulcoite-lodranite clan

Winonaites

Brachinites

Angrites

Aubrites

Howardites

Eucrites

Diogenites 
HED

Mes

Pal

Sher

Nahk

Chass

SNC

Lun.

prim.

diff.

N-A1

N-A2

A-B2

A-B3

Plag

Opx

Cpx

$\mathrm{Ol}$

SC

Mt

$\mathrm{Chr}$

Amph

$\mathrm{Bt}$

Gt

An

$\mathrm{Ab}$

Or

Wo

En

Fs

Ac

Fo

$\mathrm{Fa}$
Howardite-eucrite-diogenite suite

Mesosiderites

Pallasites

Shergottites

Nahklites

Chassignites

Shergottite-nahklite-chassignite clan

Lunar

Primitive

Differentiated

Troctolite

Norite A1

Norite A2

Anorthosite B2

Anorthosite B3

Plagioclase

Orthopyroxene

Clinopyroxene

Olivine

San Carlos olivine

Magnetite

Chromite

Amphibole

Biotite

Garnet

Anorthite

Albite

Orthoclase

Wollastonite

Enstatite

Ferrosilite

Acmite or Aegirine

Forsterite

Fayalite 
$\mathrm{Tp}$

Tephroite

BSE

Bulk silicate Earth

$\oplus$

Earth

LV

Late veneer

PLVM

Pre-late veneer mantle

sp-lhz

Spinel lherzolite

dn

Dunites

IGC

Eoarchean Itsaq Gneiss Complex

MORB

Mid-ocean ridge basalt

OIB

Ocean island basalt

ISB

Isua supracrustal belt

SOISB

South of the Isua supracrustal belt

NUB

Narssaq ultramafic body

U. Nunât

Ujaragssuit Nunât ultramafic body

BSM

Bulk silicate Moon

MB

Lunar mare basalts

HR

Lunar highland rocks

Glass

Lunar pyroclastic glass

KREEP

Soil

IR

$\mathrm{A}^{*}$

$\mathrm{N}$.

Pre-I.

HSE
Lunar potassium-, rare earth-element- and phosphor-rich breccias

Lunar soil

Lunar impact rock

Apollo *=11, 12, 14, 15, 16, 17

Nectarian

Pre-Imbrian

Highly siderophile elements 


\section{List of figures}

1.1 Timeline of the Earth-Moon accretion history . . . . . . . . . . . . 2

1.2 Characteristics of the recent meteorite flux in the Solar System . . . . . . 6

1.3 Oxygen isotope systematics . . . . . . . . . . . . . . . 9

1.4 Illustration of the $\Delta^{\prime 17} \mathrm{O}$ variation in the Solar System . . . . . . . . . 15

2.1 Classification of the gabbro family . . . . . . . . . . . . . . 20

2.2 A map of the Earth and the Moon with additional information concerning the sample sets analysed in the following chapters . . . . . . . . . . 21

3.1 Simplified schematic structure of the $\mathrm{BrF}_{5}$ fluorination line . . . . . . . 26

3.2 Gas matrix of San Carlos olivine and UWG-2 standard materials . . . . 28

3.3 Interference correction of the $\Delta^{\prime 17} \mathrm{O} \ldots \ldots \ldots$

4.1 Images of the studied rock samples . . . . . . . . . . . . . 33

4.2 Thin section images of the studied rock samples . . . . . . . . . . 36

4.3 Compiled EMP line profiles of the troctolite thin section . . . . . . . 38

4.4 Compiled EMP line profiles of the norite A1 and A2 thin section . . . . . 39

4.5 Compiled EMP line profiles of the anorthosite B2 and B3 thin section . . 40

4.6 Experiments concerning the laser fluorination of feldspar . . . . . . . . . 43

$4.7 \Delta-\Delta$ plots of the studied feldspar-rich rock . . . . . . . . . . . . . . 49

$4.8 \Delta^{\prime 17} \mathrm{O}$ vs. $\delta^{18} \mathrm{O}$ of the mineral assemblages of the studied rocks $\ldots \ldots . . \quad 50$

$4.9 \Delta^{\prime 17} \mathrm{O}$ vs. $\delta^{18} \mathrm{O}$ of lunar mare basalts and feldspar-rich lunar rocks . . . 52

5.1 Plots of $\Delta^{\prime 17} \mathrm{O}$ vs. $\delta^{\prime 18} \mathrm{O} \pm 1 \sigma \mathrm{SEM}$ of olivine from ultramafic rocks . . . 56

5.2 Missing late veneer from the Itsaq Gneiss Complex and Fiskefjord mantle relative to the mass of the Earth $\left(\mathrm{M}_{\mathrm{LV}} / \mathrm{M}_{\oplus}\right) \ldots \ldots . \ldots 59$

$6.1 \Delta^{\prime 17} \mathrm{O}$ Caltech-plot of the terrestrial, pristine and impact-influenced lunar rocks ................................ 64

6.2 Mixing model visualisation $-\mathrm{A}) \Delta^{\prime 17} \mathrm{O}$ vs. $\delta^{18} \mathrm{O}$ plot and B) impactor/target rock mixing ratios for a selection of possible impactor types . . . . . . 68

7.1 Plot of $\Delta^{\prime 17} \mathrm{O}$ vs. $\delta^{18} \mathrm{O}$ with kernel density estimate contour and line plots for the pristine lunar, pristine terrestrial, and lunar impact rock samples . 73

A.1 Image of the $\mathrm{BrF}_{5}$ fluorination line . . . . . . . . . . . . . . . 101

A.2 Image of the Thermo Scientific ${ }^{T M} M A T 253^{T M}$ IRMS . . . . . . . . . . 102

A.3 Image of the two-chamber system of the $\mathrm{BrF}_{5}$ fluorination line . . . . . 102 
A.4 Image of the air lock system _ . . . . . . . . . . . . . . 103

A.5 Images of different sample holder types . . . . . . . . . . . . . . 103

A.6 Image of the laser fluorination . . . . . . . . . . . . . . . . 104

B.1 Images of the mineral separates of the studied rocks . . . . . . . . . . 111

B.2 Individual EMP line profiles of the troctolite thin section . . . . . . . 114

B.3 EMP element mappings of the troctolite . . . . . . . . . . . . . . . . 114

B.4 Individual EMP line profiles of the norite A1 thin section . . . . . . . . 117

B.5 EMP element mappings covering an area of the norite A1 thin section . . 117

B.6 EMP element mappings of norite A1 . . . . . . . . . . . . . 118

B.7 Individual EMP line profiles of the norite A2 thin section . . . . . . . 121

B.8 EMP element mappings of norite A2 . . . . . . . . . . . . . . . 121

B.9 Individual EMP line profiles of the anorthosite B2 thin section . . . . . 124

B.10 EMP element mappings of anorthosite B2 . . . . . . . . . . . 125

B.11 Individual EMP line profiles of the anorthosite B3 thin section . . . . . 128

B.12 EMP element mappings of anorthosite B3 . . . . . . . . . . . . . 129

C.1 Mass balance calculations for missing late veneer . . . . . . . . . . . 143

D.1 Images of the pristine lunar sample set . . . . . . . . . . . . . . . . . 149

D.2 Images of the impact-influenced lunar sample set . . . . . . . . . . . 151

D.3 Gas matrix match between the lunar samples and San Carlos olivine . . . 152

D.4 $\Delta^{\prime 17} \mathrm{O}$ vs. $\delta^{18} \mathrm{O}$ of the different green glass subsamples and fractions . . 153

D.5 $\Delta^{\prime 17} \mathrm{O}$ vs. $\delta^{18} \mathrm{O}$ of the different impact rock fractions . . . . . . . . . . 154

D.6 Boxplot $-\Delta^{\prime 17} \mathrm{O}$ vs. lithology . . . . . . . . . . . . . . . 155

D.7 Study comparison concerning lunar green glass . . . . . . . . . . . 156

D.8 The relation between the HSE and $\Delta^{\prime 17} \mathrm{O}$ signatures in lunar impact rocks 160

D.9 $\delta^{18} \mathrm{O}$ literature data on mineral separates from Apollo mission samples . . 162

D.10 $\delta^{18} \mathrm{O}$ of feldspar-rich impact rocks vs. feldspar-rich highland rocks . . . . 163

D.11 Mixing model visualisation — triple oxygen isotope subplots . . . . . . . 164 


\section{List of tables}

4.1 Oxygen isotope composition of the mineral assemblages of the feldsparrich rocks . . . . . . . . . . . . . . . . . . . 41

6.1 Triple oxygen isotope data on lunar rocks $\ldots \ldots \ldots$

A.1 Oxygen isotope data on San Carlos olivine fraction 0215M . . . . . . 105

A.2 Oxygen isotope data on San Carlos olivine fraction 0919 . . . . . . . 106

A.3 Oxygen isotope data on UWG-2 garnet \#180 . . . . . . . . . . 108

A.4 Oxygen isotope data on UWG-2 garnet \#200 . . . . . . . . . . . . . . 108

B.1 EMP data on the plagioclases . . . . . . . . . . . . . 130

B.2 EMP data on the pyroxenes . . . . . . . . . . . . 131

B.3 EMP data on the olivine . . . . . . . . . . . . . . . . . . 132

B.4 EMP data on the magnetite . . . . . . . . . . . . . . . . 132

B.5 EMP data on the chromites . . . . . . . . . . . . . . . . 132

B.6 EMP data on the amphibole . . . . . . . . . . . . . . . . 133

B.7 EMP data on the micas . . . . . . . . . . . . . . . . . 133

B.8 Oxygen isotope data on the mineral assemblages . . . . . . . . . . . 134

B.9 Oxygen isotope data on the feldspar fluorination experiments . . . . . . . 135

B.10 Oxygen isotope data on San Carlos olivine fraction 0215M . . . . . . 136

B.11 Oxygen isotope data on San Carlos olivine fraction 0919 . . . . . . . . . 136

B.12 Oxygen isotope data on UWG-2 garnet . . . . . . . . . . . . . . 137

B.13 Crystallisation temperatures . . . . . . . . . . . . . . 138

B.14 Details concerning the calculated temperatures . . . . . . . . . . 138

B.15 Individual $\theta$ values of the studied mineral pairs $\ldots \ldots . . \ldots 138$

C.1 Oxygen isotope data on olivine in post-Archean mantle peridotites . . . 144

C.2 Triple oxygen isotope data on olivine in Archean ultramafic lenses . . . 145

D.1 Sample list . . . . . . . . . . . . . . . . . . . . . . . . 148

D.2 Oxygen isotope data on lunar green glass subsamples and fractions . . . 153

D.3 Oxygen isotope data on different impact rock fractions . . . . . . . . . . 154

D.4 Oxygen isotope data on San Carlos olivine 0215M . . . . . . . . . . 165

D.5 Oxygen isotope data on San Carlos olivine $0919 \ldots \ldots$. . . . . . . . . . . . . . . . . . 166

D.6 Oxygen isotope data on UWG-2 garnet . . . . . . . . . . . . . . . . . . . . . . . . . . . . . . .

D.7 Oxygen isotope data on lunar mare basalts . . . . . . . . . . . . . . . 168

D.8 Oxygen isotope data on lunar highland rocks . . . . . . . . . . . . . 169 
D.9 Oxygen isotope data on lunar pyroclastic glass . . . . . . . . . . . . . 169

D.10 Oxygen isotope data on lunar KREEP-rich breccias . . . . . . . . . . . 169

D.11 Oxygen isotope data on lunar soil . . . . . . . . . . . . . . . . . 169

D.12 Oxygen isotope data on lunar impact rocks . . . . . . . . . . . . . 170

D.13 $\delta^{18} \mathrm{O}$ estimates of selected impacts rocks . . . . . . . . . . . . . . 170

D.14 Mixing model input - impact rock data . . . . . . . . . . . . . 171

D.15 Mixing model input - meteorite data . . . . . . . . . . . . 171

D.16 Mixing model output - fit between the mixing trend and impact rock data 172

D.17 Mixing model output - average mixing ratios . . . . . . . . . . . . . 173 


\section{Introduction}

\subsection{Context}

The Earth is the only habitable planet in the Solar System. A complex and cohesive set of features is the reason why this planetary system can sustain life. It is a major goal of science to understand these features and their interplay. It will help us to understand the origin of life on Earth, and to better constrain the environments where life might have evolved beyond Earth and our Solar System. The question: 'How did Earth become a habitable planet?' can only be addressed by interdisciplinary approaches and is an effort of many. This dissertation focuses on two major aspects: the origin of the Moon and the origin of water on Earth. The existence of the Moon, as satellite of the Earth, is crucial for making Earth a habitable planet. The Moon is not only affecting life on Earth by illuminating the night or creating tides, it also stabilises the rotational axis of the Earth and by this the Earth's seasons and climate (e.g. Canup 2004a). Although the Moon is fundamental for life on Earth, its origin is still debated (e.g. Wood 1986). Another crucial requirement for a habitable Earth is the availability of liquid water, which is a indisputable pre-requisite for the evolution of life. However, Earth contains more water than expected for the third of the inner planets and its proximate position to the Sun. The origin of the vast volume of water available on Earth is still enigmatic (e.g. Peslier et al. 2017). Both, the origin of the Moon and the origin of water on Earth are directly linked to the accretion history of the Earth-Moon system. To constrain the involved processes, we need to research on the material flux in the Solar System, and in particular the timing and geochemical characteristics of the material delivered to Earth.

Since the Apollo and Luna missions (1959-1976) not only terrestrial but also lunar samples were made available to gain deeper knowledge on our planet-satellite system (e.g. Heiken et al. 1991). It might seem contra-intuitive to study the Moon to learn more about the Earth, but the Moon offers an older and less disturbed rock record compared to the geologically active planet Earth. By studying lunar rocks we can achieve a new, complementing perspective on the accretion processes of both bodies (e.g. Joy et al. 2016). The approach of the present study is to characterise triple oxygen isotope systematics of the Earth-Moon system. Striking advantages of this approach are: (I) oxygen is abundant in the Solar System and a major component in minerals and rocks, (II) only little material is required per isotope analysis, which is crucial considering the small, available extraterrestrial sample volumes, (III) as known from the meteorite record, the triple oxygen isotope variation in the Solar System is huge. At the same time, the analytical precision is exceptionally high, making this approach very sensitive for identifying and characterising different materials in the Solar System. 


\subsection{The Earth-Moon system - a history of accretion and impacts}

The history of the Earth-Moon system is a history of accretion and impacts. Most of the proto-Earth's mass was accreted within a short time after the Solar System formation (see subsec. 1.2.1). A giant impact initiated the Moon formation, after which $~ 99 \%$ of the Earth's and the Moon's material was accumulated (see subsec. 1.2.2). The final stage of accretion, called 'late accretion', comprises all material which accreted after the Moon-forming event (see subsec. 1.2.3).

Impacts are a fundamental process in the Solar System and occur on all planetary bodies. The impact scales range from collisions of planetary embryos to micrometeorite bombardment on planetary surfaces ('impact gardening'). The number, size, shape and rocks of impact craters can be studied to learn more about the age of planetary surfaces, the properties of planetary crusts and the nature of impactors (for more details see Heiken et al. 1991, Joy et al. 2016).

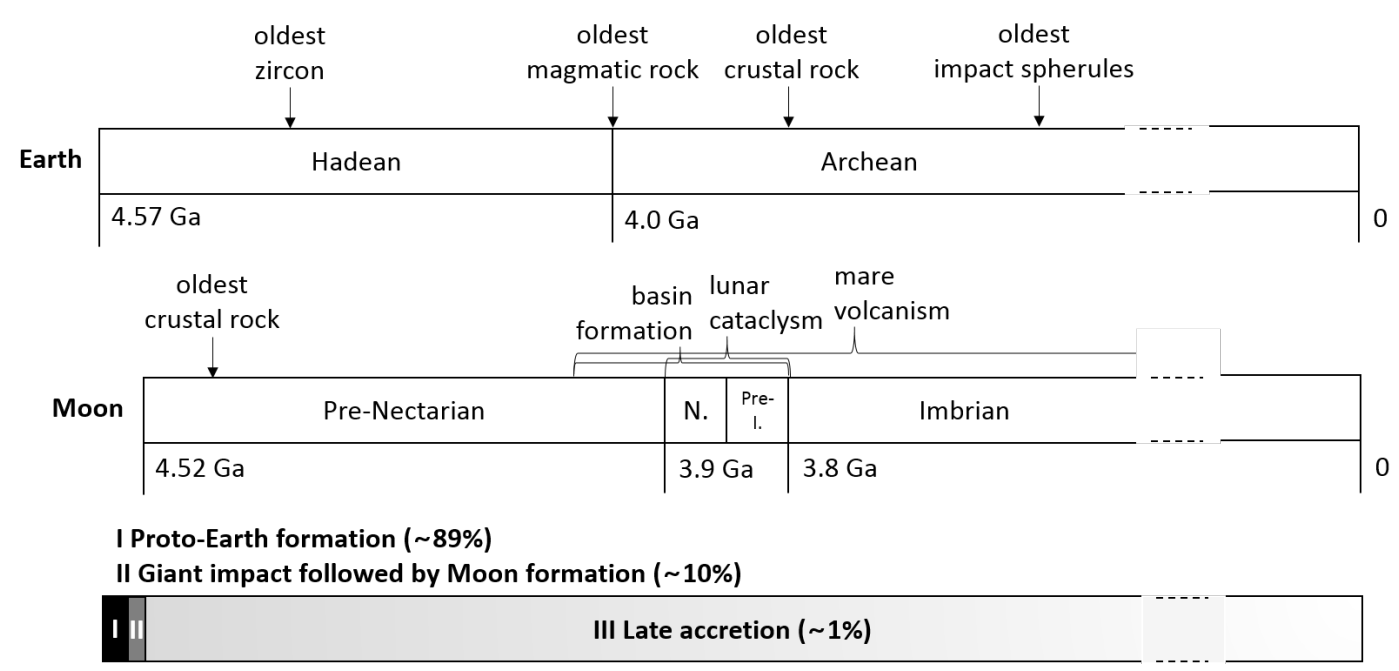

Figure 1.1: Important events of the Earth-Moon accretion history. The timeline starts with the formation of the Solar System 4.57 Ga ago (e.g. Bouvier and Wadhwa 2010; stage I in this figure). Most of the proto-Earth's mass was accreted within the first 30 Ma after Solar System formation (Albarède 2009, 89\% assuming impact settings described in Canup and Asphaug 2001). The Moon-forming impact added almost the complete missing mass to the Earth-Moon system $(\sim 10 \%$ assuming impact settings described in Canup and Asphaug 2001; stage II in this figure). In this figure we illustrate that the Moon formed 50 Ma after Solar System formation (Thiemens et al. 2019). The late accretion comprises all material, which accreted after the Moon formation until today ( $\sim 1 \%$ assuming impact settings described in Canup and Asphaug 2001; stage III in this figure). The oldest preserved zircon on Earth is from Jack Hills greenstone belt, Western Australia (4.374 Ga; e.g. Valley et al. 2014). The oldest intact magmatic rock on Earth is the Acasta Gneiss, Canada (4.0 Ga; e.g. Mojzsis et al. 2014). The oldest sedimentary (crustal) rock on Earth is the Isua Gneiss, Greenland (3.8 Ga, e.g. Nutman et al. 2007). The oldest preserved impact spherule layer on Earth is S1, Barberton greenstone belt, South Africa (3.5 Ga, e.g. Johnson and Melosh 2012). The oldest crustal rocks on the Moon are 4.45 to 4.35 Ga years old (Carlson et al. 2014). It is discussed that the impact flux spiked around $~ 3.9$ and $3.8 \mathrm{Ga}$, this scenario is called the 'lunar cataclysm' (e.g. Tera et al. 1974). It is often suggested that the lunar basin formation phase is related to this $(\sim 4.1-3.8 \mathrm{Ga}$, Morbidelli et al. 2012) and it overlaps with the occurrence of the mare volcanism (4.0-2.0 Ga, Hiesinger et al. 2000). The following abbreviations were used N. = Nectarian, Pre-I. = Pre-Imbrian.

\subsubsection{Proto-Earth formation}

The Solar System formed as a result of the partial gravitational collapse of a big molecular cloud $4.57 \mathrm{Ga}$ ago (Bouvier and Wadhwa 2010). The main mass concentrated in the 
center and formed the Sun, the rest flattened into a protoplanetary disk, the so-called solar nebula. Planetesimals formed from the solar nebula by gravitational coagulation and accretion. Differentiating planetesimals became planetary embryos. These planetesimals and planetary embryos are the precursors and building blocks of planets. The proto-Earth was formed by the collision of Mars- to Moon-sized planetary embryos and smaller planetesimals during the main phase of the planetary accretion (for more details see Badro and Walter 2015). Most of the mass of present-Earth $(\sim 89 \%)$ was gained within a relatively short period of time $(<30 \mathrm{Ma}$, Albarède 2009). The nature of Earth's building blocks is a crucial and still open question in the field of cosmochemistry. Considering meteorite collections, most models assume that Earth's building blocks originated from different heliocentric distances and had different provenances and compositions (Pahlevan and Stevenson 2007, Mastrobuono-Battisti et al. 2015, Kaib and Cowan 2015).

\subsubsection{Moon formation}

The Moon is $\sim 4.5 \mathrm{Ga}$ old, the exact age is still debated. There is no consensus yet, whether the Moon formation occurred 'early' (30-100 Ma after Solar System formation, e.g. Bottke et al. 2015, Barboni et al. 2017, Thiemens et al. 2019) or 'late' (up to $200 \mathrm{Ma}$ after Solar System formation, e.g. Borg et al. 2015, Connelly and Bizzarro 2016, Snape et al. 2016). It is well supported that the Moon formation was related to an impact process, which added nearly the final mass to the Earth-Moon system $(\sim 99 \%)$. It presumably created magma oceans on both bodies, which lead to a homogenisation of the material and final core-mantle differentiation.

The mechanism of the Moon formation is a long debated topic (see e.g. Wood 1986, Vaniman et al. 1991, Canup 2004a). The first modern formation hypothesis was proposed by Darwin (1879). He suggested that rocky material from the Earth was lost to space by fission due to a higher spin rate of the proto-Earth and accreted to form the Moon (fission hypothesis). Gerstenkorn (1955) suggested the gravitational capture of a small planetesimal, which formed somewhere else in the Solar System, as formation mechanism (capture hypothesis). Schmidt (1959) considered a co-accretion of Earth and Moon (sister planet/co-formation hypothesis). With the additional information that were obtained from the Apollo missions it became apparent, that these hypotheses cannot explain major features of the Earth-Moon system.

The Moon, as a satellite, is large compared to the size of planet Earth $(\sim 1 \%$ Earth's mass) and its density of $3.34 \mathrm{~g} \mathrm{~cm}^{-3}$ is relative low ( $\sim 60 \%$ of Earth's density). This indicates that the Moon is depleted in iron and has a smaller iron core than Earth or other Solar System bodies. The Moon's isotopic composition is also depleted in moderately volatile elements $(\mathrm{Zn}, \mathrm{K}, \mathrm{Na})$ and water. The rotation axis of the Earth is tilted by $12^{\circ}$. The angular momentum of the Earth-Moon system is relatively high in comparison to other inner planets. Tidal interactions between Earth and Moon resulted in a strong expansion of the lunar orbital radius over time and a simultaneous deceleration of the Earth's rotation. The Moon was once 15 times closer to Earth and its orbit was $10^{\circ}$ inclined to the equatorial plane (for more details see e.g. Wood 1986, Canup 2004a).

Hartmann and Davis (1975) and Cameron and Ward (1976) simultaneously developed an improved formation hypothesis explaining the significant features of the Earth-Moon system by combining certain aspects of the older hypotheses with an catastrophic impact 
scenario (which was originally suggested but not further pursued by Daly 1946). Hartmann and Davis (1975) and Cameron and Ward (1976) suggested that the proto-Earth was hit by an impactor (Hartmann and Davis 1975: Moon-sized, Cameron and Ward 1976: Mars-sized), material of both bodies was expelled to the orbit, accreted and formed the Moon. Most of the iron core of the differentiated impactor was incorporated into the Earth, more silicate-rich material was expelled and became part of the Moon. This hypothesis can explain the size and density ratios of Earth and Moon. An impact would explain the chemical similarities and be accompanied by very high temperatures explaining the depletion in moderately volatile elements of the Moon. It could also serve as an explanation for the tilted rotation axis of the Earth and the high angular momentum of the Earth-Moon system. This was the beginning of the 'giant impact theory', which became well known after a conference on the lunar origin in Hawaii 1984 (Wood 1986). In the following years many working groups started to develop giant impact simulations, but their work was limited by slow computational power and low numerical resolution (Benz et al. 1986, 1987, 1989, Cameron and Benz 1991). Numerical simulations (mostly smooth particle hydrodynamics (SPH)) improved a lot with the beginning of the 20th century. Since Cameron and Benz (1991) the models tended towards bigger impactors to expel enough material to the orbit. Cameron $(2000,2001)$ considered a large body, which impacted when the Earth was only accreted to 65\% ('Early Earth scenario'). Canup and Asphaug (2001) and Canup (2004b) considered smaller impactors and found that the impact could also have occurred later ('Late impact scenario', 95\% of Earth had already accreted).

Doubts on the giant impact hypothesis emerged when Moon and Earth were found to be isotopically very similar, e.g. in O-isotopes (Wiechert et al. 2001, chapter 6) Tiisotopes (Zhang et al. 2012), Si-isotopes (Georg et al. 2007), Cr-isotopes (Lugmair and Shukolyukov 1998) and ${ }^{182} \mathrm{~W}$ (Kruijer et al. 2015, Kruijer and Kleine 2017). An impactor from another part of the Solar System is expected to have a different isotopic composition compared to the proto-Earth, e.g. in terms of oxygen (see sec. 1.4). The Moon would be expected to differ in this value from Earth, because the preceding models predicted that the Moon accreted a higher portion of the impactor than the Earth (Canup and Asphaug 2001). As a consequence of the isotopic similarities, the impact theory itself was not questioned, but the impact conditions were reconsidered. It became apparent that mixing and isotopic re-equilibration might be the answer to the compositional constraints (Pahlevan and Stevenson 2007, Young et al. 2016) pointing towards a high-energy impact scenario. Such a scenario was previously excluded because it would result in a too high angular momentum of the Earth-Moon system. It was assumed that the angular momentum after the giant impact was predominately preserved and stayed constant through out time. Originally, the effect of tidal (e.g. Goldreich 1966, Touma and Wisdom 1994) or resonant (Kaula and Yoder 1976) interactions with the Sun and/or later accreted material (Morishima and Watanabe 2001) was considered minor, but this changed when Ćuk and Stewart (2012) found that evection resonance between Moon and Sun could have reduced the angular momentum of the Earth-Moon system until a balance between Earth and lunar tides was reached. This opened up new possibilities for more drastic highenergy impact models: impacts on a fast-spinning Earth (Ćuk and Stewart 2012), larger impactors (Canup 2012), hit-and-run impacts (Asphaug 2010, Reufer et al. 2012), multiple impacts (Rufu et al. 2017) and combining a fast spinning proto-Earth with a highly energetic impact scenario, which results in a fast spinning object of vaporised rock from 
which the Earth and the Moon condensed (synestia theory; Lock et al. 2018).

\subsubsection{Late accretion to the Earth-Moon system}

The late accretion (also referred to as 'late veneer') describes the addition of material to the Earth and the Moon after Moon formation (after the respective core-mantel differentiation). The late accretion delivered the last $\sim 1 \%$ of material to the Earth-Moon system.

This process is by definition still ongoing, though the impact rate has ceased over time with the depletion of solar nebula material. Several impact flux hypotheses describe the evolution of the impact rate ranging from a gradual decline ('accretion tail' scenario; Hartmann 1970, Neukum et al. 2001, Morbidelli et al. 2018) to an episode of enhanced bombardment. The latter hypotheses range from a sudden spike in the impact rate around 3.9 and $3.8 \mathrm{Ga}$ (named the 'late heavy bombardment' or 'lunar cataclysm' scenario; Turner et al. 1973, Tera et al. 1974, Ryder 1990, Cohen et al. 2000) to a longer phase with a less intensive rise in the impact rate (Turner 1979, Morbidelli et al. 2012). According to these hypotheses, the lunar basin formation phase between $\sim$ 4.1-3.8 Ga (Morbidelli et al. 2012) is evidence for the rise in impact rate at this time. Theoretical models on Solar System dynamics were developed to explain this phenomenon ranging from galactic scale processes (e.g. Mamajek et al. 2015, Rampino 2015, Wallner et al. 2016) to more Solar System-specific processes (e.g. Ćuk 2012). The recent 'Nice-Model' considers the disruption of the asteroid belt (or Kuiper belt or both) by the migration of the outer gas giant planets as possible cause (for more details see Joy et al. 2016 and references therein).

The composition of the late accretion is of high interest, because it may provide insights concerning the origin of terrestrial volatiles such as water. Earth belongs to the terrestrial inner planets and lays within the snow line $(\sim 3 \mathrm{au}$, distance during planetary formation; e.g. Martin and Livio 2012). Volatiles like water could not condense in significant amounts so close to the Sun and be incorporated into the growing planetesimals, which formed later Earth. One idea to explain the volatiles on Earth is that the late accretion delivered volatile-rich material. Alternative conceptual ideas are: I) wet accretion (the building blocks were indeed wet due to non-radial mixing in the Solar System) and II) ingassing from a nebular atmosphere (nebular gas dissolved in the magma ocean; Sharp 2017b). The recent material flux can be constrained by studying meteorite collections (e.g. the Antarctic Meteorite Collection; fig. 1.2) and real-time monitoring, but the ancient material flux is more difficult to reconstruct. Most of the late accretion contribution delivered to Earth was mixed into the mantle during the terrestrial magma ocean phase or later due to plate tectonics. The remnants of the $\sim$ first billion years of late accretion on Earth were erased from the surface or damaged by surface weathering. The oldest evidence found so far is an Archean impact spherule layer with an age of $\sim 3.5 \mathrm{Ga}$ (e.g. Johnson and Melosh 2012). The late accretion contribution to the Moon was also mixed into the lunar magma ocean during the first $~ 100-150$ Ma after Moon formation, then the lunar crust solidified acting as a lid (Elkins-Tanton et al. 2011). Afterwards, late accreted material was added to the lunar surface generating an ancient and comprehensive impact record (sometimes referred to as post-late accretion e.g. Joy et al. 2016). The Moon is therefore a very suitable study area for the late accretion to the Earth-Moon 

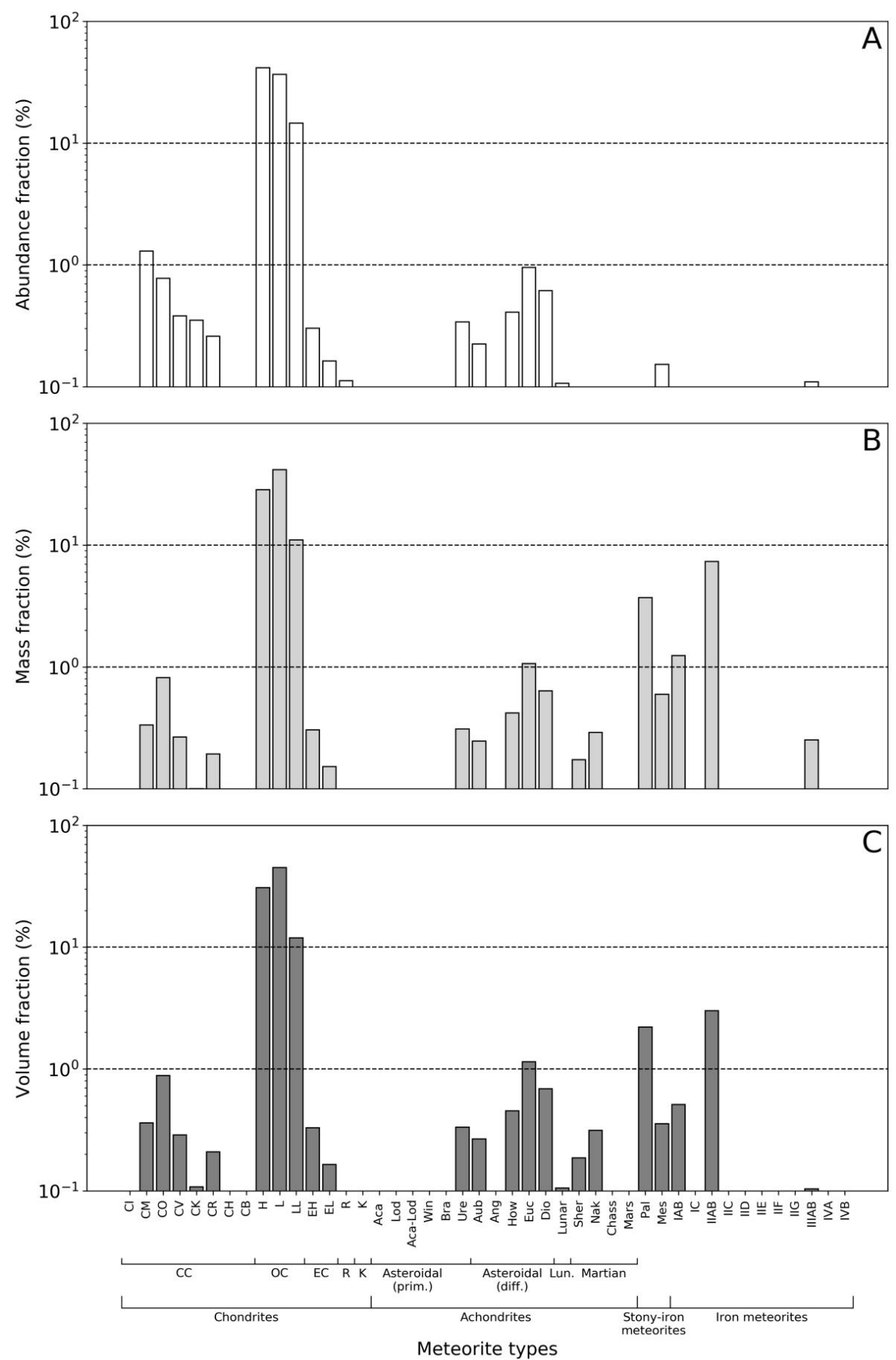

Figure 1.2: Characteristics of the recent meteorite flux in the Solar System constrained by the material frequency distribution of the Antarctic meteorite collection. The data was extracted from the Meteoritical Bulletin Database (https://www.lpi.usra.edu/meteor/, March 2020, quantity and mass information). A) displays the abundance fraction (\%) and B) the mass fraction (\%). C) shows the volume fraction (\%), which was calculated assuming a density of $3 \mathrm{~g} \mathrm{~cm}^{-3}$ for stony meteorites (chondrites and achondrites), $5.44 \mathrm{~g} \mathrm{~cm}^{-3}$ for stony-iron meteorites and $7.87 \mathrm{~g} \mathrm{~cm}^{-3}$ for iron meteorites. The modern meteorite flux is dominated by chondrites, especially ordinary chondrits (OC). Achondrites provide a much smaller contribution. The number of stony-iron and iron meteorites are even lower (A), but in this case it is important to consider the mass of the meteorites (B). The volume fraction (C) includes this information and shows that the stony-iron and iron meteorites are not negligible. For further information on the meteorite classification see sec. 1.4. Abbreviations are explained in the list of abbreviations. 
system. It is usually assumed that the average composition of the late accretion to both bodies was similar, though it was found that the Moon accreted a smaller amount than the

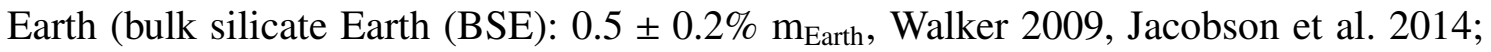
bulk silicate Moon (BSM): 0.00025\% $\mathrm{m}_{\text {Earth }}$, Day and Walker 2015). There are several hypotheses, which can explain the higher late accretion contribution of the Earth, e.g. gravitational focusing (the Earth has stronger gravitational pull; Schlichting et al. 2012) or 'stochastic accretion' (a few large bodies impacted on Earth; Bottke et al. 2010). Mass constrains on the Moon's late accretion contribution (see above) were recently questioned (Thiemens et al. 2019, Brenan et al. 2019, see also Gleißner 2019), though there is no agreement between the studies whether this would imply a more (Brenan et al. 2019) or a less (Thiemens et al. 2019) pronounced late accretion of the Moon.

The most prominent chemical approach to study the late accretion is based on highly siderophile element (HSE: Re, Os, Ir, Ru, Pt, Rh, Pd) concentrations, abundance patterns, and isotopic compositions. During planetary differentiation HSE are stripped from the silicate mantle and incorporated into the metallic planetary core. This left the terrestrial and lunar mantle and crust highly depleted in HSE, the late accretion added new HSEcontaining material (e.g. Mann et al. 2012). HSE signatures in the mantle and crustal rocks therefore only represent the late accreted material and can be used to constrain the timing (Re-Os isochron ages, e.g. Fischer-Gödde and Becker 2012), mass (e.g. Walker 2009) and composition of the late accretion (e.g. Morgan et al. 1977, Hertogen et al. 1977, Palme 1980). HSE signatures are studied in terrestrial mantle rocks (Walker 2009, Jacobson et al. 2014, Fischer-Gödde and Kleine 2017, Fischer-Gödde et al. 2020), lunar mantle rocks (Day and Walker 2015, Brenan et al. 2019) and lunar (crustal) impact rocks (e.g. Norman et al. 2002, Puchtel et al. 2008, Fischer-Gödde and Becker 2012, Sharp et al. 2014, Liu et al. 2015, Gleißner and Becker 2017, 2019). Also other elements are used to study the late accretion: siderophile elements such as W (Hf-W system, e.g. Kruijer et al. 2015, Thiemens et al. 2019) and Mo (e.g. Budde et al. 2019), chalcophile elements such as S, Se and Te (e.g. Wang and Becker 2013), lithophile elements like O (see chapter 6) and atmophile elements such as H, C, N (e.g. Alexander et al. 2012, Marty 2012). Different conclusions were drawn on the composition of the late accretion depending on the study area (terrestrial mantle, lunar mantle or crust) and element/isotope system (see chapter 7).

\subsection{Oxygen isotope systematics}

\subsubsection{Basic definitions}

Oxygen has three stable isotopes: the abundant ${ }^{16} \mathrm{O}(99.76 \%)$ and the rare isotopes ${ }^{18} \mathrm{O}$ $(0.20 \%)$ and ${ }^{17} \mathrm{O}(0.04 \%)$. The isotopes differ in their chemical and physical properties due to their varying atomic mass. These differences lead to isotope fractionation effects and, thus, to variations in stable isotope ratios (R). Isotope ratios of a phase (A; eq. 1.1) are expressed as the ratio of the heavy over the abundant light isotope.

$$
{ }^{*} R_{A}=\left(\frac{{ }^{*} \mathrm{O}}{{ }^{16} \mathrm{O}}\right)_{A}
$$


The asterisk * stands for the number 17 or 18 in case of oxygen isotopes. Stable isotope variations are typically small in terrestrial materials, only in extraterrestrial materials large values can be reached. Therefore, isotope ratios are not reported as absolute values but as deviation from an international standard material. The primary international standard for oxygen isotopes is called Vienna Standard Mean Ocean Water (VSMOW2). The $\delta$-notation (eq. 1.2) displays the difference in the isotope ratios of the sample $\left({ }^{*} R_{\text {smp }}\right)$ compared to the standard $\left({ }^{*} R_{\text {std }}\right.$; McKinney et al. 1950).

$$
\delta^{*} \mathrm{O}=\left(\frac{{ }^{*} R_{s m p}}{{ }^{*} R_{\text {std }}}-1\right) \cdot 10^{3}(\% \circ)
$$

For oxygen we can define the $\delta^{17} \mathrm{O}$ and $\delta^{18} \mathrm{O}$ value. The numerical factor 1000 has the purpose to increase the value. The $\delta^{\prime}$ (prime)-notation (eq. 1.3) is the linearised form of the $\delta$-notation (Miller 2002).

$$
\delta^{\prime *} \mathrm{O}=10^{3} \cdot \ln \left(\frac{\delta^{*} \mathrm{O}}{10^{3}}+1\right)(\% o)
$$

The $\Delta^{\prime 17} \mathrm{O}$-notation (eq. 1.4) displays small deviations of a sample from a chosen reference line in the $\delta^{\prime 17} \mathrm{O}$ vs. $\delta^{\prime 18} \mathrm{O}$ space (oxygen three-isotope plot). We use a reference line with a slope of $\lambda_{R L}=0.528$ and y-axis intercept of $\gamma_{R L}=0$ in this dissertation (fig. 1.3A).

$$
\Delta^{\prime 17} \mathrm{O}=\left(\delta^{\prime 17} \mathrm{O}-\lambda_{R L} \cdot \delta^{\prime 18} \mathrm{O}+\gamma_{R L}\right) \cdot 10^{6}(\mathrm{ppm})
$$

\subsubsection{Mass-dependent isotope fractionation}

Mass-dependent isotope fractionation results from the different isotope masses, which are associated with different zero point energies of molecular bonds (equilibrium fractionation), and different chemical reaction and diffusion behaviour (kinetic fractionation). Equilibrium isotope fractionation is linked to processes, which lead to a bidirectional isotope exchange between different substances or phases. It is controlled by temperature. Kinetic isotope fractionation is linked to processes, which include incomplete and unidirectional transport such as molecular diffusion and chemical reactions. It is controlled by time and concentration gradients. Mass-dependent isotope fractionation between different phases (A and B) is described by the power law function (eq. 1.5; Young et al. 2002):

$$
\frac{{ }^{17} R_{A}}{{ }^{17} R_{B}}=\left(\frac{{ }^{18} R_{A}}{{ }^{18} R_{B}}\right)^{\theta}
$$

The exponent $\theta$ is the triple oxygen isotope fractionation exponent. Eq. 1.5 can also be expressed in terms of the fractionation factor $\alpha$ (eq. 1.6 and 1.7).

$$
\begin{gathered}
\alpha_{A-B}^{*}=\left(\frac{{ }^{*} R_{A}}{{ }^{*} R_{B}}\right) \\
\alpha_{A-B}^{17}=\left(\alpha_{A-B}^{18}\right)^{\theta}
\end{gathered}
$$

In theory, $\theta$ can vary between 0.509 and 0.5303 for oxygen isotope fractionation (Young et al. 2002). The value for $\theta$ is different for equilibrium and kinetic fractionation processes. For equilibrium isotope fractionation $\theta$ depends on the partition function of the 
oxygen-bearing molecules. The partition function describes the translational, rotational, and vibrational energy of molecules or atoms. Most important are differences in the vibrational energy of the compounds. This way, the $\theta$ value may be obtained by quantum mechanical calculations. The high temperature $(T)$ approximation by Young et al. (2002) for any equilibrium exchange reaction between oxygen-bearing molecules derives 0.5305 for the $\theta$ high- $T$ limit $\left(T>500{ }^{\circ} \mathrm{C}\right)$. For lower temperatures $\theta$ approaches smaller values (Cao and Liu 2011). Experimentally determined $\theta$ values are still rare for specific material systems. For kinetic isotope fractionation $\theta$ depends on the kinetic energy of the involved oxygen-bearing molecules. The effective molecular mass defines the kinetic energy/reaction rates of the compounds.

Mass-dependent fractionation processes are usually described by a single linear curve on a three-isotope plot with the slope $\theta$ (Matsuhisa et al. 1978; fig. 1.3B). The slope $\theta$ has a physical meaning, it describes a specific process of isotope exchange, whether equilibrium or kinetic. The average line defined by different terrestrial materials is called the terrestrial fractionation line (TFL). The slope of this line will be called $\lambda$. The slope $\lambda$ has no physical meaning, and reports the isotope variations or trends within a certain reservoir (e.g. the terrestrial rock reservoir, Earth). The development of high-precision isotope measurement techniques have helped to resolve slightly different mass-dependent fractionation laws for several processes, resulting in variable slopes and $\theta$ values (Young et al. 2002, Miller 2002, Farquhar and Gan 2003). Variability of $\theta$ was documented for oxygen the first time by Luz et al. (1999) and Pack and Herwartz (2014). Deviations from the TFL are either small and related to different mass-dependent fraction laws or they represent mass-independent fractionation. The $\Delta^{\prime 17} \mathrm{O}$ value quantifies how far a sample deviates from the TFL (eq. 1.4, fig. 1.3A+B).
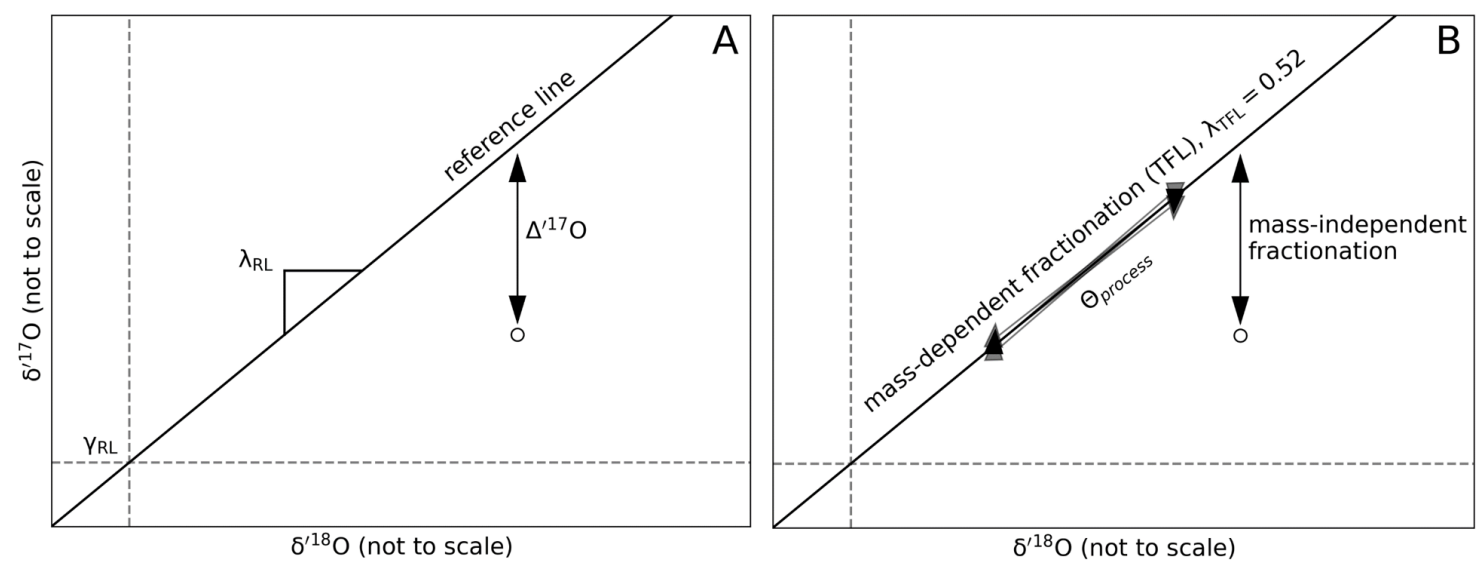

Figure 1.3: A) The $\Delta^{\prime 17} \mathrm{O}$-notation illustrated in the oxygen three-isotope plot. The chosen reference line is defined by the slope $\lambda_{R L}$ and the $\mathrm{y}$-axis intercept $\gamma_{R L}$. The $\Delta^{\prime 17} \mathrm{O}$ value describes deviations from the reference line. B) Schematic illustration of the difference between mass-dependent and mass-independent fractionation in the oxygen three-isotope plot. Mass-independent fractionation processes are associated with specific $\theta_{\text {process }}$ values and only small-scale $\Delta^{\prime 17} \mathrm{O}$ deviations from the terrestrial fractionation line (TFL), whereas mass-independent fractionation can lead to larger positive and negative $\Delta^{\prime 17} \mathrm{O}$ anomalies.

\subsubsection{Mass-independent isotope fractionation}

Some isotope effects are mass-independent. They are also referred to as isotope anomalies, because they are associated to processes, which occur only on rare occasions in 
terrestrial settings. Three processes can create mass-independent fractionation: nucleosynthesis, chemical and photochemical reactions.

\section{Nucleosynthesis}

Mass-independent oxygen isotope fractionation occurs during nucleosynthesis. Oxygen isotopes are created during different nuclear processes. The abundant ${ }^{16} \mathrm{O}$ is a 'primary' nucleus formed from hydrogen and helium during the stellar nucleosynthesis and released during supernova explosions. The rare isotopes ${ }^{17} \mathrm{O}$ and ${ }^{18} \mathrm{O}$ are 'secondary' nuclei formed from carbon, nitrogen, and oxygen precursors in zones that are rich in hydrogen and helium in both, novae and supernovae (Audouze and Vauclair 1980). Stellar ejecta cools rapidly and molecules and refractory solids form. The isotope creation is separated in time and space, consequently different reservoirs are produced with varying amounts of ${ }^{16} \mathrm{O}$. It has been argued that probably even pure ${ }^{16} \mathrm{O}$ material was formed (Clayton et al. 1973). So far, no presolar carriers were identified for oxygen (but for carbon and silicium). Isotopic homogenisation in the interstellar medium might have removed the nuclear signatures. Nevertheless, the different meteorite classes show distinct oxygen isotope anomalies and in the past it has been discussed that this signature is of nucleosynthetic origin (Clayton et al. 1973).

\section{Chemical reactions}

Ozone formation Mass-independent oxygen isotope fractionation occurs during symmetry driven recombination reactions of the ozone formation in the Earth's stratosphere (Chapman cycle). Ozone $\left(\mathrm{O}_{3}\right)$ is formed by the recombination of an oxygen singlet $(\mathrm{O})$ and molecular oxygen $\left(\mathrm{O}_{2}\right.$; eq. 1.8).

$$
\mathrm{O}+\mathrm{O}_{2}+\mathrm{M} \rightarrow \mathrm{O}_{3}+\mathrm{M}
$$

The variable $\mathrm{M}$ can represent for instance molecular nitrogen, oxygen or carbon dioxide $\left(\mathrm{CO}_{2}\right)$. The ${ }^{16} \mathrm{O}-{ }^{16} \mathrm{O}-{ }^{16} \mathrm{O}$ isotopologue has a higher symmetry than the ${ }^{17} \mathrm{O}-{ }^{16} \mathrm{O}-{ }^{16} \mathrm{O}$ and ${ }^{18} \mathrm{O}-{ }^{16} \mathrm{O}-{ }^{16} \mathrm{O}$ isotopologue. The higher symmetry leads to more forbidden orbital states and a higher reaction rate and smaller stability. Consequently, the ${ }^{16} \mathrm{O}_{-}{ }^{16} \mathrm{O}-{ }^{16} \mathrm{O}$ isotopologue is more often decomposed by photolysis to $\mathrm{O}_{2}$ and the electronically excited singlet oxygen $\mathrm{O}\left({ }^{1} \mathrm{D}\right)$ (eq. 1.9).

$$
\mathrm{O}_{3}+h v \rightarrow \mathrm{O}_{2}+\mathrm{O}\left({ }^{1} \mathrm{D}\right)
$$

This preferential decomposition of ${ }^{16} \mathrm{O}_{-}{ }^{16} \mathrm{O}-{ }^{16} \mathrm{O}$ isotopologues results in an enrichment of ${ }^{17} \mathrm{O}$ and ${ }^{18} \mathrm{O}$ in $\mathrm{O}_{3}$. The resulting positive $\Delta^{\prime 17} \mathrm{O}$ anomaly comprises a $\delta^{\prime 18} \mathrm{O} \approx 80-150 \%$ o and a $\Delta^{\prime 17} \mathrm{O} \approx 40 \%$ (Krankowsky et al. 2000, Lämmerzahl 2002, Mauersberger 1981). Simultaneously this process leads to an enrichment of ${ }^{16} \mathrm{O}$ in $\mathrm{O}_{2}$, creating a negative $\Delta^{\prime 17} \mathrm{O}$ anomaly of $\Delta^{\prime 17} \mathrm{O}=-0.365 \%$ in the tropospheric molecular oxygen reservoir (relative to $\lambda_{R L}=0.522$; Barkan and Luz 2011, Luz and Barkan 2005). The positive $\Delta^{\prime 17} \mathrm{O}$ anomaly of $\mathrm{O}_{3}$ is also transferred to other oxygen bearing trace gases via radical exchange reactions. $\mathrm{CO}_{2}$ reacts with the $\mathrm{O}\left({ }^{1} \mathrm{D}\right)$ (eq. 1.10, Yung et al. 1991):

$$
\mathrm{O}\left({ }^{1} \mathrm{D}\right)+\mathrm{CO}_{2} \rightarrow \mathrm{CO}_{3}^{*} \rightarrow \mathrm{CO}_{2}+\mathrm{O}\left({ }^{3} \mathrm{P}\right)
$$


Consequently, the $\mathrm{CO}_{2}$ from the strato- and mesosphere also carries a positive $\Delta^{\prime 17} \mathrm{O}$ anomaly (Thiemens et al. 1995, Boering 2004, Lämmerzahl 2002, Kawagucci et al. 2008). Thiemens and Heidenreich (1983) were the first to reproduce these observations in a laboratory experiment. They were also the first to propose a qualitative isotopic model for the ozone formation (Heidenreich and Thiemens 1986).

Gas-phase $\mathrm{SiO}_{2}$ formation Mass-independent oxygen isotope fractionation might have occurred during gas-phase symmetry driven recombination reactions in the solar nebula. It is another approach to explain the triple oxygen isotope heterogeneities recorded by meteorites (Thiemens and Heidenreich 1983, Heidenreich and Thiemens 1986, Gao and Marcus 2001). Marcus (2004) published a theoretical work on this topic, but Chakraborty et al. (2013) were the first to perform an experimental study. They heated silicon monoxide $(\mathrm{SiO})$ in the presence of $\mathrm{O}_{2}$ and hydrogen $\left(\mathrm{H}_{2}\right)$. The produced silicon dioxide $\left(\mathrm{SiO}_{2}\right)$ plots on a line with a slope of 1 in the oxygen three-isotope plot indicating mass independent fractionation. The extent of mass-independent fractionation increases with increasing $\mathrm{H}_{2} / \mathrm{O}_{2}$ ratio. The kinetic simulation model of Chakraborty et al. (2013) found that the most likely reaction channel is the oxidation of $\mathrm{SiO}$ by hydroxide $(\mathrm{OH})$ (eq. 1.11).

$$
\mathrm{SiO}+\mathrm{OH} \rightarrow \mathrm{SiO}_{2}+\mathrm{H}
$$

The chemical compound $\mathrm{SiO}$ is an important solar nebula species (Cho and Kim 2012, Bujarrabal et al. 1994) and it is known that it was oxidized by $\mathrm{OH}$ in the early nebula (MacPherson and Boss 2011, Ciesla and Cuzzi 2006, Walsh et al. 2010). According to Chakraborty et al. (2013) and Thiemens and Lin (2021) it seems to be a plausible mechanism for the initiating solid silicate formation in the solar nebula and the creation for the meteoritic triple oxygen isotope anomalies. This process would uniquely effect oxygen isotopes.

\section{Photochemical reactions}

Mass-independent oxygen isotope fractionation is created by isotope selective photochemistry in molecular clouds and possibly occurred also in the solar nebula (Clayton 2002). The initial setting comprises a cloud or disk composed of dust and gas, dominated by $\mathrm{H}_{2}$, carbon monoxide $(\mathrm{CO})$ and nitrogen. A star provides a strong source of ultraviolet radiation. In this setting mass-independent fractionation is created by self-shielding during the photodissociation of $\mathrm{CO}$ at the wavelength range $91-110 \mathrm{~nm}$.

$$
\mathrm{CO}+h v \rightarrow \mathrm{CO}^{*} \rightarrow \mathrm{C}+\mathrm{O}
$$

$\mathrm{CO}$ molecules absorb photons in the ultraviolet range, excite to a short-lived state and dissociate to $\mathrm{C}$ and $\mathrm{O}$ at ground state (predissociation, eq. 1.12). The excitation is wavelength-specific for the different $\mathrm{CO}$ isotopologues. ${ }^{12} \mathrm{C}^{16} \mathrm{O}$ is the most abundant isotopologue and absorbs the respective radiation in the outer part of the nebula. The ${ }^{12} \mathrm{C}^{16} \mathrm{O}$ absorption line becomes saturated (optically thick), while the lines of the rare isotopologues stay undersaturated (optically thin). Consequently, ${ }^{13} \mathrm{C}^{16} \mathrm{O},{ }^{12} \mathrm{C}^{17} \mathrm{O}$ and ${ }^{12} \mathrm{C}^{18} \mathrm{O}$ are preferentially dissociated in the interior of the nebula. This leads to enrichment of ${ }^{16} \mathrm{O}$ in the outer part, and of ${ }^{17} \mathrm{O}$ and ${ }^{18} \mathrm{O}$ in the inner part of the nebula. Subsequently, oxygen is incorporated into water $\left(\mathrm{H}_{2} \mathrm{O}\right)$ or mineral grains (Clayton 2008). This 
mechanism is called self-shielding. Self-shielding during the photodissociation of CO has been primarily discussed for molecular clouds (Bally and Langer 1982, van Dishoeck and Black 1988), quantitatively modelled (Warin et al. 1996), and observed by ultraviolet spectroscopy (Sheffer et al. 2002). The conditions in the surface region of the solar nebular were similar to those in cold low-density molecular clouds, it was suggested that self-shielding occurred also in this setting and might be the cause of meteoritic oxygen isotope anomalies (Clayton 2002, Lyons and Young 2004, 2005).

\subsection{Triple oxygen isotopes as a tool for the reconstruction of the material flux in the Solar System}

\subsubsection{Oxygen in the Solar System}

Oxygen is very abundant in the Solar System. It appears in different cosmochemical reservoirs: minerals and rocks (solid), water and carbon monoxide (gas). Its isotopic diversity is large due to extensive mass-dependent and mass-independent fractionation effects (see sec. 1.3). In form of solids oxygen easily avoids isotopic homogenisation in the interstellar medium. Oxygen isotopes are therefore a powerful tracer for the interactions of different reservoirs (for more details e.g. Clayton 1993, Sharp 2017a, Ireland et al. 2020, Thiemens and Lin 2021).

\subsubsection{Triple oxygen isotope variations in the Solar System}

The discovery A turning point for cosmochemistry were the 1970s, when extraterrestrial sample material became more accessible (e.g. Clayton 2008). The Apollo and Luna missions returned lunar material (1961-1972; 1970-1976) allowing e.g. the identification of lunar meteorites (for more details see e.g. Heiken et al. 1991). The Allende and Murchison meteorite fell in 1969 and made carbonaceous chondrite material available. The very first oxygen isotope studies on meteorites found the material isotopically very common and not 'exotic' as expected (Baertschi 1950, Silverman 1951, Vinogradov et al. 1960, Reuter et al. 1965). This was mainly due to low analytical precisions of the applied methods and unfortunate sample selection. A first attempt to establish a meteorite classification scheme based on $\delta^{18} \mathrm{O}$ was made by Taylor et al. (1965). Oxygen isotope studies of lunar rock samples revealed that the $\delta^{18} \mathrm{O}$ of lunar and terrestrial material is nearly indistinguishable in the respective lithologies (e.g. Epstein and Taylor 1970, O'Neil and Adami 1970, Onuma et al. 1970). The same observation was later also made for $\delta^{17} \mathrm{O}$ (Clayton and Mayeda 1975). These findings proved the strong genetic relationship between Earth and the Moon.

Clayton et al. (1973) revolutionised the field of stable isotope geochemistry by detecting the first anomalous oxygen isotope compositions in meteorites studying anhydrous high temperature phases (CAIs = calcium, aluminium-rich inclusions) of Allende. Not only the range in $\delta^{18} \mathrm{O}$ was huge (over $30 \%$ ), but Clayton et al. (1973) discovered also that the $\delta^{17} \mathrm{O}$ values suggested mass-independent fractionation. The CAI data formed a trend with a slope of $\sim 0.96$ in the three-oxygen isotope plot (CCAM line $=$ carbonaceous 
chondrite anhydrous mixing line; Clayton and Mayeda 1977) and clearly deviates from the mass-dependent TFL (slope $\approx 0.52$ ) and the $\Delta^{\prime 17} \mathrm{O}$ composition of the Earth-Moon system. Originally, mass-independent variations (see sec. 1.3) were considered as result of nucleosynthetic processes ('two reservoir mixing hypothesis'), but the consensus changed towards another formation mechanism: the predissociation of carbon monoxide by self-shielding in the primordial molecular cloud ('molecular cloud hypothesis'). And recently, the 'molecular cloud hypothesis' has been challenged by the hypothesis of gas-phase $\mathrm{SiO}_{2}$ formation in the solar nebula (e.g. Thiemens and Lin 2021).

The mechanism Clayton et al. (1973) explained their findings with the mixing between two reservoirs: a heavy solar nebula reservoir ('from the Solar System') and a light $\left({ }^{16} \mathrm{O}\right.$ rich), primitive, pre-solar dust reservoir ('from outside of the Solar System') ('two reservoir mixing hypothesis'). According to the model of Clayton et al. (1973) the light oxygen reservoir was created in a young helium burning star, which only produced ${ }^{16} \mathrm{O}$. Hence, this reservoir should have been extremely depleted in ${ }^{17} \mathrm{O}$ and ${ }^{18} \mathrm{O}$. Clayton (1993) assigned the heavy solar nebula reservoir a $\delta^{17} \mathrm{O}=24.2 \%$ and a $\delta^{18} \mathrm{O}=30 \%$, and the light $\left({ }^{16} \mathrm{O}\right.$-rich) pre-solar dust reservoir a $\delta^{17} \mathrm{O} \approx-42 \%$ and a $\delta^{18} \mathrm{O} \approx-40 \%$. According to this model, the CAI trend would represent mixing between a heavy nebular component and a ${ }^{16} \mathrm{O}$-rich, light, pre-solar component in the early Solar System. The most prominent issue with this model is that no correlations with other isotope systems were found so far (e.g. $\mathrm{Mg}, \mathrm{Si}$ ). This should be the case if the ${ }^{16} \mathrm{O}$-rich component was contributed by stellar nucleosynthesis (for more information see e.g. Sharp 2017a).

Thiemens and Heidenreich (1983) developed the concept of mass-independent isotope fractionation and the self-shielding mechanism by studying ozone in the stratosphere. They demonstrated that in case of the ozone anomaly, mass-independent fractionation is caused by symmetry (e.g., Michalski and Bhattacharya 2009). Nevertheless, optical selfshielding might lead to mass-independent isotope fractionation in molecular clouds. This process would result in isotopically enriched $\left({ }^{16} \mathrm{O}\right.$-poor) water, which is later incorporated in silicates. Based on that, a new model was developed ('molecular cloud hypothesis') to explain the oxygen isotope variation in the Solar System (Thiemens 1999, Clayton 2002). In this model the solar nebula reservoir (and the Sun) is isotopically depleted $\left({ }^{16} \mathrm{O}\right.$-rich) with $\delta^{17} \mathrm{O}$ and $\delta^{18} \mathrm{O}$ in the range of $\sim-50 \%$ o. This was confirmed by the Genesis mission of the NASA, which enabled oxygen isotope analyses of solar wind and found that the Sun has a $\delta^{17} \mathrm{O}$ of $-59.1 \%$ and a $\delta^{18} \mathrm{O}$ of $-58.5 \%$ (McKeegan et al. 2011, Clayton 2002). According to this model, the CAI trend would represent mixing between a light nebula component and isotopically enriched molecular cloud material in the early Solar System. The exchange between isotopically enriched water and relatively depleted silicates occurred most likely within the meteorite parent body. Inclusions in primitive meteorites show a wide range in ${ }^{16} \mathrm{O}$ from highly depleted (solar) to compositions that fall closer to the TFL.

Earth-Moon system Earth's oxygen isotope composition is inherited from its primary building blocks. Different planetesimals with variable $\Delta^{\prime 17} \mathrm{O}$ composition accreted, the material was mixed, and the bulk isotopic composition equilibrated during a magma ocean phase. It was suggested that the late accretion was less efficiently mixed into the Earth's 
mantle (e.g. Willbold et al. 2011), which might have created traceable $\Delta^{\prime 17} \mathrm{O}$ heterogeneities (see chapter 5). Geochemical oxygen isotope variations on Earth are dominated by mass-dependent fractionation effects (exception: materials that are involved or genetically linked to photochemical reactions in the upper atmosphere; e.g. Thiemens 1999). Triple oxygen isotope compositions are shifted along the TFL (slope $\approx 0.52$ ) due to kinetic and equilibrium fractionation processes accompanied by small-scale $\Delta^{\prime 17} \mathrm{O}$ variations (e.g. Pack and Herwartz 2014; see sec. 1.3). The triple oxygen isotope composition of the Moon was found to be very similar to the composition of Earth (e.g. Wiechert et al. 2001, Spicuzza et al. 2007, Hallis et al. 2010, Young et al. 2016), which has direct implications on the Moon formation mechanism (see sec. 1.2). Small differences between the two bodies are still debated (Herwartz et al. 2014, Greenwood et al. 2018, Cano et al. 2020; see chapter 6). The first studies, which analysed returned lunar samples, found the Moon very homogeneous in its oxygen isotope composition (e.g. Clayton et al. 1974a, Mayeda et al. 1975). With the recent advances in the field of isotope mass spectrometry small-scale variations are discussed concerning e.g. the $\delta^{18} \mathrm{O}$ of mare basalts (Spicuzza et al. 2007, Hallis et al. 2010) or the $\Delta^{\prime 17} \mathrm{O}$ of highland rocks (e.g. Young et al. 2016, Kohl et al. 2017; $\Delta^{\prime 17} \mathrm{O}$ lithology-dependent variations: see chapter 4, 6 and appendix sec. D.4).

Meteorites as samples of asteroids and planets Meteorites are fragments of asteroids and planets, which fall through Earth's atmosphere and impact on the surface. They are subdivided into chondrites and achondrites. The meteorite classification scheme is based on oxygen isotope variations (e.g. Clayton et al. 1976, Ireland et al. 2020).

Chondrites are considered as primitive, because their material was never melted. They are cosmic breccias and contain different components from the early Solar System. Primary components of chondrites are chondrules, CAIs, amoeboid olivine aggregates (AOA's) and the matrix (Krot et al. 2014, Scott et al. 2015). High-temperature inclusions are embedded in a low-temperature matrix affected by aqueous alteration. The hightemperature inclusions are chondrules and CAIs. There are five chondrite types: ordinary chondrites (OC; groups: H, L, LL), enstatite chondrites (EC), carbonaceous chondrites (CC; groups: $\mathrm{CI}, \mathrm{CV}, \mathrm{CM}, \mathrm{CR}, \mathrm{CH}, \mathrm{CB}, \mathrm{CK}, \mathrm{CO}$ ), rumuruti chondrites (R) and kakangari chondrites $(\mathrm{K})$. Achondrites have been thermally processed to variable degrees and lack chondritic components. In general, they are subdivided in iron, stony-iron and stony meteorites, which represents fragments of cores, material from the core-mantle boundary, and mantle material from differentiated larger bodies. We differentiate between asteroidal achondrites and planetary achondrites. Asteroidal achondrites are further subdivided into primitive and differentiated depending on the degree of thermal processing. This classification step is difficult and still subject of discussion. Greenwood et al. (2017) have subdivided the meteorite groups in the following way. Primitive achondrites: acapulcoitelodranite clan (Aca, Lod), winonaites (Win), silicate-bearing IAB and IIICD irons, brachinites (Bra), ureilites (Ure). Differentiated achondrites: angrites (Ang), aubrites (Aub), howardite-eucrite-diogenite suite (HEDs), mesosiderites (Mes), pallasites (Pal). HED and mesosiderites can be linked to the asteroid Vesta. Confirmed planetary achondrites derive either from Moon (lunar) or Mars (shergottite-nahklite-chassignite (SNC); McSween 1984), no other links to planets were found so far.

Cosmochemical oxygen isotope variations in meteorites are dominated by mass-inde- 
1.4 Triple oxygen isotopes as a tool for the reconstruction of the material flux in the Solar System
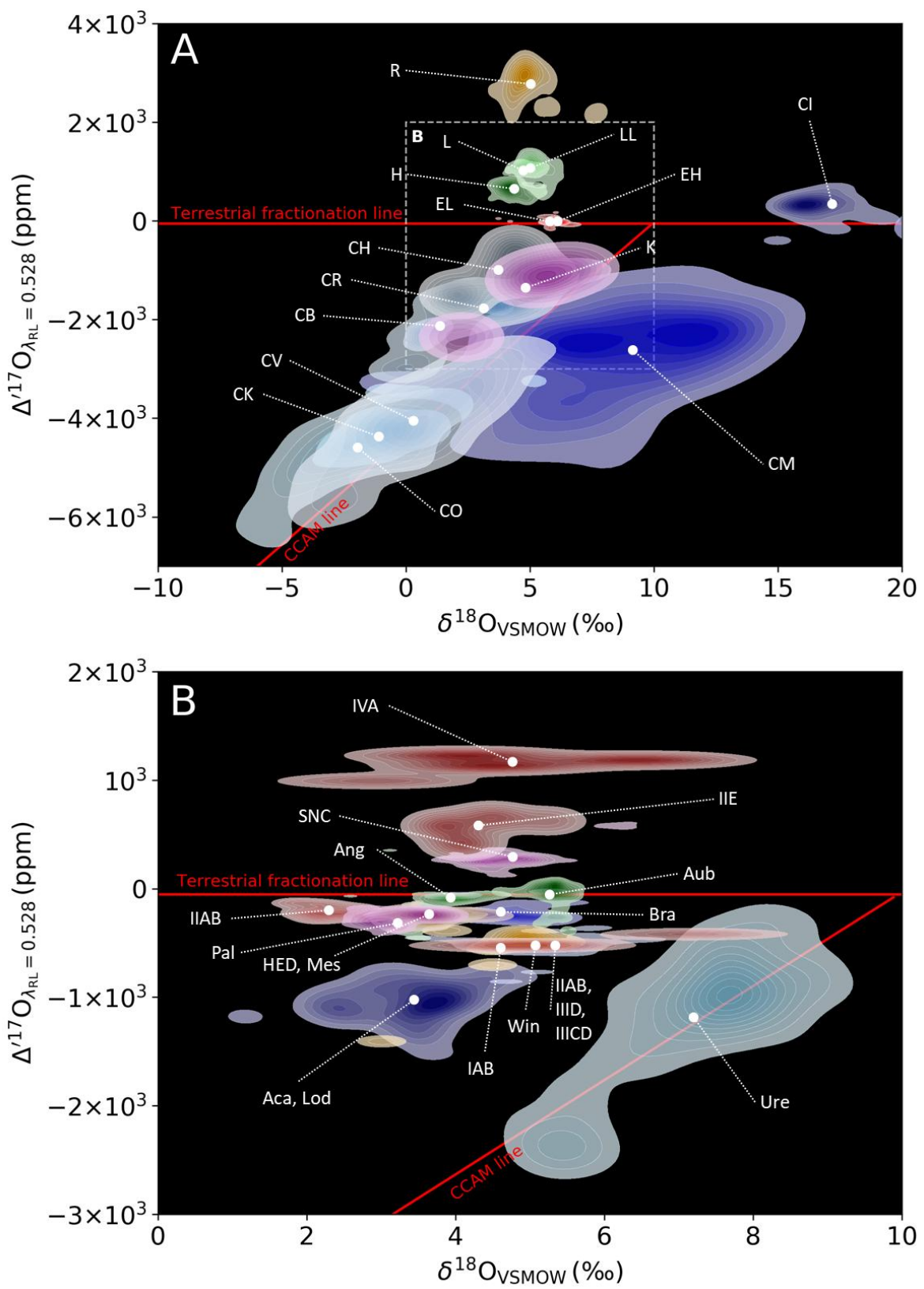

Figure 1.4: Illustration of the triple oxygen isotope variation in the Solar System based on meteorite data. This compilation comprises data from: Clayton et al. (1976), Clayton and Mayeda (1983), Clayton et al. (1983b, 1991), Rowe et al. (1994), Clayton and Mayeda (1996, 1999), Herwartz et al. (2014) and data from the Meteoritical Bulletin Database (https://www.lpi.usra.edu/meteor/, February 2020). Abbreviations are explained in the list of abbreviations. 
pendent fractionation effects, which lead to very large $\Delta^{\prime 17} \mathrm{O}$ variations (fig. 1.4). Anhydrous phases were formed first in the early Solar System, their $\delta^{17} \mathrm{O}$ and $\delta^{18} \mathrm{O}$ are low due to the equilibration with the unmodified nebula (Krot et al. 2002). Silicate minerals that were formed later exchanged and mixed with an isotopically enriched molecular cloud component. Hence, their compositions follow the mixing line (CCAM line, slope 1) towards higher delta values. Additional variation is created by I) low temperature re-equilibration/alteration on the parent body with aqueous fluids and II) loss of light water from small bodies (Young et al. 1999). Both processes are mass-dependent and follow a slope of approximately 0.52 , resulting in higher $\delta^{17} \mathrm{O}$ and $\delta^{18} \mathrm{O}$ values. Primitive chondrites exhibit the largest bulk variation in triple oxygen isotopes. The triple oxygen isotope composition of OC falls above the TFL (positive $\Delta^{\prime 17} \mathrm{O}$, isotopically enriched compared to Earth) with increasing $\delta^{18} \mathrm{O}$ and $\delta^{17} \mathrm{O}$ from $\mathrm{H}$ over L to LL chondrites (Clayton et al. 1983a, 1991). The triple oxygen isotope composition of EC are coincidentally lying on the TFL $\left(\Delta^{\prime 17} \mathrm{O}=0\right.$; Clayton et al. 1984). CC comprise the widest range in triple oxygen isotopes (Clayton and Mayeda 1999). CI have high $\delta^{18} \mathrm{O}$ values (strongly massfractionated oxygen) and show a $\Delta^{\prime 17} \mathrm{O}$ which is close to the TFL. CM show also higher $\delta^{18} \mathrm{O}$ values, but plot below the TFL (negative $\Delta^{\prime 17} \mathrm{O}$, isotopically depleted to Earth). CB, $\mathrm{CK}, \mathrm{CO}, \mathrm{CR}, \mathrm{CV}, \mathrm{CH}$ plot close to the CCAM line and all far below the TFL. R and K are very rare meteorite types. $\mathrm{R}$ have high $\Delta^{\prime 17} \mathrm{O}$ values (Bischoff et al. 2011), whereas $\mathrm{K}$ have low $\Delta^{\prime 17} \mathrm{O}$ values similar to CR (Weisberg et al. 1996). Achondrites show a smaller $\Delta^{\prime 17} \mathrm{O}$ range than primitive chondrites (Clayton and Mayeda 1996). Various samples from one differentiated body will plot along a line with the slope of $\sim 0.52$ due to mass-dependent fractionation processes. It is often speculated that Mercury and Venus might have lower $\Delta^{\prime 17} \mathrm{O}$ values (isotopically depleted) than Earth based on the information from Mars (based on SNC meteorites, Clayton and Mayeda 1983; isotopically enriched) and the Sun (based on solar wind measurements, McKeegan et al. 2011; isotopically depleted). Though, a triple oxygen isotope gradient in the inner Solar System is not yet proven. Warren (2011) found that the meteorites form two different populations in the $\Delta^{\prime 17} \mathrm{O}$ vs. $\epsilon^{54} \mathrm{Cr}$ space separated by a gap (often called 'Warren gap'). This correlation separates carbonaceous chondrites (CC) from the other non-carbonaceous (NC) chondrites and achondrites. It was suggested by Kruijer and Kleine (2017) that the formation of Jupiter created distinct inner and outer Solar System reservoirs, and that differences in the accretion history of these bodies created this dichotomy.

\subsubsection{Oxygen isotopes as tracer of impactor signatures}

Triple oxygen isotope systematics as a reconstruction tool for the provenance of impactor material in the Solar System provides three advantages: I) meteorite groups have distinct triple oxygen isotope compositions. This allows us to classify them and to characterise their parent bodies (Clayton et al. 1976, Greenwood et al. 2020); II) extraterrestrial oxygen isotope compositions often differ from the terrestrial/lunar value by several orders of magnitude (range: $\sim \pm 6000 \mathrm{ppm}$ ). This enables us to distinguish easily between material from the Earth-Moon system and beyond; III) the high analytical precision of $\Delta^{\prime 17} \mathrm{O}$ measurements $( \pm 5 \mathrm{ppm})$ - compared to the variation in the Solar System - makes this isotope system a high-resolution tool. Oxygen isotopes are consequently a very sensitive proxy for tracing extraterrestrial material (see chapter 6). 
An impact process comprises an exogenous impactor and an indigenous target (e.g. Earth or Moon). Vaporisation, excavation, mixing, melting and/or brecciation of impactor and target as well as the crater formation are consequences of an impact. Usually, most impactor material is volatilised and lost during the impact due to high temperatures and pressures, but small traces can still mix into the target rock. The product rock is called impact rock, it is changed by impact metamorphism and can contain a small addition of extraterrestrial material. Not every impact has an influence on the triple oxygen isotope composition of the product rock. Whether it does, depends on the meteorite type and the impactor/target rock mixing ratio. The mixing ratio depends on the physical parameters of the impact, for instance: impactor size, impact angle, impact velocity, and oxygen abundance of the impactor material (iron meteorites contain only little oxygen). The effect on the $\Delta^{\prime 17} \mathrm{O}$ value will be high if the impactor has a high oxygen isotope anomaly and/or the impact settings cause a high impactor/target rock mixing ratio. Not all 'impactinfluenced' rocks are also classified as impact rocks (especially on the Moon), the changes are gradual and sometimes difficult to determine. Rocks, which were clearly not modified by impacts (after the formation of the target and core segregation) are called 'pristine'. 


\subsection{Aim of the dissertation}

This dissertation aims at reconstructing the provenance of Solar System bodies accreted to the Earth-Moon system by means of oxygen isotope systematics. We strive to constrain the Moon-forming impactor as well as late accreted material to the terrestrial mantle and the lunar crust. For this purpose we analysed the triple oxygen isotope composition of rock samples from the Earth and the Moon. We want to gather information on the material flux in the Solar System to study the origin of the Moon and the water on Earth.

Project steps:

- Studying terrestrial feldspar-rich rocks as analogous to the feldspar-rich highland rocks of the Moon (chapter 4).

- Main questions: Is there a mineral-specific triple oxygen isotope anomaly affecting the measurements of feldspar-rich rocks. How precisely can we determine the triple oxygen isotope composition of feldspar-rich rocks?

- Studying pristine terrestrial and lunar rocks, which show no indication of influence by later meteoritic addition (chapter 5 and 6 ).

- Main questions: What is the pristine triple oxygen isotope composition of the bulk silicate Earth ('terrestrial background signature')? What is the pristine triple oxygen isotope composition of the bulk silicate Moon ('lunar background signature')? Are we able to constrain the provenance of the Moonforming impactor by a triple oxygen isotope comparison between Earth and Moon? Can we constrain the Moon formation scenario? Is the Moon homo- or heterogeneous in its triple oxygen isotope composition? Are there lithologydependent triple oxygen isotope variations?

- Studying terrestrial mantle rocks, which are missing a part of the late accretion (chapter 5) and lunar impact rocks, which were created by impacts during the phase of late accretion (chapter 6) in order to constrain the late accreted material.

- Main questions: Can we constrain the late accretion to the terrestrial mantle by comparing the Archean pre-late accretion mantle with the post-Archean mantle? Can we trace impactor signatures in lunar impact rocks using triple oxygen isotopes? Are we able to reconstruct the provenance of those impactors using triple oxygen isotopes? Do we find evidence that the late accretion was volatile-rich and has contributed to Earth's water budget? 


\section{Material}

This chapter provides general information on the studied rock types and the sample selection for this project. Detailed information on the individual samples can be found in the respective chapters and appendices. In this dissertation we were predominantly interested in universal or planetary-scale processes and less in individual geological settings. For our overall sample selection it was of less importance from where the sample originated then its representativeness for e.g. the studied lithology (chapter 4 and 6), a mantle reservoir (chapter 5) or a planetary body (chapter 5 and 6).

\subsection{Terrestrial feldspar-rich rocks}

Chapter 4 focuses on feldspar minerals. This mineral group consists of tectosilicates, whose crystal structure is characterised by a three-dimensional network built from negatively charged $\mathrm{SiO}_{4}$ and $\mathrm{AlO}_{4}$ tetrahedra. Positively charged cations are placed in the cavity spaces. The crystal symmetry is monoclinic or triclinic, depending on the cation composition (e.g. Papike et al. 1991, Okrusch and Matthes 2010). Three endmembers classify the feldspar mineralogy: orthoclase $\left(\mathrm{KAlSi}_{3} \mathrm{O}_{8}\right)$, albite $\left(\mathrm{NaAlSi}_{3} \mathrm{O}_{8}\right)$ and anorthite $\left(\mathrm{CaAl}_{2} \mathrm{Si}_{2} \mathrm{O}_{8}\right)$. Feldspar is the dominant rock-forming mineral of the terrestrial and lunar crust (> 50 vol\%; Okrusch and Matthes 2010, Tomkins and Pieters 1999). Feldspar minerals with a composition between the orthoclase and albite endmember are referred to as alkali feldspar (acidic feldspar) and minerals with a composition between the anorthite and albite endmember are called plagioclase (alkaline feldspar). The formation of mixed crystals is limited by an extensive miscibility gap between orthoclase and anorthite (e.g. Okrusch and Matthes 2010). The plagioclase is subdivided according to its anorthite content into: anorthite (100-90\%), bytownite (90-70\%), labradorite (70-50\%), andesine (50-30\%), oligoclase (30-10\%) and albite (10-0\%).

Terrestrial, feldspar-rich rocks are presented in chapter 4 . They resemble lunar, feldspar-rich rocks (highland rocks; see below): mafic, plutonic rocks of the gabbro family (fig. 2.1), which are predominantly composed of anorthite-rich (calcic) plagioclase (Papike et al. 1991), clino/orthopyroxene, and olivine. We selected two anorthosites, two norites, and one troctolite as material, which originate from different localities.

Three criteria were applied for sample selection: I) a high content of anorthite-rich plagioclase , II) diverse assemblages of mafic minerals, and III) a good preservation state. The preservation state became the crucial criterion, since the plagioclase has frequently shown evidence for alteration by terrestrial weathering and many samples had to be excluded from the study. The samples and the respective geological settings are described in chapter 4 in detail. 


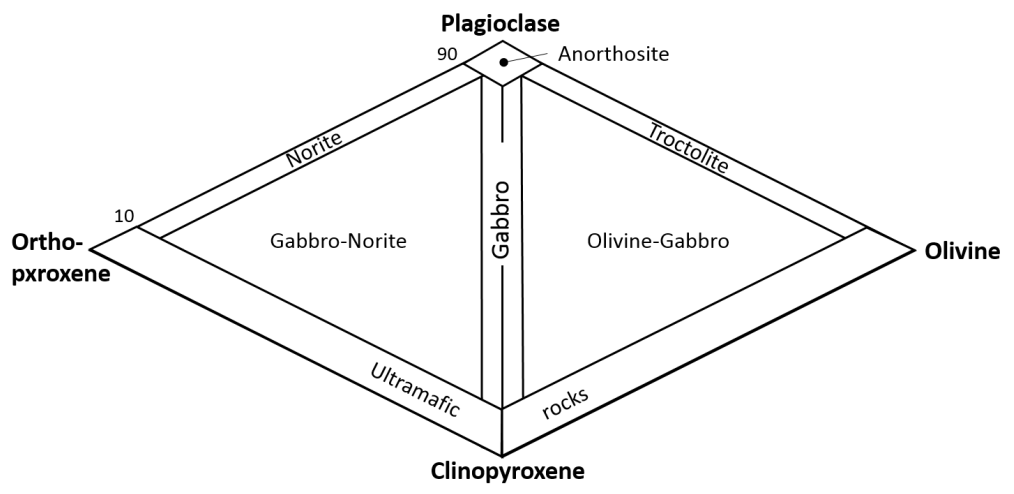

Figure 2.1: Classification of the gabbro family (modified from Maresch and Medenbach 1987). The diagramme provides an overview on the mineral assemblages of the different feldspar-rich rock types (gabbro, troctolite, norite and anorthosite).

\subsection{Terrestrial mantle rocks}

Chapter 5 of this dissertation focuses on the Earth's unaltered building material, the bulk silicate Earth. In the past, peridotites as well as mantle melts (mid ocean ridge basalts (MORB) and ocean island basalts (OIB)) were analysed representative for this domain of the Earth. We decided to study only peridotites, because mantle melts may be less reliable for our purpose (see appendix $\mathrm{C}$ for more information) and the Earth's mantle is predominantely composed of peridotite. Peridotites are ultramafic rocks (fig. 2.1), composed of at least $40 \%$ olivine, as well as orthopyroxene and clinopyroxene. The peridotite group is, according to their mineral ratios, further subdivided into dunites (mainly olivine), harzburgites (olivine and mainly orthopyroxene), wehrlites (olivine and mainly clinopyroxene) and lherzolithes (a more even mixture of the three minerals; Okrusch and Matthes 2010).

We aimed at comparing different mantle reservoirs, often referred to as the postArchean mantle (I) and the Archean pre-late veneer mantle (II). In order to study the post-Archean mantle (I) we selected material according to its pristinty and we seeked a widespread and diverse sample set. Figure 2.2A provides an overview of sample localities and how many samples were analysed. We analysed typically one sample of each locality for the post-Archean mantle reservoir. In order to characterise the Archean pre-late veneer mantle reservoir, we studied two localities in Europe and Asia in greater detail (details on the sample localities are provided in appendix C).

The sample selection was complicated by the scarce availability of unaltered peridotites at the terrestrial surface. Peridotites are usually found in form of xenolithes older mantle inclusions in younger basalts - which provide the most direct samples from the Earth's mantle. 

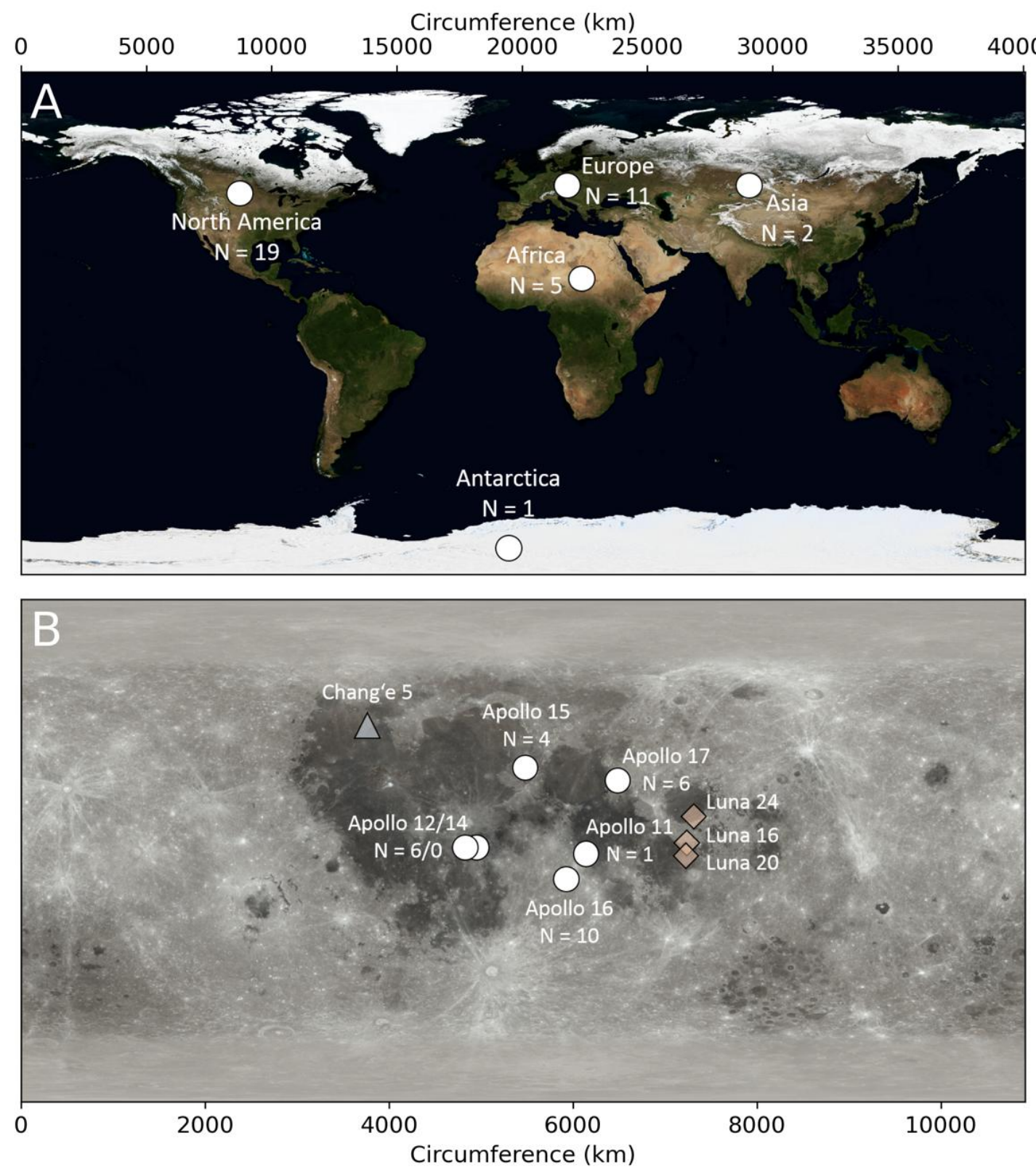

Figure 2.2: A map of the Earth (A) and the Moon (B) are shown with additional information concerning the sample sets analysed in chapter 5 and 6. A) Terrestrial samples from 5 different (sub/)continents, in total 38 samples, were analysed for the studies in chapter 5 (more details on the sample locations can be found in appendix C). Credit for the image of the Earth from April 2004 goes to Reto Stöckli, NASA Earth Observatory. B) Lunar samples from 5 different Apollo landing sites (white circles) were analysed in chapter 6. The total number of 27 lunar rocks samples is subdivided into 4 highland rocks, 8 mare basalts, 2 pyroclastic glasses, 2 KREEP-rich breccias (which are also impact rocks), 3 soils, and 8 impact rocks (more information in appendix D). The landing sites of the Luna sample return missions and Chang'e 5 are indicated by transparent orange diamonds and the transparent blue triangle, respectively. Credit for the image of the lunar surface goes to Ernie Wright and Noah Petro, NASA's Scientific Visualization Studio. 


\subsection{Lunar rocks}

The lunar geosphere was characterised by volcanism and impact processes in the early history, forming a diverse petrology in the first billion years of the Moon's existence, but is considered geologically inactive since then. Due to the lack of an atmo-, hydro-, or biosphere, the Moon's surface is not affected by weathering, transport, and sedimentation processes that we know from the Earth. However, the absence of an atmosphere enables alteration processes on the lunar surface, which we do not know from Earth (space weathering; e.g. Hörz et al. 1991, Lucey et al. 2006). The knowledge of the Moon's geology has improved dramatically since the Apollo missions and lunar sample return (e.g. Heiken et al. 1991). Nevertheless, there is still a need of further research, which is complicated by very severe accessibility. Next to the Apollo missions (USA; No.: 11-12, 14-17; year: 1969-1972; sample quantity: $382 \mathrm{~kg}$ ), only the Luna missions (UdSSR; No.: 16, 20, 24; year: 1970, 1972; sample quantity: $300 \mathrm{~g}$ ) and the Chang'e 5 mission (China; year: 2020; sample quantity: $2 \mathrm{~kg}$ ) returned lunar rock samples (Vaniman et al. 1991, fig. 2.2).

Chapter 6 of this dissertation focuses on (I) the pristine Moon and (II) the geological impact record of the Moon. We studied 27 lunar rock samples from the Apollo missions provided by the NASA's Curation and Analysis Planning Team for Extraterrestrial Materials (CAPTEM) along with all relevant lunar lithologies. Figure 2.2B provides an overview of the sample origin. In the following, we refer to a simple lithological classification scheme, a comprehensive summary of more elaborate classification schemes can be found e.g. in Taylor et al. (1991).

In part (I) of chapter 4 we investigated lunar highland rocks, mare basalts, and pyroclastic glasses. These rock types are pristine, not contaminated by impactor material, and represent the original Moon.

The highland rock group comprises ferroan anorthosites, $\mathrm{Mg}$-rich(/-suite) rocks (norites, troctolites, gabbros and dunites), and KREEP-rich rocks (e.g. Taylor et al. 1991). These rocks are the oldest lunar lithologies and the ferroan anorthosites represent the primordial lunar crust. The term 'highland rocks' was chosen because these rock types form the rough mountain ranges that determine the topography on the lunar surface (e.g. Vaniman et al. 1991). Highland rock areas are heavily cratered by meteorite impacts due to their ancient age (oldest rocks are 4.45 to $4.35 \mathrm{Ga}$, Carlson et al. 2014). All of these rocks contain a large amount of white, anorthite-rich plagioclase (Papike et al. 1991, see above feldspar-rich rocks), which causes the bright colour of the lunar crust. The leading theory concerning this phenomenon is part of the lunar magma ocean hypothesis: plagioclase with a relatively low density was accumulated in the lunar crust because the mineral floated to the surface during the solidification of the lunar magma ocean (Wood et al. 1970). The formation of ferroan anorthosites is considered to be directly linked to this mechanism. Other highland rock types have formed at a later stage (Taylor et al. 1991). The Mg-suite rocks could have formed by the magma ocean, but most of the rocks are younger and seem to have assimilated urKREEP material (see below) and ferroan anorthosites indicating a later volcanic origin (e.g. Vaniman et al. 1991). An alternative explanation for the variety of lunar lithologies is serial magmatism (Longhi and Ashwal 1985). KREEP-rich rocks are rich in potassium (K), rare-earth elements (REE), phosphor $(\mathrm{P})$, and often also in uranium and thorium. The leading hypothesis is that the KREEP signature originates from a special zone in the lunar mantle, which represents the last 
crystallisation residuum of the lunar magma ocean — so-called urKREEP — that was extremely enriched in incompatible elements (Warren and Wasson 1979). KREEP-rich rocks are typically breccias or basalts, which gained the urKREEP component by assimilation or impact-induced brecciation. Only a comparably small number of KREEP-rich samples are pristine, most are impact-influenced breccias (Warren and Wasson 1979). The KREEP-rich breccias that were investigated for this dissertation are not pristine, but impact-influenced (see below).

The mare basalts are younger and were created during the mare volcanism $(4.0-2.0 \mathrm{Ga}$, e.g. Hiesinger et al. 2000). They were produced by the partial melting of lunar mantle cumulates (rich in olivine and pyroxene) that were created during the magma ocean phase. The mare volcanism occurred during a time where the Moon was still heavily bombarded and basaltic material flooded many craters, creating the so-called maria. These dark coloured basins are visible from Earth and cover approximately $16 \%$ of the lunar surface on the nearside (farside only 1\%; Vaniman et al. 1991). The mare basalts were intensively sampled by the sample return missions, also because the robust, flat maria surfaces provided adequate landing sides for spacecrafts. There are several mare basalt types with strongly varying titanium oxide $\left(\mathrm{TiO}_{2}\right)$ content (e.g. Pieters 1978). The simplest classification scheme separates mare basalts according to their $\mathrm{TiO}_{2}$ content (e.g. Taylor et al. 1991): high-Ti mare basalts (>9 wt\%; mainly Apollo 11 and 17), low-Ti mare basalts (1.5-9 wt\%, a diverse group sampled during Apollo 12, 15 and 16), and very low-Ti mare basalts (VLT; $<1.5 \mathrm{wt} \%$, rare, sampled during Apollo 17 and Luna missions).

Lunar pyroclastic glasses were also created during the mare volcanism by degassingdriven lava fountain eruptions (e.g. Taylor et al. 1991). These glasses represent the most primitive and direct samples of the lunar mantle. Most of these pyroclastic deposits experienced transportation, only the orange glass sampled during Apollo 17 was found in proximity to the lava fountain location (Taylor et al. 1991). Glass droplets are also created during meteorite impacts, making the separation between these two glass types an important, yet difficult task (see e.g. Delano 1986).

We studied lunar impact rocks (melt rocks and breccias) and soils for the second part of the study (II). Both lithologies are - if not directly created by impact events (impact rocks) - at least strongly influenced by those (soils). Impact-influenced rocks dominate the lunar surface due to the constant and unblocked meteorite bombardment. The most convenient way of distinguishing between pristine and impact-influenced rocks is analysing their HSE concentrations (see chapter 1).

Lunar soil is the fine-grained fraction $(<1 \mathrm{~cm})$ of the lunar regolith (unconsolidated debris, e.g. McKay et al. 1991), which covers the lunar surface with a several meter thick layer. Regolith is created by micrometeorite bombardment, which results in shattering, mixing, melting of material, and the formation of glassy agglutinates (e.g. Spray 2016). Solar wind irradiation leads to the implantation of $\mathrm{H}, \mathrm{He}$ and other elements (Hörz et al. 1991). These maturation processes continue until the material is buried by a new layer of ejecta from an impact event. The regolith layer is stratified with several soil horizons (e.g. Spray 2016). The maturity of a lunar soil can be assessed by the grain size distribution, as well as the amount of implanted solar wind and agglutinates (McKay et al. 1991). Next to indirect evidence (chemical signatures), regolith also contains the most direct evidence of accretion: projectiles. Intact asteroidal fragments were found in lunar regolith (e.g. Joy et al. 2012), but so far no planetary or cometary silicate debris were identified (e.g. Joy 
et al. 2016).

Impact rocks are created by large high-energy impact events, which overprint the target rock with impact metamorphism: vaporisation, excavation, mixing, melting, and/or brecciation. These rocks can vary between polymict breccias and impact melt rocks. Polymict breccias are composed of shattered, mixed, and recompacted older rock fragments. Impact melt rocks were formed by impact-induced melting (melt pool material). Both rock types are predominantly composed of the target rock but may also contain chemical traces of the impactor material (impactor contamination; e.g. Puchtel et al. 2008). Impact rocks are typically characterised by a complex petrography, making the classification a challenging task, since clasts, matrix, and texture(s) have to be considered (e.g. Taylor et al. 1991). They are subdivided into fragmental breccias (matrix: fine-grained fragments), glassy melt breccias (matrix: impact melt glass), crystalline melt breccias (matrix: crystallised impact melt), clast-poor impact melt rocks, granulitic (metamorphic) breccias (alteration and recrystallisation of older breccias), dimict (twocomponent) breccias (target rock and impact melt), and regolith breccias (compacted regolith, preserved features). Monomict breccias are classified as crushed but still pristine lunar (highland) rocks (Taylor et al. 1991). 


\section{High-precision triple oxygen isotope measurements of silicates}

This chapter describes the analytical procedure of the conducted triple oxygen isotope measurements. The rock studies in chapter 4 were complemented by petrographical examinations of thin sections and electron microprobe measurements. Additional information on these analyses can be found in the respective chapter and appendix.

Laser fluorination in combination with dual-inlet gas source isotope ratio mass spectrometry (IRMS) is currently the most precise method to acquire high-precision triple oxygen isotope measurements of silicates (Sharp 1990, Pack et al. 2016). The preceding conventional technique comprised the fluorination at $600-700{ }^{\circ} \mathrm{C}$ in externally heated nickel (Ni) reaction vessels (Clayton and Mayeda 1963). Laser fluorination of rock samples advanced to a degree which allows to detect smallest - also mass-dependent variations in silicates (Pack and Herwartz 2014). However, this approach requires careful and precise sample pretreatment, reaction, gas purification, and measurements which will be described in the following.

\subsection{Laser fluorination technique}

The laser fluorination technique is a procedure to extract oxygen gas $\left(\mathrm{O}_{2}\right)$ from silicates and was conducted using the bromine pentafluoride $\left(\mathrm{BrF}_{5}\right)$ fluorination line at the University of Göttingen (fig. A.1). The fluorination line consists of a high-vacuum, stainless steel tube system for the extraction and purification of $\mathrm{O}_{2}$. The analytical procedure is subdivided in four major steps: (I) sample preparation, (II) $\mathrm{O}_{2}$ extraction from silicates by means of laser fluorination with a $\mathrm{BrF}_{5}$ reagent, (III) gradual $\mathrm{O}_{2}$ purification, and (IV) $\mathrm{O}_{2}$ transfer to the IRMS. The procedure was stepwisely automated using LabView ${ }^{T M}$ in order to enhance both, analytical reproducibility and the sample throughput. During the period of triple oxygen isotope measurements described in chapter 4 , only the gas purification procedure and the transfer to the mass spectrometer were automated. The complete analytical procedure was automated at a later stage (chapter 5 and 6).

Sample preparation Terrestrial rock samples (see chapter 4 and 5) were analysed as grained mineral separates. The rocks were crushed using a steel mortar and material was sieved in different grain size fractions. Mineral separates were prepared from the 0.50 $0.25 \mathrm{~mm}$ or the $0.25-0.125 \mathrm{~mm}$ fraction. The grains were all inspected by microscopy to ensure analysis of clear, unweathered grains only. We analysed lunar samples (chapter 6) predominantly as whole rock samples, either as powder or as fine-grained material 
in order to achieve homogeneity. In case of rock chips, we crushed the material in an agate mortar under clean conditions. In some cases we also prepared different lunar rock fractions (see appendix D).

Depending on the sample type and the chosen laser fluorination system (see below), samples and standard material were put on one 14-pit sample holder or eight 2-pit sample holders (fig. A.5), both composed of Ni alloy. The sample amounts were adapted, so that $\sim 30 \mu \mathrm{mol} \mathrm{O}_{2}$ was released during the laser fluorination $(\approx 1.8-2.1 \mathrm{mg}$ depending on the chemical composition of the sample).

Laser fluorination Silicates are reacted with excess $\mathrm{BrF}_{5}(p \sim 100$ mbar) under laser heating in a stainless-steel sample chamber to release $\mathrm{O}_{2}\left(50 \mathrm{~W} \mathrm{CO}_{2}\right.$ laser, Synrad, Washington, USA; eq. 3.1).

$$
5 \mathrm{SiO}_{2}+4 \mathrm{BrF}_{5} \rightarrow 5 \mathrm{SiF}_{4}+5 \mathrm{O}_{2}+2 \mathrm{Br}_{2}
$$

The laser heating was originally controlled manually (chapter 4), but was later automated (chapters 5 and 6). The automated laser heating of the samples is based on a line scan pattern covering the selected circular pit on the holder. This procedure allows a very regular and accurate heating of the sample during laser fluorination and maximises the reproducibility. Though, different materials require different laser methods, the number of scans and required laser intensities can vary depending on the reactivity of the selected material (fig. A.6).

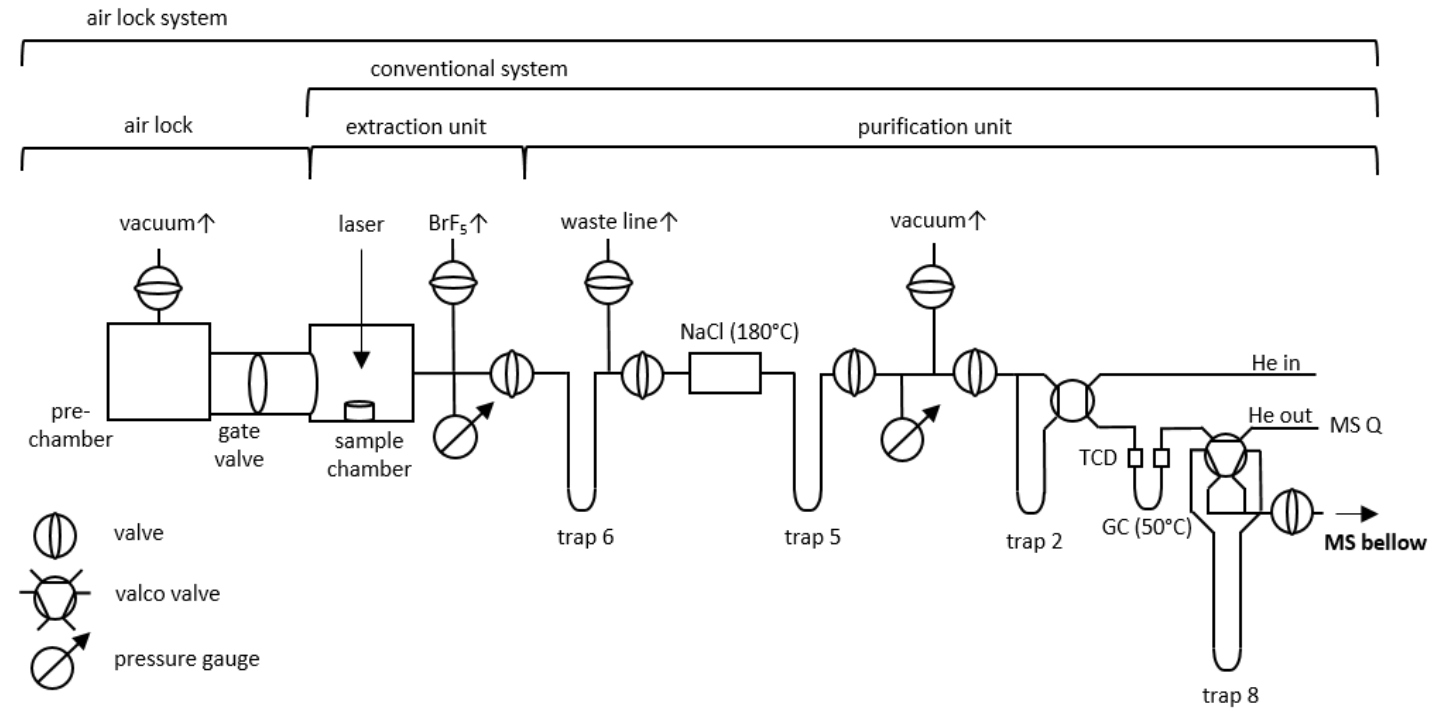

Figure 3.1: Simplified schematic structure of the $\mathrm{BrF}_{5}$ fluorination line (modified after Pack et al. 2016). The fluorination line consists of a high-vacuum tube system to extract and purify $\mathrm{O}_{2}$ from silicate materials. The line is fully computer operated and automated (using LabView $\left.{ }^{T M}\right)$. All illustrated traps are cooled cryogenically using liquid nitrogen $\left(\mathrm{N}_{2} ; T=-192^{\circ} \mathrm{C}\right)$ and can be automatically heated during sample runs $\left(T \approx 500^{\circ} \mathrm{C}\right)$. A pre-chamber with an air lock (air lock system) was attached to the sample chamber in addition to the conventional system. Several aspects were omitted in this figure for simplicity. The most crucial differences are, that (I) the $\mathrm{BrF}_{5}$ fluorination line has two parallel sample chambers for continuous measurements, (II) alternatively to $\mathrm{BrF}_{5}$ also fluorine ( $\mathrm{F}_{2}$ ) can be used for the laser fluorination, (III) an argon (Ar) bottle is attached to the system for venting the chambers, (IV) the vacuum system (two rough pumps, one turbomolecular pump) and (V) the waste system are more complex $\left(\mathrm{BrF}_{5}\right.$ and other fluoridic side products are reacted with activated carbon for disposal), and (VI) there is an extra cryogenic trap upstream of the gas chromatograph (GC) as extra safety measure and for the cleaning of helium (He).

The conventional system (fig. 3.1) is used for robust material types (e.g. olivine, pyroxene), which do not spontaneously react with $\mathrm{BrF}_{5}$ at room temperature. In this case a 
14-pit sample holder is directly inserted into the sample chamber. During every extraction the sample chamber is set under $\mathrm{BrF}_{5}$ atmosphere and the samples are fluorinated individually by targeting and heating with the laser. The air lock system (fig. 3.1, fig. A.4) was designed to process more labile or water-bearing material types (e.g. feldspar, clay minerals), which may spontaneously react with $\mathrm{BrF}_{5}$ at room temperature. In this case the samples are stored in an evacuated pre-chamber and individual 2-pit sample holders are inserted into the sample chamber with a linear transfer stage. Using this analytical setup we can avoid the contact between labile samples and $\mathrm{BrF}_{5}$ during an analytical session until the fluorination of these samples is intended. This makes pre-reactions impossible and prohibits cross-contamination during the measurements. The conventional system was used for the measurements described in chapter 5 and 6. The air lock system was used for most of the analytical work in chapter 4 . We conducted an experimental study on the laser fluorination of feldspar and compared the conventional system with the air lock system (for more details see chapter 4).

Before initiating the laser fluorination, the samples were often pre-melted depending on the material type, and afterwards the sample chamber was pre-fluorinated $(\sim 4$ times, $\sim 50 \mathrm{mbar}^{\mathrm{BrF}} 5,10 \mathrm{~min}$ ) to eliminate moisture. In case of the conventional system this pre-fluorination is cleaning not only the sample chamber, but also the 14-pit sample holder. This cannot be applied to the 2-pit sample holders of the air lock system without risking the pre-reaction of the labile sample material. Hence, the sample chamber is pre-fluorinated without any sample holder. Blank measurements were routinely performed before the beginning of each session. We found via the blank measurements that the moisture on the relative small 2-pit sample holder is negligible (for more details see chapter 4).

Gas cleaning The extracted $\mathrm{O}_{2}$ is purified using a cryogenic trap (\#6; liquid $\mathrm{N}_{2}: T=$ $-192{ }^{\circ} \mathrm{C}$ ) to eliminate residual $\mathrm{BrF}_{5}$ and other condensable gases (reaction side products). The remaining gas was further cleaned from other fluoridic components $\left(\mathrm{F}_{2}, \mathrm{HF}\right.$ etc. $)$ by a heated sodium chloride trap $\left(\mathrm{NaCl} ; T=180^{\circ} \mathrm{C}\right)$, which binds fluorine $\left(\mathrm{F}_{2}\right)$ and releases chlorine $\left(\mathrm{Cl}_{2}\right)$. The $\mathrm{Cl}_{2}$ is separated afterwards by another cryogenic trap (\#5; eq. 3.2).

$$
\mathrm{F}_{2}+2 \mathrm{NaCl} \rightarrow 2 \mathrm{NaF}+\mathrm{Cl}_{2}
$$

The $\mathrm{O}_{2}$ is then trapped on a $5 \AA$ molecular sieve using liquid nitrogen (trap \#2) and passed through a gas chromatograph (GC; Hewlett Packard 5890 Series II gas chromatograph, $T=50^{\circ} \mathrm{C}$ ), which uses a helium $(\mathrm{He})$ carrier gas with a flow rate set to $10 \mathrm{ml} \mathrm{min}^{-1}$ to remove traces of nitrogen $\left(\mathrm{N}_{2}\right)$, nitrogen trifluoride $\left(\mathrm{NF}_{3}\right)$ or carbon tetrafluoride $\left(\mathrm{CF}_{4}\right)$. A quadrupole mass spectrometer (MS Q; PrismaPlus QMG $220 M$ by Pfeiffer Vacuum, Asslar, Germany) was connected to the system to monitor the gas separation of the GC. An in-line thermal conductivity detector (TCD) allowed to monitor the extracted gas volumes (yield determination, uncertainty $\pm 3 \%$ ).

Transfer to the mass spectrometer The purified $\mathrm{O}_{2}$ is passed to the mass spectrometer in a He stream through capillaries and collected cryogenically on another $5 \AA$ molecular sieve immersed in liquid nitrogen (trap \#8). After pumping residual $\mathrm{He}$, the trap is set to $50{ }^{\circ} \mathrm{C}$ (water bath) and the $\mathrm{O}_{2}$ is expanded into the sample bellow of the dual-inlet system. 


\subsection{Stable isotope ratio mass spectrometry}

Triple oxygen isotope compositions were measured with a Thermo Scientific ${ }^{T M} M A T$ $253^{T M}$ and a Thermo Scientific ${ }^{T M} 253$ Plus ${ }^{T M} 10 \mathrm{kV}$ IRMS (fig. A.2). ${ }^{17} \mathrm{O} /{ }^{16} \mathrm{O}$ and ${ }^{18} \mathrm{O} /{ }^{16} \mathrm{O}$ ratios of the samples were determined by measuring $\mathrm{O}_{2}^{+}$ion beams with $m / z=32,33,34$ for 60 cycles (equals to $\sim 2 \mathrm{~h}$; chapter 4: 20-40 cycles), relative to a reference gas that was calibrated against the VSMOW2 water standard (Pack et al. 2016, dual-inlet technique). The reference gas oxygen (6.0 grade) has an isotopic composition of $\delta^{18} \mathrm{O}=15.7 \%$ and $\Delta^{\prime 17} \mathrm{O}=-450 \mathrm{ppm}$ vs. VSMOW2. $26 \mathrm{~s}$ integration time and $15 \mathrm{~s}$ idle time were applied for the measurements. The target signal intensity on mass 32 was adjusted to 5-5.5 V. No automatic filtering of the data for outliers was applied.

We routinely scanned the sample gas composition in the range from 11 to $100 \mathrm{amu}$ using the mass spectrometer to check for gas contamination (fig. 3.2). This is a useful tool to monitor the performance of the extraction and purification procedure. Most malfunctions of the $\mathrm{BrF}_{5}$ fluorination line system have an effect on the sample gas matrix and can be detected during the session using the mass scans. We also monitored the match between the gas matrices of different sample materials. Differences in the gas matrices could create systematic artefacts leading to wrong interpretations. Already small interferences on mass 33 created by contaminants can significantly affect the $\Delta^{\prime 17} \mathrm{O}$ (see e.g. Pack et al. 2007). We cleaned our sample gas intensively (only smallest traces of $\mathrm{Ar}, \mathrm{N}_{2}$ and $\mathrm{CF}$-compounds remained) and did not observe any significant gas matrix variations for the studied silicates. We payed special attention to this during the analytical work performed in chapter 6 (for more details see this chapter). By checking the gas matrices we ensured highest measurement quality.

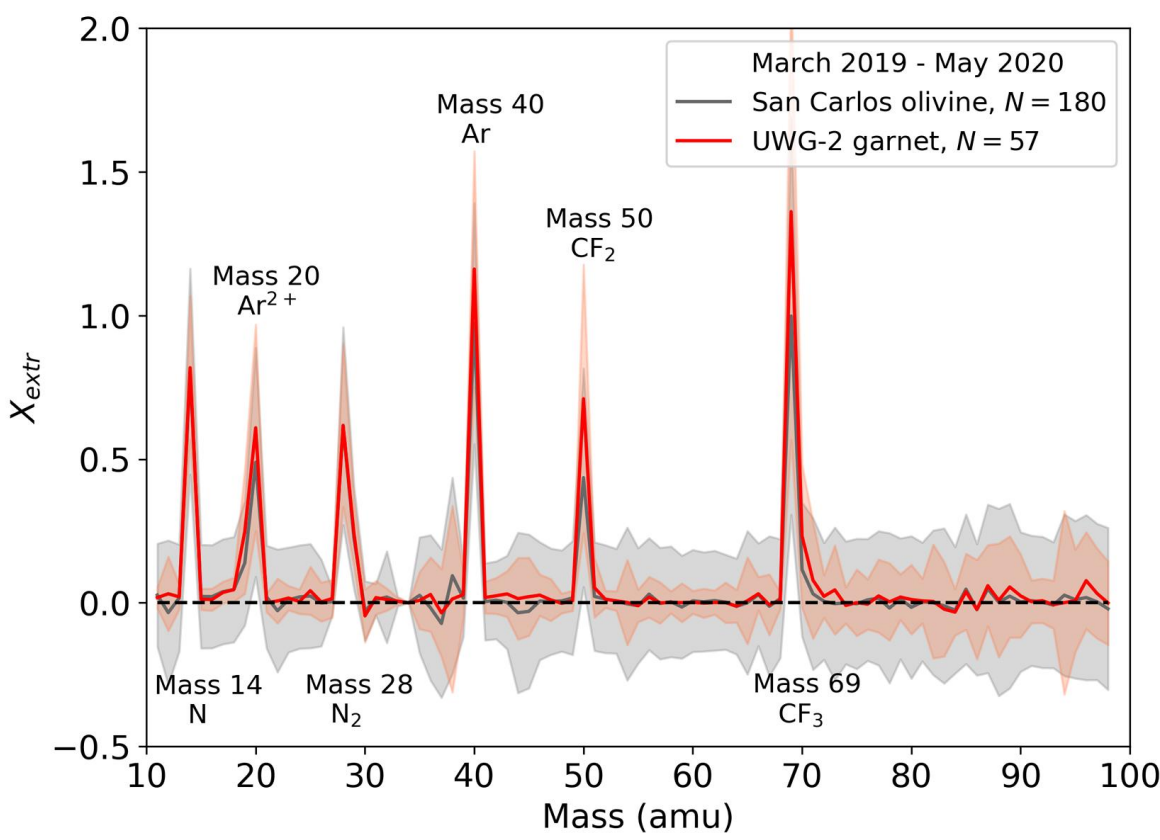

Figure 3.2: Gas matrix match of the San Carlos olivine and UWG-2 garnet standards between March 2019 and May 2020 (time period of the lunar rock measurements). The average gas matrix match between the UWG-2 (red line) and the terrestrial San Carlos olivine standard (grey line) is shown $\pm 1 \sigma \mathrm{SD} . \mathrm{X}_{\text {extr }}$ represents the excess of components in the sample gas relative to the reference gas (normalised to mass 34 and on log scale; eq. 3.3). $\mathrm{X}_{\text {extr }}$ is displayed on the $\mathrm{y}$-axis for the masses 11-100 (x-axis). The plot helps to visualise trace contaminations in the sample gas, which originate from the laser fluorination. 


$$
X_{\text {extr }}=\log \left(\frac{\left(\frac{\mathrm{I}(\operatorname{mass} \mathrm{x})}{\mathrm{I}(\operatorname{mass} 34)}\right)_{s m p}}{\left(\frac{\mathrm{I}(\operatorname{mass} \mathrm{x})}{\mathrm{I}(\operatorname{mass} 34)}\right)_{s t d}}\right)
$$

The parameter I represents the intensity of the respective mass in $\mathrm{mV}$ measured for the sample (smp) and reference gas (std).

\subsection{Standard normalisation}

Two mineral standards were used during the analytical work of this dissertation: San Carlos olivine and UWG-2 garnet. San Carlos olivine originates from olivine nodules of a peridotite (spinel lherzolite) located near Globe, Arizona, USA (Lausen 1927). UWG2 garnet originates from garnet porphyroblasts in a mafic amphibolite (granulite facies) from the Gore Mountain mine, Adirondack Mountains, New York, USA (Valley et al. 1995). We typically analysed 2-3 standards for each rock sample. We applied standard bracketing to monitor the performance of the session effectively. All triple oxygen isotope data in this dissertation is normalised to the San Carlos olivine or UWG-2 garnet measured in the respective analytical session (average deviation). We used two different San Carlos olivine fractions, internally referred to as $0215 \mathrm{M}$ and 0919 , which have different $\delta^{18} \mathrm{O}$ values $(5.18 \%$ and $5.34 \%$; based on UWG-2 garnet: table A.1 and A.2), but within uncertainty identical $\Delta^{\prime 17} \mathrm{O}$ values of $-51.8 \mathrm{ppm}$ (mean value of the following studies Pack et al. 2016, Sharp et al. 2016, Wostbrock et al. 2020). The San Carlos olivine 0215M was used for all sessions with sample IDs smaller than 5900, the San Carlos olivine 0919 was used for sessions with higher sample IDs (the sample ID information can be found in the detailed tables in the respective appendices). Two different UWG-2 fractions were used (\#180 and \#200), which have identical triple oxygen isotope compositions within uncertainty: $\delta^{18} \mathrm{O}=5.75 \%$ (Valley et al. 1995), $\Delta^{\prime 17} \mathrm{O}_{0.528}=-59.9 \mathrm{ppm}$ (based on San Carlos olivine: table A.3 and A.4). The UWG-2 garnet \#180 was used for all sessions with sample IDs smaller than 5902, the UWG-2 garnet \#200 was used for sessions with higher sample IDs.

\subsection{Corrections}

$\Delta^{\prime 17} \mathrm{O}$ values measured in November-December 2018 were additionally corrected against an interference on mass 33. The exact nature of the interfering species could not be determined, but the effect in $\Delta^{\prime 17} \mathrm{O}$ was accompanied by a rise of mass 88 . This might indicate the influence of $\mathrm{CF}_{4}$, which was fragmented and reacted with other compounds in the ion source. We determined the relation between mass 88 and the $\Delta^{\prime 17} \mathrm{O}$ empirically using standard materials (San Carlos olivine and UWG-2 garnet, fig. 3.3). The $\Delta^{\prime 17} \mathrm{O}$ was measured $\sim 10-20 \mathrm{ppm}$ too high in this time period, hence the data was corrected (eq. 3.4). This interference affected only the measurements of one session reported in chapter 4.

$$
\Delta^{\prime 17} \mathrm{O}_{\text {corr }}=\Delta^{\prime 17} \mathrm{O}_{\text {meas }}-\left(\left(\frac{\mathrm{I}(\operatorname{mass} 88)}{\mathrm{I}(\operatorname{mass} 34)}\right)_{\text {smp }} \cdot \text { slope }\right)
$$


The variable I represents the intensity of the respective mass in $\mathrm{mV}$ measured for the sample gas ( $s m p)$. The variable slope describes the relation between mass 88 and the $\Delta^{\prime 17} \mathrm{O}$ and was determined using standard materials (fig. 3.3).

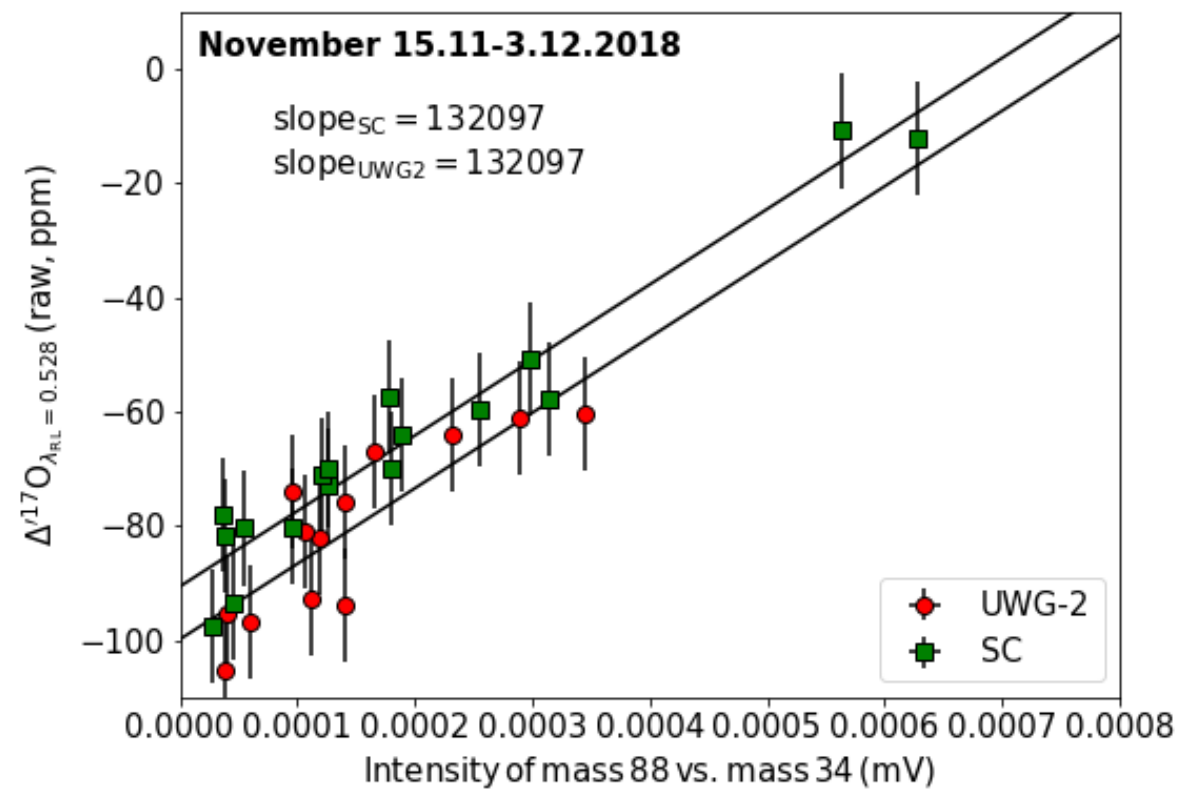

Figure 3.3: Correlation between the $\Delta^{\prime 17} \mathrm{O}$ values of the San Carlos olivine (SC) and the UWG-2 standard vs. the intensity of mass 88 normalised to the intensity of mass 34 . The $\Delta^{\prime 17} \mathrm{O}$ was affected due to an interference on mass 33 , which was associated with a rise of mass 88 (assumed: $\mathrm{CF}_{4}$ ). The correlation was used to correct the interference for the measurements conducted in November, which had elevated mass 88 levels.

\subsection{Analytical precision}

Long-term external reproducibility of the measurement procedure was $\pm 0.1 \%$ o $\left(\delta^{18} \mathrm{O}\right.$, $\pm 1 \sigma \mathrm{SD})$ and $\pm 5 \mathrm{ppm}\left(\Delta^{\prime 17} \mathrm{O}, \pm 1 \sigma \mathrm{SD}\right.$; based on San Carlos olivine data from the studies presented in chapter 4, 5 and 6). The measurement performance improved over time due to many technical upgrades. The most important improvements were the two-sample chamber setup (fig. A.3) and the full automatisation of the measurement procedure. This allowed us to run continuous, highly reproducible measurements with little possibility of personal biases ( $\sim 30 \mathrm{~h}$ sessions). We were able to extend the measurement time of the mass spectrometer and to run a higher standard-to-sample ratio, which decreased the instrumental and analytical uncertainty. One drawback of the air lock system is that it does not yet support the full automatisation of the measurement procedure.

For the work reported in chapter 4 our analytical precision (SD $\pm 1 \sigma)$ based on the San Carlos olivine fractions was $0.09 \%$ for $\delta^{18} \mathrm{O}$ and $7 \mathrm{ppm}$ for $\Delta^{\prime 17} \mathrm{O}(N=34)$. Every mineral specimen was analysed 3-10 times, resulting in a typical uncertainty of 0.03$0.04 \%$ in $\delta^{18} \mathrm{O}$ and $2-4 \mathrm{ppm}$ in $\Delta^{\prime 17} \mathrm{O}$. We discarded measurements with gas extraction yields $<80 \%$. For the work reported in chapter 6 our analytical precision based on the San Carlos olivine fractions was $\delta^{18} \mathrm{O}: 0.1 \%$ and $\Delta^{\prime 17} \mathrm{O}: 6 / 4 \mathrm{ppm}$ (San Carlos olivine $0215 \mathrm{M} / 0919 ; N=57 / 122$ ). This results in a $4 / 3 \mathrm{ppm}$ error for lunar samples that were measured twice. 


\section{Triple oxygen isotope fractionation in feldspar-rich rocks}

\subsection{Abstract}

This study is inspired by the debate on the origin of measured oxygen isotope compositions of feldspar-rich lunar rocks (highland rocks). It has been proposed that anorthiterich plagioclase shows a preference for ${ }^{16} \mathrm{O}$ over ${ }^{17} \mathrm{O}$ and ${ }^{18} \mathrm{O}$ leading to a systematically lower $\Delta^{\prime 17} \mathrm{O}$ in lunar highland rocks compared to mare basalts (Kohl et al. 2017). Crystal-chemical effects of the tectosilicate lattice structure were discussed as possible explanation for the lower $\Delta^{\prime 17} \mathrm{O}$ values. Alternative explanations are analytical artefacts concerning the oxygen isotope measurements of plagioclase or a more complex rock genesis including e.g. impact processes. We present high-precision triple oxygen isotope data on co-genetic mineral assemblages of five comparable terrestrial feldspar-rich rocks. Petrography and mineral chemistry of the samples were studied to confirm equilibrium between selected mineral phases. We found that oxygen isotope equilibrium in feldsparrich plutonic rocks is easily modified by secondary processes. We observed no systematically lower $\Delta^{\prime 17} \mathrm{O}$ values for the mineral plagioclase, and therefore found no evidence for a feldspar-specific isotope effect. Methodical deficiencies cannot be ruled out as an explanation for the currently available oxygen isotope data of feldspar-rich lunar rocks. Possible $\Delta^{\prime 17} \mathrm{O}$ heterogeneities of lunar rocks are on debate yet.

\subsection{Introduction}

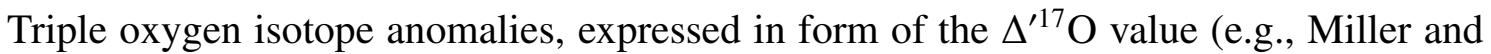
Pack 2021; $\left.\Delta^{\prime 17} \mathrm{O}=10^{3}\left[10^{3} \ln \left(\delta^{17} \mathrm{O} / 10^{3}+1\right)-0.528 * 10^{3} \ln \left(\delta^{18} \mathrm{O} / 10^{3}+1\right)\right]\right)$, are useful to reveal the provenance of rocky bodies in the Solar System (Clayton et al. 1973, Clayton 1993). High-precision measurements of lunar and terrestrial samples were applied for instance in the search for traces of the Moon-forming impactor (Wiechert et al. 2001, Spicuzza et al. 2007, Herwartz et al. 2014, Young et al. 2016, Greenwood et al. 2018, Cano et al. 2020). Kohl et al. (2017) observed systematically lower $\Delta^{\prime 17} \mathrm{O}$ values in lunar feldspar-rich rocks (highland rocks) compared to other lunar rocks e.g. mare basalts (average $\Delta \Delta^{\prime 17} \mathrm{O}_{M B-H R} \approx 12 \mathrm{ppm}$ ). The lattice structure of tectosilicates like anorthite, the dominant feldspar type on the Moon, was discussed by Kohl et al. (2017) as a possible reason for a preference of ${ }^{16} \mathrm{O}$ over ${ }^{17} \mathrm{O}$ and ${ }^{18} \mathrm{O}$ resulting in lower $\Delta^{17} \mathrm{O}$ values (crystalchemical effect). We refer to this hereafter as 'feldspar effect'. Alternatively, the variation 
in $\Delta^{\prime 17} \mathrm{O}$ of lunar rocks could be a measurement artefact. Resolvable variations are in the few-ppm range and interferences on mass 33 could lead to a small negative shift in $\Delta^{\prime 17} \mathrm{O}$ without visible effect on the $\delta^{18} \mathrm{O}$. Also, variations in the pressure baseline effect can lead to artefacts in $\Delta^{\prime 17} \mathrm{O}$ (Yeung et al. 2018). And, the laser fluorination of feldspar is challenging and could also be the cause for mineral-specific variations. A third possibility is that the studied lunar anorthosites record an actual heterogeneity within the Moon created e.g. by its formation (Cano et al. 2020), a more complex magmatic history or impactor contamination. This, however, will not be addressed in this chapter (see chapter 6 and appendix D).

We test the hypothesis of feldspar-specific enrichment of ${ }^{16} \mathrm{O}$ by studying well equilibrated anorthite-containing terrestrial mafic rocks. If feldspar has a preference for ${ }^{16} \mathrm{O}$, this should be resolved by a comparison of feldspar with other mafic minerals from the same rock (studied mafic minerals: clino/orthopyroxene, olivine, amphibole, biotite, magnetite or chromite). We had to assure that the minerals of each investigated sample crystallised in isotopic equilibrium for the accurate interpretation of our oxygen isotope data. The co-genetic relation of minerals in these rocks was carefully assessed using petrographical tools (polarisation microscopy, EMP measurements, line profiles and element mappings) and oxygen isotope measurements.

We also performed tests with different gas extraction protocols using the air lock system and conventional system in order to identify any analytical artefacts. It was argued that unaltered feldspar might instantly react with the fluorination agent. If multiple feldspar samples are placed in the sample chamber for consecutive oxygen extraction by laser fluorination (conventional analytical setup), the instability of feldspar may therefore lead to cross-contamination of isotopically fractionated oxygen (referred to as matrix oxygen) between different samples. The reactive behaviour of feldspar during fluorination was first observed by Clayton and Mayeda (1963), who extracted oxygen from feldspar by reacting it with $\mathrm{BrF}_{5}$ at $100{ }^{\circ} \mathrm{C}$. Elsenheimer and Valley (1992) reported that the reaction between $\mathrm{BrF}_{5}$ and feldspar starts already at $20^{\circ} \mathrm{C}$. Fiebig and Hoefs (2002) observed also matrix oxygen at room temperature using $\mathrm{F}_{2}$ for the laser fluorination.

Our aim is to provide insights into the oxygen isotope fractionation behaviour of feldspar and the methodical challenges associated with this material. We want to contribute to the discussion on the correct interpretation of the lunar oxygen isotope data.

\subsection{Samples and methods}

\subsubsection{Sampling}

We have investigated five mafic terrestrial rocks, which macroscopically appeared to be fresh and well equilibrated: one troctolite (ID: SOTA-07-04), two norites (A1, ID: AMI0-16; A2, ID: Norite-881647) and two anorthosites (B2, ID: DR-S2; B3, ID: DR-S3; fig. 4.1).

The troctolite is a crustal xenolith from the Casablanca volcano in central Chile (LopezEscobar et al. 1995). The Casablanca strato-volcano is the highest eruptive center of the Antillanca volcanic complex (Bertrand et al. 2008, González-Ferrán 1994). The Antillanca volcanic complex is part of the Central Southern Volcanic Zone (CSVC) of the 
Andes (Hickey-Vargas et al. 2016). The sample was collected from the phreatomagmatic deposits of the Rayhuén crater (Casablanca 4 unit).

The two norite samples (A1 and A2) originate from the Amikoq Layered Complex in the Fiskefjord area, southwest Greenland. The Amikoq complex (3050-3071 Ma, Szilas et al. 2015a) is one of several deformed layered intrusive complexes of the Mesoarchean Akia terrane. These complexes are composed of mainly mafic amphibolites, metagabbroic rocks and ultramafic peridotites (Garde 2007). Our samples represent mafic norites, which are intercalated with peridotites in the Amikoq complex (Szilas et al. 2015a). The norite samples A1 and A2 were sampled at different outcrops.

The two anorthosite samples (B2 and B3) are from the $2.05 \mathrm{Ga}$ old layered intrusion of the Bushveld Igneous Complex (South Africa), which is composed of ultramafic-mafic cumulates. The samples comprise the host anorthosite (footwall) interleaved with the Upper Group (UG1) stratiform chromitite layers/seams (Upper Critical Subzone of the eastern limb of the complex; Voordouw et al. 2009). The rocks were sampled from an outcrop close to the Dwars River National Monument.

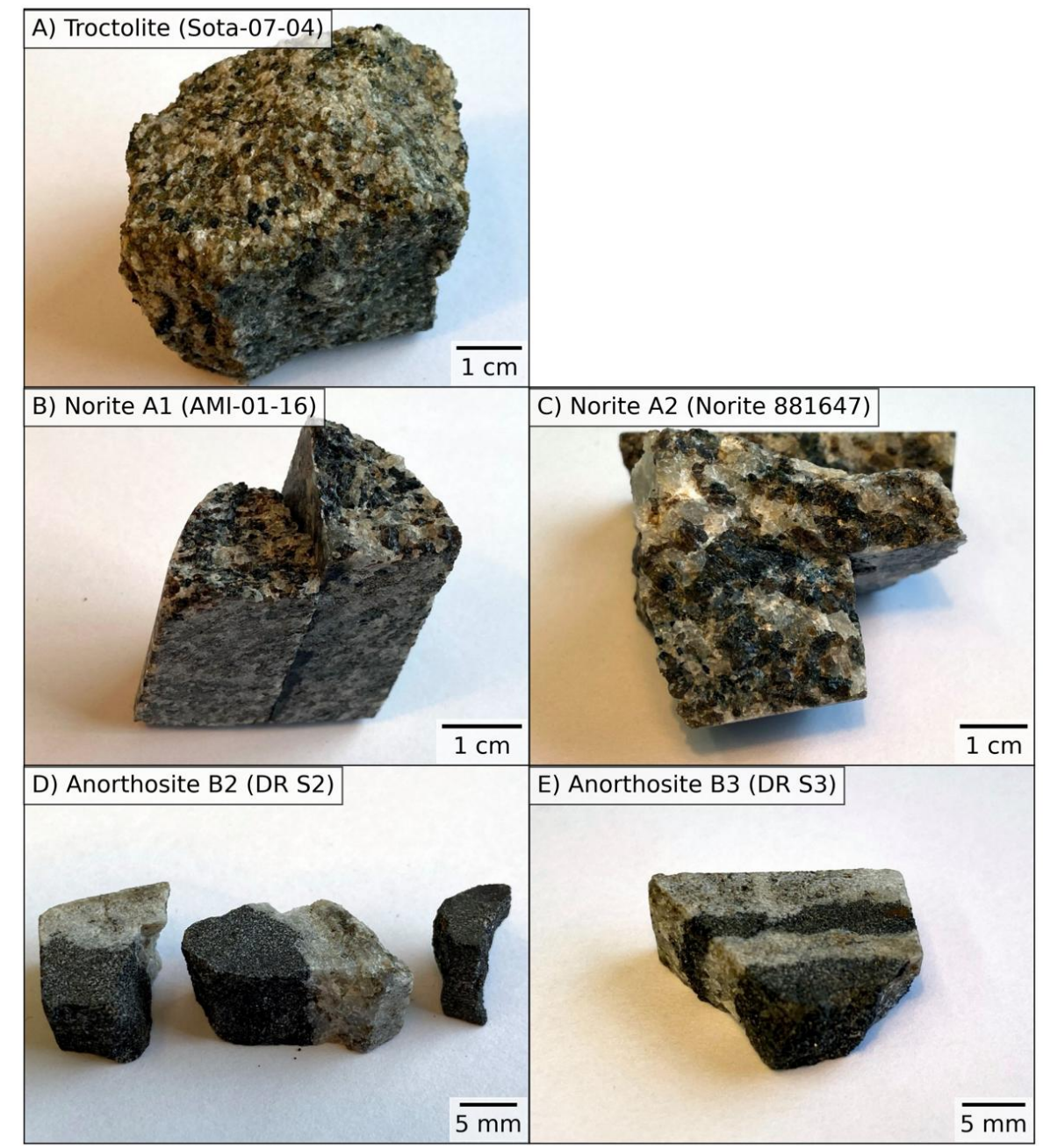

Figure 4.1: Images of the studied rock samples: troctolite (A), norite A1 (B) and A2 (C), anorthosite B2 (D) and B3 (E). Anorthosite $\mathrm{B} 2$ and $\mathrm{B} 3$ comprise light-coloured anorthosite intercalated with dark chromitite layers. 


\subsubsection{Petrographic examination}

Thin sections of the samples were prepared and studied by means of polarisation microscopy (Axioplan, ZEISS). Images were acquired using the attached microscope camera (AxioCam MRc5, ZEISS).

\subsubsection{Electron probe micro analyses (EPMA)}

The compositions of the mineral assemblages of each rock sample were determined using a JEOL JXA 8900 RL electron microprobe. Line profiles and element mappings across grain boundaries were generated in order to test for mineral zonation, diffusive exchange of elements or other alteration features. The quantitative measurements were conducted using $20 \mathrm{kV}$ accelerating potential and a beam current of $0.6 \mathrm{nA}$. In case of the feldspar the electron beam was defocused (beam diameter: $20 \mu \mathrm{m}$ ) to prevent beam damage of the sample. The EPMA data are reported with the respective $2 \sigma$ errors.

\subsubsection{Oxygen isotope analyses}

We conducted oxygen isotope measurements on mineral separates applying laser fluorination in combination with a dual-inlet gas source isotope ratio mass spectrometry (IRMS) (Sharp 1990) according to the procedure described in chapter 3 (additional information in appendix sec. B.1). The air lock system was connected to the $\mathrm{BrF}_{5}$ fluorination line in order to use the pre-chamber and small 2-pit sample holders. Using this analytical setup we can avoid the contact between feldspar samples and $\mathrm{BrF}_{5}$ during an analytical session until the fluorination of these samples is intended. The air lock system was used for most of the measurements. For the other measurements an equivalently precise and accurate alternative was used, the conventional system in combination with the conversion of the sample into a glass bead by melting prior to the fluorination (see sec. 4.5). Two different fractions of San Carlos olivine and UWG-2 garnet were used as standard materials for this study (SC 0215M and SC 0919, UWG-2 \#180 and UWG-2 \#200). Every mineral specimen was analysed 3-10 times, resulting in an uncertainty for the samples of typically $0.03-0.04 \%$ in $\delta^{18} \mathrm{O}$ and 2-4 ppm in $\Delta^{\prime 17} \mathrm{O}$. We discarded measurements with gas extraction yields $<80 \%$. The uncertainty of the yield calculation is $\pm 3 \%$.

\subsection{Results}

\subsubsection{Petrography}

Troctolite The troctolite is composed of $\sim 45 \mathrm{vol} \%$ transparent plagioclase, $\sim 50 \mathrm{vol} \%$ yellow-green olivine, $\sim 4$ vol\% dark green clinopyroxene, and $\sim 1$ vol\% opaque magnetite (fig. 4.2A/B, fig. B.1A-C). The rock has a fine- to medium-grained phaneritic, equigranular texture. Only the magnetite is fine-grained and typically occurs as inclusion in the other minerals. The main minerals are subhedral and their shapes are equant to tabular. The fabric is hypidiomorph. There are some cracks and undulosity effects. 
Norite A1 and A2 Norite A1 is composed of 50 vol\% transparent plagioclase, 35 vol\% brown orthopyroxene, and $\sim 15$ vol\% green amphibole (fig. 4.2C/D, fig. B.1DF). Texture is medium-grained, phaneritic and equigranular. The orthopyroxene and amphibole show a weak preferred orientation, which could be inherited from the cumulate layering of the protolith that was later partly annealed. The orthopyroxene and amphibole grains are tabular, the plagioclase grains are equant. The fabric is hypidiomorph to xenomorph. Plagioclase often shows $120^{\circ}$ triple point junctions. The sample is a cumulate that has been recrystallised and re-equilibrated. The rock experienced depressurisation, this is indicated by concentrical cracks around plagioclase inclusions in orthopyroxene.

Norite A2 is composed of $60 \mathrm{vol} \%$ transparent plagioclase, $\sim 35 \mathrm{vol} \%$ brown orthopyroxene, $\sim 5 \mathrm{vol} \%$ dark brown biotite (fig. 4.2E/F, fig. B.1G-H) and has a texture similar to norite A1. In contrast to norite A1, plagioclase crystals can reach up to $1 \mathrm{~cm}$ in diameter. The rock features no cumulate layering, but this might be caused by an unfortunate crosscut of the thin section or sample selection. The fabric is hypidiomorph to xenomorph and the plagioclase grain boundaries show perfect $120^{\circ}$ triple point junctions. The plagioclase and orthopyroxene grains have an equant shape. The biotite shape is acicular, but in many places rounded and incorporated in plagioclase and orthopyroxene due to re-equilibration. The biotite seems to be primary. This rock is also a re-equilibrated, cumulate rock.

Anorthosite B2 and B3 Anorthosite B2 and B3 comprise anorthosite interleaved with thin chromitite seams (fig. 4.1D/E). We refer to the average modal abundances reported by Voordouw et al. (2009), because our sample pieces are too small to be representative. Voordouw et al. (2009) reported that the anorthosite is composed of $\sim 85 \mathrm{vol} \%$ transparent plagioclase, $\sim 11 \mathrm{vol} \%$ brown orthopyroxene and $\sim 3$ vol\% black chromite (DR anorthosite); the chromitite layers are composed of $\sim 31$ vol $\%$ plagioclase, $\sim 15 \mathrm{vol} \%$ orthopyroxene and $\sim 53$ vol\% chromite (UG1 chromitite; fig. 4.2G/H;I/J, fig. B.1I-K;L-N). Both samples contain red-brown biotite as accessory mineral. The texture of the rocks can be described in general as fine- to medium-grained, phaneritic and equigranular. The fabric is hypidiomorph in the anorthositic sections. The plagioclase has an equant or tabular shape, the chromite is equant, the orthopyroxene is interstitial. The biotite is often but not always associated with the orthopyroxene and has sometimes an acicular shape. The fabric of the chromitite seams is hypidiomorph. The chromite is equant and varies in size between $\sim 0.05 \mathrm{~mm}$ and $0.6 \mathrm{~mm}$. The plagioclase is often interstitial and the orthopyroxene is interstitial or poikilitic.

All five rocks are well preserved. No alteration features or signs of later exchange processes are present, for instance: exsolution lamellae, secondary minerals, zonation or reaction rims. 


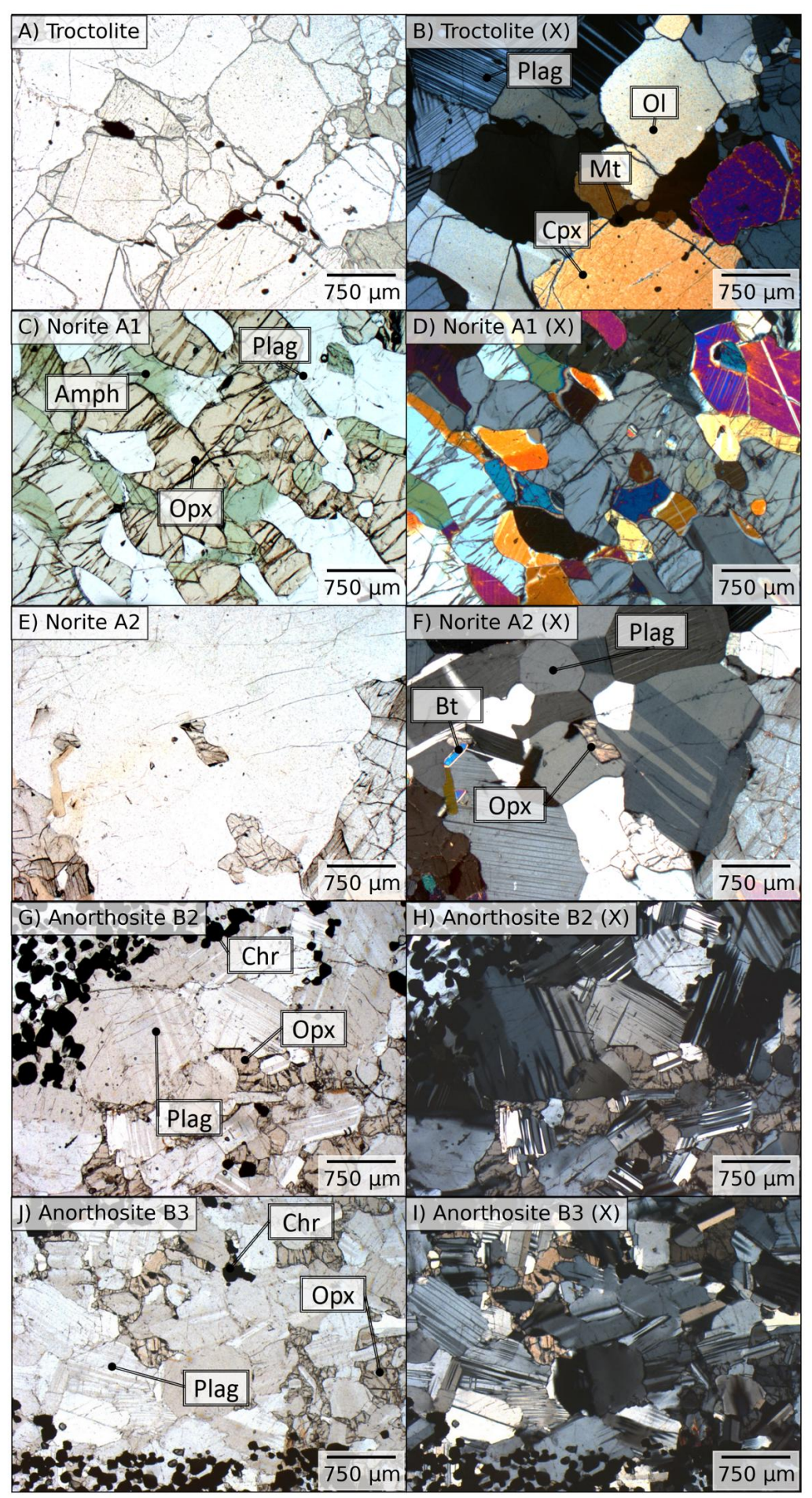

Figure 4.2: Thin section images of the troctolite (A, B), norite A1 (C, D) and norite A2 (E, F), anorthosite B2 (G, H) and anorthosite B3 $(\mathrm{I}, \mathrm{J})$ in plane polarised light and in cross-polarised light (X). The following abbreviations were used: plagioclase (Plag), orthopyroxene (Opx), clinopyroxene (Cpx), olivine (Ol), amphibole (Amph), biotite (Bt), magnetite (Mt) and chromite (Chr). 


\subsubsection{Mineral chemistry}

Troctolite The troctolite is composed of bytownite $\left(\mathrm{An}_{87} \mathrm{Ab}_{13}\right)$, diopside $\left(\mathrm{Wo}_{44} \mathrm{En}_{43^{-}}\right.$ $\left.\mathrm{Fs}_{11} \mathrm{Ac}_{1}\right)$, forsterite $\left(\mathrm{Fo}_{76} \mathrm{Fa}_{24}\right)$ and magnetite (mean phase formulas are given). The minerals of the troctolite are chemically homogeneous in the range of $<2 \%$ (expressed as average element concentration divided by the standard deviation of the element concentration). No systematic zoning within the minerals is observed (fig. 4.3). Additional information can be found in appendix B (for average oxide compositions see table B.1B.4; for individual line profiles and BSE images see: fig. B.2; for element mappings see: fig. B.3).

Norite A1 and A2 Norite A1 is composed of anorthite $\left(\mathrm{An}_{92} \mathrm{Ab} \mathrm{b}_{8}\right)$, enstatite $\left(\mathrm{Wo}_{1} \mathrm{En}_{79^{-}}\right.$ $\left.\mathrm{Fs}_{20}\right)$ and calcic magnesio-hornblende. Norite $\mathrm{A} 2$ is composed of bytownite $\left(\mathrm{An}_{87} \mathrm{Ab}_{13}\right)$, enstatite $\left(\mathrm{En}_{83} \mathrm{Fs}_{17}\right)$ and biotite. We did not observe any striking convergence of cation levels between the minerals of both rock samples (fig. 4.4). The minerals are chemically homogeneous on the $<1 \%$ level. Additional information can be found in appendix B (for average oxide compositions see table B.1, B.2, B.6, B.7; for individual line profiles and BSE images see: fig. B.4 and fig. B.7; for element mappings see: fig. B.5 and fig. B.8).

Anorthosite B2 and B3 Anorthosite B2 is composed of bytownite $\left(\mathrm{An}_{74} \mathrm{Ab}_{25} \mathrm{Or}_{1}\right.$, grain cores), enstatite $\left(\mathrm{Wo}_{2} \mathrm{En}_{78} \mathrm{Fs}_{20}\right)$, chromite and biotite. Anorthosite $\mathrm{B} 3$ is composed of bytownite $\left(\mathrm{An}_{77} \mathrm{Ab}_{22} \mathrm{Or}_{1}\right)$, enstatite $\left(\mathrm{Wo}_{1} \mathrm{En}_{80} \mathrm{Fs}_{19}\right)$, chromite and biotite. The mean phase formulas are less accurate for anorthosite B2 and B3, because their minerals are less homogeneous in their chemical composition (fig. 4.5). The anorthite content of the plagioclase is varying and the margins are often anorthite-richer ( 10-13 An\%; fig. B.10 profile 1, fig. B.12 profile 1). The anorthite-rich margins seems to be associated to the chromitite layers. Anorthite-rich areas enclose often chromite crystals. The orthopyroxene shows variations concerning the magnesium $(\mathrm{Mg})$ and iron $(\mathrm{Fe})$ content (fig. B.10.Mg/Fe, fig. B.12. $\mathrm{Mg} / \mathrm{Fe})$. In the chromitite layer the orthopyroxene is $\mathrm{Mg}$-richer/Fe-poorer $(\mathrm{En} / \mathrm{Fs}$ ratio is shifting by $\sim 8 \%$ ) than in the anorthosite. There are also concentration gradients within the grains. The orthopyroxene shows also small variations in calcium $(\mathrm{Ca})$ and aluminium ( $\mathrm{Al}$; e.g. fig. B.10 profile 4). In some cases the mineral core is richer in these elements than the margins. There are inter and intra variations of chromium $(\mathrm{Cr})$ and $\mathrm{Fe}$ in the chromite grains (fig. B.10.Cr/Fe, fig. B.12. $\mathrm{Cr} / \mathrm{Fe}$ ). Additional information can be found in appendix B (for average oxide compositions see table B.1, B.2, B.5; for individual line profiles and BSE images see: fig. B.9 and fig. B.11; for element mappings see: fig. B.10 and fig. B.12).

All five rocks are well preserved, no alteration features are present. However, anorthosite B2 and B3 show strong evidence for exchange processes: chemical variations between grains of the same mineral phase, zonation, reaction rims and the biotite might be a secondary phase. 
A) Troctolite (2 profiles)

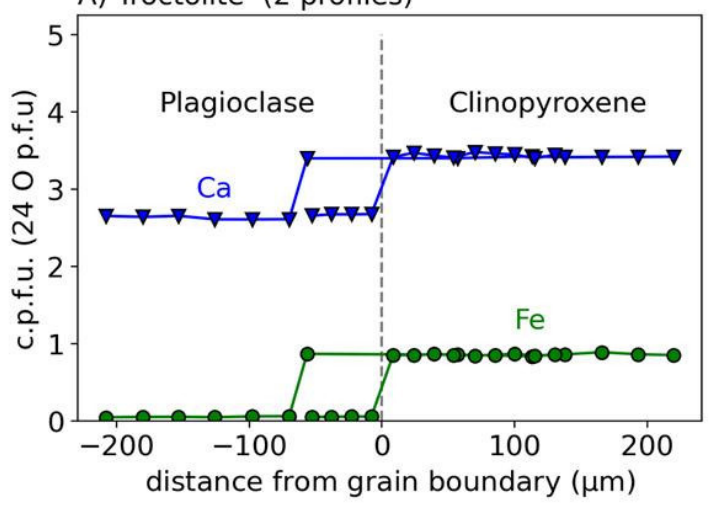

C) Troctolite (1 profile )

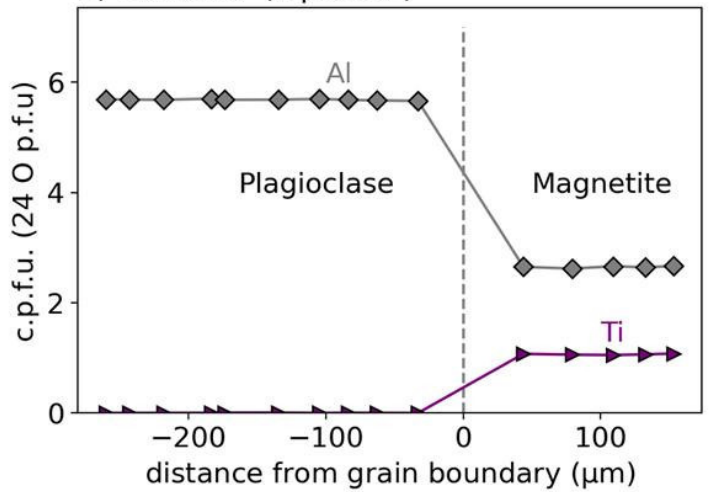

E) Troctolite (1 profile )

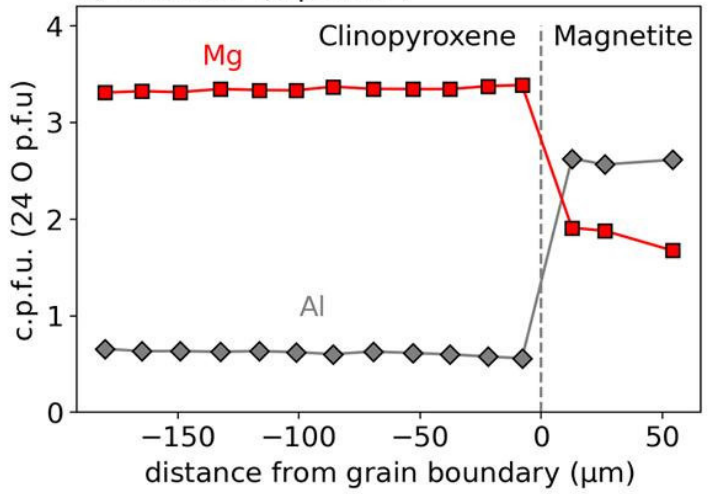

B) Troctolite (3 profiles)

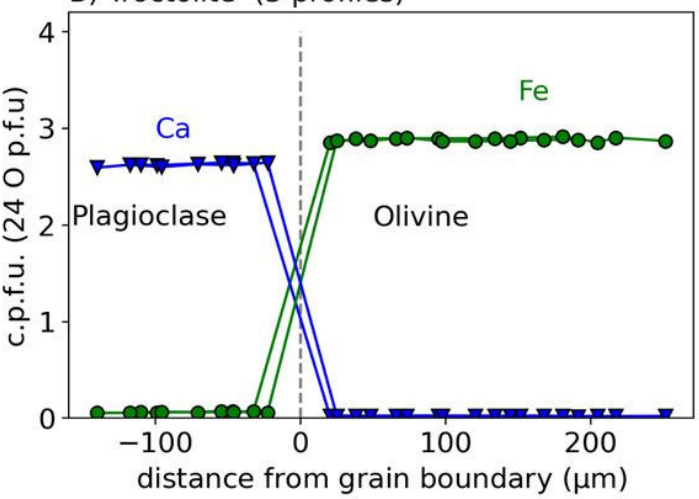

D) Troctolite (1 profile )

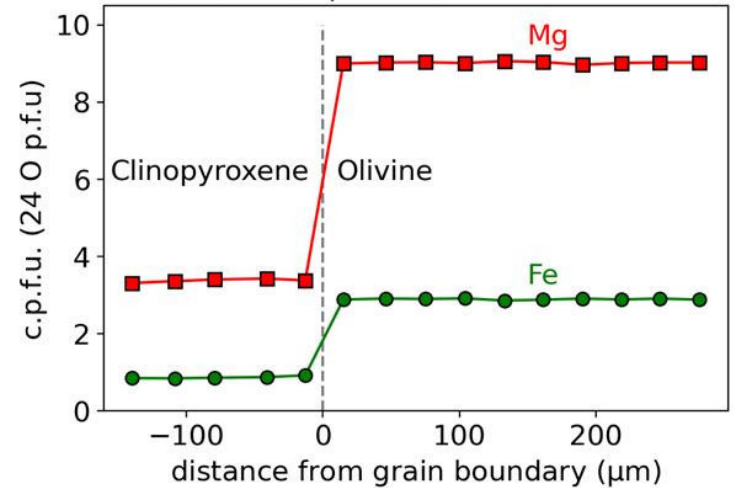

F) Troctolite (1 profile )

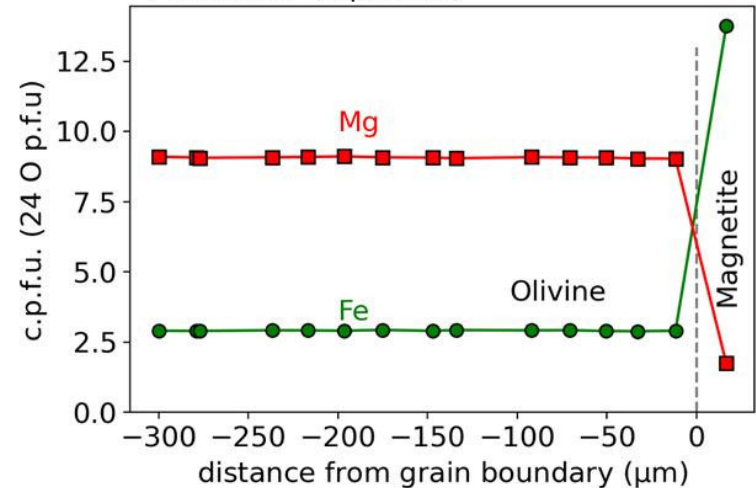

Figure 4.3: Compiled EMP line profiles of the troctolite thin section. The plots display the cation per formula unit numbers (c.p.f.u, calculated for $24 \mathrm{O}$ ) on each laser spot of the respective line profile. The line profiles were placed crossing grain boundaries. Each subplot (A-F) illustrates the line profiles of two characteristic elements of a specific mineral pair (A: Plagioclase-Clinopyroxene (Ca, $\mathrm{Fe} ; N=2$ ), B: Plagioclase-Olivine (Ca, Fe; $N=3)$ ), C: Plagioclase-Magnetite (Al, Ti; $N=1)$, D: Clinopyroxene-Olivine (Mg, Fe; $N=1)$, E: Clinopyroxene-Magnetite $(\mathrm{Mg}, \mathrm{Al} ; N=1)$; F: Olivine-Magnetite $(\mathrm{Mg}, \mathrm{Fe} ; N=1))$. The silicates in troctolite sample are chemically homogeneous. 
A) Norite A1 (3 profiles)

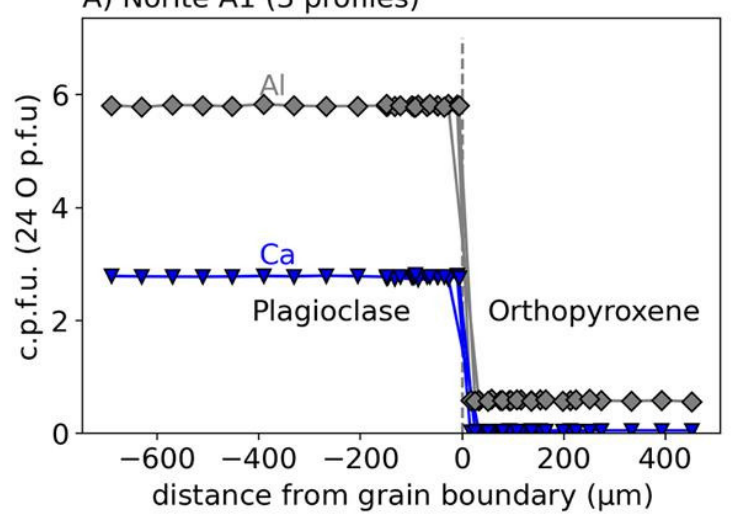

C) Norite Al (3 profiles)

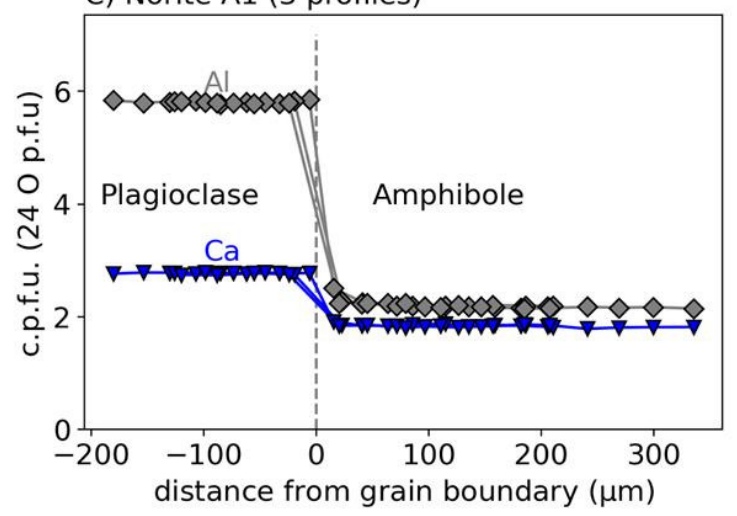

E) Norite A1 (3 profiles)

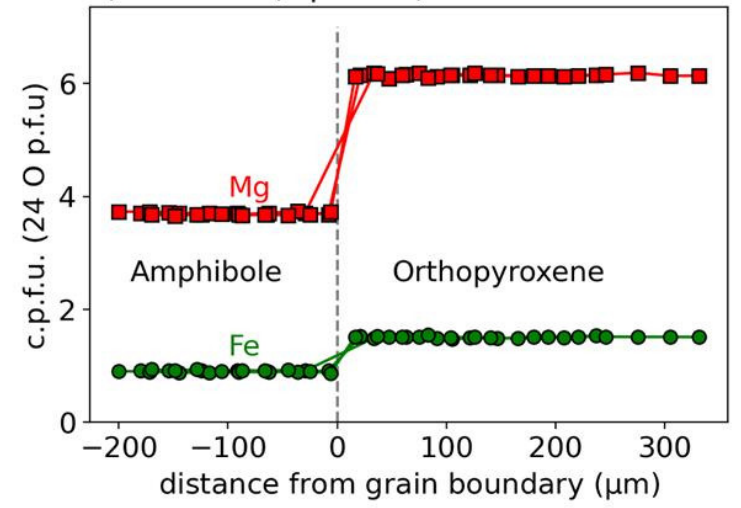

B) Norite A2 (3 profiles)

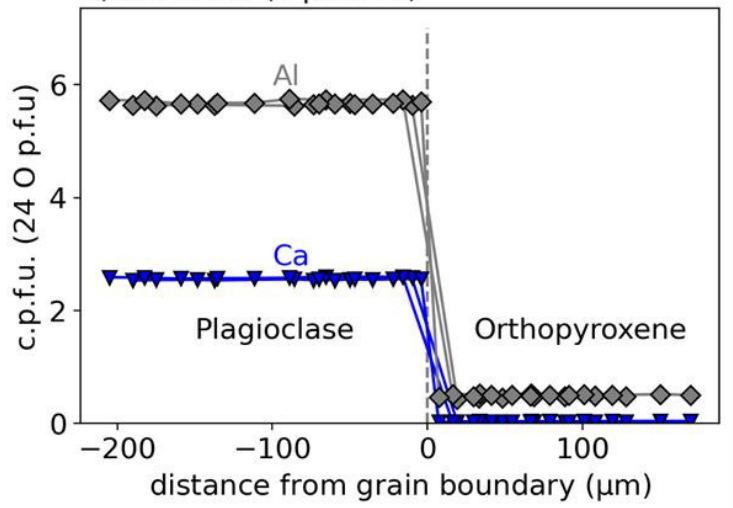

D) Norite A2 (3 profiles)

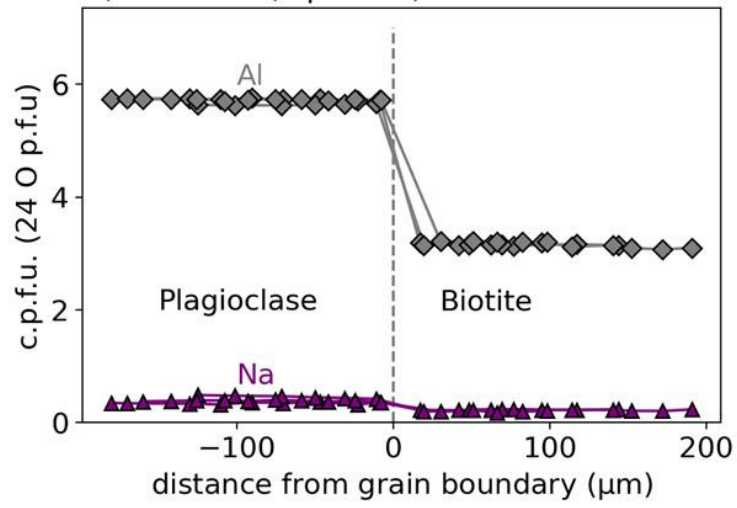

F) Norite A2 (3 profiles)

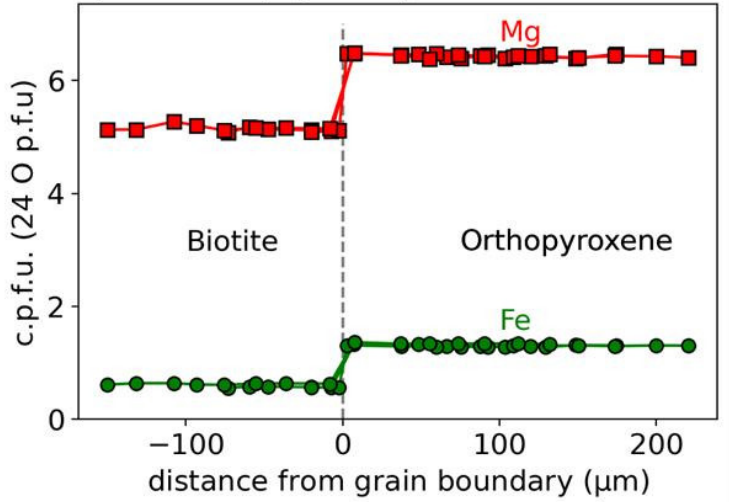

Figure 4.4: Compiled EMP line profiles of the norite A1 (A,C,E) and A2 (B,D,F) thin section. The plots display the cation per formula unit numbers (c.p.f.u, calculated for $24 \mathrm{O}$ ) on each laser spot of the respective line profile. The line profiles were placed crossing grain boundaries. Each subplot (A-F) illustrates the line profiles of two characteristic elements of a specific mineral pair (A: PlagioclaseOrthopyroxene (A1; $\mathrm{Ca}, \mathrm{Al} ; N=3$ ), B: Plagioclase-Orthopyroxene (A2; $\mathrm{Ca}, \mathrm{Al} ; N=3$ ), C: Plagioclase-Amphibole (A1; $\mathrm{Ca}, \mathrm{Al}$; $N=3$ ), D: Plagioclase-Biotite (A2; $\mathrm{Ca}, \mathrm{Al}, N=3$ ), E: Amphibole-Orthopyroxene (A1; Mg, Fe; $N=3$ ), Biotite-Orthopyroxene (A2; $\mathrm{Mg}, \mathrm{Fe} ; N=3)$. The silicates in norite $\mathrm{A} 1$ and $\mathrm{A} 2$ are chemically homogeneous. 
A) Anorthosite B2 (4 profiles)

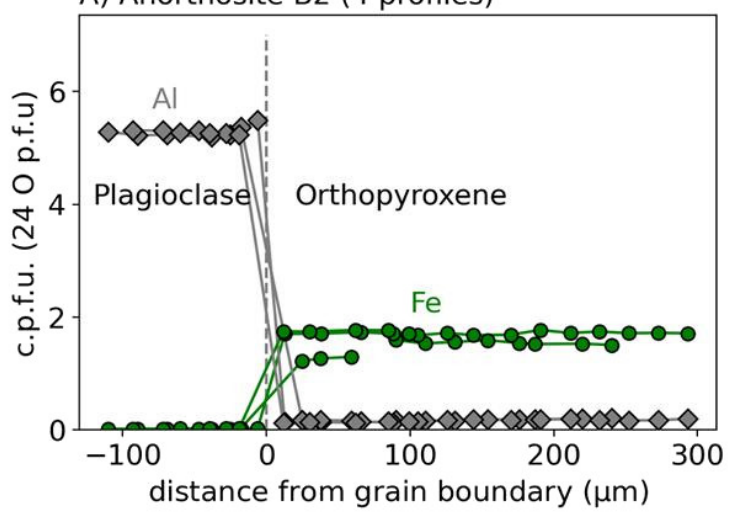

C) Anorthosite B2 (3 profiles)

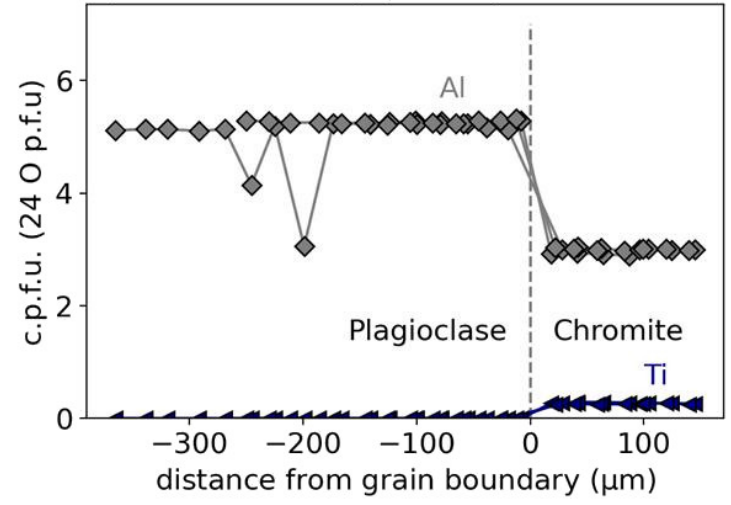

E) Anorthosite B2 (2 profiles)

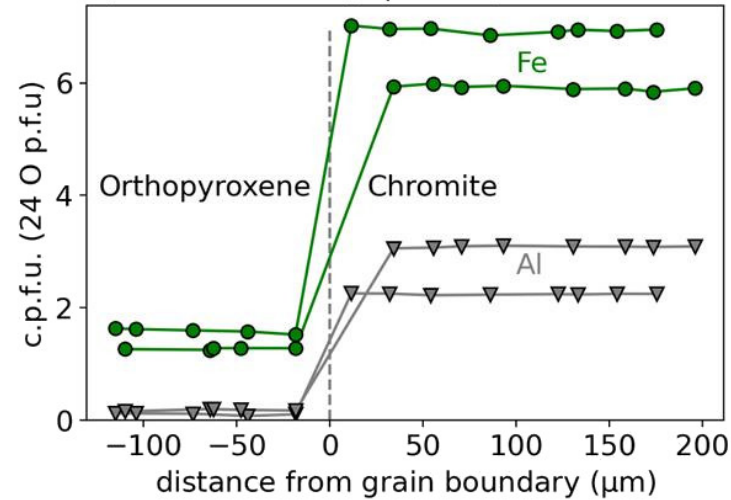

B) Anorthosite B3 (3 profiles)

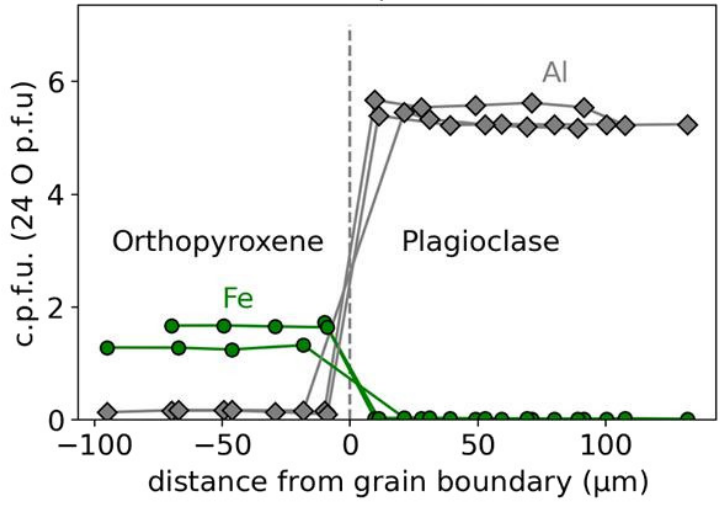

D) Anorthosite B3 (3 profiles)

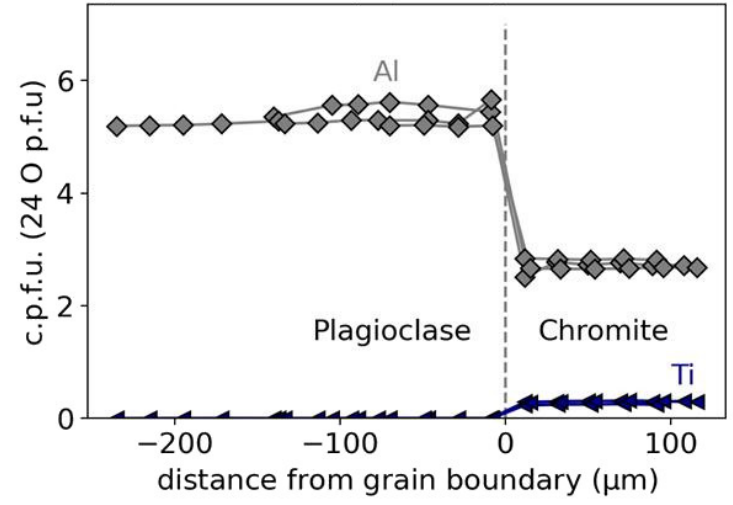

F) Anorthosite B3 (3 profiles)

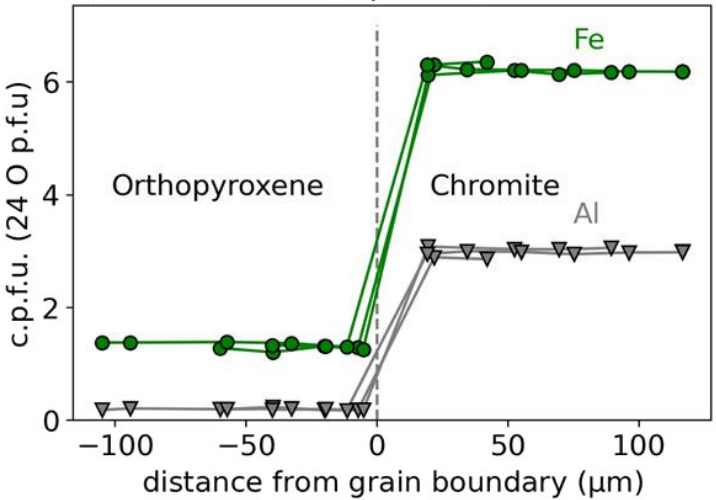

Figure 4.5: Compiled EMP line profiles of the anorthosite B2 (A,C,E) and B3 (B,D,F) thin section. The plots display the cation per formula unit numbers (c.p.f.u, calculated for $24 \mathrm{O}$ ) on each laser spot of the respective line profile. The line profiles were placed crossing grain boundaries. Each subplot (A-F) illustrates the line profiles of two characteristic elements of a specific mineral pair (A: Plagioclase-Orthopyroxene (B2; Al, Fe; $N=3$ ), B: Plagioclase-Orthopyroxene (B3; Al, Fe; $N=3$ ), C: Plagioclase-Chromite (B2; Al, Ti; $N=3)$, D: Plagioclase-Chromite (B2; Al, Ti; $N=3$ ), E: Orthopyroxene-Chromite (B2; Al, Fe; $N=2$ ), F: OrthopyroxeneChromite (B3; $\mathrm{Al}, \mathrm{Fe} ; N=3)$ ). The silicates in anorthosite $\mathrm{B} 2$ and $\mathrm{B} 3$ are chemically heterogeneous. 


\subsubsection{Stable isotopes}

The results of the oxygen isotope measurements are listed in table 4.1. Single measurement results of the minerals assemblages of the feldspar-rich rocks are listed in table B.8 and B.9 and results of the standards are listed in table B.10-B.12 (San Carlos olivine 0215 and 0919, UWG-2 garnet).

Table 4.1: Oxygen isotope composition of the mineral assemblages of the feldspar-rich rock (mean values $\pm 1 \sigma$ SEM). The following abbreviations were used: plagioclase (Plag), orthopyroxene (Opx), clinopyroxene (Cpx), olivine (Ol), amphibole (Amph), biotite (Bt), magnetite (Mt) and chromite (Chr), San Carlos olivine (SC), garnet (Gt).

\begin{tabular}{cccccccccc}
\hline Sample ID & Mineral & $\begin{array}{l}\delta^{17} \mathrm{O} \\
(\%)\end{array}$ & $\pm 1 \sigma$ & $\begin{array}{l}\delta^{18} \mathrm{O} \\
(\% o)\end{array}$ & $\pm 1 \sigma$ & $\begin{array}{l}\Delta^{\prime 17} \mathrm{O} \\
(\mathrm{ppm})\end{array}$ & $\pm 1 \sigma$ & $\mathrm{N}$ & Outlier \\
\hline Troctolite & $\mathrm{Plag}$ & 2.82 & 0.05 & 5.45 & 0.09 & -53 & 4 & 6 & 0 \\
Troctolite & $\mathrm{Cpx}$ & 2.44 & 0.05 & 4.73 & 0.09 & -55 & 3 & 5 & 0 \\
Troctolite & O1 & 2.52 & 0.02 & 4.87 & 0.03 & -53 & 4 & 5 & 2 \\
Norite A1 & Plag & 3.04 & 0.01 & 5.88 & 0.03 & -60 & 1 & 41 & 0 \\
Norite A1 & Opx & 2.85 & 0.02 & 5.52 & 0.05 & -58 & 3 & 9 & 2 \\
Norite A1 & Amph & 2.39 & 0.05 & 4.65 & 0.09 & -64 & 3 & 9 & 0 \\
Norite A2 & Plag & 2.96 & 0.04 & 5.72 & 0.08 & -58 & 3 & 9 & 1 \\
Norite A2 & Opx & 2.82 & 0.01 & 5.45 & 0.03 & -57 & 3 & 10 & 0 \\
Anorthosite B2 & Plag & 3.43 & 0.03 & 6.62 & 0.06 & -61 & 6 & 5 & 0 \\
Anorthosite B2 & Opx & 3.28 & 0.06 & 6.31 & 0.12 & -50 & 4 & 1 & 0 \\
Anorthosite B2 & Chr & 1.23 & 0.04 & 2.41 & 0.08 & -46 & 3 & 3 & 0 \\
Anorthosite B3 & Plag & 3.47 & 0.03 & 6.69 & 0.06 & -56 & 2 & 5 & 0 \\
Anorthosite B3 & Opx & 3.28 & 0.06 & 6.33 & 0.12 & -59 & 4 & 1 & 0 \\
Anorthosite B3 & Chr & 1.12 & 0.06 & 2.20 & 0.11 & -46 & 3 & 4 & 0 \\
Sc 0215M & Ol & 2.69 & 0.01 & 5.20 & 0.01 & -52 & 1 & 38 & 1 \\
SC 0919 & Ol & 2.76 & 0.02 & 5.34 & 0.04 & -52 & 1 & 10 & 0 \\
UWG-2 & Gt & 2.96 & 0.01 & 5.72 & 0.01 & -60 & 1 & 40 & 3 \\
\hline
\end{tabular}

\subsection{Discussion}

\subsubsection{Methodical aspects concerning the laser fluorination of feldspar}

There are different options how to apply the laser fluorination technique to feldspar:

(I) storage and fluorination of feldspar in a reaction chamber (conventional system),

(II) pretreatment of the feldspar before it is fluorinated in the reaction chamber (conventional system):

(II.I) creation of a non-reactive fluoride layer on the sample surface,

(II.II) addition of a resistant layer (e.g. gold coating) on the sample surface,

(II.III) converting the sample into a glass bead by melting it with a laser under vacuum, and

(III) storage of feldspar in a pre-chamber and fluorination of individual samples in the reaction chamber (air lock system).

The fluorination of untreated feldspar samples with the conventional system (I) can give biased results if multiple samples are placed inside the reaction chamber, because the 
feldspar samples may in part react with the fluorination agent at room temperature, while a sample of interest is fluorinated (Fiebig and Hoefs 2002). Such reactions at room temperature are problematic, because they are likely associated with kinetic isotope effects that can modify the oxygen isotope composition of the residual sample. Moreover, the $\mathrm{O}_{2}$ released by such reactions can contaminate $\mathrm{O}_{2}$ that is extracted from the sample of interest. Pretreatments (II) were applied in the past to prevent the pre-reaction of feldspar. The creation of a non-reactive fluoride layer was performed by Elsenheimer and Valley (1992). This approach is very time-consuming (from a few hours to more than a week) and may only be effective when $\mathrm{BrF}_{5}$, not $\mathrm{F}_{2}$, is used as the fluorination agent (Fiebig and Hoefs 2002). The coating of a sample with e.g. gold did not give reliable results for the fluorination with $\mathrm{F}_{2}$ (Fiebig and Hoefs 2002). The conversion of a feldspar sample into a glass bead before fluorination (hereafter: pre-melting) is promising as a pretreatment method. It reduces the surface area of the sample and creates a glass, which is typically less reactive at room temperature with fluorination agents than untreated feldspar. However, there are concerns that the pre-melting itself already alters the isotope composition of the sample by evaporation. A light component might be lost during such evaporation processes. The air lock system (III) eliminates the issue of unwanted feldspar samples reacting at room temperature, because each of the samples is exposed to $\mathrm{BrF}_{5}$ or $\mathrm{F}_{2}$ only when it is heated with the laser. A potential downside, however, is that a pre-fluorination can only be performed for the reaction chamber, and not for a 2-pit sample holder that is introduced via the air lock. The blank of the air lock system is therefore potentially higher.

In order to achieve the best possible results for our study on triple oxygen isotope fractionation in feldspar-rich rocks, we conducted a series of experiments to test different analytical setups (conventional system vs. air lock system) and pretreatment methods (untreated vs. pre-melted) for the laser fluorination of feldspar samples (grains vs. powders). Plagioclase from norite A1 was used as the test sample. We evaluated the blank, yields, precision and accuracy of the experiments. The blank of the 2-pit sample holder that is introduced via the air lock system is indistinguishable from the blank of an empty sample chamber $(\sim 0.2 \%$ of the sample gas intensity on mass $32, N=1)$. The 2-pit sample holders are very small (low surface area) and can be prepared with minimal moisture contamination. Moreover, we were not able to trace elevated blanks for the conventional system testing a 14-pit sample holder filled with 8 plagioclase samples, which would proof the release of matrix oxygen and the pre-reaction of the plagioclase. The first blank, measured before the start of the session, comprised $\sim 0.3 \%$ blank fraction $(N=1)$. This value decreased after $\sim 4$ measurements to a level of $\sim 0.1 \%$ blank fraction $(N=2)$. This is identical with values measured for a 14-pit sample holder loaded with robust sample materials. The yields of the oxygen extraction from plagioclase were close to one hundred percent for all setups: $99 \pm 1 \%$ (not pre-melted conv., grains, $N=4$ ), $98 \pm 1 \%$ (pre-melted conv., grains, $N=4$ ) and $98 \pm 1 \%$ (air lock, grains, $N=5$ ). The yield and blank measurements for the experiments with plagioclase powder were compromised by difficulties during maintenance work. Of the analytical setups that were tested, the conventional system yields the most precise results for the analysis of pre-melted plagioclase, directly followed by the setup with the air lock system for the analysis of untreated and pre-melted plagioclase. Measurement results for untreated plagioclase in the conventional setup are less precise than the results for pre-melted plagioclase, and are also less precise than the 
results for plagioclase that was analysed with the air lock system (fig. 4.6). The analysis of untreated plagioclase using the conventional system also yields apparently systematically higher $\Delta^{\prime 17} \mathrm{O}$ values for the fluorination of powders compared to grains. Plagioclase in the conventional setup that was pre-melted, and also plagioclase that was analysed in the setup with air lock system, in contrast, give indistinguishable results for the fluorination of sample grains and powders. We therefore render the analysis of untreated plagioclase with the conventional system less accurate than the other analytical methods that were tested here. Young et al. (2016) discussed the possibility that absorbed air moisture can lead to elevated $\Delta^{\prime 17} \mathrm{O}$ values for plagioclase powders. For analyses that were done with the conventional system, the untreated plagioclase powder is indeed on average $\sim 8 \mathrm{ppm}$ higher in $\Delta^{\prime 17} \mathrm{O}$ compared to the plagioclase grains. However, for analyses that were done with the air lock system, in contrast, the mean value for untreated plagioclase powder is identical to the mean value for plagioclase that was analysed as grains. We therefore argue that the higher $\Delta^{\prime 17} \mathrm{O}$ of untreated plagioclase powder in the conventional setup is not an effect of moisture, but rather reflects a mild pre-reaction of the sample with $\mathrm{BrF}_{5}$ in the reaction chamber. The pre-melting of plagioclase powder seems to eliminate the affinity of the powder to pre-react, yielding results identical to the air lock system. The infrared lamp-heating used by Young et al. (2016) might have a comparable effect, although it must be kept in mind that other parameters between the studies are variable as well, e.g., different fluorination agents were used $\left(\mathrm{BrF}_{5}\right.$ vs. $\mathrm{F}_{2}$ : Young et al. 2016).
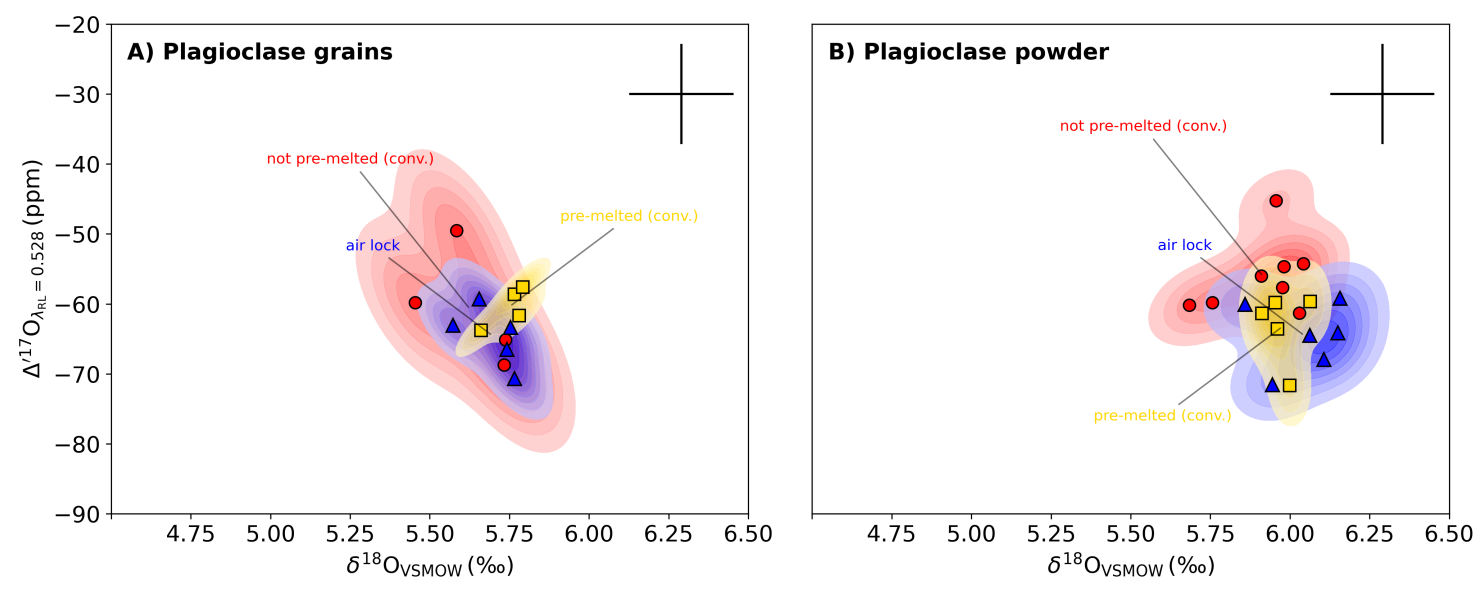

Figure 4.6: The plagioclase of norite A1 was analysed as grains A) and as powder B) using different analytical setups and pretreatments. Single measurements are plotted. The cross in the upper right corner of the subplots is illustrating the measurement uncertainty. The material was analysed with the air lock system (blue triangles) and with the conventional system, untreated (red dots) and pre-melted (yellow squares). In case of the air lock system, the difference between untreated and pre-melted plagioclase is unobtrusive, more information can be found in table B.9. The data populations are highlighted using kernel density estimate contour plots $($ level $=10)$. The conventional system in combination with pre-melting of feldspar yields good results.

The experiments show that consistent laser fluorination data for feldspar samples can be obtained if the samples are analysed with our air lock system or, alternatively, are pre-melted prior to analysis in a conventional laser fluorination setup. For our study on triple oxygen isotope fractionation in feldspar-rich rocks, we therefore used the air lock system (troctolite and norite A1 and A2) and in some cases the conventional system in combination with pre-melting (anorthosite B2 and B3). 


\subsubsection{Triple oxygen isotope fractionation between feldspar and asso- ciated minerals}

\subsubsection{Prerequisite: equilibrium conditions}

In order to investigate triple oxygen isotope fractionation between co-existing phases, it is crucial that the minerals in our rock samples record equilibrium conditions. Oxygen isotope ratios of co-existing phases in plutonites seldom record equilibrium conditions, because pluton emplacement is often associated with hydrothermal activity (Agemar et al. 1999) and feldspar is more susceptible to subsolidus oxygen isotope exchange with fluids than other typical phases in plutonites (Elsenheimer and Valley 1992, Gregory et al. 1986). However, recrystallisation of plutonites after hydrothermal alteration can restore isotopic equilibrium between co-existing phases (Chiba et al. 1989). In order to assess whether given mineral pairs in our samples are in equilibrium, we performed a petrographic study of the samples and applied geothermometry methods. We checked for agreement between the oxygen isotope and cation exchange temperatures (Blundy and Holland 1990, Bottinga and Javoy 1975, Chiba et al. 1989, Loucks 1996, Matthews et al. 1983, Zheng 1991, 1993a,b). We also investigated whether the $\theta$ values of mineral pairs lie within the feasible range for mass-dependent equilibrium fractionation at igneous or metamorphic temperatures $(0.529-0.521$, Young et al. 2002).

Troctolite We found no petrographical evidence for alteration of the troctolite sample. However, the rock is slightly brittle, the forsterite is a little yellowish and the plagioclase has a slightly matt colour (but no sericitization or saussuritizaton is present; fig. B.1A-C). The troctolite has a purely magmatic texture.

The EMP data revealed no diffusive exchange for all chemical elements. The general distribution of the chemical elements indicates that the minerals reflect equilibrium crystallisation conditions. The cation exchange temperature of the rock was calculated as $\sim 1100^{\circ} \mathrm{C}$ according to the clinopyroxene-olivine thermometer of Loucks (1996) (table B.13). This temperature is indicative for crystallisation in a magmatic regime.

If the calculated oxygen isotope temperatures of three different mineral pairs are in agreement with each other, it is safe to assume isotopic equilibrium for a rock (Bottinga and Javoy 1975). This is not the case, for this particular sample (fig. 4.7A, table B.13). The fractionation between plagioclase and clinopyroxene $\left(\Delta^{18} \mathrm{O}_{\text {plag-cpx }}\right)$ of $0.72 \%$ o yields a typical crystallisation temperature of a plutonic rock, $700-800{ }^{\circ} \mathrm{C}$ (Bottinga and Javoy 1975, Matthews et al. 1983, Chiba et al. 1989, Zheng 1993a). But, the $\Delta^{18} \mathrm{O}_{\text {plag-ol }}$ $\left(0.58 \%\right.$ ) result in much higher temperatures $\left(1400-1600^{\circ} \mathrm{C}\right.$ : Bottinga and Javoy 1975 , Chiba et al. 1989, Zheng 1993a).

The fractionation of ${ }^{18} \mathrm{O} /{ }^{16} \mathrm{O}$ between clinopyroxene and olivine is negative $\left(\Delta^{18} \mathrm{O}_{c p x-o l}\right.$ $=-0.14 \%$ ). This feature was observed and discussed in the past intensively (Kyser et al. 1981, Gregory et al. 1986, Kyser et al. 1986, Rosenbaum et al. 1994, Mattey et al. 1994). Kyser et al. (1981, 1986) established and defended the concept that equilibrium isotope fractionation between clinopyroxene and olivine may lead to a crossover at high temperatures, and developed a pyroxene-olivine-thermometer that was based on this concept. This thermometer was disproved and the crossover alternatively explained as a feature of hydrothermal alteration by a low $\delta^{18} \mathrm{O}$-fluid (Gregory et al. 1986 and Rosenbaum et al. 
1994). This study was again disproved by the first laser fluorination data on this matter by Mattey et al. (1994), who re-measured many of the previously studied samples and showed that most of the negative $\Delta^{18} \mathrm{O}_{c p x-o l}$ values from previous studies reflect analytical artefacts that were related to the conventional fluorination technique. However, Perkins et al. (2006) measured negative $\Delta^{18} \mathrm{O}_{c p x-o l}$ applying the laser fluorination technique. This result suggests that pyroxene indeed preferentially exchanges oxygen isotopes with hydrothermal fluids to olivine, and revived the former theory of a negative $\Delta^{18} \mathrm{O}_{c p x-o l}$ as a feature of hydrothermal alteration (Perkins et al. 2006).

The $\Delta^{18} \mathrm{O}$ values of the troctolite sample are reasonably explained by interaction of the sample with an infiltrating low $\delta^{18}$ O-fluid at high temperatures (Gregory et al. 1986, Rosenbaum et al. 1994, Perkins et al. 2006). A second possibility - which is preferred here - is that the negative $\Delta^{18} \mathrm{O}$ of the troctolite sample reflects its origin as a crystal cumulate. Olivine is an early liquidius phase, and would have crystallised from a comparatively pristine mafic magma. Pyroxene and plagioclase in the troctolite sample would have crystallised later, and could therefore have formed from a magma with modified oxygen isotope composition compared to the pristine magma from which olivine formed, e.g., due to the assimilation of hydrothermally altered wall rocks by the magma reservoir (Bindeman 2008). This interpretation is also consistent with the negative $\Delta^{18} \mathrm{O}_{c p x-o l}$, the too low $\Delta^{18} \mathrm{O}_{\text {plag-ol }}$ and the reasonable $\Delta^{18} \mathrm{O}_{\text {plag-cpx }}$.

The $\Delta^{\prime 17} \mathrm{O}$ values of all olivine, pyroxene and plagioclase are similar and are typical for magmatic rocks (Pack and Herwartz 2014), but the slope $\lambda$ through the data is with $0.531 \pm 0.128$ high (fig. 4.8A). Only $\theta_{\text {plag-cpx }}(0.528)$ lies within the expected $\theta$ range for equilibrium isotopic fractionation processes, $\theta_{p l a g-o l}$ and $\theta_{c p x-o l}$ exceed it (individual $\theta$ in table B.15). This observation is consistent with our interpretation that co-existing minerals of the sample do not record equilibrium conditions with respect to oxygen isotopes, and are consistent with the admixing of a fluid-altered component, e.g., introduced by assimilation of the wall rock.

Norite A1 Before we assess whether co-existing phases in the norite sample record oxygen isotope equilibrium conditions, it is important to discuss if the amphibole in the sample represents a primary igneous phase, a phase that formed by fluid-assisted metamorphic processes or, alternatively, an uralitic amphibole that formed by the replacement of pyroxene at low-temperature, hydrothermal conditions.

Aarestrup et al. (2020) studied the petrography and chemistry of norites from the Amikoq Layered Complex and concluded that the type of amphibole that we analysed in the present study (green Ca-amphibole) can be relic magmatic amphibole in some cases, but often formed by metamorphic processes. There are some petrographical arguments in favour for a magmatic origin of the amphibole in our sample: the shape of the amphibole is in some places hypidiomorph, the grain boundaries are well developed, the crystals look homogeneous and regular. There is also no petrographical indication of alteration for any of the other minerals in the rock sample. Amphibole and orthopyroxene crystals are intergrown, one explanation could be that this is part of the cumulate texture, though another explanation is that this represents nucleation and bulk replacement of orthopyroxene by amphibole (Veblen and Buseck 1981). The amphibole has in most cases a xenomorph shape and complements the grain shape of the orthopyroxene. We also find amphibole blebs in the pyroxene (e.g. fig. 4.2C), which is indicative for an uralitic 
amphibole (Agemar et al. 1999).

The amphibole is a calcic magnesio-hornblende, i.e. an amphibole species that can form by magmatic or metamorphic processes, but is usually not a product of hydrothermal alteration. A typical uralitic amphibole is fibrous actinolite (Agemar et al. 1999). However, it is important to consider that the parental pyroxene in the norite sample for uralite formation would have been enstatite, and hornblende has been observed as uralite in less Fe-rich pyroxenes (Oliver 1951). There is no evidence for diffusive exchange of elements between minerals in sample norite A1 from the EMP data. The amphibole has homogeneous $\mathrm{Mg}$ and $\mathrm{Fe}$ concentrations and does not show elevated silicon ( $\mathrm{Si}$ ) concentrations that could be indicative for uralite (Agemar et al. 1999). The plagioclase shows no sign of Ca-leaching (albitization) and no sericitization or saussuritizaton, which are common features of hydrothermal alteration (Agemar et al. 1999, Fiebig and Hoefs 2002). A cation exchange temperature of $\sim 900{ }^{\circ} \mathrm{C}$ was determined using the plagioclase-amphibole thermometer of Holland and Blundy (1994) (table B.13). The value lies within the temperature range reported by Aarestrup et al. (2020), $\sim 800-1070{ }^{\circ} \mathrm{C}$. This temperature suggests a plutonic origin of the rock (and of the amphibole) or, alternatively, equilibration of the mineral pairs at high-temperature metamorphic conditions.

The oxygen isotope compositions of different mineral pairs correspond to variable temperatures (fig. 4.7B, table B.13), suggesting that not all major phases in the rock sample are at equilibrium conditions. Multiple oxygen isotope thermometers were suggested for plagioclase-pyroxene fractionation (Bottinga and Javoy 1975, Matthews et al. 1983, Chiba et al. 1989, Zheng 1993a). The calculated temperatures from these thermometers vary from 1000 to $1200{ }^{\circ} \mathrm{C}$ for the measured $\Delta^{18} \mathrm{O}_{\text {plag-opx }}$ of $0.35 \%$. Theoretical thermometers were proposed for plagioclase-amphibole and pyroxene-amphibole fractionation (Bottinga and Javoy 1975, Zheng 1993a,b). The plagioclase-amphibole thermometer corresponds to a temperature of $500-600{ }^{\circ} \mathrm{C}$ for the measured $\Delta \Delta^{18} \mathrm{O}_{\text {plag-amph }}$ value of $1.23 \%$. The orthopyroxene-amphibole thermometer corresponds to an unrealistically low equilibrium temperature of $200-400{ }^{\circ} \mathrm{C}$ for the measured $\Delta^{18} \mathrm{O}_{\text {opx }- \text { amph }}$ of $0.87 \pm 0.10 \%$. According to Bottinga and Javoy (1975), $\Delta^{18} \mathrm{O}_{\text {opx-amph }}$ is $\sim 0.1 \%$ at magmatic temperatures.

Not only the $\delta^{18} \mathrm{O}$ values, but also the $\Delta^{\prime 17} \mathrm{O}$ values indicate that the mineral pairs of norite $\mathrm{A} 1$ are not in equilibrium. The combined $\delta^{18} \mathrm{O}$ and $\Delta^{\prime 17} \mathrm{O}$ values result in a slope $\lambda$ of $0.532 \pm 0.06$ (fig. 4.8B), i.e. a value that is high compared to the expected value at high-temperature equilibrium conditions. $\theta_{\text {plag-opx }}$ is too low, whereas $\theta_{\text {plag-amph }}$ and $\theta_{o p x-a m p h}$ are too high to reflect equilibrium conditions (individual $\theta$ values are given in table B.15). We suggest that the oxygen isotope compositions of the minerals of norite A1 are explained by interaction of the sample with a low $\delta^{18} \mathrm{O}$ and low $\Delta^{\prime 17} \mathrm{O}$-fluid, a process that possibly also led to uralitization. This scenario would explain the anomalously low $\delta^{18} \mathrm{O}$ value of the amphibole. Fine-grained uralitic intergrowth in orthopyroxene (Veblen and Buseck 1981), in turn, could explain the comparatively low $\delta^{18} \mathrm{O}$ of orthopyroxene, although such intergrowth was not observed during our EMP investigations. In summary, sample norite A1 has a complex geological history: The layered intrusion from which the sample was derived possibly experienced alteration by hydrothermal activity, a process that could have led to the observed oxygen isotope disequilibrium between different phases, and the formation of uralite. The rock recrystallised (re-equilibrated) subsequently, such that some of the chemical memory of the alteration processes was 
erased.

Norite A2 There are no petrographic indications that the sample experienced alteration. Biotite in the sample seems to be of primary, magmatic origin. The $120^{\circ}$ plagioclase intersection angles indicate that the sample recrystallised at metamorphic conditions. The EMP line profiles and the EMP element map suggest that there was no diffusive mobilisation of any of the elements that were studied. We did for instance not observe leaching of $\mathrm{Ti}$ and potassium (K) from biotite, as would be expected if the biotite formed by hydrothermal alteration (Fiebig and Hoefs 2002). We have only few indications for mineral equilibrium temperatures of this sample (fig. 4.7C, table B.13), because there is no cation exchange thermometer available for the plagioclase-orthopyroxene-biotite assemblage, and we did not measure the oxygen isotope composition of biotite. The only temperature that we can study to investigate equilibrium conditions is from the plagioclase-pyroxene thermometers of Bottinga and Javoy (1975), Matthews et al. (1983), Chiba et al. (1989), Zheng (1993a). These plagioclase-pyroxene thermometers correspond to a temperature range of $1200-1400{ }^{\circ} \mathrm{C}$ for the measured plagioclase and pyroxene compositions. The $\Delta^{\prime 17} \mathrm{O}$ values of the minerals are in a reasonable range for high-temperature isotopic equilibrium as well: The $\theta$ value for all samples is $0.525 \pm 8.206$, which is consistent for isotopic equilibrium at igneous or high-grade metamorphic temperatures (fig. 4.8C, table B.15). However, the relative small $\Delta^{18} \mathrm{O}_{\text {plag-opx }}$ of the sample corresponds to a comparatively large uncertainty for the calculated $\theta$ value. In summary, the minerals of sample norite A2 seem to be in chemical and isotopic equilibrium.

Anorthosite B2/B3 Anorthosite B2 and B3 will be discussed together, because the samples are from the same outcrop and have similar mineral assemblages and isotope compositions. No indications for alteration were observed in the petrography of the samples, with the possible exception that rare biotite is present. However, the EMP analyses of the samples reveal variations in mineral compositions for all major elements in contact zones between chromitite and anorthosite. This observation is in agreement with the more extensive study by Veksler et al. (2015) on samples from the same area of the Bushveld Complex (UG2/3). These anomalous features relate to the complex formation of the layered intrusion (e.g. Veksler et al. 2015). As the co-existing minerals are not in chemical equilibrium, calculated cation exchange temperatures do not have any physical meaning.

Our oxygen isotope data for plagioclase and orthopyroxene in anorthosite samples B2 and $\mathrm{B} 3$ are in good agreement with the $\delta^{18} \mathrm{O}$ data of samples from UG2 and UG3 reported by Schannor et al. (2018). Anorthosite B2 and B3 belong to a stratigraphically lower unit (UG1). Our results concerning the chromite separates are slightly higher in $\delta^{18} \mathrm{O}$ $\left(\sim 0.1-0.3 \%\right.$ o). This might support the trend towards lower $\delta^{18} \mathrm{O}$ values with increasing stratigraphical height that was suggested by Schannor et al. (2018).

Equilibrium oxygen isotope temperatures calculated from the measured $\Delta^{18} \mathrm{O}_{\text {plag-opx }}$ (A-B2: $0.31 \%$; A-B3: $0.36 \%$ ) are higher $\sim 1000-1300{ }^{\circ} \mathrm{C}$ than equilibrium temperatures calculated from the $\Delta^{18} \mathrm{O}_{\text {plag-chr }}$ (A-B2: $4.21 \%$; A-B3: 4.49\%o) and $\Delta^{18} \mathrm{O}_{\text {opx-chr }}$ (A-B2: 3.91\%o; A-B3: $4.13 \%$ ), which are $\sim 500-700{ }^{\circ} \mathrm{C}$ (fig. 4.7D-E; detailed information can be found in table B.13; Bottinga and Javoy 1975, Matthews et al. 1983, Chiba et al. 1989, Zheng 1991, 1993a). The slopes $\lambda$ are $0.526 \pm 0.018$ and $0.525 \pm 0.021$ for anorthosite B2 
and B3, respectively, and are in good agreement with values expected for equilibrium isotope fractionation between mineral phases at magmatic temperatures (fig. 4.8D-E, table B.15). The $\Delta^{\prime 17} \mathrm{O}$ values of the orthopyroxenes comprise only single measurements, and it is therefore not surprising that the respective $\theta$ values have large uncertainties. However, the $\theta_{\text {plag-chr }}$ values have lower uncertainties and are consistent with oxygen equilibrium isotope fractionation at igneous temperatures. The advantage of anorthosite B2 and B3 to our study is that the large $\delta^{18} \mathrm{O}$ differences between minerals have the potential to result in comparatively precise $\theta$ values. Nevertheless, the different calculated equilibrium oxygen isotope temperatures indicate that the co-existing mineral phases in the samples are not in isotopic equilibrium. The apparent disequilibrium between the mineral phases may be inherent to the formation process of the chromitite seams in the Bushveld complex, which is still a debated topic. The formation hypotheses comprise that either a chromite slurry intruded into the silicate host rock (Sampson 1932, Bateman 1951) or that chromite formed as a cumulus phase due to the mixing of silicate magma (Irvine 1977). In case of an intrusive origin, the co-genesis of the minerals can be questioned. The disequilibrium between the mineral separates could therefore reflect the different origins of the host rock (anorthosite; plagioclase/orthopyroxene separates) and the chromitite seams (chromite separates). If the chromite formed as cumulus co-genetic with the minerals of the host rock, the disequilibrium between the chromite and plagioclase/orthopyroxene could have originated from fluid-rock interaction. Schannor et al. (2018) reported subsolidus equilibration temperatures for the chromitite seams UG2 and UG3 in contrast to magmatic temperatures for the host rock (pyroxenite, UG2). Following this study both rock types equilibrated at different temperatures and not with each other. Moreover, Schannor et al. (2018) found that the lower equilibration temperatures are associated with anomalous strontium ( $\mathrm{Sr}$ ) isotope compositions and concluded that aqueous, crustal fluids played a major role during the late or post-magmatic equilibration of the chromitite seams.

In summary, samples anorthosite B2 and B3 had a complex formation history that resulted in chemical and isotopic disequilibrium between the studied mineral assemblages. 

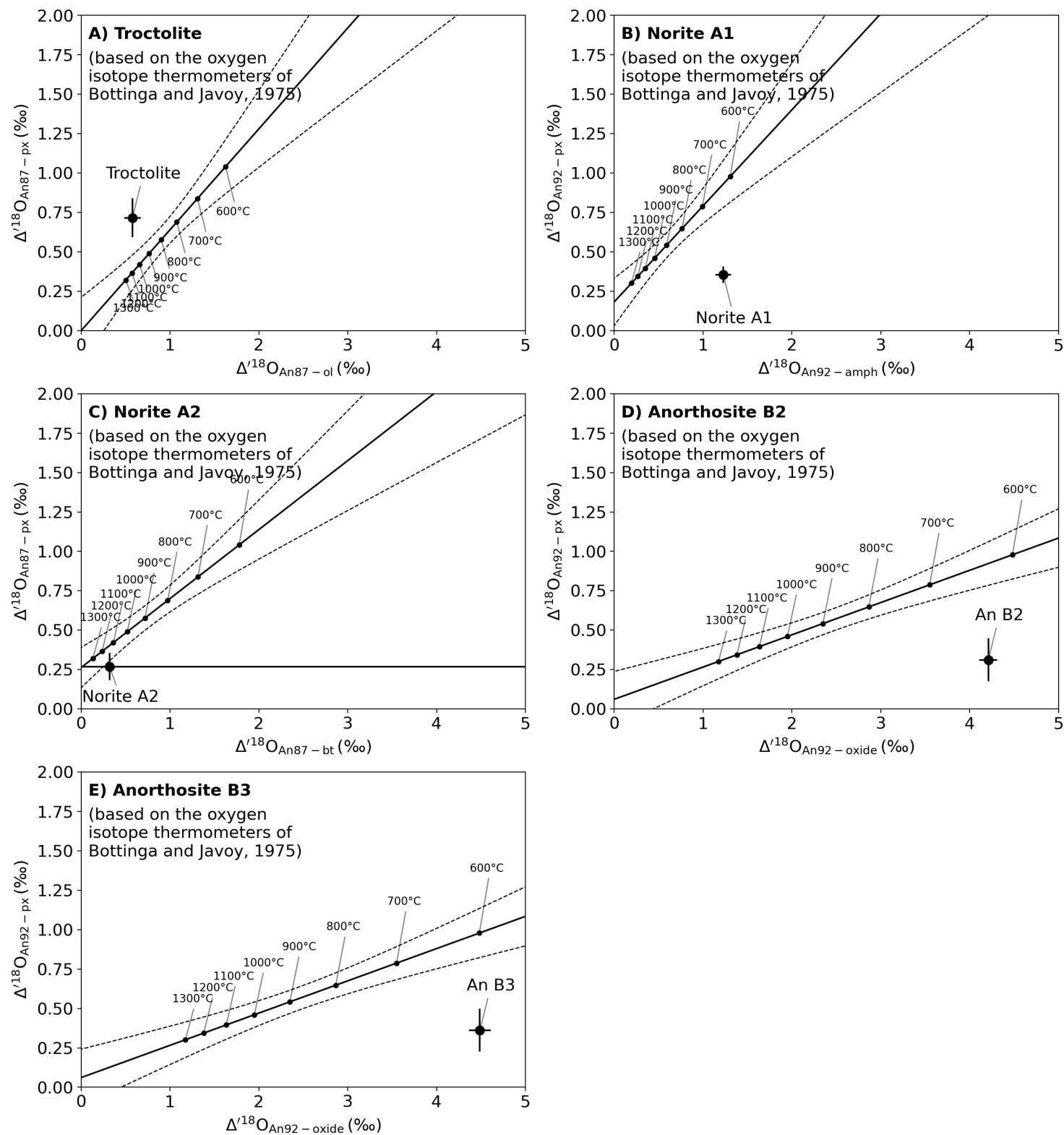

Figure 4.7: $\Delta-\Delta$ plots for the sample troctolite (A), norite A1 (B) and norite A2 (C), anorthosite B2 (D) and anorthosite B3 (E). Every subplot shows the plagioclase(An(anorthite content))-mineralA vs. plagioclase(An)-mineralB fractionation. The solid lines represent the mineralA-mineralB equilibrium fractionation according to Bottinga and Javoy (1975).

A) The troctolite shows a positive deviation from the equilibrium fractionation line. The An87-pyroxene (px) fractionation gives a low temperature, the An87-olivine (ol) fractionation a too high temperature and both deviate from the cation exchange temperature (based on Loucks 1996). The minerals are in isotopic disequilibrium.

B) Norite A1 shows a negative deviation from the equilibrium fractionation line. The An92-pyroxene fractionation gives a temperature $\sim 1200{ }^{\circ} \mathrm{C}$, which is in poor agreement with the cation exchange temperature (based on Blundy and Holland 1990). Moreover, the An92-amphibole (amph) fractionation gives a far too low temperature. The minerals are not all in equilibrium, hence the rock records isotopic disequilibrium conditions.

C) We did not measure the oxygen isotope composition of the biotite (bt), the $\mathrm{x}$ value is unknown. The An87-pyroxene fractionation results in temperature of $\sim 1500^{\circ} \mathrm{C}$, which is too high. Though, other thermometers also yield reasonable magmatic temperatures, e.g. $\sim 1200^{\circ} \mathrm{C}$ (Zheng 1993a). We assume that the mineral assemblage of norite A2 preserved isotopic equilibrium.

$\mathrm{D}$ and $\mathrm{E})$ The anorthosites show a negative deviation from the equilibrium fractionation line. The An87-pyroxene fractionation gives a temperature around $\sim 1300^{\circ} \mathrm{C}$, the An87-chromite (chr) fractionation gives lower values around $\sim 600^{\circ} \mathrm{C}$. The samples record isotopic disequilibrium conditions. 

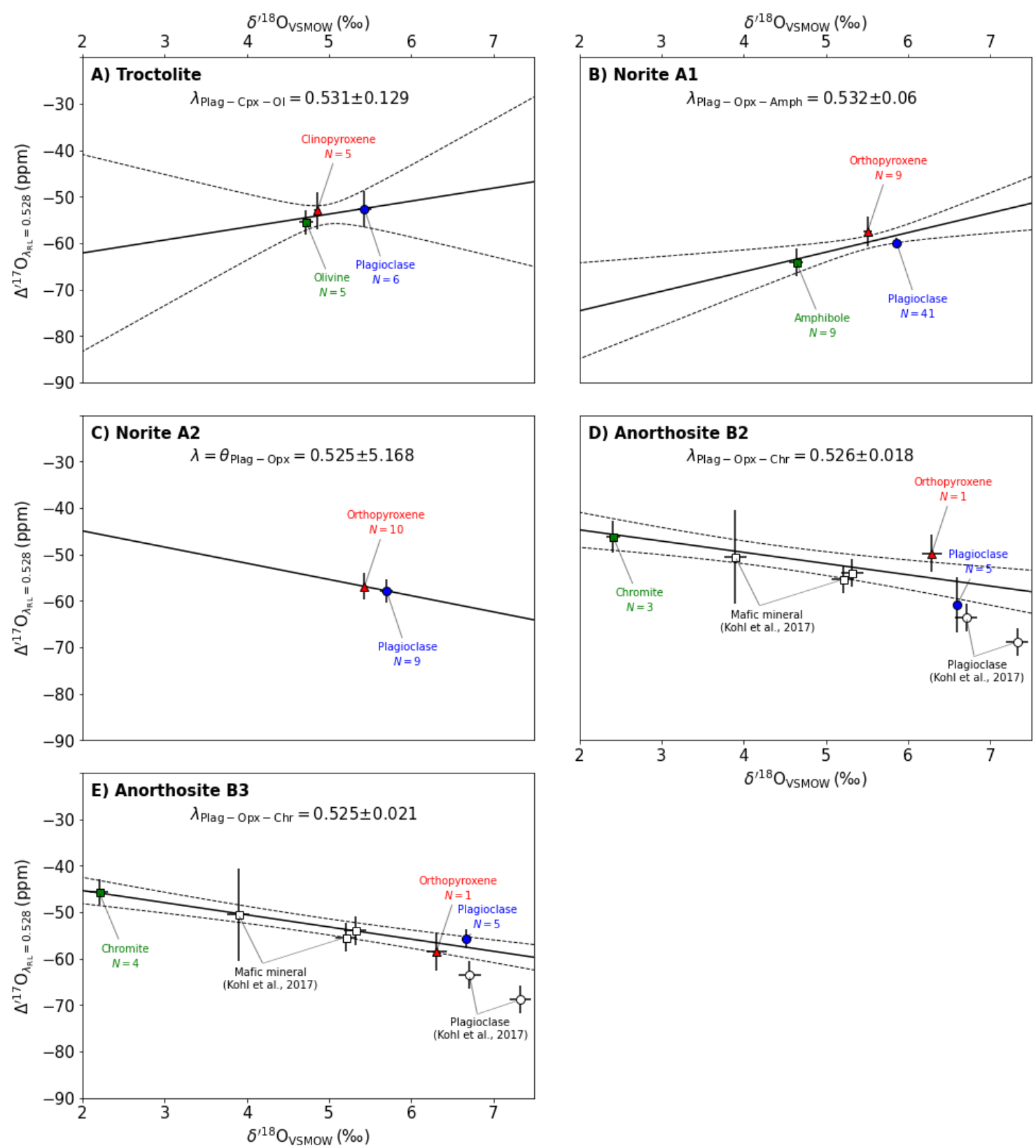

Figure 4.8: $\Delta^{\prime 17} \mathrm{O}$ vs. $\delta^{18} \mathrm{O}$ of the mineral assemblages of the studied feldspar-rich rocks (A: troctolite, B: norite A1, C: norite A2, D: anorthosite B2, E: anorthosite B3). The average triple oxygen isotope compositions of the plagioclase separates are plotted as blue dots. The average compositions of the clino- or orthopyroxenes are displayed as red triangles. The average result of the olivine, amphibole or chromite separates is shown as green squares. Regression lines are plotted along with error envelopes based on Monte Carlo simulations $(N=5000)$. The slopes $(\lambda)$ were calculated and are plotted in the figures. The errors of $\lambda$ were determined using the Monte Carlos simulations. C) The slope of the regression line is also the $\theta$ value of the plagioclase-pyroxene system. D and E) data from Kohl et al. (2017) is plotted for comparison. The grey squares represent the oxygen isotope composition of mafic mineral separates and the grey dots represent the results of plagioclase separates from the Bushveld anorthosite (left dot) and the Bushveld diabase (right dot). 


\subsubsection{Triple oxygen isotope composition of feldspar compared to co-existing min- erals}

The major phases appear to be in chemical and isotopic equilibrium only in one of five examined feldspar-rich rocks. To find unaltered and well-equilibrated samples of this rock type has proven to be challenging. The mineral assemblage of norite A2 (plagioclase and orthopyroxene) is unaltered, co-genetic and seems to be in isotopic equilibrium. It fulfils the prerequisites for investigating whether there is a feldspar-specific isotope fractionation effect. The $\Delta^{18} \mathrm{O}_{\text {plag-opx }}$ combined with the $\Delta \Delta^{\prime 17} \mathrm{O}$ of $1 \mathrm{ppm}$ corresponds to a $\theta$ value of 0.525 , which is a reasonable value for equilibrium isotope fractionation at high-temperature magmatic or metamorphic temperatures. This finding tentatively argues against a 'feldspar effect', although, the uncertainty on the calculated $\theta$ value is comparatively large due to the small $\delta^{18} \mathrm{O}$ difference between the minerals.

The suggestion for a 'feldspar effect' by Kohl et al. (2017) was inspired by data on anorthosite samples from the Bushveld Igneous Complex (grey data in fig. 4.8D/E). Our analyses of anorthosite B2 and B3, as well as the work of Schannor et al. (2018), demonstrate, however, that mineral assemblages of the Bushveld anorthosites with chromitite seams are often in disequilibrium, and therefore cannot be used to assess the isotope fractionation behaviour of plagioclase. In general, the triple oxygen isotope data for the plagioclase separates that Kohl et al. (2017) analysed are comparable with our results. One important difference is though, that Kohl et al. (2017) compared plagioclase data from the Bushveld Complex with data of mafic minerals from other, unrelated samples. We studied closely-related chromite separates.

We showed that the samples troctolite and norite A1 were hydrothermally altered and therefore cannot be used to assess equilibrium oxygen isotope fractionation behaviour of feldspar. Nevertheless, even those altered rocks do not show drastically lower $\Delta^{\prime 17} \mathrm{O}$ values in feldspar than in the associated minerals. From the perspective of our study, there is no indication for a preference of ${ }^{16} \mathrm{O}$ over the ${ }^{17} \mathrm{O}$ and ${ }^{18} \mathrm{O}$ in the plagioclase lattice structure (Kohl et al. 2017). Cano et al. (2020) studied five feldspar-bearing magmatic rocks (terrestrial), and did not find evidence for a feldspar-specific isotope fractionation effect either. We therefore rule out such an effect as the cause for the apparently lower $\Delta^{\prime 17} \mathrm{O}$ values in the previous analyses of feldspar-rich lunar highland rocks compared to mare basalts (Young et al. 2016, Kohl et al. 2017).

\subsubsection{Alternative explanations for the low $\Delta^{\prime 17} \mathrm{O}$ of the lunar feldspar-rich rocks}

The triple oxygen isotope comparison between the two lunar lithologies, mare basalts and highland rocks, is delicate. The rock types are only $0.3 \%$ on average different in $\delta^{18} \mathrm{O}$ (fig. 4.9 ), which leads to a very challenging $\theta$ determination. Already small $\Delta^{\prime 17} \mathrm{O}$ inaccuracies can lead to anomalous $\theta$ values. Abundant triple oxygen isotope data is available for mare basalts, and the average composition of mare basalts is therefore reasonably well known. The feldspar-rich lunar highland rocks, in contrast, were analysed less often, and identical samples were measured repeatedly. The total number of lunar feldspar-rich rocks that were analysed is only 9 compared to 56 mare basalts (considering WR measurements and only publications which are providing sample IDs). It is important to keep in mind that in contrast to our mineral study, feldspar-rich lunar rocks and mare basalts are clearly not co-genetic. They are rock types, created at different times due to different processes 
(see chapter 2). Most of the feldspar-rich rocks are thought to be primordial and were created in the end phase of the lunar magma ocean. The mare basalts are younger, and were created during later episodes of mantle partial melting. The different ages of the two rock types open up the possibility that the feldspar-rich highland rocks and mare basalts were affected by post-crystallisation processes at the lunar surface by different degrees. Cano et al. (2020) proposed that $\Delta^{\prime 17} \mathrm{O}$ offset between both lithologies could be the consequence of a different interaction with a low $\Delta^{\prime 17} \mathrm{O}$ silicate vapour, which was created by the Moon-forming impact. Here we propose that surface processes on the Moon, e.g. impact gardening, could also have affected the oxygen isotope composition of rocks near the lunar surface by the addition of meteorite material or by the impact process itself (see chapter 6). The older highland rocks rocks were exposed to surface processes for a longer time than the mare basalts, and could therefore have been affected to a different extent by such processes than the mare basalts.

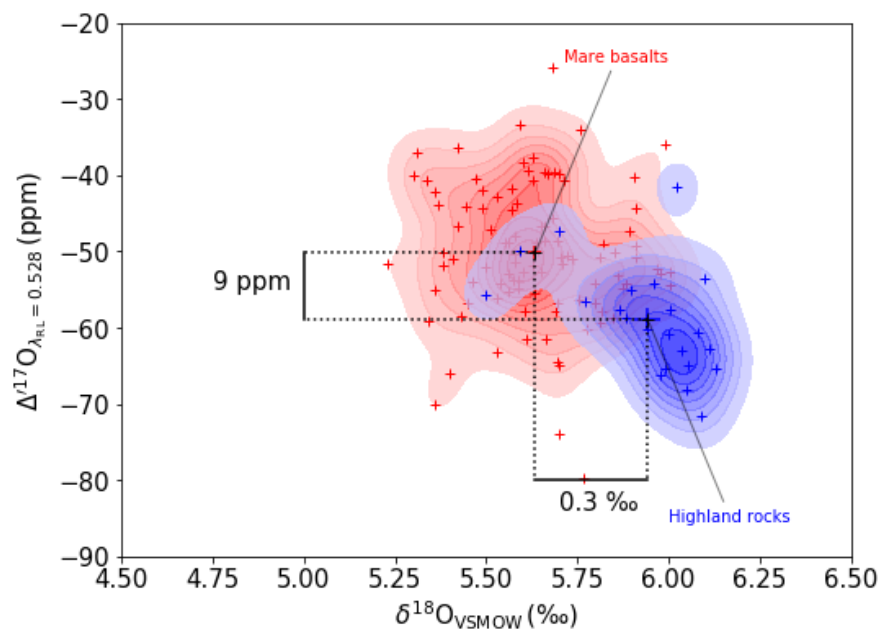

Figure 4.9: $\Delta^{\prime 17} \mathrm{O}$ vs. $\delta^{18} \mathrm{O}$ of lunar mare basalts (red) and feldspar-rich lunar rocks (highland rocks, blue). The data is from following publications: Wiechert et al. (2001), Spicuzza et al. (2007), Hallis et al. (2010), Herwartz et al. (2014), Young et al. (2016), Greenwood et al. (2018), Cano et al. (2020). The data was normalised to a $\Delta^{\prime 17} \mathrm{O}$ of San Carlos olivine of $-52 \mathrm{ppm}$ or a $\Delta^{\prime 17} \mathrm{O}$ of UWG-2 of $-60 \mathrm{ppm}$. The data populations are highlighted using kernel density estimate contour plots $($ level $=10)$. The differences in $\Delta^{\prime 17} \mathrm{O}$ and $\delta^{18} \mathrm{O}$ between the mean values of the mare basalt and highland rock data set are illustrated.

\subsection{Conclusion}

We found no evidence for a preference of the feldspar crystal lattice to incorporate ${ }^{16} \mathrm{O}$ over ${ }^{17} \mathrm{O}$ and ${ }^{18} \mathrm{O}$. We observed no systematically lower $\Delta^{\prime 17} \mathrm{O}$ values for plagioclase compared to the co-genetic clinopyroxene/orthopyroxene, olivine, amphibole or chromite in terrestrial plutonic rocks. Also, we found no evidence that analytical difficulties can lead to systematically lower $\Delta^{\prime 17} \mathrm{O}$ values for feldspar. Still, we cannot exclude analytical artefacts completely as explanation for the frequently reported low $\Delta^{\prime 17} \mathrm{O}$ values of the feldspar-rich lunar highland rocks, because the fluorination setups and measurement protocols used for the lunar rock data sets are laboratory-specific. To achieve precise triple oxygen isotope data for feldspar is challenging. Alternatively, the different triple oxygen isotope compositions of feldspar-rich lunar rocks and mare basalts could also indicate no co-genesis of the respective lithologies and/or later external processes (e.g. impacts). 


\section{Tight bounds on missing late veneer in early Archean peridotite from triple oxygen isotopes}

This chapter is based on the manuscript: Peters, S.T.M, Fischer, M.B, Pack, A., Szilas, K., Appel, P.W.U, Münker, C., Dallai, L., Marien, C.S. (2021) Tight bounds on missing late veneer in early Archean peridotite from triple oxygen isotopes. Geochemical Perspective Letters, 18, 27-31 (doi: 10.7185/geochemlet.2120). Own contribution: assistance with preceding methodical experiments, assistance with sample search and selection, assistance with sample preparation and analysis, provision of remarks on the manuscript.

\subsection{Abstract}

Oxygen isotopes provide a unique possibility to study Earth's late accretion phase from a lithophile element perspective, because most carbonaceous chondrites - meteorites that likely resemble the composition of the terrestrial late veneer — have markedly different $\Delta^{\prime 17} \mathrm{O}$ values than the silicate Earth. Ultramafic rocks in the early Archean assemblage of southwest Greenland have not incorporated the full amount of late accreted materials, and therefore possibly record the $\Delta^{17} \mathrm{O}$ of the mantle before late accretion. We measured ${ }^{17} \mathrm{O} /{ }^{16} \mathrm{O}$ and ${ }^{18} \mathrm{O} /{ }^{16} \mathrm{O}$ ratios of olivine from these ultramafic rocks and compared them with olivine from post-Archean mantle peridotite. A missing late veneer component was not resolved. The missing component from the early Archean mantle is therefore restricted to $\leq 0.12 \% \mathrm{M}_{\oplus}$ for most carbonaceous chondrite-like materials, unless the missing component resembles CI chondrites - the only carbonaceous chondrites with similar $\Delta^{\prime 17} \mathrm{O}$ as the silicate Earth. If the early Archean mantle had incorporated $60 \%$ late veneer, the overall late accreted mass would be restricted to $\leq 0.3 \% \mathrm{M}_{\oplus}$ for most types of carbonaceous chondrites, with a more massive late veneer only possible for CI-like chondrites. 


\subsection{Introduction}

\subsubsection{Missing late veneer in early Archean mantle domains}

Earth formed by the accretion of rocky materials in a protoplanetary disk. The final $\sim 0.5 \%$ of these materials escaped metal-silicate equilibrium during core formation processes, and are commonly referred to as the late veneer (Walker 2009). The composition of these late accreted materials is interesting to study, because they possibly contributed a large portion of volatile elements and water to the Earth's mass (Wang and Becker 2013). Platinum and possibly tungsten isotope ratios indicate that some Archean mantle domains did not incorporate the full amount of late veneer (e.g., Creech et al. 2016, Willbold et al. 2011). Such mantle domains provide unique windows into the final stages of Earth's accretion and its earliest evolution. An unambiguous pre-late veneer signal is present in ultramafic enclaves that are entrained in the Eoarchean Itsaq Gneiss Complex and Mesoarchean Fiskefjord region of southwest Greenland. These rocks show a uniform excess in s-process $\mathrm{Ru}$ nuclides compared to r-process $\mathrm{Ru}$ nuclides relative to the bulk silicate Earth (Fischer-Gödde et al. 2020). The excess s-process Ru in the ultramafic enclaves is best explained by a deficit in late accreted materials that carried a deficit in s-process $\mathrm{Ru}$. Whereas both carbonaceous and non-carbonaceous chondrite groups carry deficits in s-process $\mathrm{Ru}$, the s-process deficit is only sufficiently large in carbonaceous chondrite groups to potentially account for the observed s-process excess in the ultramafic enclaves, given the concentrations of platinum-group elements in the Eoarchean mantle (Fischer-Gödde et al. 2020). This conclusion is important, because it would support a volatile-rich, carbonaceous chondrite-like late veneer, and therewith complement evidence from volatile chalcophile elements in the post-Archean mantle (Braukmüller et al. 2019, Varas-Reus et al. 2019, Wang and Becker 2013).

\subsubsection{Potential of studying triple oxygen isotope ratios}

Oxygen stable isotope ratios $\left({ }^{17} \mathrm{O} /{ }^{16} \mathrm{O},{ }^{18} \mathrm{O} /{ }^{16} \mathrm{O}\right)$ are a unique tool for studying late accretion processes from a lithophile element perspective (Reimink et al. 2018, Rumble et al. 2013, Valley et al. 2014, Young et al. 2016), because bulk asteroids in the Solar System show $\sim 6000 \mathrm{ppm}$ variations in $\Delta^{\prime 17} \mathrm{O}$ (Clayton 1993). This is comparatively large to the $\sim 5 \mathrm{ppm}$ analytical resolution of state-of-the-art laser fluorination techniques. Henceforth, we use a definition for $\Delta^{\prime 17} \mathrm{O}$ with $\Delta^{\prime 17} \mathrm{O}=10^{3}\left[10^{3} \ln \left(\delta^{17} \mathrm{O} / 10^{3}+1\right)-0.528 *\right.$ $\left.10^{3} \ln \left(\delta^{18} \mathrm{O} / 10^{3}+1\right)\right]$. Carbonaceous chondrites have lower $\Delta^{\prime 17} \mathrm{O}$ values than the silicate Earth, with only $\mathrm{CI}$ chondrites having similar but slightly higher $\Delta^{\prime 17} \mathrm{O}$ and much higher $\delta^{18} \mathrm{O}$ values than the silicate Earth (Clayton 1993). If the early Archean ultramafic enclaves from southwest Greenland would have been deprived of a late veneer component that resembles most carbonaceous chondrite types (CM, CV, CO, CK, CR, CH, CB chondrites), samples from the early Archean ultramafic enclaves would therefore be expected to have an elevated $\Delta^{\prime 17} \mathrm{O}$ compared to the silicate Earth. Only if the ultramafic enclaves would be missing a late veneer component that resembles CI chondrites, they would have a similar or lower $\Delta^{\prime 17} \mathrm{O}$ than the silicate Earth. In order to study mass and composition of the missing late veneer component from the early Archean ultramafic enclaves of southwest Greenland, we therefore compared their olivine $\Delta^{\prime 17} \mathrm{O}$ values with olivine in 
post-Archean mantle peridotite.

\subsection{Samples and methods}

The suite of post-Archean mantle peridotite sample comprises 14 lherzolithic xenoliths that were erupted in Phanerozoic magmas from diverse geological settings, and 1 dunite sample from the Beni Boussera massif (appendix sec. C.1). The ultramafic enclaves with s-process Ru excess (Fischer-Gödde et al. 2020) that we studied are from two localities within the $>3.7 \mathrm{Ga}$ Isua supracrustal belt (ISB), one locality south of the Isua supracrustal belt (SOISB), the $\sim 3.8 \mathrm{Ga}$ Narssaq ultramafic body (NUB) and the $\sim 3.8 \mathrm{Ga}$ Ujaragssuit Nunât ultramafic body. The early Archean ultramafic bodies were interpreted either as slivers of residual mantle peridotite, as metamorphosed cumulates from (ultra)mafic magmas, or, for one location, as an ultramafic layered intrusion (appendix sec. C.1). We also studied peridotite samples from the Fiskefjord region that are geologically related to the Mesoarchean Seqi peridotite body (Szilas et al. 2015a), for which an excess in sprocess Ru compared to the silicate Earth was also reported (Fischer-Gödde et al. 2020). Olivine samples were analysed for their triple oxygen isotope compositions $\left(\delta^{17} \mathrm{O}, \delta^{18} \mathrm{O}\right)$, using laser-assisted fluorination protocols (appendix sec. C.2). All samples were analysed relative to San Carlos olivine, which is considered here to have a $\Delta^{\prime 17} \mathrm{O}=-51.8 \mathrm{ppm}$ relative to VSMOW2.

\subsection{Results}

Olivine $\delta^{18} \mathrm{O}$ values of the post-Archean mantle peridotite samples are on average $\delta^{18} \mathrm{O}=$ $5.21 \pm 0.08 \% \circ( \pm 1 \sigma \mathrm{SD}, N=15)$, which is in good agreement with previous data for olivine in mantle peridotite (e.g., Mattey et al. 1994; table C.1). The post-Archean mantle peridotite samples have an average olivine $\Delta^{\prime 17} \mathrm{O}$ value of $-51.6 \pm 2.1 \mathrm{ppm}( \pm 1 \sigma \mathrm{SD}$, $N=15$; fig. 5.1A), which is in line with data on mafic and ultramafic rocks from previous studies (Herwartz et al. 2014, Greenwood et al. 2018, Cano et al. 2020). No variations in olivine $\Delta^{\prime 17} \mathrm{O}$ values were found for the post-Archean mantle peridotite samples. The peridotite samples from the Archean ultramafic enclaves in the Itsaq Gneiss Complex and Fiskefjord region show a much wider range in olivine $\delta^{18} \mathrm{O}$ values $\left(\delta^{18} \mathrm{O}=2.8-6.2 \%\right.$; table C.2). For Ujaragssuit Nunât, our new olivine $\delta^{18} \mathrm{O}$ data agree with previous measurements by Lowry et al. (2003). Olivine $\Delta^{\prime 17} \mathrm{O}$ values of the early Archean ultramafic bodies are on average $\Delta^{\prime 17} \mathrm{O}=-50.9 \pm 3.2 \mathrm{ppm}( \pm 1 \sigma \mathrm{SD}, N=23)$; a value that is indistinguishable from the $\Delta^{\prime 17} \mathrm{O}$ value of post-Archean mantle olivine. The early Archean peridotite samples show decreasing olivine $\Delta^{17} \mathrm{O}$ values with increasing $\delta^{18} \mathrm{O}$ values (fig. 5.1B). 

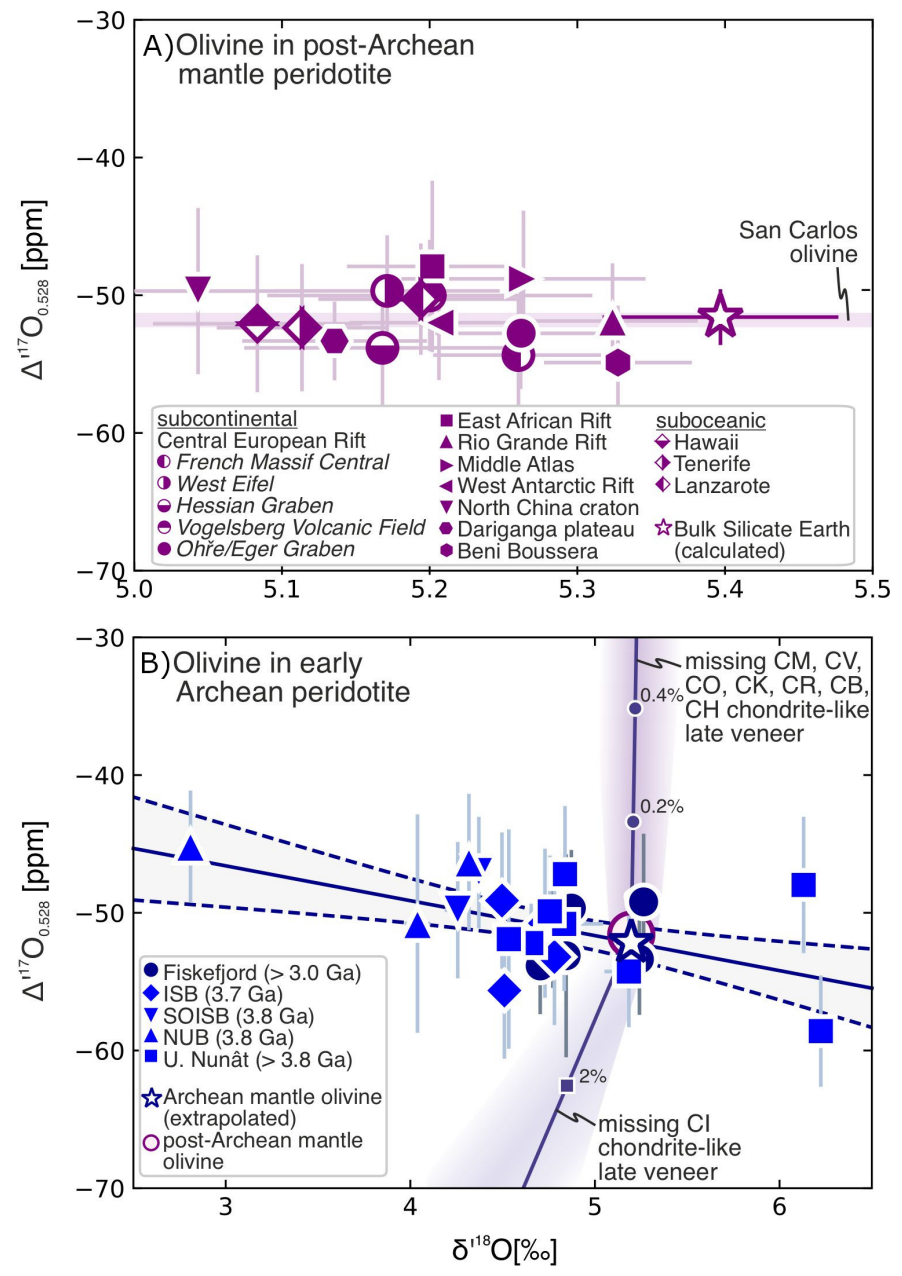

Figure 5.1: Plots of $\Delta^{\prime 17} \mathrm{O}$ vs. $\delta^{\prime 18} \mathrm{O} \pm 1 \sigma$ SEM of olivine from ultramafic rocks. A) Olivine in peridotites that were erupted as xenoliths in Phanerozoic magmas and from the Beni Boussera massif, relative to the composition of San Carlos olivine (horizontal line; $\Delta^{\prime 17} \mathrm{O}=-51.8 \mathrm{ppm}$, appendix sec. C.2). The composition of the bulk silicate Earth (star) is calculated from the mean olivine compositions from this study $\pm 1 \sigma \mathrm{SD}$ and is based on $-0.2 \%$ fractionation in $\delta^{18} \mathrm{O}$ and a $\theta$ value of 0.53 for fractionation between olivine and bulk peridotite. B) Olivine from early Archean ultramafic enclaves with excess s-process Ru (Fischer-Gödde et al. 2020). The curve corresponds to a linear fit $\pm 1 \sigma$ SD through the Archean peridotite data in $\delta^{17} \mathrm{O}$ versus $\delta^{18} \mathrm{O}$ space and is used to extrapolate the compositions of the samples, which were in part altered by fluid-rock reactions, to the $\Delta^{17} \mathrm{O}$ of pristine olivine in the early Archean mantle with $\delta^{18} \mathrm{O}=5.21 \%$ o (star). Shadowed fields correspond to calculated olivine compositions if carbonaceous chondrites would be missing from the ultramafic enclaves, considering all carbonaceous chondrite meteorites for which data are available in the Meteoritical Bulletin Database (https://www.lpi.usra.edu/meteor/) as possible end member compositions for the late veneer. Curves are shown for missing late veneer with the average composition of $\mathrm{CM}, \mathrm{CV}, \mathrm{CO}, \mathrm{CK}, \mathrm{CR}, \mathrm{CH}, \mathrm{CB}$ chondrites and the average composition of CI chondrites, respectively, with the percentages of missing late veneer indicated relative to the mass of the Earth. The following abbreviations were used: ISB = Isua supracrustal belt, SOISB = South of the Isua supracrustal belt, NUB = Narssaq ultramafic body, U. Nunât = Ujaragssuit Nunât ultramafic body. 


\subsection{Discussion and conclusion}

\subsubsection{Effects of fluid-rock reactions}

Olivine $\delta^{18} \mathrm{O}$ values of the early Archean peridotites predominantly deviate towards lower values compared to post-Archean mantle olivine. We reported similarly low and variable olivine $\delta^{18} \mathrm{O}$ values for a $>2.7 \mathrm{Ga}$ peridotite body that is entrained in the Kuummiut terrane in southeast Greenland, for which the low and variable $\delta^{18} \mathrm{O}$ values reflect the effects of fluid-rock reactions that were followed by dehydration of the peridotites protoliths at high-grade metamorphic conditions (Peters et al. 2020b). Likewise, we suggest that the ultramafic enclaves in the Itsaq Gneiss Complex and Fiskefjord region experienced hydration and dehydration events during their metamorphic history that modified their primary olivine $\delta^{18} \mathrm{O}$ values, a process that is likely common for ultramafic rocks in Archean highgrade metamorphic terranes (Nishio et al. 2019; appendix sec. C.1). Fluid-rock reactions cannot only have shifted the $\delta^{18} \mathrm{O}$ values of the Archean peridotite samples, but may also have altered the $\Delta^{\prime 17} \mathrm{O}$ values of the peridotite samples (e.g., Sengupta and Pack 2018). In order to obtain the $\Delta^{\prime 17} \mathrm{O}$ value of pristine olivine in the ultramafic rocks before they interacted with fluids, we extrapolated the measured $\Delta^{\prime 17} \mathrm{O}$ values to the $\delta^{18} \mathrm{O}$ value of typical mantle olivine (this study: $\delta^{18} \mathrm{O}=5.21 \%$; fig. 5.1B). The extrapolated $\Delta^{\prime 17} \mathrm{O}$ value of pristine olivine in the early Archean mantle is $-52.3 \pm 1.7 \mathrm{ppm}( \pm 1 \sigma \mathrm{SD})$; a value that is only $1.4 \mathrm{ppm}$ lower than the average $\Delta^{\prime 17} \mathrm{O}$ of the uncorrected data.

\subsubsection{Implications for missing late veneer}

The suggested $\Delta^{\prime 17} \mathrm{O}$ value of pristine olivine in the early Archean ultramafic rocks is indistinguishable from the mean $\Delta^{\prime 17} \mathrm{O}$ value of olivine in post-Archean mantle peridotite (fig. 5.1B). A pre-late veneer signal in the Archean ultramafic enclaves is thus not resolved with respect to oxygen isotopes. This conclusion corroborates earlier results from a laser fluorination study on the Acasta Gneiss Complex and Isua supracrustal belt (Rumble et al. 2013), and lower resolution SIMS data for the Jack Hills zircons, as well as zircons from the Acasta Gneiss Complex (Reimink et al. 2018, Valley et al. 2014). Using the new data, we calculated the uppermost likely limits for missing late veneer from the Itsaq Gneiss Complex and Fiskefjord mantle, assuming the compositions of carbonaceous chondrite groups as the missing components (c.f. Fischer-Gödde et al. 2020). In general, and by definition, the compositions of the mantle before the late veneer (hereafter: pre-late veneer mantle, PLVM), the bulk silicate Earth and the late veneer plot on a mixing line in $\delta^{17} \mathrm{O}$ versus $\delta^{18} \mathrm{O}$ space. The slope $m$ and intercept $i$ of this mixing line are given by the $\delta^{17} \mathrm{O}$ and $\delta^{18} \mathrm{O}$ values of the bulk silicate Earth and the composition of the late veneer. In $\delta^{\prime 17} \mathrm{O}$ versus $\delta^{\prime 18} \mathrm{O}$ space, the composition of the pre-late veneer mantle also plots on a line with slope 0.528 and intercept $\Delta^{\prime 17} \mathrm{O}$ that equals the value for the pre-late veneer mantle. The point of intersection of the two relations in ${\delta^{\prime 17}}^{17}$ versus $\delta^{\prime 18} \mathrm{O}$ space is given by:

$$
0.528 \cdot \delta^{\prime 18} \mathrm{O}_{P L V M}+\frac{\Delta^{\prime 17} \mathrm{O}_{P L V M}}{10^{3}}=10^{3} \ln \left(m e^{\frac{\delta^{\prime 18} \operatorname{OPLVM}_{10}}{10^{3}}}-m+\frac{i}{10^{3}}+1\right)
$$

and can be approximated with the Newton-Raphson method. The intersect $\delta$-values then allow determining the oxygen atom fraction of missing late veneer from the pre-late veneer mantle (appendix sec. C.4). 

isotopes

Based on eq. 5.1 we modelled possible masses of missing late veneer if carbonaceous chondrite groups would be missing from the Itsaq Gneiss Complex and Fiskefjord mantle, using a Monte Carlo approach (fig. 5.2). In order to account for the large spread in $\Delta^{\prime 17} \mathrm{O}$ values within carbonaceous chondrite groups (Clayton 1993), we considered each meteorite specimen for which data are available in the Meteoritical Bulletin Database as a possible end member composition for the late veneer. We adopted concentrations in the mixing calculations of $46.5 \mathrm{wt} \%$ oxygen in carbonaceous chondrites and $44.33 \mathrm{wt} \%$ oxygen in the terrestrial mantle, respectively (Palme and O'Neill 2003). In the simulations, the $\Delta^{\prime 17} \mathrm{O}$ values for the bulk silicate Earth and the pre-late veneer mantle were sampled from normally distributed populations that are described by the mean values and standard deviations for post-Archean mantle peridotite and the extrapolated $\Delta^{\prime 17} \mathrm{O}$ value for pristine olivine in early Archean peridotite from this study, respectively. We consider the $97.72^{\text {nd }}$ percentiles of the outcomes of the simulations as the uppermost likely values for missing late veneer. These uppermost values correspond to a missing late veneer component relative to the Earth's mass $\left(\mathrm{M}_{\oplus}\right)$ of $\leq 0.12 \% \mathrm{M}_{\oplus}$ if the missing component would resemble $\mathrm{CM}, \mathrm{CV}, \mathrm{CO}, \mathrm{CK}, \mathrm{CR}, \mathrm{CH}, \mathrm{CB}$, but not $\mathrm{CI}$ chondrites (fig. $5.2 \mathrm{~A}$ ); $\leq 0.11 \% \mathrm{M}_{\oplus}$ if the missing component would resemble only $\mathrm{CM}$ chondrites (fig. 5.2B); and $\leq 1.2 \%$ $\mathrm{M}_{\oplus}$ if the missing component would resemble CI chondrites (fig. 5.2C).

Our modelling results have implications for the materials that comprised Earth's late veneer. Fischer-Gödde et al. (2020) estimated based on their Ru isotope data that a late veneer component of up to $0.3 \% \mathrm{M}_{\oplus}$ of carbonaceous chondrite-like materials could be missing from the Itsaq Gneiss Complex and Fiskefjord mantle, and favoured CM chondrites as the missing component. The oxygen isotope data, in contrast, imply that only a much smaller component of carbonaceous chondrites $\left(\leq 0.12 \% \mathrm{M}_{\oplus}\right)$ can possibly be missing from the early Archean ultramafic enclaves with respect to oxygen, unless this component comprises $\mathrm{CI}$ chondrites. We propose two end member scenarios that best reconcile the triple oxygen isotope data with the available $\mathrm{Ru}$ isotope data. In one end-member scenario, the missing late veneer component indeed resembles $\mathrm{CM}$ chondrites with the equivalent mass of $\leq 0.11 \% \mathrm{M}_{\oplus}$ (fig. 5.2B). This scenario implies that the early Archean mantle had incorporated more than ca. $>86 \%$ late veneer with respect to lithophile elements, which agrees with some estimates from the concentrations of highly siderophile elements in the early Archean mantle (van de Löcht et al. 2018), but not with others (Dale et al. 2017). The missing CM chondrite-like component was possibly complemented by a missing component of carbonaceous group iron meteorite-like materials, e.g., materials similar to the IID and IVA irons that have comparable Ru isotope compositions compared to carbonaceous chondrites (Fischer-Gödde and Kleine 2017) and high Ru concentrations, but are deficient in $\mathrm{O}$. This scenario is consistent with highly siderophile element concentrations and ${ }^{187} \mathrm{Os} /{ }^{188} \mathrm{Os}$ ratios in lunar impact rocks and in the upper mantle (FischerGödde and Becker 2012). In the second end-member scenario, the missing late veneer component resembles the composition of CI chondrites (fig. 5.2C). This scenario is feasible only if the s-process $\mathrm{Ru}$ deficit in CI chondrites is greater than was considered in the modelling by Fischer-Gödde et al. (2020). We consider this a reasonable suggestion, because the $\mathrm{Ru}$ isotope composition of $\mathrm{CI}$ chondrites is constrained at present by a single meteorite specimen only, whereas carbonaceous chondrite groups show internal $\mathrm{Ru}$ isotope variations (Fischer-Gödde and Kleine 2017). 

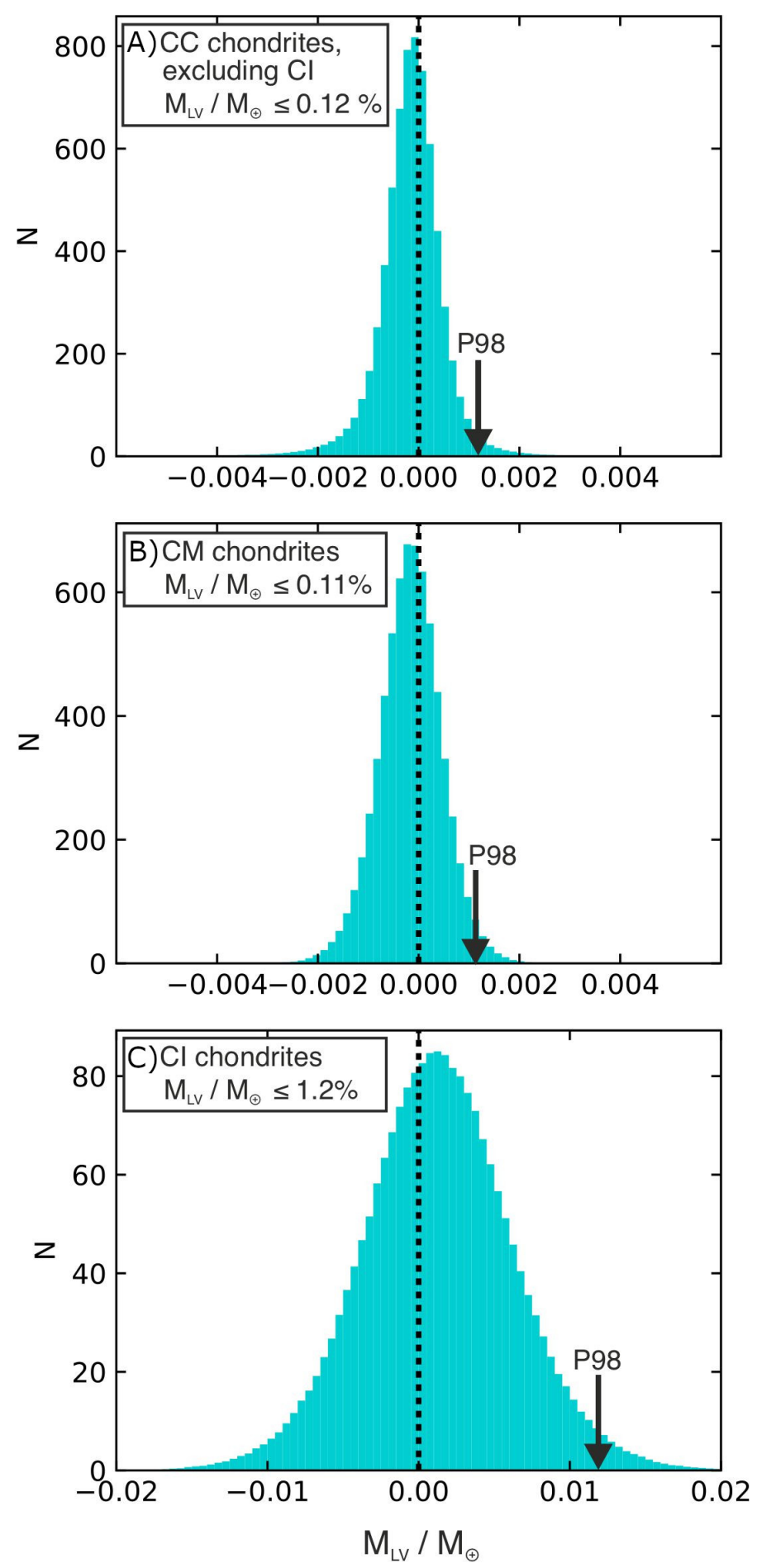

Figure 5.2: Missing late veneer from the Itsaq Gneiss Complex and Fiskefjord mantle relative to the mass of the Earth $\left(\mathrm{M}_{\mathrm{LV}} / \mathrm{M}_{\oplus}\right)$, calculated from the data in this study and from available triple oxygen isotope data for carbonaceous chondrites from the Meteoritical Bulletin Database (https://www.lpi.usra.edu/meteor/; Monte Carlo simulation, $N=10^{6}$ runs). The $\delta^{18} \mathrm{O}$ value of the silicate Earth was considered to be $0.2 \%$ higher than olivine in mantle peridotite from this study, i.e. $\delta^{18} \mathrm{O}_{\mathrm{BSE}}=5.41 \%$. The $97.72^{\text {nd }}$ percentiles (P98) of the outcomes are shown by arrows and are given in the panel headings as percentages; and are considered uppermost bounds for missing late veneer. Outcomes with negative values correspond to hypothetical scenarios in which the Itsaq Gneiss Complex and Fiskefjord mantle contain excess late veneer. Dotted lines show outcomes where $\mathrm{M}_{\mathrm{LV}} / \mathrm{M}_{\oplus}=0$. A) carbonaceous chondrites, excluding $\mathrm{CI}$ chondrites; B) CM chondrites only; C) CI chondrites only. 
5 Tight bounds on missing late veneer in early Archean peridotite from triple oxygen isotopes

The discussion of our data thus far concerns the mass and composition of a late veneer component that can possibly be missing from the early Archean mantle. It can be assumed instead that the early Archean mantle is deficient in 40\% late accreted materials (Dale et al. 2017). Following this line of logic, the triple oxygen isotope data imply a maximum late accreted mass of $\leq 0.3 \% \mathrm{M}_{\oplus}$ for $\mathrm{CM}, \mathrm{CV}, \mathrm{CO}, \mathrm{CK}, \mathrm{CR}, \mathrm{CH}, \mathrm{CB}$ chondrites; and $\leq 0.3 \% \mathrm{M}_{\oplus} \mathrm{CI}$ chondrites. In conjunction with the absolute concentrations of highly siderophile elements in the post-Archean mantle, this conclusion would imply that the late veneer contained abundant CI-like materials; a scenario that is agrees well with the Se isotope composition of the post-Archean mantle (Varas-Reus et al. 2019). 


\section{Tracing impactor signatures in lunar rocks using triple oxygen isotope systematics}

\subsection{Abstract}

The variation in triple oxygen isotope ratios is large in the Solar System making this isotope system a high-precision tool for tracing extraterrestrial, rocky material. We reinvestigated the triple oxygen isotope comparison between pristine terrestrial and lunar rocks to trace the Moon-forming impactor. In contrast to some previous results, our data shows that Earth and Moon are identical within $1 \mathrm{ppm}$ indicating either similar isotopic compositions of the impactor and the Earth prior to the impact, or particular impact conditions that suppressed an initial heterogeneity. We studied lunar impact rocks to trace later meteoritic additions to the Moon and identified distinct triple oxygen isotope compositions, which can be used to constrain the provenance of the respective impactor material. Hence, we can study the composition of the late accretion on the Earth-Moon system by analysing the isotopic changes inflicted by impacts on lunar impact rocks.

\subsection{Introduction}

Impacts belong to the most fundamental processes in the Solar System. They can occur on all scales. Consequences of impact processes are impact gardening and the addition of extraterrestrial material. Most impactor material is volatilised and lost during impacts due to high temperatures and pressures, but small traces can be mixed into the target rock. These traces might create small triple oxygen isotope anomalies (expressed as $\Delta^{\prime 17} \mathrm{O}$, here defined as $\left.\Delta^{\prime 17} \mathrm{O}=10^{3}\left[10^{3} \ln \left(\delta^{17} \mathrm{O} / 10^{3}+1\right)-0.528 * 10^{3} \ln \left(\delta^{18} \mathrm{O} / 10^{3}+1\right)\right]\right)$ in the product rock, because different bodies in the Solar System have distinct and highly variable triple oxygen isotope compositions (in the range of $\sim 6000 \mathrm{ppm}$, e.g. Clayton 1993).

The lunar formation was an impact scenario occurring $4.5 \mathrm{Ga}$ ago. This catastrophic formation scenario was first formulated by Daly (1946) and three decades later specified by Hartmann and Davis (1975) and Cameron and Ward (1976). The canonical giant impact hypothesis satisfies many chemical and physical constrains, but suffers to adequately explain the uniform isotope data sets of Earth and Moon. The impactor is commonly expected to have a $\Delta^{\prime 17} \mathrm{O}$ distinct from the proto-Earth. The canonical model implies that the Moon accreted a higher portion of impactor than the Earth (e.g. Canup and Asphaug 
2001), hence the Moon should also differ in its $\Delta^{\prime 17} \mathrm{O}$ from Earth. A few studies have addressed the oxygen isotope difference between Earth and Moon with high-precision approaches, but with contrasting results. Reported differences in $\Delta^{\prime 17} \mathrm{O}_{\text {Moon-Earth }}$ range between 0 and $19 \mathrm{ppm}$ (Clayton and Mayeda 1996, Wiechert et al. 2001, Spicuzza et al. 2007, Hallis et al. 2010, Herwartz et al. 2014, Young et al. 2016, Greenwood et al. 2018, Cano et al. 2020). A difference in $\Delta^{\prime 17} \mathrm{O}$ between the two bodies would indicate a trace of the impactor, whereas identical triple oxygen isotope compositions would mean that the impact scenario occurred under different conditions. Here, (I) we re-assess the $\Delta^{\prime 17} \mathrm{O}$ Earth-Moon comparison by means of improved high-precision ${ }^{18} \mathrm{O} /{ }^{16} \mathrm{O}$ and ${ }^{17} \mathrm{O} /{ }^{16} \mathrm{O}$ measurements.

Since the solidification of the lunar crust, impact processes are modifying the lunar surface by the formation of impact rocks. With every impact the rocks are overprinted by impact metamorphism: vaporisation, excavation, mixing, melting and/or brecciation. In theory, the $\Delta^{\prime 17} \mathrm{O}$ impact rock record can be used to study the material delivered to the Earth-Moon system during the late accretion. Some studies have reported lithologydependent $\Delta^{\prime 17} \mathrm{O}$ variations indicating lunar heterogeneities (Young et al. 2016, Kohl et al. 2017, Cano et al. 2020), but no one was yet able to resolve impact-related $\Delta^{\prime 17} \mathrm{O}$ variations (e.g. Wiechert et al. 2001). The nature of these late accreted impactors is important with respect to the origin of Earth's water. Water was possibly delivered late during the accretion history by volatile-rich chondritic material (e.g. Albarède 2009, Alexander et al. 2012, Marty 2012, Braukmüller et al. 2019). This late accreted material, which is also responsible for the siderophile element concentrations in the Earth mantle, has been termed the late accretion or the late veneer (e.g. Mann et al. 2012). Here, (II) we use our improved analytical technique to study impact-related $\Delta^{\prime 17} \mathrm{O}$ variations as proxy for late accreted impactors.

We strive to constrain the lunar formation from an oxygen isotope point of view: is there a trace of the giant impactor and under which conditions did the impact occur? We also target to resolve $\Delta^{\prime 17} \mathrm{O}$ signatures in Apollo 16 and 17 impact rocks to study meteoritic additions during the late accretion.

\subsection{Samples and methods}

Our lunar sample set $(N=27)$ comprises pristine rocks (mare basalts, highland rocks, pyroclastic glasses; fig. D.1) that were not affected by impact processes (other than the Moon-forming impact) and impact-influenced rocks (soils, breccias and impact rocks; fig. D.2; additional information in appendix D.1). We describe samples as impactinfluenced', if they have impact-related features, e.g. elevated HSE concentrations relative to pristine lunar rocks. Elevated HSE concentrations compared to crustal values reflect meteoritic addition during the late accretion (table D.1), because the lunar crust was depleted in HSE during the differentiation of the planetesimal. Lunar rock samples were analysed for their triple oxygen isotope compositions $\left(\delta^{17} \mathrm{O}, \delta^{18} \mathrm{O}\right)$ using laser-assisted fluorination protocols (see appendix D.2). All samples were analysed relative to San Carlos olivine, which is considered here to have a $\Delta^{\prime 17} \mathrm{O}=-51.8 \mathrm{ppm}$ relative to VSMOW2. 


\subsection{Results}

We report a comprehensive set of 88 high-precision triple oxygen isotope analyses on lunar samples. The data are listed in table 6.1 and illustrated in fig. 6.1. The pristine lunar lithologies (mare basalts, highland rocks, pyroclastic glasses) are isotopically homogeneous with a mean $\Delta^{\prime 17} \mathrm{O}_{\text {Moon }}=-51.2 \pm 0.5 \mathrm{ppm}( \pm 1 \sigma \mathrm{SEM}, N=14)$. This number is within uncertainty identical to the number obtained from 169 measurements of terrestrial San Carlos olivine $\left(\Delta^{\prime 17} \mathrm{O}_{\mathrm{SC}}=-51.8 \pm 0.4 \mathrm{ppm}\right)$. In chapter 5 was shown that the San Carlos olivine is representative for the Earth mantle.

Apart of the pristine lithologies, a number of soils, impact rocks and breccias were analysed. The impact rocks vary in their $\Delta^{\prime 17} \mathrm{O}$ between -61 and $-50 \mathrm{ppm}$, i.e., their $\Delta^{\prime 17} \mathrm{O}$ is lower than that of the pristine lunar lithologies. The studied impact-influenced rocks tend also towards lower $\delta^{18} \mathrm{O}$ values. The soil samples are an exception (soil maturation: appendix D.5.1).

Table 6.1: Triple oxygen isotope data of lunar rocks. The pristine lunar samples were analysed mostly as WR (whole rock) and chips. The mean value of different green glass fractions and subsamples (F) are given for 15426/15421 (fig. D.1, fig. D.4, table D.2). The lunar impact-influenced samples were mostly analysed as WR and chips. The mean value of different sample fractions (F) are given for 60335, 67935, 72395 and 73215 (fig. D.2, fig. D.5, table D.3). Average values are displayed (single measurements: table D.4- D.12). The following abbreviations were used: $\mathrm{MB}=$ mare basalts, $\mathrm{HR}=$ highland rocks, Glass = pyroclastic glass, $\mathrm{KREEP}=\mathrm{KREEP}-\mathrm{rich}$ breccias, $\mathrm{IR}=$ Impact rocks, $\mathrm{A}=$ Apollo, $\mathrm{SC}=$ San Carlos olivine, $\mathrm{Ol}=$ olivine, $\mathrm{Gt}=$ garnet, $\mathrm{Wt}$. $=$ weighted.

\begin{tabular}{|c|c|c|c|c|c|c|c|c|c|c|}
\hline Sample ID & Lithology & Origin & Type & $\begin{array}{l}\delta^{17} \mathrm{O} \\
(\% \circ)\end{array}$ & $\pm 1 \sigma$ & $\begin{array}{l}\delta^{18} \mathrm{O} \\
(\% \circ)\end{array}$ & $\pm 1 \sigma$ & $\begin{array}{l}\Delta^{\prime 17} \mathrm{O} \\
(\mathrm{ppm})\end{array}$ & $\pm 1 \sigma$ & $\mathrm{N}$ \\
\hline \multicolumn{11}{|l|}{ Pristine Moon } \\
\hline 10071.122 & High-Ti MB & A11 & WR & 2.92 & 0.03 & 5.63 & 0.05 & -51 & 4 & 2 \\
\hline 70215.324 & High-Ti MB & A17 & WR & 2.92 & 0.02 & 5.64 & 0.04 & -53 & 3 & 2 \\
\hline 75035.226 & High-Ti MB & A17 & WR & 2.98 & 0.02 & 5.74 & 0.04 & -48 & 3 & 2 \\
\hline 12018.267 & Low-Ti MB & A12 & WR & 2.87 & 0.03 & 5.53 & 0.05 & -52 & 4 & 2 \\
\hline 12038.264 & Low-Ti MB & A12 & WR & 2.91 & 0.03 & 5.60 & 0.05 & -49 & 4 & 2 \\
\hline 12039.(47/65) & Low-Ti MB & A12 & WR & 2.86 & 0.03 & 5.52 & 0.05 & -52 & 4 & 2 \\
\hline 12045.26 & Low-Ti MB & A12 & WR & 2.84 & 0.03 & 5.47 & 0.05 & -47 & 4 & 2 \\
\hline 15495.202 & Low-Ti MB & A15 & WR & 2.83 & 0.02 & 5.46 & 0.04 & -53 & 3 & 2 \\
\hline 15415.171 & HR & A15 & WR & 2.99 & 0.02 & 5.77 & 0.04 & -52 & 3 & 3 \\
\hline $60025 .(842 / 173)$ & HR & A16 & WR & 2.96 & 0.02 & 5.72 & 0.04 & -53 & 3 & 3 \\
\hline 61224.52 & HR & A16 & WR & 2.96 & 0.03 & 5.71 & 0.05 & -51 & 4 & 2 \\
\hline 62255.311 & HR & A16 & WR & 2.94 & 0.02 & 5.68 & 0.04 & -51 & 3 & 3 \\
\hline $15426 / 15421$ & Glass & A 15 & $\mathrm{~F}$ & 2.81 & 0.01 & 5.43 & 0.02 & -52 & 1 & 10 \\
\hline 74220.942 & Glass & A17 & WR & 2.87 & 0.02 & 5.54 & 0.03 & -50 & 3 & 3 \\
\hline Wt. average & & & & 2.90 & 0.02 & 5.57 & 0.03 & -51.2 & 0.5 & \\
\hline \multicolumn{11}{|c|}{ Impact-influenced rocks } \\
\hline 68115.112 & KREEP & A16 & WR & 2.77 & 0.02 & 5.37 & 0.03 & -58 & 3 & 3 \\
\hline 68815.400 & KREEP & A16 & WR & 2.80 & 0.01 & 5.41 & 0.03 & -59 & 2 & 4 \\
\hline 12001.22 & Soil & A12 & WR & 2.97 & 0.02 & 5.74 & 0.03 & -58 & 2 & 4 \\
\hline 12010.78 & Soil & A12 & WR & 2.90 & 0.02 & 5.59 & 0.03 & -50 & 2 & 4 \\
\hline 15421.70R & Soil & A15 & $\mathrm{F}$ & 2.94 & 0.02 & 5.69 & 0.05 & -57 & 4 & 1 \\
\hline 60035.64 & IR & A16 & WR & 2.70 & 0.01 & 5.23 & 0.03 & -60 & 2 & 5 \\
\hline 60335.159 & IR & A16 & $\mathrm{F}$ & 2.73 & 0.02 & 5.29 & 0.03 & -61 & 2 & 4 \\
\hline 61015.113 & IR & A16 & WR & 2.72 & 0.02 & 5.27 & 0.03 & -58 & 2 & 4 \\
\hline 65055.54 & IR & A16 & WR & 2.77 & 0.02 & 5.35 & 0.03 & -51 & 2 & 4 \\
\hline 67935.40 & IR & A16 & $\mathrm{F}$ & 2.78 & 0.02 & 5.37 & 0.03 & -56 & 2 & 4 \\
\hline 72395.109 & IR & A17 & $\mathrm{F}$ & 2.73 & 0.02 & 5.28 & 0.03 & -55 & 2 & 3 \\
\hline 73215.19 & IR & A17 & $\mathrm{F}$ & 2.73 & 0.02 & 5.29 & 0.03 & -57 & 2 & 4 \\
\hline 77017.200 & IR & A17 & WR & 2.81 & 0.02 & 5.44 & 0.03 & -59 & 2 & 4 \\
\hline Wt. average & & & & 2.78 & 0.02 & 5.39 & 0.04 & -57.0 & 0.8 & \\
\hline \multicolumn{11}{|l|}{ Standards } \\
\hline $\mathrm{SC} 0215 \mathrm{M}$ & & USA & $\mathrm{Ol}$ & 2.68 & 0.01 & 5.18 & 0.01 & -51.8 & 0.7 & 57 \\
\hline SC 0919 & & USA & $\mathrm{Ol}$ & 2.77 & 0.00 & 5.34 & 0.01 & -51.8 & 0.5 & 112 \\
\hline UWG-2 & & USA & $\mathrm{Gt}$ & 2.98 & 0.01 & 5.77 & 0.02 & -59.3 & 1.4 & 23 \\
\hline
\end{tabular}




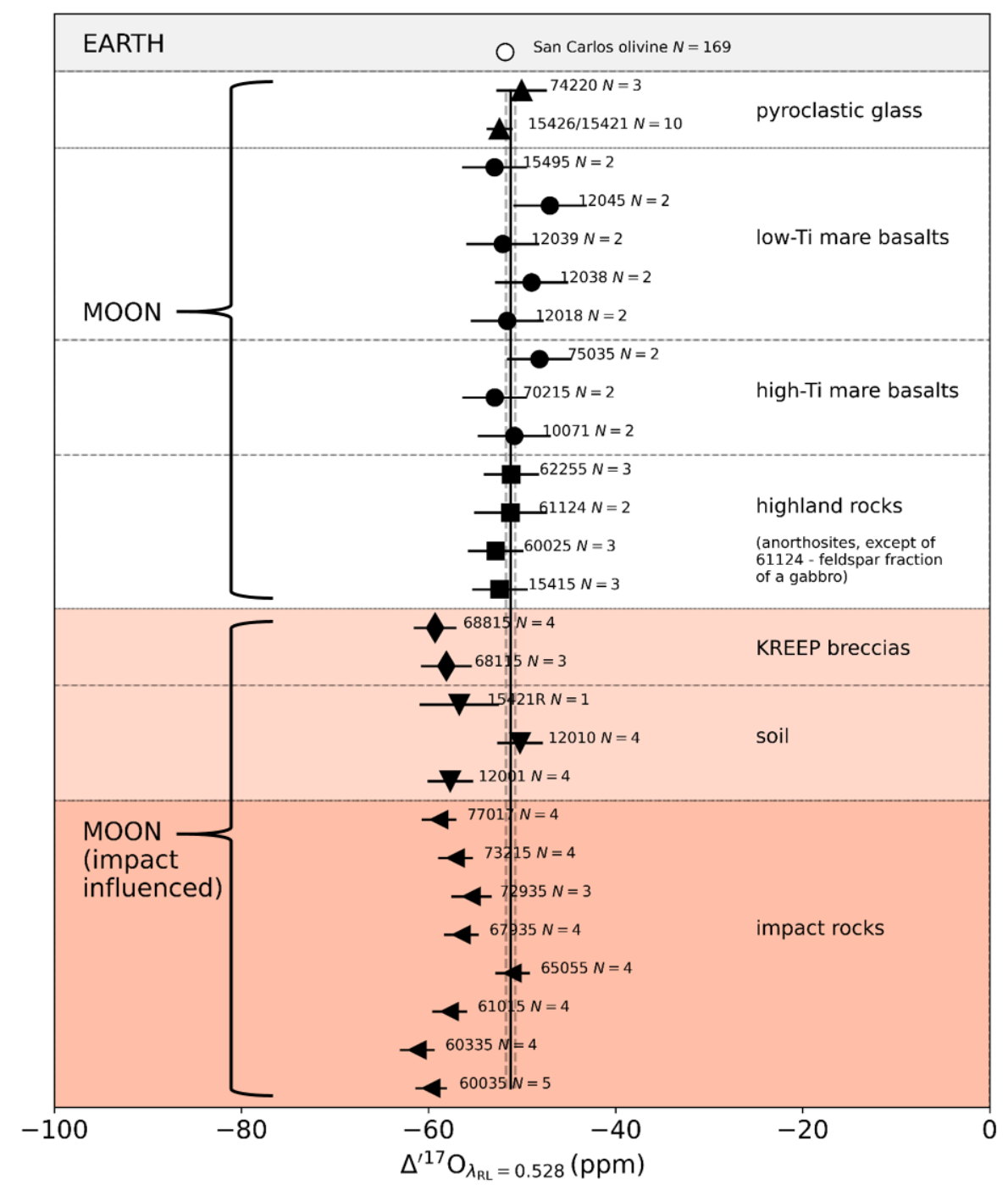

Figure 6.1: $\Delta^{\prime 17} \mathrm{O}$ Caltech-plot of the pristine terrestrial (grey area), pristine lunar (white area) and impact-influenced lunar rocks (red area). Mean values \pm SEM $( \pm 1 \sigma)$ are plotted for individual samples. The Earth mantle is represented by San Carlos olivine. The vertical line displays the weighted mean \pm SEM $( \pm 1 \sigma)$ of the pristine lunar data set (pyroclastic glasses, mare basalts and highland rocks). The lunar rocks are sorted according to lithology. The lunar samples are labelled with the respective sample ID and number of measurements. The pristine terrestrial and lunar samples show indistinguishable $\Delta^{\prime 17} \mathrm{O}$ values, whereas $\Delta^{\prime 17} \mathrm{O}$ variations are apparent for impact-influenced rocks. The impact-influenced rocks are on average $6 \mathrm{ppm}$ lower in $\Delta^{\prime 17} \mathrm{O}$. The data set shows some variation. Sample 12010 and 65055 have typical $\Delta^{\prime 17} \mathrm{O}$ values of the bulk Moon for instance, whereas sample 60335 and 60035 are 9-10 ppm lower. 


\subsection{Discussion}

\subsubsection{Earth-Moon comparison}

Moon and Earth are identical in $\Delta^{\prime 17} \mathrm{O}$ within $1 \mathrm{ppm}$. Our data is in agreement with studies, who found the $\Delta^{\prime 17} \mathrm{O}$ of Earth and Moon indistinguishable within uncertainty (Wiechert et al. 2001, Spicuzza et al. 2007, Hallis et al. 2010, Young et al. 2016, Greenwood et al. 2018; more details in appendix D.4.2, fig. D.6). The Moon seems to be homogeneous in $\Delta^{\prime 17} \mathrm{O}$. The results of our study do not indicate lithology-dependent $\Delta^{\prime 17} \mathrm{O}$ variations in lunar rocks as discussed in other studies (Kohl et al. 2017, Cano et al. 2020; more details in appendix D.4.1). Our interpretation of the Earth-Moon comparison is not hindered by lunar heterogeneities.

\subsubsection{The Moon formation}

The canonical giant impact model states that a Mars-sized body collided with the protoEarth and that the Moon is dominantly made from impactor material. The identical $\Delta^{\prime 17} \mathrm{O}$ values of Earth and Moon found in this study supports the original finding of Wiechert et al. (2001), that this canonical model is inaccurate. The spectrum of studies aiming to explain the isotopic similarity can be divided in three categories: (I) the impactor and the proto-Earth had the same $\Delta^{\prime 17} \mathrm{O}$, because they accreted at a similar heliocentric distance (Wiechert et al. 2001); (II) the impact was more energetic compared to the classical giant impact model and led to effective homogenisation along with isotopic re-equilibration (Pahlevan and Stevenson 2007); (III) the difference between Earth and Moon was suppressed because of the way the material was distributed after the impact. The differences might have been balanced (and erased) by mass proportions (Canup 2012) or the Moon was completely made from terrestrial material (Ćuk and Stewart 2012).

Impactor formation from the same isotopic reservoir as Earth (option I), is principally supported by the study on planetary accretion of Mastrobuono-Battisti et al. (2015), but calculations that consider the large $\Delta^{\prime 17} \mathrm{O}$ diversity in the Solar System highlight this explanation as highly unlikely (Pahlevan and Stevenson 2007, Young et al. 2016). Oxygen isotope re-equilibration alone (option II) efficiently reduces larger initial isotopic heterogeneity, but due to the exponential relationship it is virtually impossible to reach identical compositions of Earth and Moon. Combination of this mechanism with a high energy impact scenario is required to attain the observed similarity of $1 \mathrm{ppm}$. High energy impact scenarios are achieved with models with larger impactors (Canup 2012), hit-and-run impact models (Reufer et al. 2012), multiple impacts (Rufu et al. 2017), or a smaller impactor hitting a fast spinning proto-Earth (Ćuk and Stewart 2012). Combining a fast spinning proto-Earth with a highly energetic impact scenario has been suggested to result in a fast spinning object of vaporised rock (synestia theory) from which the Earth and the Moon condensed (Lock et al. 2018).

A new idea - that has not yet been considered - is an impactor mainly composed of iron metal. Impact erosion may have stripped large proportions of the silicate mantle from the impactor (example: Mercury). Such an iron-rich impactor would have left the $\Delta^{\prime 17} \mathrm{O}$ of the Moon unaffected, due to its low oxygen content. Only 6\% of the meteorite volume recently delivered to Earth is of iron or stony-iron composition (based on the Antarctic 
Meteorite Collection), hence the feasibility of an iron-rich, silicate-poor giant impactor is not exceedingly high. However, the other options have similarly low probabilities and a silicate poor impactor could be a part of the puzzle.

The nature of the Moon-forming impactor cannot be assessed by a $\Delta^{\prime 17} \mathrm{O}$ Earth-Moon comparison because the initial compositions were identical or fully re-equilibrated.

\subsubsection{Impact-dependent $\Delta^{\prime 17} \mathrm{O}$ variations}

We found that the pristine Moon has a well-defined $\Delta^{\prime 17} \mathrm{O}$ signature, from which the $\Delta^{\prime 17} \mathrm{O}$ of impact-influenced rocks often deviate. These deviations are so small that they are only apparent in high-precision data and were therefore not detected in previous studies (Wiechert et al. 2001). Not every impact has an influence on the triple oxygen isotope composition. If an impact effects the $\Delta^{\prime 17} \mathrm{O}$ of the impact rock depends on the meteorite type and the impactor/target rock mixing ratio. The mixing ratio depends on the physical parameters of the impact, for instance impactor size, impact angle and impact velocity. The effect on the $\Delta^{\prime 17} \mathrm{O}$ will be high if the impactor type had a high oxygen isotope anomaly and/or the impact settings led to a high impactor/target rock mixing ratio (for more details see appendix D.5).

The offset between pristine and impact rocks in our sample set is always negative in $\Delta^{\prime 17} \mathrm{O}$. We also observe a corresponding negative shift in $\delta^{18} \mathrm{O}, 0.2-0.3 \%$. The only impactors, which could explain the combined $\delta^{18} \mathrm{O}$ and $\Delta^{\prime 17} \mathrm{O}$ signature by impact contamination are enstatite chondrites or differentiated angrites or aubrites, but each of these scenarios results most likely in unreasonable high impactor/target rock mixing ratios (though it cannot be completely excluded). Alteration of the $\delta^{18} \mathrm{O}$ is expected for soils due to soil maturation processes (and the soil samples are therefore excluded in the following discussion; appendix D.5.1) but not for the other impact-influenced rocks (breccias and impact rocks). This could imply that the surface of the Moon was bombarded with a meteorite type that is still missing in modern meteorite collections. There are, however, three alternative ways to explain the low $\delta^{18} \mathrm{O}$ values of the impact rocks: (I) a sampling effect due preferential analyses of mafic-rich components (breccias are heterogeneous rocks), (II) the target rock was already low in $\delta^{18} \mathrm{O}$, or (III) the $\delta^{18} \mathrm{O}$ of the impact rocks are influenced by additional impact-related processes.

- To exclude sampling effects, we analysed several fractions of the same impact rocks (for more details see appendix D.3). Sample 60035, composed almost purely of feldspar, was analysed in a dedicated session $(N=2)$ along with pristine anorthosites of similar composition $\left(N=3\right.$; fig. D.10). The observed offset in $\delta^{18} \mathrm{O}$ of $0.2-0.3 \%$ o remained, providing a strong argument against a sampling effect.

- The Moon is not homogeneous in $\delta^{18} \mathrm{O}$ (opposite to the $\Delta^{\prime 17} \mathrm{O}$ ). The lunar crust is dominated by feldspar-rich highland rocks, only a small fraction is composed of mare basalts (Vaniman et al. 1991). The $\delta^{18} \mathrm{O}$ of the highland rocks is determined by the $\delta^{18} \mathrm{O}$ of the mineral plagioclase, which constitutes between 40 to $99 \%$ of the rocks depending on the lithology (gabbro-anorthosite). We compiled literature data on the $\delta^{18} \mathrm{O}$ of mineral separates from the Moon (fig. D.9, see references therein) to approximate pristine $\delta^{18} \mathrm{O}$ of the target rocks (table D.13). The $\delta^{18} \mathrm{O}$ estimates varied between 5.5 and $5.6 \%$ o $(60335,65505)$ for the Apollo 16 and between 5.5 
and $5.8 \%$ o $(72395,77017)$ for the Apollo 17 site. Consequently, the $0.2-0.3 \%$ o offset in $\delta^{18} \mathrm{O}$ cannot be explained with the $\delta^{18} \mathrm{O}$ of the target rock.

- Impact related stable isotope fractionation is observed for moderately volatile elements such as $\mathrm{Zn}, \mathrm{Cu}$ and $\mathrm{Cl}$. It has been discussed in several studies that vaporisation leads to the creation of a vapour depleted in heavy isotopes by kinetic fractionation, which can partially redeposits on the surrounding rocks resulting in light isotope signatures of these elements. This was first detected for lunar pyroclastic glasses and certain mare basalts (Moynier et al. 2006, Sharp et al. 2010, Paniello et al. 2012). The vapour was in these settings created by magmatism (fumerol activity). Later, light $\mathrm{Zn}$ isotopes signatures were also detected in brecciated highland rocks, which are connected to impact settings (for instance 'Rusty Rock' 66095; Kato et al. 2015, Day et al. 2017). This effect was not yet reported for lithophile elements, but we suggest that oxygen might be affected by the same process. This might not have been detected so far, because the effect is small. Based on a kinetic triple oxygen isotope exponent $\left(\theta_{\mathrm{kin}}\right)$ of Wang et al. (1994), a shift in $\delta^{18} \mathrm{O}$ by $0.25 \%$ o corresponds to a shift in $\Delta^{\prime 17} \mathrm{O}$ by $4.6 \mathrm{ppm}$. The vaporisation effect is obscuring the impact signature and was therefore corrected. We will now use respective values to put constraints on the types of meteorites that have impacted the lunar surface.

\subsubsection{Impactor reconstruction (mixing model)}

We strived to identify impactor signatures in the triple oxygen isotope composition of the impact rocks. Possible impactor types can be identified by extrapolating mixing curves between the impact rocks and the pristine lunar target to see if they intercept with the various meteorite types for reasonable impactor/target rock mixing ratios (similar to the approach of HSE studies, see appendix D.5).

- Our impact rock sample set comprises 10 impact rocks (table D.14) that were corrected for the vaporisation effect. The correction is simplified and we will consider this during the evaluation of the model results.

- The $\Delta^{\prime 17} \mathrm{O}$ of the lunar target is based on our measurements of pristine lunar rocks, $-51 \pm 1 \mathrm{ppm}$ (table 6.1). A collective $\delta^{18} \mathrm{O}$ input value of $5.625 \%$ with a SEM $( \pm 1 \sigma)$ of $0.1 \%$ is used for all Apollo 16 and 17 samples.

- The compiled triple oxygen isotope data on possible impactor types includes WR and mineral separate data. Meteorite types with similar triple oxygen isotope compositions and thus almost identical mixing trends are grouped together (table D.15, see references therein).

The mixing curves between the meteorite types and the lunar target were calculated using the mean $\delta^{17} \mathrm{O}$ and $\delta^{18} \mathrm{O}$ of the data sets (fig. D.11). The mixing model determines if the impact rock data and the different mixing curves fit within the uncertainty (target: $\pm 1 \sigma$ SEM, meteorites: SD) and the resulting impactor/target rock mixing ratio (fig. 6.2; uncertainties of the mixing ratios are estimated by a Monte Carlo simulation, $N=1000$ ). 

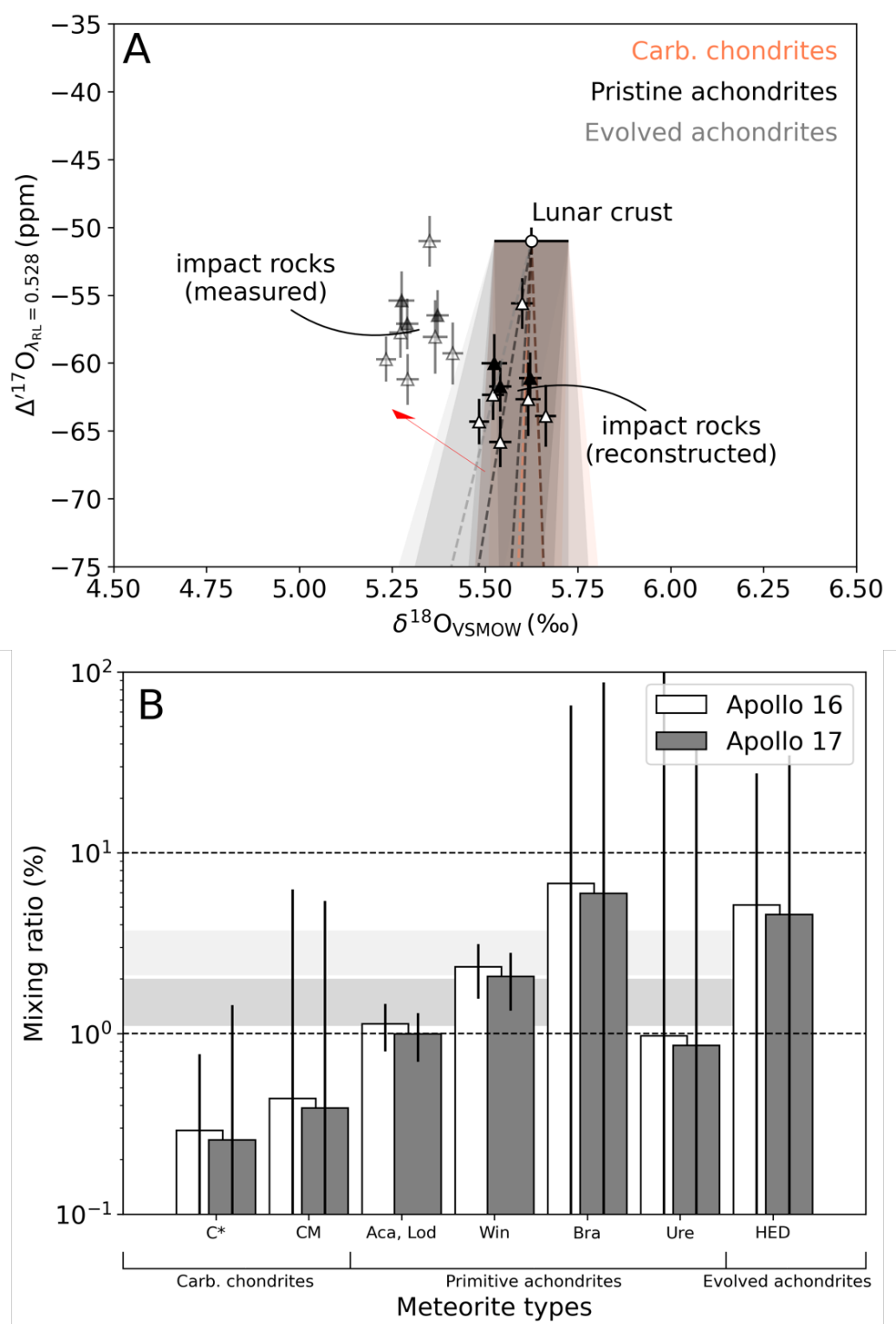

Figure 6.2: Mixing model visualisation - A) $\Delta^{\prime 17} \mathrm{O}$ vs. $\delta^{18} \mathrm{O}$ plot and B) impactor/target rock mixing ratios for a selection of possible impactor types. A) illustrates the fit between the target-impactor mixing curves and the impact rocks. The vaporisation corrected triple oxygen isotope composition of the impact rock data set (Apollo 16, Apollo 17) is shown in solid symbols (white, black). The red arrow illustrates the effect of condensation of an impact-induced light vapour. CB, CK, CO, CR, CV, CH fit $100 \%$ of the samples, CM fit $90 \%$, Aca, Lod fit 100\%, Win fit 100\%, Bra fit 100\%, Ure fit $90 \%$ and HED fit $90 \%$. Comparable plots for the individual impactor types can be found in fig. D.11. B) illustrates how much percent impactor component of each possible impactor type can explain the observed triple oxygen isotope composition of the impact rock. The white columns group the Apollo 16 samples $(N=7)$. The grey columns group the Apollo 17 samples $(N=3)$. The uncertainties of the mixing ratios were determined with a Monte Carlo simulation $(N=1000)$. The horizontal dark grey (Apollo 16) and light grey bar (Apollo 17) illustrate the mixing ratio range based on the mean Iridium (Ir) concentration of the samples (table D.14) and assuming Ir concentrations of a primitive impactor between $\sim 370-670 \mathrm{ppb}$ (based on data of Fischer-Gödde et al. 2011). Mixing ratios based on Ir data for evolved achondrites would exceed the scale of the plot, they contain very little Ir. The following abbreviations were used: Carb. $=$ carbonaceous, $\mathrm{C}^{*}=\mathrm{CB}, \mathrm{CK}, \mathrm{CO}, \mathrm{CR}, \mathrm{CV}, \mathrm{CH}, \mathrm{Aca}$, Lod $=$ Acapulcoite-lodranite clan, Win $=$ Winonaites, $\mathrm{Bra}=$ Brachinites, Ure $=$ Ureilites, $\mathrm{HED}=$ Howardite-ecurite-diogenite suite. 
The impact rocks have lower $\Delta^{\prime 17} \mathrm{O}$ values than the target rock. This observation excludes ordinary chondrites (H, L, LL), CI chondrites, R chondrites, SNC meteorites or the silicate portions of IIE and IVA iron meteorites as possible impactors. Hence, the meteorite flux 3.5-4 Ga ago differed compared to the recent flux, which is dominated by ordinary chondrites (see frequency distribution of the Antarctic meteorite collection in chapter 1, fig. 1.2). The following potential impactors remain: carbonaceous chondrites (CB, CK, CO, CR, CV, CH, CM), primitive achondrites (Aca, Lod, Win, Bra, Ure), evolved stony achondrites (HED), evolved stony-iron meteorites (Pal, Pal PES, Mes) and evolved iron meteorites (IAB, IIIAB). The possibility of a K or enstatite chondrite (EH, EL), Aub, Ang or IIAB, IIID, IIICD impactor cannot be assessed due to the high uncertainty in the oxygen isotope composition of this meteorite types, but these scenarios are also not very likely (table D.16).

This selection of potential impactors can be narrowed down further by considering impactor/target rock mixing ratios (table D.17). Stony-iron and iron meteorites can be excluded, because only their rare silicate phases contain oxygen resulting in unreasonable high impactor/target rock mixing ratios. HEDs are also unreasonable, because their low Ir concentrations cannot explain the elevated Ir content of the lunar impact rocks (fig. 6.2B).

Further differentiating the quality of the fit is challenging due to the uncertainties in the meteorite data and the assumptions concerning the $\delta^{18} \mathrm{O}$ values. From our data, several valid candidates remain, that can explain the triple oxygen isotope composition of the impact rocks. Assuming the recent abundance distribution of the Antarctic Meteorite Collection (see fig. 1.2), our findings would imply that a carbonaceous, volatile-rich impactor $(\sim 76 \%)$ would be more likely than a non-carbonaceous, volatile-poor impactor $(\sim 24 \%)$. This would indicate that volatile-rich carbonaceous material might have played a more important role during the late accretion.

\subsection{Conclusion}

The Earth and the Moon are indistinguishable in their triple oxygen isotope composition. The extraordinary similarity between the two bodies suggests already similar isotopic compositions of the impactor and the Earth prior to the impact, or particular impact conditions that suppressed an initial heterogeneity. The results of our study do not indicate lithology-dependent $\Delta^{\prime 17} \mathrm{O}$ variations.

We found $\Delta^{\prime 17} \mathrm{O}$ variations between pristine and impact-influenced rocks. The pristine Moon is homogeneous in $\Delta^{\prime 17} \mathrm{O}$, but impact processes on the Moon are able to modify the triple oxygen isotope composition. Impact metamorphism (impact vapour re-condensation) and impactor material leave a trace in the oxygen isotope composition $\left(\Delta^{\prime 17} \mathrm{O}, \delta^{18} \mathrm{O}\right)$ of lunar impact rocks. These signatures aid in identifying possible impactor types of the solidified lunar surface billions of years ago. 



\section{Reconstructing the provenance of Solar System bodies accreted to the Earth-Moon system by means of oxygen isotope systematics}

\subsection{The Moon-forming impactor}

The nature of the Moon-forming impactor is a crucial information to further constrain the Moon formation mechanism and, thus, the origin of the Moon (chapter 1). In order to trace the Moon-forming impactor by means of oxygen isotope systematics, it is necessary to establish a representative $\Delta^{\prime 17} \mathrm{O}$ comparison between the pristine Earth and the pristine Moon (chapter 6).

Earth In chapter 5 we revisited the $\Delta^{\prime 17} \mathrm{O}$ of the pristine Earth (former studies: e.g. Herwartz et al. 2014, Greenwood et al. 2018, Cano et al. 2020). Selecting a representative sample set, that is not compromised by a subsequent $\Delta^{\prime 17} \mathrm{O}$ overprint resulting from subduction, is critical for the assessment of the pristine mantle. Admixture of crustal material which was e.g. altered by interaction with the atmosphere or the hydrosphere (e.g. Peters et al. 2020a, Pack 2021, Herwartz 2021, Cao and Bao 2021) may lead to a change in the mantle's $\Delta^{\prime 17} \mathrm{O}$.

Previous studies included glasses and phenocrysts from mid-ocean ridge basalts (MORB) and ocean island basalts (OIB) (Greenwood et al. 2018, Cano et al. 2020), whose mantle sources are often contaminated by subducted, altered oceanic crust and sediments (Eiler et al. 2000, Cao et al. 2019). We propose that mantle peridotites provide a better representation of the pristine Earth's $\Delta^{\prime 17} \mathrm{O}$ than mantle melts. We chose olivine separates from this rock type, because olivine is less prone to be affected by mantle metasomatism than other minerals (Perkins et al. 2006), and to circumvent possible mineral-dependent effects during the analytical procedure (e.g. Young et al. 2016) or hypothesised mineralspecific crystal-chemical effects in $\Delta^{\prime 17} \mathrm{O}$ (Kohl et al. 2017).

This way we determined a high precision $\Delta^{\prime 17} \mathrm{O}$ average value for the mantle $\left(\Delta^{\prime 17} \mathrm{O}_{\text {Earth }}\right.$ $=-51.6 \pm 0.5 \mathrm{ppm} ; \pm 1 \sigma \mathrm{SEM}, N=15)$ based on olivine separates from post-Archean peridotites (see fig. 7.1).

Moon In chapter 6 we revisited the $\Delta^{\prime 17} \mathrm{O}$ of the pristine Moon with an improved analytical setup and a diverse sample set $(N=27)$. However, small-scale $\Delta^{\prime 17} \mathrm{O}$ variations 
7 Reconstructing the provenance of Solar System bodies accreted to the Earth-Moon system by means of oxygen isotope systematics

of certain lunar lithologies are subject of recent discussion and could potentially hinder a determination of a representative $\Delta^{\prime 17} \mathrm{O}$ of the pristine Moon (Young et al. 2016, Kohl et al. 2017, Cano et al. 2020).

In order to address this question, we studied terrestrial feldspar-rich rocks as preparation for the measurements of feldspar-rich, lunar highland rocks (chapter 4). Young et al. (2016), Kohl et al. (2017) studied lunar highland rocks and proposed the hypothesis that a feldspar-specific oxygen isotope anomaly ('feldspar effect') shifts the $\Delta^{\prime 17} \mathrm{O}$ of (lunar and terrestrial) feldspar-rich rocks towards lower values. It was suggested that crystalchemical effects of the tectosilicate lattice structure may explain this observation (Kohl et al. 2017). We tested this by studying (I) the fractionation behaviour of plagioclase in the terrestrial analogous rocks, and (II) analytical aspects of the laser fluorination of plagioclase. We did not reproduce the phenomenon of systematically lower $\Delta^{\prime 17} \mathrm{O}$ associated with plagioclase, which is also in agreement with experimental results of Cano et al. (2020).

In chapter 6 we studied a variety of pristine lunar lithologies (highland rocks, high-Ti and low-Ti mare basalts, and pyroclastic glasses; fig. 7.1). Lunar highland rock samples (III, $N=4$ ) do also not indicate a 'feldspar effect'. Considering the small number of analysed highland rocks we do not exclude the possibility that the $\Delta^{\prime 17} \mathrm{O}$ of this rock type is sometimes slightly lower, but we question whether this would evidence an anomaly in the oxygen isotope fractionation during plagioclase formation as proposed by Kohl et al. (2017). A systematic study on co-genetic mineral separates of individual samples is required to draw conclusions on the isotope fractionation behaviour (as performed in chapter 4 and Cano et al. 2020). However, Kohl et al. (2017) compared two domains (highland rocks vs. mare basalts) represented by several samples from different localities, which did not evolve co-genetically. Cano et al. (2020) performed a study on lunar cogenetic mineral separates and found that individual samples often demonstrate isotopic disequilibrium. An equivalent approach for terrestrial samples in the same study did not reproduce this observation. Based on the findings from these studies (chapters 4 and 6, as well as Cano et al. 2020) the 'feldspar effect' is rebutted (additional information can be found in sec. D.4.1).

Cano et al. (2020) also discuss lithology-dependent $\Delta^{\prime 17} \mathrm{O}$ variations concerning lunar rocks, based on the observed shift in their data towards lower $\Delta^{\prime 17} \mathrm{O}$ from lunar green glass over high-Ti mare basalts, low-Ti mare basalts to highland rocks in a range of $\sim$ $40 \mathrm{ppm}$. They suggest that this shift is caused by various degrees of exchange between the primary material of the respective lithology with a vapour phase of anomalous $\Delta^{\prime 17} \mathrm{O}$ created during the Moon-forming impact. Most of the $\Delta^{\prime 17} \mathrm{O}$ variation reported by Cano et al. (2020) is attributed to the green glass sample 15426. We revisited this hypothesis with our pristine lunar sample set and report considerably smaller $\Delta^{\prime 17} \mathrm{O}$ variations for all lunar lithologies including 15426 (additional information is provided in sec. D.4.1). Our results suggest that the pristine Moon is homogeneous in $\Delta^{\prime 17} \mathrm{O}$ as originally stated (e.g. Wiechert et al. 2001, Greenwood et al. 2018).

The observed $\Delta^{\prime 17} \mathrm{O}$ homogeneity in lunar rocks allows us to constrain the pristine Moon by averaging the triple oxygen isotope composition of the studied pristine lunar lithologies, $\Delta^{\prime 17} \mathrm{O}_{\text {Moon }}=-51.2 \pm 0.5 \mathrm{ppm}( \pm 1 \sigma$ SEM $N=14)$, even if the sample set is confined (e.g. no direct mantle samples and only material from the nearside). 
Moon formation We found the pristine Earth and Moon indistinguishable in their $\Delta^{\prime 17} \mathrm{O}$ (see chapter 6). This finding is in agreement with the studies of Wiechert et al. (2001), Spicuzza et al. (2007), Hallis et al. (2010), Young et al. (2016), and contradicting Herwartz et al. (2014), Greenwood et al. (2018), and Cano et al. (2020). The intriguing triple oxygen isotope similarity is also in agreement with findings from studies on other isotope systems: Ca (Dauphas et al. 2015, Schiller et al. 2018), Ti (Zhang et al. 2012), Si (Georg et al. 2007, Armytage et al. 2012), Cr (Lugmair and Shukolyukov 1998), and Hf-W (Dauphas et al. 2014, Kruijer et al. 2015, Kruijer and Kleine 2017). The similarity between both bodies already suggests similar isotopic compositions of the impactor and the Earth prior to the impact, or particular impact conditions that suppressed an initial heterogeneity (see chapter 6 and references therein). Post-impact re-equilibration and intensive mixing may have been the driving mechanisms behind the isotopic similarity between Earth and Moon (Pahlevan and Stevenson 2007, Young et al. 2016). The nature of the Moon-forming impactor can therefore not be assessed by oxygen isotope systematics, the trace of the impactor is not detectable.

Other isotope approaches came to opposing results concerning the nature of the Moonforming impactor, there is evidence for an NC-like (enstatite-like, based on $\mathrm{O}, \mathrm{Ca}, \mathrm{Ti}, \mathrm{Nd}$, Cr, Ni, Mo, and Ru isotopes; Dauphas et al. 2015, Dauphas 2017) as well as CC-like Moon-forming impactor (based Mo isotopes; Budde et al. 2019). Kruijer and Kleine (2017) are questioning an impact scenario in general due to the difficulty of generating identical $\varepsilon^{182} \mathrm{~W}$ values for Earth and Moon, though Thiemens et al. (2019) is offering an alternative explanation of the $\varepsilon^{182} \mathrm{~W}$ (see below).

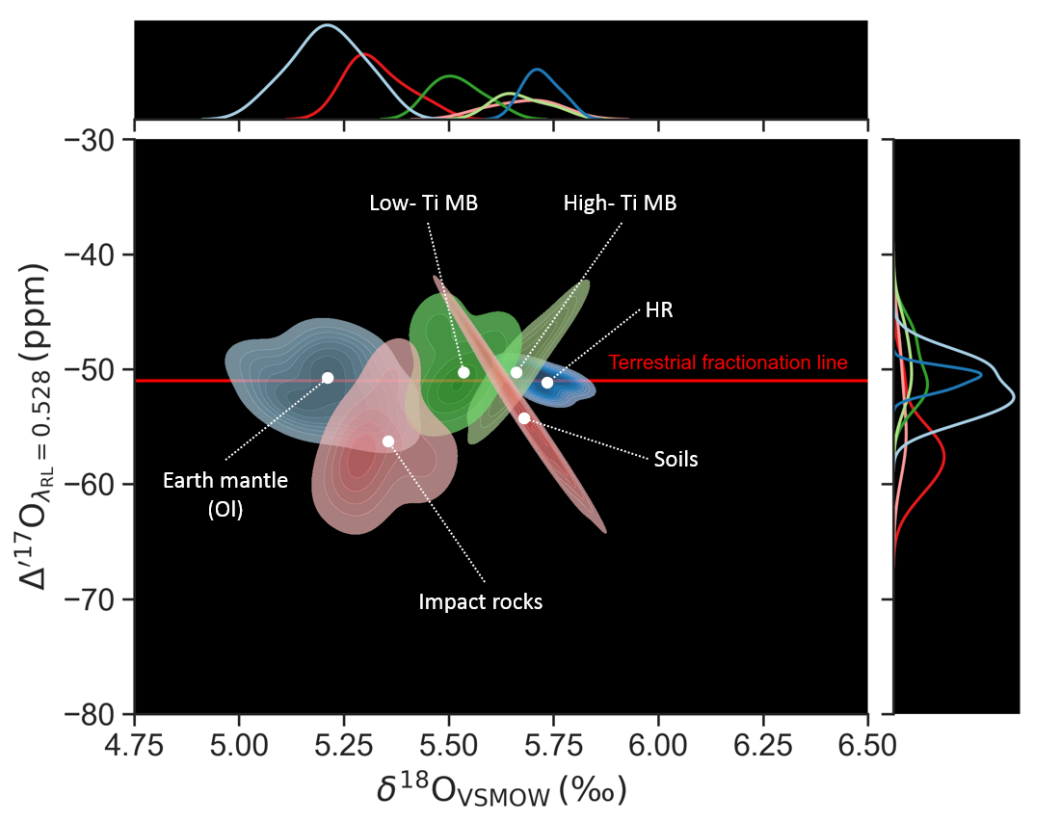

Figure 7.1: Plot of $\Delta^{\prime 17} \mathrm{O}$ vs. $\delta^{18} \mathrm{O}$ with kernel density estimate contour plots and line plots (on the axes; level 10) for the pristine lunar (highland rocks: $N=4$, low-Ti mare basalts: $N=5$, high-Ti mare basalts: $N=3$, pyroclastic glasses: $N=2$ ), pristine terrestrial (olivine separates from post-Archean peridotites: $N=15$ ), and lunar impact rock samples (soils: $N=3$, impact rocks: $N=10$ ). The terrestrial fractionation line is plotted as reference. Pristine lunar and terrestrial samples are indistinguishable in $\Delta^{\prime 17} \mathrm{O}$, but impact-influenced lunar rocks show lower $\Delta^{\prime 17} \mathrm{O}$ compositions. $\delta^{18} \mathrm{O}$ differences occur between the different sample sets due to their mineralogy and mass-dependent fractionation processes (e.g. lunar soil maturation, impact metamorphism). The following abbreviations were used: $\mathrm{MB}=$ mare basalts, $\mathrm{HR}=$ highland rocks, $\mathrm{Ol}=$ olivine . 


\subsection{The late accretion contribution to the Earth-Moon system}

There are several reservoirs on the Earth-Moon system, which incorporated different amounts of late accretion material: the terrestrial mantle, the lunar mantle, and the lunar crust (see sec. 1.2.3). The terrestrial mantle is presumably the most representative reservoir for the average late accretion contribution, because it is considered to hold the largest amount of late accreted material (Walker 2009). However, the terrestrial mantle experienced extensive processing since, resulting in dilution of the late accretion material in this large reservoir, whereas the lunar crust offers a very detailed record for a specific time period of the late accretion. This impact record may not be representative for the entire late accretion period, but has been preserved in a much better way.

The terrestrial mantle In chapter 5 we strived to constrain the composition of the late accretion by studying the $\Delta^{\prime 17} \mathrm{O}$ of the terrestrial mantle. Decreasing $\varepsilon^{182} \mathrm{~W}$ in rock samples over the geological record suggests that the mixing of late accretion material into the terrestrial mantle was protracted (Moynier et al. 2010, Willbold et al. 2011, Touboul et al. 2015, Rizo et al. 2016). Ru isotope data also suggests that the mantle sources of some Archean ultramafic rocks did not incorporate the full amount of late accretion material, and that these rocks reflect the pre-late accretion mantle (Fischer-Gödde et al. 2020). In order to constrain the late accreted material we studied the $\Delta^{\prime 17} \mathrm{O}$ of a sample set from these Archean localities (Itsaq Gneiss Complex (IGC) and the Fiskefjord region in southwest Greenland) and compared it to a post-Archean peridotite sample set, which incorporated the full amount of late accretion material (comparable to the approach of Fischer-Gödde et al. 2020). In contrast to the Ru isotope data (Fischer-Gödde et al. 2020), we found the $\Delta^{\prime 17} \mathrm{O}$ of pre- and post-late accretion mantle indistinguishable. A missing late accretion contribution from the IGC and Fiskefjord ultramafic rocks was therefore not detected with respect to their oxygen isotope compositions.

Based on their Ru isotope data, Fischer-Gödde et al. (2020) estimated that a late accretion component of up to $0.3 \%$ carbonaceous chondrite-like materials may be missing in the sampled Archean mantle. A carbonaceous chondrite-like late accretion material was also suggested by terrestrial studies on U-Pb and I-XE chronologies (Albarède 2009), Se, Te and S ratios (Wang and Becker 2013), Se isotopes (Varas-Reus et al. 2019), and the volatile element depletion pattern (Braukmüller et al. 2019). Fischer-Gödde et al. (2020) favoured CM chondrites as the missing component, based on a comparison of their data with the concentrations of platinum-group elements (Creech et al. 2016) and on the relative abundances of volatile elements in the silicate Earth (Wang and Becker 2013, Braukmüller et al. 2019, Varas-Reus et al. 2019).

We propose two possible end-member scenarios that would explain our triple oxygen isotope data in conjunction with the available $\mathrm{Ru}$ isotope data by Fischer-Gödde et al. (2020): (I) a CM-like late accretion contribution not larger than $<0.11 \%$ of the Earth's mass, or, alternatively, (II) a CI chondrite-like late accretion contribution. A CI-like late accretion would have only been feasible if a larger s-process deficit would be considered for CI chondrites, than it was by Fischer-Gödde et al. (2020). This seems reasonable, given that their modelling was based on the composition of a single CI meteorite 
specimen, whereas carbonaceous chondrite groups show internal $\mathrm{Ru}$ isotope variations (Fischer-Gödde and Kleine 2017). A missing late accretion component that resembles the oxygen isotope composition of CI chondrites, not CM chondrites, is also supported by the similarity in $\Delta^{\prime 17} \mathrm{O}$ between the Earth and lunar mare basalts (e.g. chapter 6), assuming that the average $\Delta^{\prime 17} \mathrm{O}$ of lunar mare basalts is representative for the Earth's $\Delta^{\prime 17} \mathrm{O}$ before late accretion, which is debated (Thiemens et al. 2019).

The lunar surface In chapter 6 we focused on the the late accretion contribution that was potentially preserved in the lunar crater record. There are two rock types, which can be studied for this purpose: lunar impact rocks and soils. Both lithologies are - if not directly created by the impact events (impact rocks) - at least strongly influenced by those (soils). The advantage of impact rocks over soils is that the formation of impact rocks can be better assigned to specific impact crater events (Joy et al. 2016). So far only HSE concentrations and abundance patterns were studied to constrain the provenance of late accreted material in lunar impact rocks (e.g. Norman et al. 2002, Puchtel et al. 2008, Fischer-Gödde and Becker 2012, Sharp et al. 2014, Liu et al. 2015, Gleißner and Becker 2017, 2019). Those studies analysed samples (Apollo missions 14 to 17) which were older than $3.8 \mathrm{Ga}$ and detected different impactor signatures for individual impact events. It is still debated whether the HSE signatures represent the composition of a single impactor (Sharp et al. 2014) or the mixed composition of several impactors (FischerGödde and Becker 2012, Gleißner and Becker 2017, 2019). It was also argued that the HSE concentrations and ratios may be affected by large-scale fractional crystallisation of metal within impact melt pools (Vaughan et al. 2013), though Gleißner and Becker (2017) refuted this hypothesis. We determined the $\Delta^{\prime 17} \mathrm{O}$ of ten impact rocks from Apollo 16 and 17 which were also studied by means of HSE techniques (see sec. D.5.2; Puchtel et al. 2008, Fischer-Gödde and Becker 2012, Gleißner and Becker 2017). Our data demonstrate — for the first time - that the effect of impactor contamination is visible in a lowered $\Delta^{\prime 17} \mathrm{O}$ of impact rocks and soils (see fig. 7.1).

In previous HSE studies several sample sets were interpreted to reflect the addition of chondritic impactor material or unknown primitive material, because the relative HSE abundances in many rocks were found to be too high to be explained by any known meteoritic material (suprachondritic; Norman et al. 2002, Puchtel et al. 2008, Sharp et al. 2014, Liu et al. 2015). The addition of (non-chondritic) differentiated metal impactors e.g. fragments of planetary cores was discussed to explain this phenomenon (Morgan et al. 1972, 1974, Fischer-Gödde and Becker 2012). Gleißner and Becker (2017, 2019) found that the HSE data from all analysed impact rocks fall on a gradual trend and that two ancient samples with similar age (67935: $4.21 \mathrm{Ga}$, non-chondritic signature, Nectaris basin; 65055: 4.20 Ga, chondritic signature, Serenitas basin) and opposing HSE signatures form the end-members of this trend. Gleißner and Becker (2017) suggested that two ancient impact events (represented by these end-members) affected most of the lunar nearside and that therefore all impact rock signatures represent varying degrees of mixing between those two components and the target (three-component mixing model).

The use of triple oxygen isotopes systematics to trace non-chondritic differentiated impactor signatures (iron or stony-iron meteorites) in lunar impact rocks is very limited, because a predominantly metallic impactor would contain only negligible amounts of oxygen. $\Delta^{\prime 17} \mathrm{O}$ is also not suitable to identify terrestrial or enstatite chondrites impactor 
signatures, because they are both too similar to the $\Delta^{\prime 17} \mathrm{O}$ of the Moon. There are also several possible impactor types, which we cannot assess because too little triple oxygen isotope data is available (e.g. comets, $\mathrm{K}$ chondrites) or the uncertainty concerning this data is too large (e.g. aubrites, angrites). However, triple oxygen isotope systematics are very sensitive for primitive chondritic bodies, because they show the most anomalous and distinct oxygen isotope compositions. In chapter 6, we show that the oxygen isotope composition of the analysed Apollo 16 and 17 impact rocks are lower compared to the pristine Moon and could be explained by the addition of CC-like material (exception: CI) or primitive achondrites. Assuming the suggested three-component mixing model of Gleißner and Becker (2017) on the impactor contamination of the lunar surface we possibly narrowed down the chondritic end-member applying oxygen isotope systematics (for more details see sec. D.5.2).

The late accretion from a triple oxygen isotope perspective Our triple oxygen isotope study on the terrestrial mantle (chapter 5) in conjunction with published Ru isotope data (Fischer-Gödde et al. 2020) indicates that either a small CM- or a CI-like late accretion contribution may serve to explain the difference between pre- and post-late accretion mantle. The triple oxygen isotope study on lunar impact rocks and the lunar crust is in agreement with a CC (except CI)-like composition of the late accretion or with late accreted material that resembled primitive achondrites. The findings from the two reservoirs do not need to be identical considering that both reservoirs record different stages of late accretion on different scales (see sec. 1.2.3). The terrestrial mantle received the largest portion of late accretion material and was then mixed very well, resulting in an averaging of the numerous impactors' oxygen isotope compositions. The Moon received a far smaller late accretion contribution, and the lunar crust only the fraction which accreted after $200 \mathrm{Ma}$ (Elkins-Tanton et al. 2011). Moreover, the impactor signatures were not as efficiently homogenised and averaged. The lunar impact rock study is a more in situ approach that provides information on more specific impact events. However, it is striking that the result of both approaches can be resolved with the late accretion of CC-like material, which is also suggested by studies on Ru (Fischer-Gödde et al. 2020) and Se, Te and S (Wang and Becker 2013), and Mo (though here the Moon-forming impactor is the most likely impactor; Budde et al. 2019) on the terrestrial mantle. It is in agreement with $\mathrm{H}, \mathrm{C}$, and $\mathrm{N}$ studies on the terrestrial volatile budget (Alexander et al. 2012, Marty 2012), the volatile depletion pattern (Se, Te, S; Braukmüller et al. 2019), the Se isotope signature (Varas-Reus et al. 2019), and there is also some evidence from the HSE studies on lunar impact rocks (e.g. Fischer-Gödde and Becker 2012). Hence, our assessment of the composition of the late accretion based on oxygen isotope systematics supports the theory that volatile-rich material was accreted late (Albarède 2009, Wang and Becker 2013, Varas-Reus et al. 2019, Fischer-Gödde et al. 2020) and not earlier e.g. during the Moon-forming impact (Budde et al. 2019). 


\section{Summary, conclusions and outlook}

\subsection{Summary and conclusions}

The aim of this dissertation was to reconstruct the provenance of Solar System bodies accreted to the Earth-Moon system by means of oxygen isotope systematics. For this purpose we conducted three experimental studies, which included (I) setting up a measurement protocol, (II) assessing the possibility of a triple oxygen isotope anomaly affecting the results of feldspar-bearing rocks, constraining the triple oxygen isotope composition of the Earth (III) and the Moon (IV) as well as evaluating if triple oxygen isotopes can be used to reconstruct the impactor material which accreted to the terrestrial mantle (V) and the lunar crust (VI). We are interested in studying the Moon-forming impactor as well as the material delivered during the late accretion (after the Moon formation). If this material was volatile-rich, then it might have been a crucial contribution to the water content of the Earth.

In the first study, we investigated the oxygen isotope fractionation in terrestrial feldsparbearing rocks as a conceptual model of common lunar feldspar-rich lithologies (highland rocks). We characterised their petrography, chemistry and performed oxygen isotope measurements on mineral separates. We studied the equilibrium fractionation behaviour between anorthite-rich plagioclase and other co-genetic minerals. The study revealed that there is no direct indication for an oxygen isotope anomaly connected to plagioclase, which would lead to a systematically lower $\Delta^{\prime 17} \mathrm{O}$ in feldspar-bearing terrestrial or lunar rocks. We evaluated different approaches to accurately analyse feldspar using the laser fluorination technique and we discussed alternative explanations for the low $\Delta^{\prime 17} \mathrm{O}$ values of lunar feldspar-rich rocks as reported in the literature.

In the second study, we reassessed the triple oxygen isotope composition of the Earth's post-Archean mantle, and the Archean mantle prior to the late accretion. We determined the $\Delta^{\prime 17} \mathrm{O}$ of the post-Archean mantle with improved precision based on a comprehensive sample set of subcontinental and suboceanic lithospheric mantle peridotites: $-51.6 \pm 1.1 \mathrm{ppm}\left(1 \sigma, \lambda=0.528\right.$, relative to San Carlos olivine: $\left.\Delta^{\prime 17} \mathrm{O}=-51.8 \mathrm{ppm}\right)$. We compared this value with the $\Delta^{\prime 17} \mathrm{O}$ of ultramafic rocks from the Eoarchean Itsaq Gneiss Complex (IGC) and the Mesoarchean Fiskefjord region in southwest Greenland, whose mantle source did not incorporate the full amount of Earth's late accreted material based on ruthenium $(\mathrm{Ru})$ isotope data. We found no significant $\Delta^{\prime 17} \mathrm{O}$ offset between the post-Archean and the Archean pre-late accretion mantle. This restricts the late accretion contribution to the terrestrial mantle to $\leq 0.12 \%$ of Earth's mass assuming material similar to most carbonaceous chondrites $(\mathrm{CM}, \mathrm{CV}, \mathrm{CO}, \mathrm{CK}, \mathrm{CR}, \mathrm{CH}, \mathrm{CB}$, excluding $\mathrm{CI}$ ), to $\leq 0.11 \%$ of Earth's mass assuming CM-like material, or to $\leq 1.2 \%$ of Earth's mass 
assuming CI-like material. A CI-like late accretion is the only option which is in agreement with a larger late accretion contribution, because CI chondrites resemble the Earth in $\Delta^{\prime 17} \mathrm{O}$.

In the third study, we reassessed the triple oxygen isotope composition of the Moon. We determined the $\Delta^{\prime 17} \mathrm{O}$ of the pristine Moon with improved precision based on feldsparrich highland rocks, mare basalts and pyroclastic glass: $-51.2 \pm 0.5 \mathrm{ppm}(1 \sigma, \lambda=0.528$, relative to San Carlos olivine: $\Delta^{\prime 17} \mathrm{O}=-51.8 \mathrm{ppm}$ ). We found that Earth and Moon are identical within $1 \mathrm{ppm}$ in their $\Delta^{\prime 17} \mathrm{O}$. We studied various lunar rock types and found no indication for the discussed lithology-dependent $\Delta^{\prime 17} \mathrm{O}$ variations (e.g. no systematically lower $\Delta^{\prime 17} \mathrm{O}$ values of the highland rocks). However, the $\Delta^{\prime 17} \mathrm{O}$ of impact-influenced lunar rocks (soils, impact melt rocks and breccias) deviates from the pristine lunar $\Delta^{\prime 17} \mathrm{O}$. We conclude that impactor signatures can be traced using triple oxygen isotope systematics. The oxygen isotope data of Apollo 16 and Apollo 17 impact rocks is resolvable with a carbonaceous chondrite (CC, exception $\mathrm{CI}$ )-like or primitive chondrite-like late accretion contribution to the lunar crust.

Our studies reveal no trace of the Moon-forming impactor by means of triple oxygen isotopes, which implicates either a similar isotopic composition of the impactor and the proto-Earth, or particular impact conditions that suppressed an initial heterogeneity (e.g. high-energy impact). We found no indication for lithology-dependent $\Delta^{\prime 17} \mathrm{O}$ variations in lunar rocks, which would affect this conclusion (e.g. a feldspar-specific isotope anomaly). Our findings concerning late accreted material to the terrestrial mantle and the lunar crust support the concept of a heterogeneous accretion of the Earth and a late delivery of volatile-rich material. We resolved, for the first time, impactor signatures in the triple oxygen isotope composition of lunar impact rocks.

\subsection{Outlook}

Triple oxygen isotope systematics were used to trace and assess the chemical signatures of accreted bodies. To improve this approach we need to further our understanding on the triple oxygen isotope composition of rocky material in the Solar System, but samples are scarce. The meteorite collections are very useful, but they are only fragments delivered to the Earth-Moon system by chance. We need information on sample locations and the history of the respective parent body. We still cannot link most of the meteorites to their asteroidal parent bodies and the current meteorite record could be incomplete. We need to refine our knowledge on inner Solar System materials. Our cosmochemical knowledge on outer Solar System material is even more limited. The Stardust mission provided information on the triple oxygen isotope composition of cometary particles (McKeegan et al. 2006, Nakamura et al. 2008, Bridges et al. 2012), but so far we lack data on cometary ice or the gas giant planets and their Moons (see e.g. Ireland et al. 2020).

Sample return missions are challenging and expensive, but they can lead to great progress. The identification of lunar meteorites was only possible because of the Apollo missions. Returned samples can be analysed with more elaborate analytical techniques and instruments achieving more accurate and precise data. The samples can be stored and re-analysed whenever a new or improved method is available. Nowadays, mission like Hayabusa 2 (C-type asteroid), OSIRIS REx (C-type asteroid), Chang'e 5 (Moon) 
or the follow-up sample return of the Mars2020 mission will expand, together with the improvement of remote analysis, our knowledge in this field.

The approach to constrain bodies accreted to the Earth-Moon system by means of oxygen isotope systematics has great potential for the investigation of the impact record on the lunar crust. So far, we studied only a small amount of impact rocks from the Apollo 16 and 17 landing site. In the future studies on Apollo 14 and 15 impact rocks might lead to new insights. There might be variations in the impactor signatures preserved in lunar impact rocks, which we did no detect yet due to our sample set. The effect of (largescale) impact metamorphism on the triple oxygen isotope composition of impact rocks (especially the $\delta^{18} \mathrm{O}$ ) could be studied in greater detail. The effect of (small-scale) impact gardening on mature lunar soils could be reinvestigated with respect not only to the ${ }^{18} \mathrm{O}$ but also to the ${ }^{17} \mathrm{O}$ (extension of the work of Epstein and Taylor Jr. 1971, Clayton et al. 1974a and Clayton et al. 1974b). It might be possible to use also soil samples in the future to draw conclusions on late accreted material. 



\section{Bibliography}

Aarestrup, E., Jørgensen, T. R. C., Armitage, P. E., Nutman, A. P., Christiansen, O., and Szilas, K.: 2020, Mineralogical Magazine pp 1-78

Agemar, T., Wörner, G., and Heumann, A.: 1999, Contributions to Mineralogy and Petrology 136, 331

Albarède, F.: 2009, Nature 461(7268), 1227

Alexander, C. M. O., Bowden, R., Fogel, M. L., Howard, K. T., Herd, C. D. K., and Nittler, L. R.: 2012, Science 337(6095), 721

Armytage, R., Georg, R. B., Williams, H. M., and Halliday, A. N.: 2012, Geochimica et Cosmochimica Acta 77, 504

Asphaug, E.: 2010, Geochemistry 70(3), 199

Audouze, J. and Vauclair, S.: 1980, An Introduction To Nuclear Astrophysics, Dorderecht: D. Reidel Publishing Company

Badro, J. and Walter, M.: 2015, The Early Earth: Accretion and Differentiation, John Wiley \& Sons, Inc, Hoboken, NJ

Baertschi, P.: 1950, Nature 166(4211), 112

Bally, J. and Langer, W. D.: 1982, The Astrophysical Journal 255, 143

Barboni, M., Boehnke, P., Keller, B., Kohl, I. E., Schoene, B., Young, E. D., and McKeegan, K. D.: 2017, Science advances 3(1), e1602365

Barkan, E. and Luz, B.: 2011, Rapid Communications in Mass Spectrometry 25(16), 2367

Bateman, A. M.: 1951, Economic Geology 46(4), 404

Bennett, V. C., Nutman, A. P., and Esat, T. M.: 2002, Geochimica et Cosmochimica Acta 66(14), 2615

Benz, W., Cameron, A., and Melosh, H. J.: 1989, Icarus 81(1), 113

Benz, W., Slattery, W. L., and Cameron, A.: 1986, Icarus 66, 515

Benz, W., Slattery, W. L., and Cameron, A.: 1987, Icarus 71(1), 30 
Bertrand, S., Castiaux, J., and Juvigné, E.: 2008, Quaternary Research 70(03), 343

Bindeman, I.: 2008, Reviews in Mineralogy and Geochemistry 69(1), 445

Bischoff, A., Vogel, N., and Roszjar, J.: 2011, Geochemistry 71(2), 101

Blundy, J. D. and Holland, T. J. B.: 1990, Contributions to Mineralogy and Petrology 104(2), 208

Boering, K. A.: 2004, Geophysical Research Letters 31(3), 4103

Borg, L. E., Gaffney, A. M., and Shearer, C. K.: 2015, Meteoritics $\mathcal{F}$ Planetary Science 50(4), 715

Bottinga, Y. and Javoy, M.: 1975, Reviews of Geophysics and Space Physics (13), 401

Bottke, W. F., Vokrouhlický, D., Marchi, S., Swindle, T., Scott, E. R. D., Weirich, J. R., and Levison, H.: 2015, Science 348(6232), 321

Bottke, W. F., Walker, R. J., Day, J. M. D., Nesvorny, D., and Elkins-Tanton, L.: 2010, Science 330(6010), 1527

Bouvier, A. and Wadhwa, M.: 2010, Nature Geoscience 3(9), 637

Boynton, W. V., Chou, C.-L., Robinson, K. L., Warren, P. H., and Wasson, J. T.: 1976, Proceedings of Lunar Science Conference 7 pp 727-742

Braukmüller, N., Wombacher, F., Funk, C., and Münker, C.: 2019, Nature Geoscience 12(7), 564

Brenan, J. M., Mungall, J. E., and Bennett, N. R.: 2019, Nature Geoscience 12(9), 701

Bridges, J. C., Changela, H. G., Nayakshin, S., Starkey, N. A., and Franchi, I. A.: 2012, Earth and Planetary Science Letters 341-344, 186

Brunfelt, A. O., Heier, K. S., and Steiennes, E.: 1971, Proceedings of Lunar Science Conference 2 2, 1281

Budde, G., Burkhardt, C., and Kleine, T.: 2019, Nature Astronomy 3(8), 736

Bujarrabal, V., Fuente, A., and Omont, A.: 1994, Astronomy and Astrophysics (285), 247

Cameron, A.: 2000, Origin of the Earth and Moon (eds. R.M. Canup and K. Righter). University of Arizona Press, Tucson pp 133-144

Cameron, A. and Benz, W.: 1991, Icarus 92(2), 204

Cameron, A. G. W.: 2001, Meteoritics E Planetary Science 36(1), 9

Cameron, A. G. W. and Ward, W. R.: 1976, Lunar and Planetary Science Conference 7, 120

Cano, E. J., Sharp, Z. D., and Shearer, C. K.: 2020, Nature Geoscience 13(4), 270 
Canup, R. M.: 2004a, Annual Review of Astronomy and Astrophysics 42(1), 441

Canup, R. M.: 2004b, Icarus 168(2), 433

Canup, R. M.: 2012, Science 338, 1052

Canup, R. M. and Asphaug, E.: 2001, Nature 412(6848), 708

Cao, X. and Bao, H.: 2021, Reviews in Mineralogy and Geochemistry 86(1), 463

Cao, X., Bao, H., Gao, C., Liu, Y., Huang, F., Peng, Y., and Zhang, Y.: 2019, Acta Geochimica 38(3), 327

Cao, X. and Liu, Y.: 2011, Geochimica et Cosmochimica Acta 75(23), 7435

Carlson, R. W., Borg, L. E., Gaffney, A. M., and Boyet, M.: 2014, Philosophical transactions. Series A, Mathematical, physical, and engineering sciences 372(2024), 20130246

Chakraborty, S., Yanchulova, P., and Thiemens, M. H.: 2013, Science 342(6157), 463

Chazot, G., Lowry, D., Menzies, M., and Mattey, D.: 1997, Geochimica et Cosmochimica Acta 61(1), 161

Chiba, H., Chacko, T., Clayton, R. N., and Goldsmith, J. R.: 1989, Geochimica et Cosmochimica Acta 53, 2985

Cho, S.-H. and Kim, J.: 2012, The Astronomical Journal 144(5), 129

Chou, C.-L., Baedecker, P. A., Bild, R. W., and Wasson, J. T.: 1974, Proceedings of Lunar Science Conference 5 pp 1645-1658

Ciesla, F. and Cuzzi, J.: 2006, Icarus 181(1), 178

Clayton, R. N.: 1993, Annual Review of Earth and Planetary Sciences. (21), 115

Clayton, R. N.: 2002, Lunar and Planetary Science Conference 33, abstract \#1326

Clayton, R. N.: 2008, Reviews in Mineralogy and Geochemistry 68(1), 5

Clayton, R. N., Grossman, L., and Mayeda, T. K.: 1973, Science (182), 485

Clayton, R. N., Hurd, J. M., and Mayeda, T. K.: 1974a, Geochimica et Cosmochimica Acta (2), 1535

Clayton, R. N. and Mayeda, T. K.: 1963, Geochimica et Cosmochimica Acta 27, 43

Clayton, R. N. and Mayeda, T. K.: 1975, Proceedings of Lunar Science Conference 6 pp $1761-1769$

Clayton, R. N. and Mayeda, T. K.: 1977, Geophysical Research Letters 4(7), 295

Clayton, R. N. and Mayeda, T. K.: 1983, Earth and Planetary Science Letters 62(1), 1 
Clayton, R. N. and Mayeda, T. K.: 1996, Geochimica et Cosmochimica Acta 60(11), 1999

Clayton, R. N. and Mayeda, T. K.: 1999, Geochimica et Cosmochimica Acta 63(13-14), 2089

Clayton, R. N., Mayeda, T. K., Goswami, J., and Olsen, E. J.: 1991, Geochimica et Cosmochimica Acta 55(8), 2317

Clayton, R. N., Mayeda, T. K., and Hurd, J. M.: 1974b, Proceedings of Lunar Science Conference 5 pp 1801-1809

Clayton, R. N., Mayeda, T. K., Hutcheon, I. D., Molini-Velsko, C., Onuma, N., Ikeda, Y., and Olsen, E. J.: 1983a, in E. A. King (ed.), Chondrules and Their Origins, pp 37-43

Clayton, R. N., Mayeda, T. K., Olsen, Edward, J., and Prinz, M.: 1983b, Earth and Planetary Science Letters 65, 229

Clayton, R. N., Mayeda, T. K., and Rubin, A. E.: 1984, Journal of Geophysical Research: Solid Earth 89(S01), C245

Clayton, R. N., Onuma, N., and Mayeda, T. K.: 1971, NASA Report pp 1-5

Clayton, R. N., Onuma, N., and Mayeda, T. K.: 1976, Earth and Planetary Science Letters 30(1), 10

Cohen, B. A., Swindle, T. D., and Kring, D. A.: 2000, Science 290(5497), 1754

Compston, W., Foster, J. J., and Gray, C. M.: 1977, Proceedings of Lunar Science Conference 8 pp 2525-2549

Connelly, J. N. and Bizzarro, M.: 2016, Earth and Planetary Science Letters 452, 36

Creech, J. B., Baker, J. A., Handler, M. R., Lorand, J.-P., Storey, M., Wainwright, A. N., Luguet, A., Moynier, F., and Bizzarro, M.: 2016, Geochemical Perspectives Letters pp 94-104

Ćuk, M.: 2012, Icarus 218(1), 69

Ćuk, M. and Stewart, S. T.: 2012, Science (New York, N.Y.) 338(6110), 1047

Dale, C. W., Kruijer, T. S., and Burton, K. W.: 2017, Earth and Planetary Science Letters 458, 394

Daly, R. A.: 1946, Proceedings of the American Philosophical Society 90(2), 104

Darwin, G. H.: 1879, Philosophical Transactions of the Royal Society of London 170, 447

Dauphas, N.: 2017, Nature 541(7638), 521 
Dauphas, N., Burkhardt, C., Warren, P. H., and Fang-Zhen, T.: 2014, Philosophical transactions. Series A, Mathematical, physical, and engineering sciences 372(2024), 20130244

Dauphas, N., Chen, J. H., and Papanastassiou, D. A.: 2015, Lunar and Planetary Science Conference 46(1832), 2436

Day, J. M. and Walker, R. J.: 2015, Earth and Planetary Science Letters 423, 114

Day, J. M. D., Moynier, F., and Shearer, C. K.: 2017, Proceedings of the National Academy of Sciences of the United States of America 114(36), 9547

Delano, J.: 1986, Journal of Geophysical Research: Solid Earth 91(B4), 201

Dymek, R. F., Albee, A., and Chodos, A. A.: 1976, Proceedings of Lunar Science Conference 7 pp 2335-2378

Dymek, R. F., Boak, J. L., and Brothers, S. C.: 1988, American Mineralogist 73(5-6), 547

Ebihara, M., Wolf, R., Warren, P. H., and Anders, E.: 1992, Proceedings of Lunar Science Conference 22 pp 417-426

Eiler, J. M.: 2001, Reviews in Mineralogy and Geochemistry (43), 319

Eiler, J. M., Schiano, P., Kitchen, N., and Stolper, E. M.: 2000, Nature 403(6769), 530

Elkins-Tanton, L. T., Burgess, S., and Yin, Q.-Z.: 2011, Earth and Planetary Science Letters 304(3), 326

Elsenheimer, D. and Valley, J. W.: 1992, Chemical Geology 101, 21

Epstein, S. and Taylor, H. P.: 1970, Science 167(3918), 533

Epstein, S. and Taylor, H. P.: 1972, Proceedings of Lunar Science Conference 3 pp $1429-1454$

Epstein, S. and Taylor Jr., H. P.: 1971, Proceedings of Lunar Science Conference 2 pp $1421-1441$

Farquhar, G. D. and Gan, K. S.: 2003, Plant, Cell E Environment 26(9), 1579

Fiebig, J. and Hoefs, J.: 2002, European Journal of Mineralogy 14(1), 49

Fischer-Gödde, M. and Becker, H.: 2012, Geochimica et Cosmochimica Acta 77, 135

Fischer-Gödde, M., Becker, H., and Wombacher, F.: 2011, Chemical Geology 280(3), 365

Fischer-Gödde, M., Elfers, B.-M., Münker, C., Szilas, K., Maier, W. D., Messling, N., Morishita, T., van Kranendonk, M., and Smithies, H.: 2020, Nature 579(7798), 240

Fischer-Gödde, M. and Kleine, T.: 2017, Nature 541(7638), 525 
Frei, R., Polat, A., and Meibom, A.: 2004, Geochimica et Cosmochimica Acta 68(7), 1645

Friend, C., Bennett, V., and Nutman, A.: 2002, Contributions to Mineralogy and Petrology 143(1), 71

Friend, C. and Nutman, A.: 2011, Geology 39(7), 663

Ganapathy, R., Morgan, J. W., Higuchi, H., Anders, E., and Anderson, A. T.: 1974, Proceedings of Lunar Science Conference 5 pp 1659-1683

Ganapathy, R., Morgan, J. W., Krahenbuhl, U., and Anders, E.: 1973, Proceedings of Lunar Science Conference 4 2, 1239

Gao, Y. Q. and Marcus, R. A.: 2001, Science (New York, N.Y.) 293(5528), 259

Garde, A. A.: 2007, Journal of the Geological Society, London 164, 565

Georg, R. B., Halliday, A. N., Schauble, E. A., and Reynolds, B. C.: 2007, Nature 447(7148), 1102

Gerstenkorn, H.: 1955, Zeitschrift fur Astrophysik 36, 245

Gleißner, P.: 2019, Nature Geoscience 12(9), 683

Gleißner, P. and Becker, H.: 2017, Geochimica et Cosmochimica Acta 200, 1

Gleißner, P. and Becker, H.: 2019, Meteoritics $\mathcal{F}$ Planetary Science 54(9), 2006

Goldreich, P.: 1966, Reviews of Geophysics 4(4), 411

González-Ferrán, O.: 1994, Instituto Geografico militar, Santiago, Chile p. 635

Greenwood, R. C., Barrat, J.-A., Miller, M. F., Anand, M., Dauphas, N., Franchi, I. A., Sillard, P., and Starkey, N. A.: 2018, Science advances 4(3), 1

Greenwood, R. C., Burbine, T. H., and Franchi, I. A.: 2020, Geochimica et Cosmochimica Acta 277, 377

Greenwood, R. C., Burbine, T. H., Miller, M. F., and Franchi, I. A.: 2017, Geochemistry 77(1), 1

Gregory, R. T., Taylor, H. P., Kyser, T. K., O’Neil, J. R., and Carmichael, I. S. E.: 1986, Contributions to Mineralogy and Petrology 93(1), 114

Hallis, L. J., Anand, M., Greenwood, R. C., Miller, M. F., Franchi, I. A., and Russell, S. S.: 2010, Geochimica et Cosmochimica Acta 74(23), 6885

Hartmann, W. K.: 1970, Icarus 13(2), 299

Hartmann, W. K. and Davis, R. D.: 1975, Icarus 24, 504 
Heidenreich, J. E. and Thiemens, M. H.: 1986, The Journal of Chemical Physics 84(4), 2129

Heiken, G. H., Vaniman, D. T., and French, B. M. (eds.): 1991, Lunar Sourcebook, A User's Guide to the Moon, Cambridge University Press

Hertogen, J., Janssens, M.-J., Takahashi, H., Palme, H., and Anders, E.: 1977, Proceedings of Lunar Science Conference 8 1, 17

Herwartz, D.: 2021, Reviews in Mineralogy and Geochemistry 86(1), 291

Herwartz, D., Pack, A., Friedrichs, B., and Bischoff, A.: 2014, Science 344(6188), 1146

Hickey-Vargas, R., Holbik, S., Tormey, D., Frey, F. A., and Moreno Roa, H.: 2016, Lithos 258-259, 115

Hiesinger, H., Jaumann, R., Neukum, G., and Head, J. W.: 2000, Journal of Geophysical Research: Planets 105(E12), 29239

Higuchi, H. and Morgan, J. W.: 1975a, Proceedings of Lunar Science Conference 6 pp $1625-1651$

Higuchi, H. and Morgan, J. W.: 1975b, Proceedings of Lunar Science Conference 6 pp 364-366

Holland, T. and Blundy, J.: 1994, Contributions to Mineralogy and Petrology 116(4), 433

Hörz, F., Grieve, R., Heiken, G., Spudis, P., and Binder, A.: 1991, in G. H. Heiken, D. T. Vaniman, and B. M. French (eds.), Lunar Sourcebook, A User's Guide to the Moon, pp 61-120, Cambridge University Press

Hudgins, J. A., Spray, J. G., Kelley, S. P., Korotev, R. L., and Sherlock, S. C.: 2008, Geochimica et Cosmochimica Acta 72(23), 5781

Ireland, T. R., Avila, J., Greenwood, R. C., Hicks, L. J., and Bridges, J. C.: 2020, Space Science Reviews 216(25), 1

Irvine, T. N.: 1977, Geology 5(5), 273

Jacobson, S. A., Morbidelli, A., Raymond, S. N., O’Brien, D. P., Walsh, K. J., and Rubie, D. C.: 2014, Nature 508(7494), 84

James, O. B., Flohr, M. K., and Lindstrom, M. M.: 1984, Journal of Geophysical Research 89(S01), C63

Johnson, B. C. and Melosh, H. J.: 2012, Nature 485(7396), 75

Joy, K. H., Crawford, I. A., Curran, N. M., Zolensky, M., Fagan, A. F., and Kring, D. A.: 2016, Earth, Moon, and Planets 118(2), 133

Joy, K. H., Zolensky, Michael, E., Nagashima, K., Huss, Gary, R, Ross, D., Kent, McKay, David, S., and Kring, D. A.: 2012, Science 336, 1426 
Kaib, N. A. and Cowan, N. B.: 2015, Icarus 252, 161

Kato, C., Moynier, F., Valdes, M. C., Dhaliwal, J. K., and Day, J. M. D.: 2015, Nature communications $\mathbf{6}, 7617$

Kaula, W. M. and Yoder, C. F.: 1976, Lunar and Planetary Science Conference 7, 440

Kawagucci, S., Tsunogai, U., Kudo, S., Nakagawa, F., Honda, H., Aoki, S., Nakazawa, T., Tsutsumi, M., and Gamo, T.: 2008, Atmospheric Chemistry and Physics 8(20), 6189

Kharkar, D. P. and Turekian, K. K.: 1971, Proceedings of Lunar Science Conference 2 pp $1301-1305$

Kohl, I. E., Warren, P. H., Schauble, E. A., and Young, E. D.: 2017, Lunar and Planetary Science Conference 48, abstract \#2292

Korotev, R. L.: 1987, Journal of Geophysical Research: Solid Earth 92(B4), E411

Krahenbuhl, U., Ganapathy, R., Morgan, J. W., and Anders, E.: 1973a, Proceedings of Lunar Science Conference 4 pp 1325-1348

Krahenbuhl, U., Ganapathy, R., Morgan, J. W., and Anders, E.: 1973b, Science 180(4088), 858

Krankowsky, D., Lämmerzahl, P., and Mauersberger, K.: 2000, Geophysical Research Letters 27(17), 2593

Krot, A. N., Keil, K., Scott, E. R. D., Goodrich, C. A., and Weisberg, M. K.: 2014, Meteorites and Cosmochemical Processes 1, 1

Krot, A. N., McKeegan, K. D., Leshin, L. A., MacPherson, G. J., and Scott, E. R. D.: 2002, Science 295(5557), 1051

Kruijer, T. S. and Kleine, T.: 2017, Earth and Planetary Science Letters 475, 15

Kruijer, T. S., Kleine, T., Fischer-Gödde, M., and Sprung, P.: 2015, Nature 520(7548), 534

Kyser, T. K., O’Neil, J. R., and Carmichael, I. S. E.: 1981, Contributions to Mineralogy and Petrology 77, 11

Kyser, T. K., O’Neil, J. R., and Carmichael, I. S. E.: 1986, Contributions to Mineralogy and Petrology 93, 120

Lämmerzahl, P.: 2002, Geophysical Research Letters 29(12), 2426

Laul, J. C., Hill, D. W., and Schmitt, R. A.: 1974, Proceedings of Lunar Science Conference 5 pp 1047-1066

Laul, J. C., Morgan, J. W., Ganapathy, R., and Anders, E.: 1971, Proceedings of Lunar Science Conference 2 pp 1139-1158 
Laul, J. C. and Schmitt, R. A.: 1974, Earth and Planetary Science Letters pp 206-219

Lausen, C.: 1927, American Journal of Science s5-14(82), 293

Lindstrom, M. M. and Lindstrom, D. J.: 1986, Journal of Geophysical Research 91(B4), 263

Liu, J., Sharp, M., Ash, R. D., Kring, D. A., and Walker, R. J.: 2015, Geochimica et Cosmochimica Acta 155, 122

Lock, S. J., Stewart, S. T., Petaev, M. I., Leinhardt, Z., Mace, M. T., Jacobsen, S. B., and Cuk, M.: 2018, Journal of Geophysical Research: Planets 123(4), 910

Longhi, J. and Ashwal, L. D.: 1985, Journal of Geophysical Research 90(S02), C571

Lopez-Escobar, L., Cembrano, J., and and Moreno, H.: 1995, Revista Geológica de Chile 22(2), 219

Loucks, R. R.: 1996, Contributions to Mineralogy and Petrology 125(2-3), 140

Lowry, D., Appel, P., and Rollinson, H. R.: 2003, Precambrian Research 126(3), 273

Lucey, P., Korotev, R. L., Gillis, J. J., Taylor, L. A., Lawrence, D., Campbell, B. A., Elphic, R., Feldman, B., Hood, L. L., Hunten, D., Mendillo, M., Noble, S., Papike, J. J., Reedy, R. C., Lawson, S., Prettyman, T., Gasnault, O., and Maurice, S.: 2006, Reviews in Mineralogy and Geochemistry 60(1), 83

Lugmair, G. W. and Shukolyukov, A.: 1998, Geochimica et Cosmochimica Acta 62(16), 2863

Luz, B. and Barkan, E.: 2005, Geochimica et Cosmochimica Acta (69), 1099

Luz, B., Barkan, E., Bender, M. L., Thiemens, M. H., and Boering, K. A.: 1999, Nature 400(6744), 547

Lyons, J. R. and Young, E. D.: 2004, Lunar and Planetary Science Conference 35, abstract \#1970

Lyons, J. R. and Young, E. D.: 2005, Nature 435(7040), 317

MacPherson, G. J. and Boss, A.: 2011, Proceedings of the National Academy of Sciences of the United States of America 108(48), 19152

Mamajek, E. E., Barenfeld, S. A., Ivanov, V. D., Kniazev, A. Y., Väisänen, P., Beletsky, Y., and Boffin, H. M. J.: 2015, The Astrophysical Journal Letters 800(1), L17

Mann, U., Frost, D. J., Rubie, D. C., Becker, H., and Audétat, A.: 2012, Geochimica et Cosmochimica Acta 84, 593

Marcus, R. A.: 2004, The Journal of Chemical Physics 121(17), 8201

Maresch, W. and Medenbach, O.: 1987, Steinbachs Naturführer: Gesteine, Mosaik Verlag, München 
Martin, R. G. and Livio, M.: 2012, Monthly Notices of the Royal Astronomical Society: Letters 425(1), L6

Marty, B.: 2012, Earth and Planetary Science Letters 313-314, 56

Marvin, U. B. and Warren, P. H.: 1980, Proceedings of Lunar Science Conference 11 pp $508-521$

Mastrobuono-Battisti, A., Perets, H. B., and Raymond, S. N.: 2015, Nature 520(7546), 212

Matsuhisa, Y., Goldsmith, J. R., and Clayton, R. N.: 1978, Geochimica et Cosmochimica Acta (42), 173

Mattey, D., Lowry, D., and Macpherson, C.: 1994, Earth and Planetary Science Letters 128(3-4), 231

Matthews, A., Goldsmith, J. R., and Clayton, R. N.: 1983, Geochimica et Cosmochimica Acta 47, 631

Mauersberger, K.: 1981, Geophysical Research Letters 8(8), 935

Mayeda, T. K., Shearer, J., and Clayton, R. N.: 1975, Proceedings of Lunar Science Conference 6 pp 1799-1802

McCallum, I. S., Mathez, E. A., Okamura, F. P., and Ghose, S.: 1974, Proceedings of Lunar Science Conference 5 pp 287-302

McKay, D., Heiken, G., Basu, A., Blanford, G., Simon, S., Reedy, R., French, B. M., and Papike, J.: 1991, in G. H. Heiken, D. T. Vaniman, and B. M. French (eds.), Lunar Sourcebook, A User's Guide to the Moon, pp 285-365, Cambridge University Press

McKeegan, K. D., Aléon, J., Bradley, J., Brownlee, D., Busemann, H., Butterworth, A., Marc Chaussidon, Stewart Fallon, Floss, C., Gilmour, J., Gounelle, M., Graham, Graham, G., Heck, P. R., Hoppe, P., Hutcheon, I. D., Huth, J., Ishii, H., Ito, M., Jacobsen, S. B., Kearsley, A., Leshin, L. A., Liu, M.-C., Lyon, I., Marhas, K., Marty, B., Matrajt, G., Meibom, A., Messenger, S., Mostefaoui, S., Mukhopadhyay, S., NakamuraMessenger, K., Nittler, L., Palma, R., Pepin, R. O., Papanastassiou, D. A., Robert, F., Schlutter, D., Snead, C. J., Stadermann, F. J., Stroud, R., Tsou, P., Westphal, A., Young, E. D., Ziegler, K., Zimmermann, L., and Zinner, E.: 2006, Science 314(5806), 1724

McKeegan, K. D., Kallio, A. P. A., Heber, V. S., Jarzebinski, G., Mao, P. H., Coath, C. D., Kunihiro, T., Wiens, R. C., Nordholt, J. E., Moses, R. W., Reisenfeld, D. B., Jurewicz, A. J. G., and Burnett, D. S.: 2011, Science 332(6037), 1528

McKinney, C. R., McCrea, J. M., Epstein, S., Allen, H. A., and Urey, H. C.: 1950, Review of Scientific Instruments 21, 724

McSween, H. Y.: 1984, Geology 12(1), 3 
Michalski, G. and Bhattacharya, S. K.: 2009, Proceedings of the National Academy of Sciences 106(14), 5493

Miller, M. F.: 2002, Geochimica et Cosmochimica Acta 66, 1881

Miller, M. F. and Pack, A.: 2021, Reviews in Mineralogy and Geochemistry 86(1), 1

Mojzsis, S. J., Cates, N. L., Caro, G., Trail, D., Abramov, O., Guitreau, M., Blichert-Toft, J., Hopkins, M. D., and Bleeker, W.: 2014, Geochimica et Cosmochimica Acta 133, 68

Morbidelli, A., Marchi, S., Bottke, W. F., and Kring, D. A.: 2012, Earth and Planetary Science Letters 355-356, 144

Morbidelli, A., Nesvorny, D., Laurenz, V., Marchi, S., Rubie, D. C., Elkins-Tanton, L., Wieczorek, M., and Jacobson, S.: 2018, Icarus 305, 262

Morgan, J. W., Ganapathy, R., Higuchi, H., Krahenbuhl, U., and Anders, E.: 1974, Proceedings of Lunar Science Conference 5 2, 1703

Morgan, J. W., Ganapathy, R., and Higuchi, H., Anders, E.: 1977, Proceedings of the Soviet-American Conference on Cosmochemistry of the Moon and Planets 2, 659

Morgan, J. W., Laul, J. C., Krähenbühl, U., Ganapathy, R., and Anders, E.: 1972, Lunar and Planetary Science Conference 3, 1377

Morgan, J. W. and Petrie, R. K.: 1979, Proceedings of Lunar Science Conference $10 \mathrm{pp}$ 789-801

Morishima, R. and Watanabe, S.-i.: 2001, Earth, Planets and Space 53(3), 213

Morris, R. V.: 1978, Proceedings of Lunar Science Conference 9 pp 2287-2297

Moynier, F., Albarède, F., and Herzog, G. F.: 2006, Geochimica et Cosmochimica Acta 70(24), 6103

Moynier, F., Qing-Zhu Yin, Irisawa, K., Boyet, M., Jacobsen, B., and Rosing, M. T.: 2010, Proceedings of the National Academy of Sciences 107(24), 10810

Nakamura, T., Noguchi, T., Tsuchiyama, A., Ushikubo, T., Kita, N. T., Valley, J. W., Zolensky, M., Kakazu, Y., Sakamoto, K., Mashio, E., Uesugi, K., and Nakano, T.: 2008, Science 321(5896), 1664

Neukum, G., Ivanov, B. A., and Hartmann, W. K.: 2001, In: Kallenbach R., Geiss J., Hartmann W.K. (eds) Chronology and Evolution of Mars. Space Sciences Series of ISSI 12, 55

Nishio, I., Morishita, T., Szilas, K., Pearson, G., Tani, K.-I., Tamura, A., Harigane, Y., and Guotana, J. M.: 2019, Geosciences 9(4), 153

Norman, M. D., Bennett, V. C., and Ryder, G.: 2002, Earth and Planetary Science Letters 202(2), 217 
Nutman, A. P., Friend, C. R., Horie, K., and Hidaka, H.: 2007, in M. J. van Kranendonk, R. H. Smithies, and V. C. Bennett (eds.), Developments in Precambrian Geology : Earth's Oldest Rocks, Vol. 15, pp 187-218, Elsevier

Nutman, A. P., McGregor, V. R., Friend, C. R., Bennett, V. C., and Kinny, P. D.: 1996, Precambrian Research 78(1), 1

Okrusch, M. and Matthes, S.: 2010, Mineralogie: Eine Einfuihrung in die spezielle Mineralogie, Petrologie und Lagerstättenkunde, Springer-Lehrbuch, Springer, Berlin, 8., vollst. überarb., erw. und aktual. aufl. edition

Oliver, T. A.: 1951, American Mineralogist 36, 421

O’Neil, J. R. and Adami, L. H.: 1970, Proceedings of Apollo 11 Lunar Science Conference 2, 1425

Onuma, N., Clayton, R. N., and Mayeda, T. K.: 1970, Proceedings of Lunar Science Conference 112,1429

Pack, A.: 2021, Reviews in Mineralogy and Geochemistry 86(1), 217

Pack, A. and Herwartz, D.: 2014, Earth and Planetary Science Letters 390, 138

Pack, A., Tanaka, R., Hering, M., Sengupta, S., Peters, S., and Nakamura, E.: 2016, Rapid Communications in Mass Spectrometry 30(13), 1495

Pack, A., Toulouse, C., and Przybilla, R.: 2007, Rapid Communications in Mass Spectrometry 21(22), 3721

Pahlevan, K. and Stevenson, D. J.: 2007, Earth and Planetary Science Letters 262(3-4), 438

Palme, H.: 1980, Lunar and Planetary Science Conference Proceedings 1, 481

Palme, H., Baddenhausen, H., Blum, K., Cendales, M., Dreibus, G., Hofmeister, H., Kmse, H., Palme, C., Spettel, B., Vilcsek, E., and Wanke, H.: 1978, Proceedings of Lunar Science Conference 9 pp 25-57

Palme, H. and O’Neill, H.: 2003, Treatise on Geochemistry 2, 568

Paniello, R. C., Day, J. M. D., and Moynier, F.: 2012, Nature 490(7420), 376

Papike, J., Taylor, L., and Simon, S.: 1991, in G. H. Heiken, D. T. Vaniman, and B. M. French (eds.), Lunar Sourcebook, A User's Guide to the Moon, pp 121-182, Cambridge University Press

Perkins, G. B., Sharp, Z. D., and Selverstone, J.: 2006, Contributions to Mineralogy and Petrology 151(6), 633

Peslier, A. H., Schönbächler, M., Busemann, H., and Karato, S.-i.: 2017, Space Science Reviews 212(1), 743 
Peters, S., Alibabaie, N., Pack, A., McKibbin, S. J., Raeisi, D., Nayebi, N., Torab, F., Ireland, T., and Lehmann, B.: 2020a, Geology 48(3), 211

Peters, S. T., Szilas, K., Sengupta, S., Kirkland, C. L., Garbe-Schönberg, D., and Pack, A.: 2020b, Earth and Planetary Science Letters 544, 116331

Pieters, C. M.: 1978, Lunar and Planetary Science Conference 9 pp 2825-2849

Puchtel, I. S., Walker, R. J., James, O. B., and Kring, D. A.: 2008, Geochimica et Cosmochimica Acta 72(12), 3022

Rampino, M. R.: 2015, Monthly Notices of the Royal Astronomical Society 448(2), 1816

Regier, M., Miškovic, A., Ickert, R. B., Pearson, D. G., Stachel, T., Stern, R. A., and Kopylova, M.: 2018, Geochemical Perspectives Letters 9, 6

Reimink, J. R., Chacko, T., Carlson, R. W., Shirey, S. B., Liu, J., Stern, R. A., Bauer, A. M., Pearson, D. G., and Heaman, L. M.: 2018, Earth and Planetary Science Letters 494, 12

Reufer, A., Meier, M. M., Benz, W., and Wieler, R.: 2012, Icarus 221(1), 296

Reuter, J. H., Epstein, S., and Taylor, H. P.: 1965, Geochimica et Cosmochimica Acta (29), 481

Rizo, H., Walker, R. J., Carlson, R. W., Horan, M. F., Mukhopadhyay, S., Manthos, V., Francis, D., and Jackson, M. G.: 2016, Science 352(6287), 809

Rollinson, H.: 2007, Contributions to Mineralogy and Petrology 154(3), 241

Rollinson, H. R., Appel, P., and Frei, R.: 2002, Journal of Petrology 43(11), 2143

Rosenbaum, J. M., Kyser, T., and Walker, D.: 1994, Geochimica et Cosmochimica Acta 58(12), 2653

Rowe, M. W., Clayton, R. N., and Mayeda, T. K.: 1994, Geochimica et Cosmochimica Acta 58(23), 5341

Rufu, R., Aharonson, O., and Perets, H. B.: 2017, Nature Geoscience 10(2), 89

Rumble, D., Bowring, S., lizuka, T., Komiya, T., Lepland, A., Rosing, M. T., and Ueno, Y.: 2013, Geochemistry, Geophysics, Geosystems

Ryder, G.: 1990, Eos, Transactions American Geophysical Union 71(10), 313

Sampson, E.: 1932, Economic Geology 27(2), 113

Schannor, M., Veksler, I. V., Hecht, L., Harris, C., Romer, R. L., and Manyeruke, T. D.: 2018, Chemical Geology 485, 100

Schiller, M., Bizzarro, M., and Fernandes, V. A.: 2018, Nature 555(7697), 507 
Schlichting, H. E., Warren, P. H., and Yin, Q.-Z.: 2012, The Astrophysical Journal 752(1), 8

Schmidt, O. Y.: 1959, A Theory of the Origin of the Earth, Lawrence and Wishart, London

Scott, E. R. D., Keil K., Goldstein J. I., Asphaug E., Bottke W. F., and Moskovitz N. A.: 2015, in P. Michel, F. E. DeMeo, and W. F. Bottke (eds.), Asteroids IV, pp 573-595

Sengupta, S. and Pack, A.: 2018, Chemical Geology 495, 18

Sharp, M., Gerasimenko, I., Loudin, L. C., Liu, J., James, O. B., Puchtel, I. S., and Walker, R. J.: 2014, Geochimica et Cosmochimica Acta 131, 62

Sharp, Z.: 2017a, Open Textbooks

Sharp, Z. D.: 1990, Geochimica et Cosmochimica Acta 54(1353-1357)

Sharp, Z. D.: 2017b, Chemical Geology 448, 137

Sharp, Z. D., Gibbons, J. A., Maltsev, O., Atudorei, V., Pack, A., Sengupta, S., Shock, E. L., and Knauth, L. P.: 2016, Geochimica et Cosmochimica Acta 186, 105

Sharp, Z. D., Shearer, C. K., McKeegan, K. D., Barnes, J. D., and Wang, Y. Q.: 2010, Science 329(5995), 1050

Sharp, Z. D. and Wostbrock, J. A.: 2021, Reviews in Mineralogy and Geochemistry 86(1), 179

Sheffer, Y., Lambert, D. L., and Federman, S. R.: 2002, The Astrophysical Journal Letters (574)

Silverman, S. R.: 1951, Geochim. Cosmochim. Acta (2), 26

Simon, S. B., Papike, J. J., and Laul, J. C.: 1981, Proceedings of Lunar Science Conference 12 pp 371-388

Snape, J. F., Nemchin, A. A., Bellucci, J. J., Whitehouse, M. J., Tartèse, R., Barnes, J. J., Anand, M., Crawford, I. A., and Joy, K. H.: 2016, Earth and Planetary Science Letters 451, 149

Spicuzza, M. J., Day, J. M., Taylor, L. A., and Valley, J. W.: 2007, Earth and Planetary Science Letters 253(1-2), 254

Spray, J. G.: 2016, Annual Review of Earth and Planetary Sciences 44(1), 139

Starkey, N. A., Jackson, C., Greenwood, R. C., Parman, S., Franchi, I. A., Jackson, M., Fitton, J. G., Stuart, F. M., Kurz, M., and Larsen, L. M.: 2016, Geochimica et Cosmochimica Acta 176, 227

Szilas, K., Kelemen, P. B., and Bernstein, S.: 2015a, GeoResJ 7, 22 
Szilas, K., Kelemen, P. B., and Rosing, M. T.: 2015b, Gondwana Research 28(2), 565

Taylor, G. J., Warren, P., Ryder, G., Delano, J., Pieters, C., and Lofgren, G.: 1991, in G. H. Heiken, D. T. Vaniman, and B. M. French (eds.), Lunar Sourcebook, A User's Guide to the Moon, pp 183-284, Cambridge University Press

Taylor, H. P., Duke, M. B., Silver, L. T., and Epstein, S.: 1965, Geochimica et Cosmochimica Acta 29(5), 489

Taylor, H. P. and Epstein, S.: 1970, Proceedings of Lunar Science Conference 11 2, 1613

Taylor, H. P. and Epstein, S.: 1973, Proceedings of Lunar Science Conference 4 2, 1657

Taylor, S. R.: 1973, The moon 7(1-2), 181

Tera, F., Papanastassiou, D. A., and Wasserburg, G. J.: 1974, Earth and Planetary Science Letters 22(1), 1

Thiemens, M. H.: 1999, Science 283(5400), 341

Thiemens, M. H. and Heidenreich, J. E.: 1983, Science (219), 1073

Thiemens, M. H., Jackson, T., Zipf, E. C., Erdman, P. W., and van Egmond, C.: 1995, Science 270(5238), 969

Thiemens, M. H. and Lin, M.: 2021, Reviews in Mineralogy and Geochemistry 86(1), 35

Thiemens, M. M., Sprung, P., Fonseca, R., Leitzke, F. P., and Münker, C.: 2019, Nature Geoscience 12(9), 696

Tomkins, S. and Pieters, C. M.: 1999, Meteoritics $\mathcal{E}$ Planetary Science 34, 25

Touboul, M., Puchtel, I. S., and Walker, R. J.: 2015, Nature 520(7548), 530

Touma, J. and Wisdom, J.: 1994, The Astronomical Journal 108, 1943

Turner, G.: 1979, Lunar and Planetary Science Conference 10 2, 1917

Turner, G., Cadogan, P. H., and Yonge, C. J.: 1973, Lunar and Planetary Science Conference 4 2, 1889

Valley, J. W., Cavosie, A. J., Ushikubo, T., Reinhard, D. A., Lawrence, D. F., Larson, D. J., Clifton, P. H., Kelly, T. F., Wilde, S. A., Moser, D. E., and Spicuzza, M. J.: 2014, Nature Geoscience 7(3), 219

Valley, J. W., Kitchen, N., Kohn, M. J., Niendorf, C. R., and Spicuzza, M. J.: 1995, Geochimica et Cosmochimica Acta (59), 5223

van de Löcht, J.: 2019, Ph.D. thesis, Universität zu Köln

van de Löcht, J., Hoffmann, J. E., Li, C., Wang, Z., Becker, H., Rosing, M. T., Kleinschrodt, R., and Münker, C.: 2018, Geology 46(3), 199 
van de Löcht, J., Hoffmann, J. E., Rosing, M. T., Sprung, P., and Münker, C.: 2020, Geochimica et Cosmochimica Acta 280, 1

van Dishoeck, E. F. and Black, J. H.: 1988, Astrophysical Journal (334), 771

Vaniman, D., Dietrich, J., Taylor, G. J., and Heiken, G.: 1991, in G. H. Heiken, D. T. Vaniman, and B. M. French (eds.), Lunar Sourcebook, A User's Guide to the Moon, pp 5-26, Cambridge University Press

Vaniman, D. and Papike, J.: 1980, in J. Papike and R. B. Merrill (eds.), Proc. Conf. Lunar Highlands Crust, pp 271-337, Pergamon, Lunar Planetary Institute, Houston

Varas-Reus, M. I., König, S., Yierpan, A., Lorand, J.-P., and Schoenberg, R.: 2019, Nature Geoscience 12(9), 779

Vaughan, W. M., Head, J. W., Wilson, L., and Hess, P. C.: 2013, Icarus 223(2), 749

Veblen, D. R. and Buseck, P. R.: 1981, American Mineralogist 66, 1107

Veksler, I. V., Reid, D. L., Dulski, P., Keiding, J. K., Schannor, M., Hecht, L., and Trumbull, R. B.: 2015, Journal of Petrology 56(6), 1229

Vinogradov, A. P., Dontsova, E. I., and Chupakhin, M. S.: 1960, Geochimica et Cosmochimica Acta 18(3-4), 278

Voordouw, R., Gutzmer, J., and Beukes, N. J.: 2009, Mineralogy and Petrology 97(1-2), 75

Walker, D., Longhi, J., Grove, T., Stolper, E., and Hays, J. F.: 1973, Lunar and Planetary Science Conference 4 pp 1013-1032

Walker, R. J.: 2009, Geochemistry 69(2), 101

Walker, R. J., Horan, M. F., Shearer, C. K., and Papike, J. J.: 2004, Earth and Planetary Science Letters 224, 399

Wallner, A., Feige, J., Kinoshita, N., Paul, M., Fifield, L. K., Golser, R., Honda, M., Linnemann, U., Matsuzaki, H., Merchel, S., Rugel, G., Tims, S. G., Steier, P., Yamagata, T., and Winkler, S. R.: 2016, Nature 532(7597), 69

Walsh, C., Millar, T. J., and Nomura, H.: 2010, The Astrophysical Journal 722(2), 1607

Wang, J., Davis, A. M., Clayton, R. N., and Mayeda, T. K.: 1994, Lunar and Planetary Science Conference 25, 1459

Wang, Z. and Becker, H.: 2013, Nature 499(7458), 328

Wänke, H., Baddenhausen, H., Dreibus, G., Jagoutz, E., Kruse, H., Palme, H., Spettel, B., and Teschke, F.: 1973, Proceedings of Lunar Science Conference 4 pp 1461-1481 
Wänke, H., Palme, H., Baddenhausen, H., Dreibus, G., Jagoutz, E., Kruse, H., Palme, C., Spettel, B., Teschke, F., and Thacker, R.: 1975, Proceedings of Lunar Science Conference 6 pp 1313-1340

Wänke, H., Palme, H., Baddenhausen, H., Dreibus, G., Jagoutz, E., Kruse, H., Spettel, B., Teschke, F., and Thacker, R.: 1974, Proceedings of Lunar Science Conference 5 pp 1307-1335

Wänke, H., Palme, H., Kruse, H., Baddenhausen, H., Cendales, M., Dreibus, G., Hofmeister, H., Jagoutz, E., Palme, C., Spettel, B., and Thacker, R.: 1976, Proceedings of Lunar Science Conference 7 pp 3479-3499.

Wänke, H., Wlotzka, F. M., and Rieder, R.: 1971, Proceedings of Lunar Science Conference 2 2, 1187

Warin, S., Benayoun, J. J., and Viala, Y. P.: 1996, Astronomy and Astrophysics (308), 535

Warren, P. H.: 2011, Earth and Planetary Science Letters 311(1-2), 93

Warren, P. H. and Wasson, J. T.: 1979, Reviews of Geophysics 17(1), 73

Warren, P. H. and Wasson, J. T.: 1980, Proceedings of Lunar Science Conference 11 pp $431-470$

Wasson, J. T., Warren, P. H., Kallemeyn, G. W., McEwing, C. E., Mitdefehldt, D. W., and Boynton, W. V.: 1977, Proceedings of Lunar Science Conference 8 pp 2237-2252

Weisberg, M. K., Prinz, M., Clayton, R. N., Mayeda, T. K., Grady, M. M., Franchi, I., Pillinger, C. T., and Kallemeyn, G. W.: 1996, Geochimica et Cosmochimica Acta 60(21), 4253

Wiechert, U., Halliday, A. N., Lee, D.-C., Snyder, G. A., Taylor, L. A., and Rumble, D.: 2001, Science 294(5541), 345

Wiechert, U., Ionov, D. A., and Wedepohl, K. H.: 1997, Contributions to Mineralogy and Petrology 126(4), 345

Willbold, M., Elliott, T., and Moorbath, S.: 2011, Nature 477(7363), 195

Wolf, R., Woodrow, A., and Anders, E.: 1979, Proceedings of Lunar Science Conference 10 pp 2107-2130

Wood, J. A.: 1986, In: Origin of the Moon; Proceedings of the Conference, Kona, HI, October 13-16, 1984 pp 17-55

Wood, J. A., Dickey, J. S., Marvin, U. B., and Powel, B. N.: 1970, Science 167(3918), 602

Wostbrock, J. A. G., Cano, E. J., and Sharp, Z.: 2020, Chemical Geology (553), 119432

Yeung, L. Y., Hayles, J. A., Hu, H., Ash, J. L., and Sun, T.: 2018, Rapid communications in mass spectrometry : RCM 32(20), 1811 
Young, E. D., Ash, R. D., England, P., and Rumble, D.: 1999, Science 286(5443), 1331

Young, E. D., Galy, A., and Nagahara, H.: 2002, Geochimica et Cosmochimica Acta (66), 1095

Young, E. D., Kohl, I. E., Warren, P. H., Rubie, D. C., Jacobson, S. A., and Morbidelli, A.: 2016, Science 351(6272), 493

Yung, Y. L., DeMore, W. B., and Pinto, J. P.: 1991, Geophysical Research Letters 18(1), 13

Zhang, J., Dauphas, N., Davis, A. M., Leya, I., and Fedkin, A.: 2012, Nature Geoscience 5(4), 251

Zheng, Y.-F.: 1991, Geochimica et Cosmochimica Acta 55(8), 2299

Zheng, Y.-F.: 1993a, Geochimica et Cosmochimica Acta 57(5), 1079

Zheng, Y.-F.: 1993b, Earth and Planetary Science Letters 120(3), 247 
Appendix 



\section{A Supplementary information: High-precision triple oxygen isotope measurements of silicates}

\section{A.1 Additional figures}

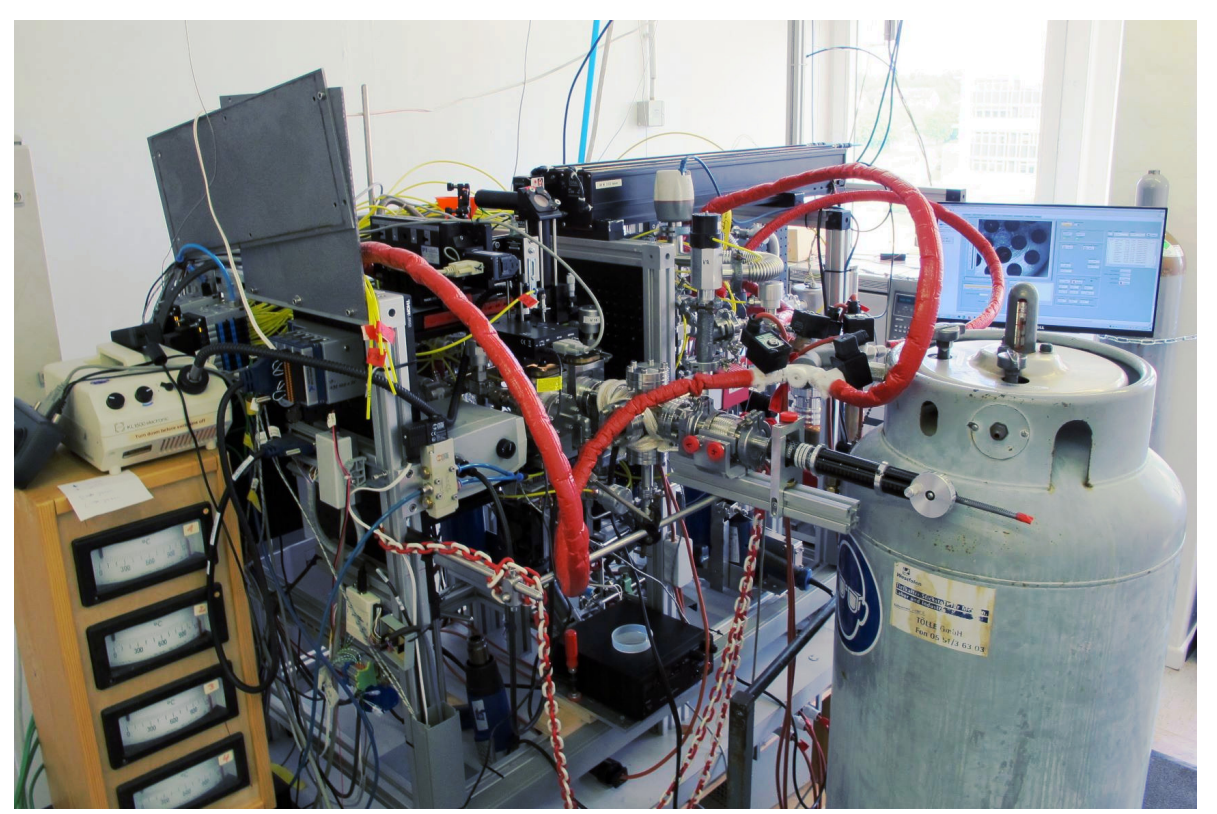

Figure A.1: Image of the $\mathrm{BrF}_{5}$ fluorination line (May 2019). The air lock system is attached to chamber 2 and a liquid $\mathrm{N}_{2}$ tank is connected to the automated cooling system of the traps. 
A Supplementary information: High-precision triple oxygen isotope measurements of silicates

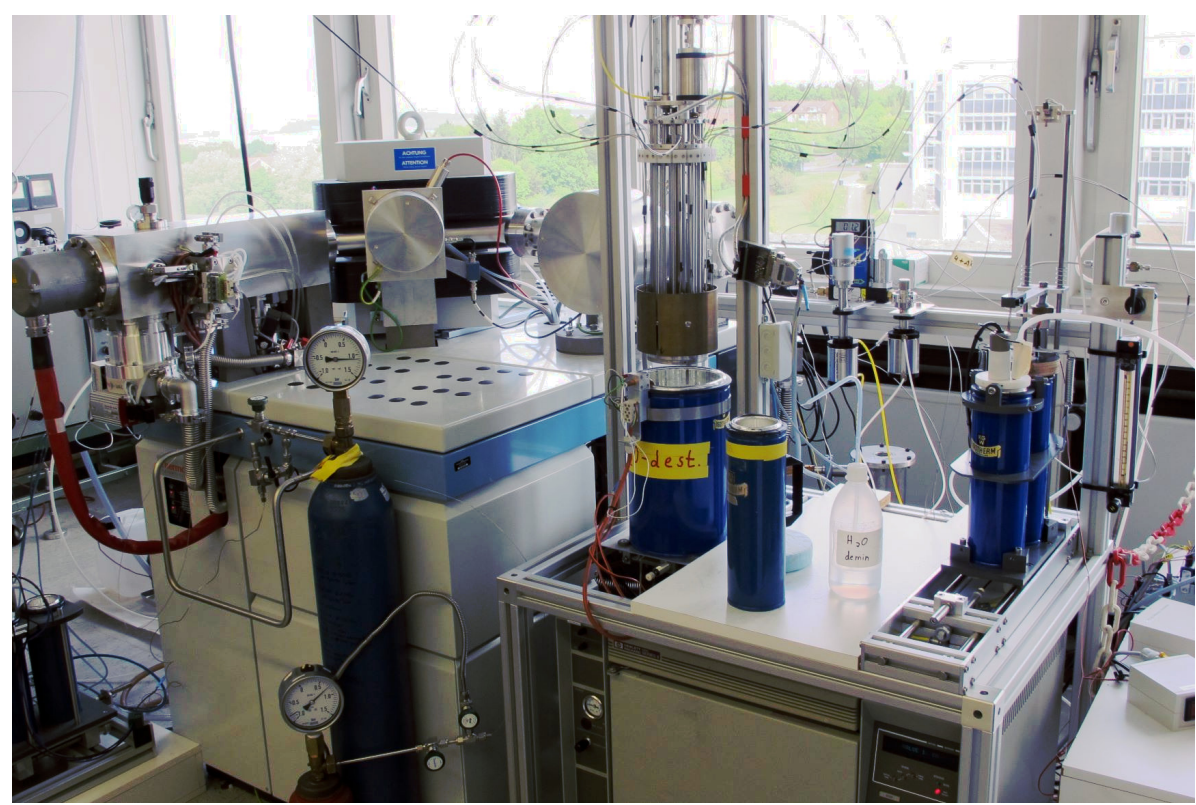

Figure A.2: Image of the Thermo Scientific ${ }^{T M} M A T 253^{T M}$ IRMS and the automated trap 8 (May 2019).

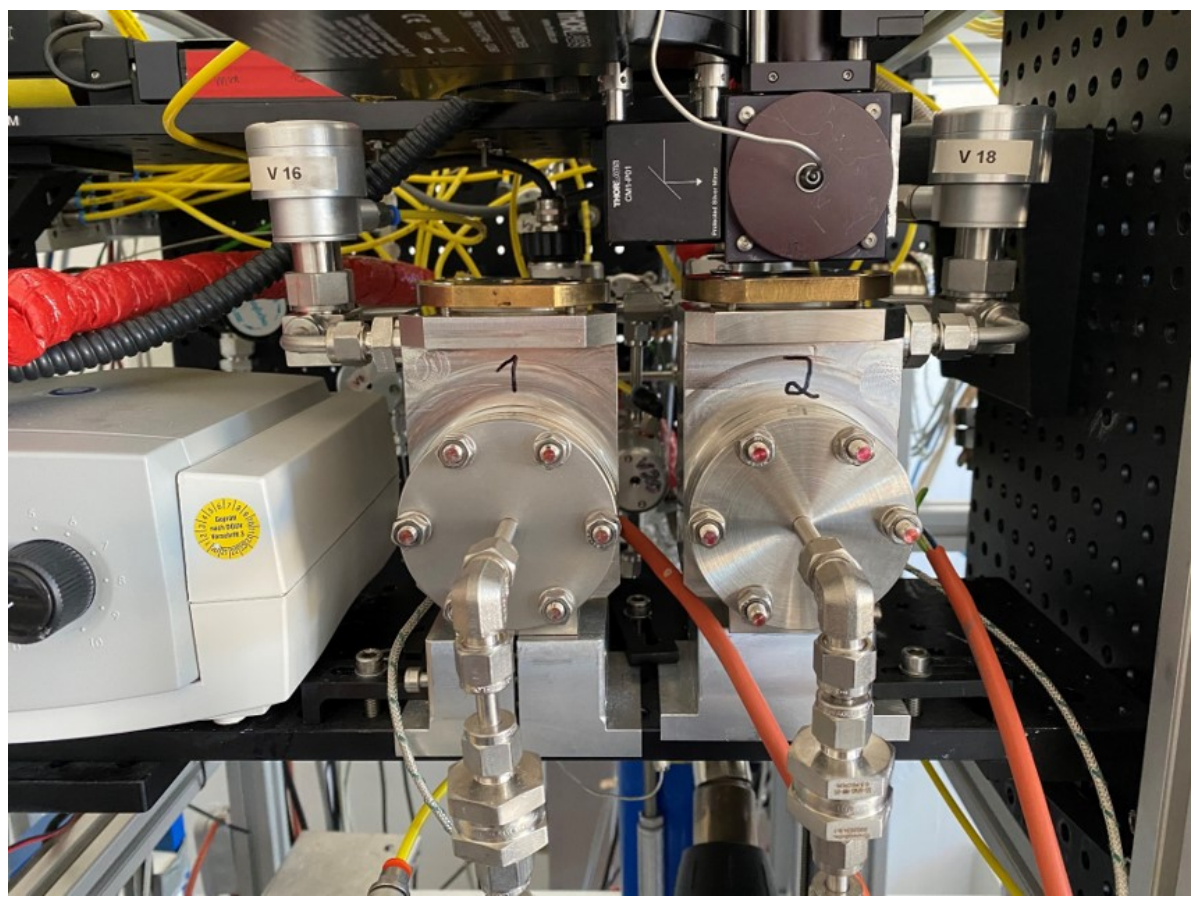

Figure A.3: Image of the two-chamber system of the $\mathrm{BrF}_{5}$ fluorination line (March 2021). The laser objective is above chamber 2. The advantage of two sample chambers is that measurements can be run continuously. Samples are extracted in one chamber, while the other chamber can be reloaded and vacuum can be pumped. 


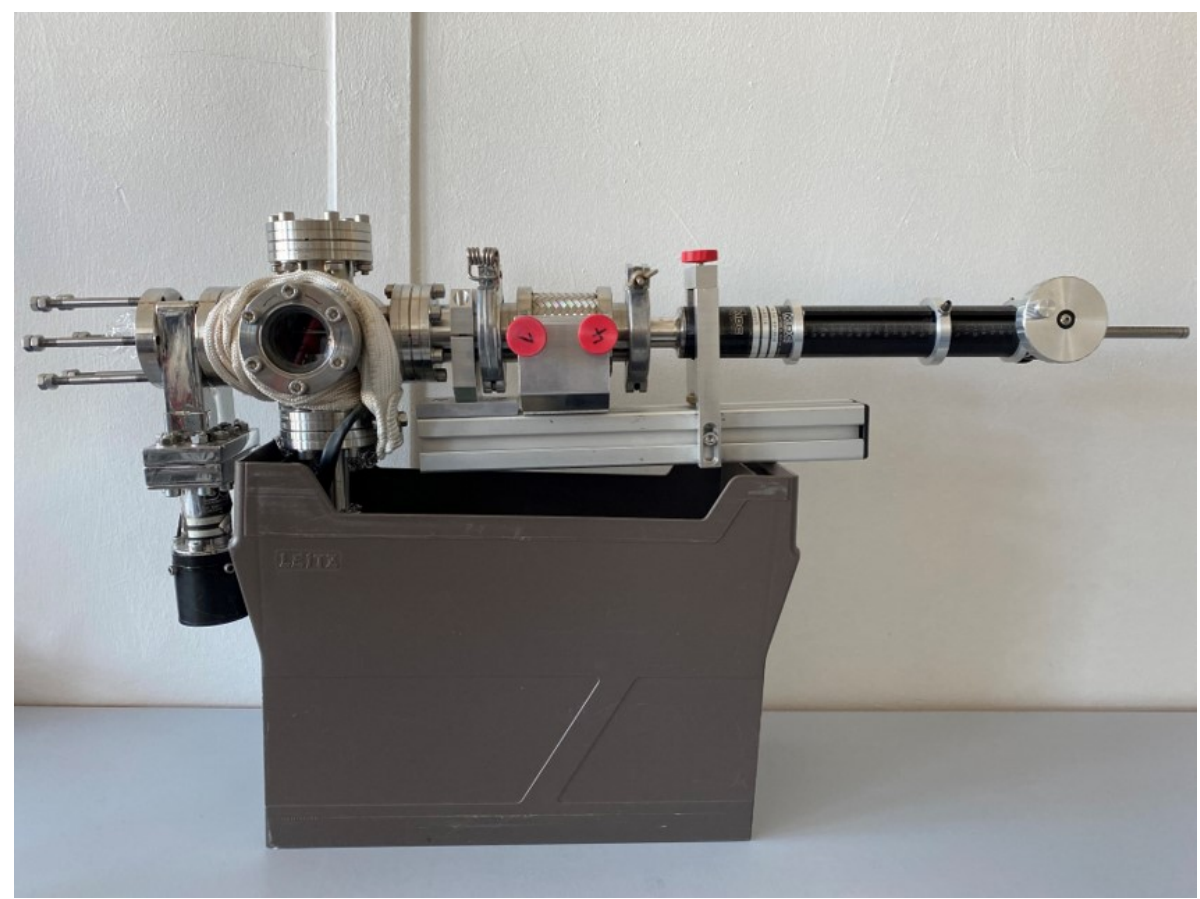

Figure A.4: Image of the unattached air lock system (March 2021). The screws on the left side are used to attach the air lock system to the respective chamber. The pre-chamber is separated from the the reaction chamber by a gate valve. A window allows to see into the pre-chamber from the side. In the middle of the pre-chamber is a sample carousel, which can be rotated. Samples are mounted onto the carousel via the top flange. Samples are moved from the pre-chamber into the sample chamber with a fork (long bar with tongs). The fork can be moved with the silver gear wheel (on the right side). The red gear wheels are used to center the fork. Vacuum can be pumped on the pre-chamber via another flange connection (on the back of the air lock system in this image).

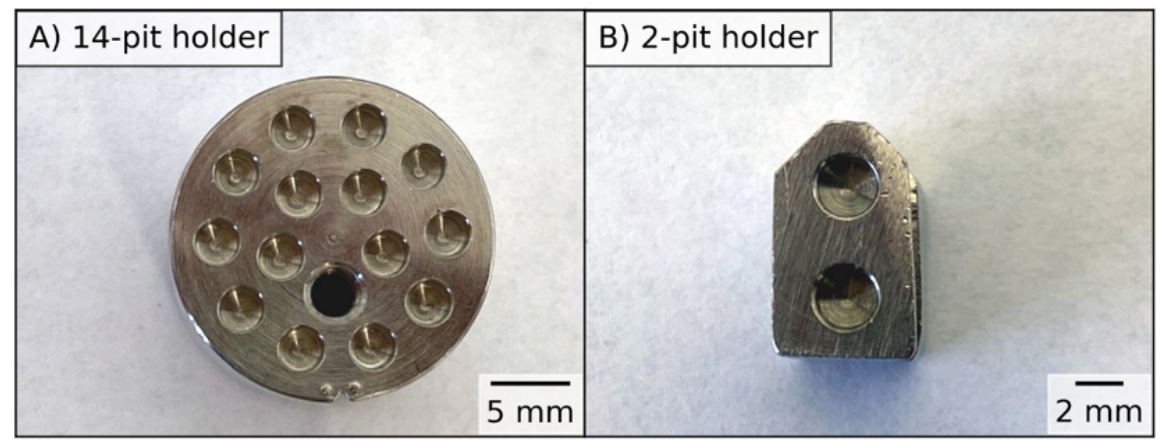

Figure A.5: Image of a 14-pit sample holder (A) and a 2-pit sample holder (B). 14-pit sample holder are used in combination with the conventional system, 2-pit sample holder are used in combination with the air lock system. 
A Supplementary information: High-precision triple oxygen isotope measurements of silicates

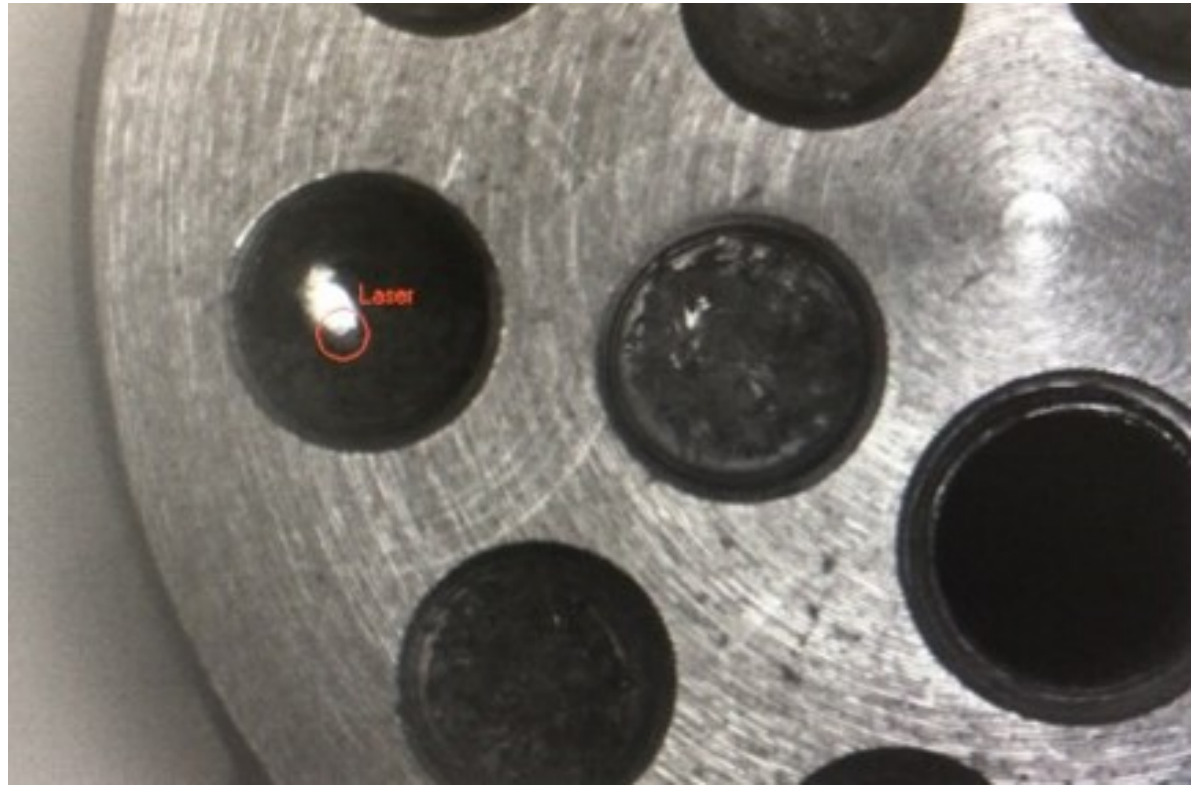

Figure A.6: View into the sample chamber with the camera (May 2019), which is attached to the laser objective. The sample chamber is filled with $\mathrm{BrF}_{5}$ and the laser beam is heating the selected sample on the 14-pit sample holder triggering the fluorination. The stronger the reaction the brighter the light emission. 


\section{A.2 Additional tables}

Table A.1: Oxygen isotope data of San Carlos olivine fraction 0215M $(N=57)$ measured in sessions together with UWG-2 garnet.

\begin{tabular}{|c|c|c|c|c|c|c|c|}
\hline ID & $\begin{array}{l}\delta^{17} \mathrm{O} \\
(\% o)\end{array}$ & $\pm 1 \sigma$ & $\begin{array}{l}\text { delO } \\
(\% o)\end{array}$ & $\pm 1 \sigma$ & $\begin{array}{l}\Delta^{\prime 17} \mathrm{O} \\
(\mathrm{ppm})\end{array}$ & $\pm 1 \sigma$ & Outlier \\
\hline 5419 & 2.66 & 0.11 & 5.15 & 0.09 & -54 & 6 & \\
\hline 5421 & 2.72 & 0.11 & 5.26 & 0.09 & -54 & 6 & \\
\hline 5423 & 2.69 & 0.11 & 5.21 & 0.09 & -54 & 6 & \\
\hline 5425 & 2.72 & 0.11 & 5.26 & 0.09 & -54 & 6 & \\
\hline 5426 & 2.67 & 0.11 & 5.16 & 0.09 & -53 & 6 & \\
\hline 5428 & 2.69 & 0.11 & 5.21 & 0.09 & -60 & 6 & \\
\hline 5430 & 2.67 & 0.11 & 5.15 & 0.09 & -46 & 6 & \\
\hline 5432 & 2.65 & 0.11 & 5.14 & 0.09 & -62 & 6 & \\
\hline 5444 & 2.68 & 0.11 & 5.20 & 0.09 & -56 & 6 & \\
\hline 5449 & 2.64 & 0.11 & 5.11 & 0.09 & -50 & 6 & \\
\hline 5456 & 2.68 & 0.11 & 5.20 & 0.09 & -60 & 6 & \\
\hline 5458 & 2.68 & 0.11 & 5.21 & 0.09 & -63 & 6 & \\
\hline 5459 & 2.75 & 0.11 & 5.33 & 0.09 & -62 & 6 & \\
\hline 5468 & 2.70 & 0.11 & 5.19 & 0.09 & -40 & 6 & \\
\hline 5471 & 2.71 & 0.11 & 5.22 & 0.09 & -43 & 6 & \\
\hline 5472 & 2.67 & 0.11 & 5.14 & 0.09 & -44 & 6 & \\
\hline 5475 & 2.61 & 0.11 & 5.05 & 0.09 & -57 & 6 & \\
\hline 5476 & 2.67 & 0.11 & 5.17 & 0.09 & -59 & 6 & \\
\hline 5478 & 2.56 & 0.11 & 4.96 & 0.09 & -56 & 6 & \\
\hline 5482 & 2.73 & 0.11 & 5.26 & 0.09 & -42 & 6 & \\
\hline 5576 & 2.69 & 0.11 & 5.20 & 0.09 & -57 & 6 & \\
\hline 5578 & 2.66 & 0.11 & 5.16 & 0.09 & -58 & 6 & \\
\hline 5580 & 2.70 & 0.11 & 5.22 & 0.09 & -48 & 6 & \\
\hline 5583 & 2.65 & 0.11 & 5.13 & 0.09 & -52 & 6 & \\
\hline 5585 & 2.63 & 0.11 & 5.09 & 0.09 & -54 & 6 & \\
\hline 5587 & 2.60 & 0.11 & 5.03 & 0.09 & -48 & 6 & \\
\hline 5589 & 2.64 & 0.11 & 5.11 & 0.09 & -49 & 6 & \\
\hline 5590 & 2.68 & 0.11 & 5.18 & 0.09 & -48 & 6 & \\
\hline 5614 & 2.63 & 0.11 & 5.09 & 0.09 & -57 & 6 & \\
\hline 5617 & 2.63 & 0.11 & 5.09 & 0.09 & -56 & 6 & \\
\hline 5619 & 2.67 & 0.11 & 5.14 & 0.09 & -38 & 6 & \\
\hline 5621 & 2.70 & 0.11 & 5.21 & 0.09 & -50 & 6 & \\
\hline 5622 & 2.67 & 0.11 & 5.16 & 0.09 & -54 & 6 & \\
\hline 5626 & 2.63 & 0.11 & 5.10 & 0.09 & -57 & 6 & \\
\hline 5628 & 2.63 & 0.11 & 5.07 & 0.09 & -48 & 6 & \\
\hline 5633 & 2.64 & 0.11 & 5.11 & 0.09 & -57 & 6 & \\
\hline 5682 & 2.78 & 0.11 & 5.36 & 0.09 & -48 & 6 & \\
\hline 5684 & 2.76 & 0.11 & 5.31 & 0.09 & -47 & 6 & \\
\hline 5686 & 2.77 & 0.11 & 5.35 & 0.09 & -47 & 6 & \\
\hline 5688 & 2.77 & 0.11 & 5.34 & 0.09 & -51 & 6 & \\
\hline 5689 & 2.70 & 0.11 & 5.22 & 0.09 & -50 & 6 & \\
\hline 5691 & 2.68 & 0.11 & 5.19 & 0.09 & -53 & 6 & \\
\hline 5693 & 2.59 & 0.11 & 5.03 & 0.09 & -60 & 6 & \\
\hline 5694 & 2.67 & 0.11 & 5.17 & 0.09 & -58 & 6 & \\
\hline 5810 & 2.67 & 0.11 & 5.15 & 0.09 & -46 & 6 & \\
\hline 5819 & 2.71 & 0.11 & 5.24 & 0.09 & -53 & 6 & \\
\hline 5820 & 2.62 & 0.11 & 5.06 & 0.09 & -51 & 6 & \\
\hline 5821 & 2.64 & 0.11 & 5.10 & 0.09 & -53 & 6 & \\
\hline 5822 & 2.61 & 0.11 & 5.05 & 0.09 & -57 & 6 & \\
\hline 5886 & 2.72 & 0.11 & 5.26 & 0.09 & -49 & 6 & \\
\hline 5887 & 2.70 & 0.11 & 5.21 & 0.09 & -49 & 6 & \\
\hline 5889 & 2.65 & 0.11 & 5.13 & 0.09 & -53 & 6 & \\
\hline 5891 & 2.74 & 0.11 & 5.29 & 0.09 & -44 & 6 & \\
\hline 5893 & 2.71 & 0.11 & 5.22 & 0.09 & -44 & 6 & \\
\hline 5896 & 2.72 & 0.11 & 5.26 & 0.09 & -57 & 6 & \\
\hline 5898 & 2.72 & 0.11 & 5.28 & 0.09 & -65 & 6 & \\
\hline 5900 & 2.77 & 0.11 & 5.35 & 0.09 & -53 & 6 & \\
\hline Average & 2.68 & 0.01 & 5.18 & 0.01 & -52 & 1 & 3 \\
\hline
\end{tabular}


A Supplementary information: High-precision triple oxygen isotope measurements of silicates

Table A.2: Oxygen isotope data of San Carlos olivine fraction $0919(N=91)$ measured in sessions together with UWG-2 garnet.

\begin{tabular}{|c|c|c|c|c|c|c|c|}
\hline ID & $\begin{array}{l}\delta^{17} \mathrm{O} \\
(\% o)\end{array}$ & $\pm 1 \sigma$ & $\begin{array}{l}\delta^{18} \mathrm{O} \\
(\% o)\end{array}$ & $\pm 1 \sigma$ & $\begin{array}{l}\Delta^{\prime 17} \mathrm{O} \\
(\mathrm{ppm})\end{array}$ & $\pm 1 \sigma$ & Outlier \\
\hline 6493 & 2.79 & 0.03 & 5.39 & 0.05 & -55 & 5 & \\
\hline 6494 & 2.76 & 0.03 & 5.32 & 0.05 & -46 & 5 & \\
\hline 6497 & 2.75 & 0.03 & 5.32 & 0.05 & -51 & 5 & \\
\hline 6498 & 2.75 & 0.03 & 5.31 & 0.05 & -50 & 5 & \\
\hline 6501 & 2.77 & 0.03 & 5.36 & 0.05 & -56 & 5 & \\
\hline 6510 & 2.81 & 0.03 & 5.42 & 0.05 & -50 & 5 & \\
\hline 6511 & 2.77 & 0.03 & 5.34 & 0.05 & -48 & 5 & \\
\hline 6516 & 2.76 & 0.03 & 5.33 & 0.05 & -47 & 5 & \\
\hline 6517 & 2.76 & 0.03 & 5.34 & 0.05 & -59 & 5 & \\
\hline 6518 & 2.76 & 0.03 & 5.33 & 0.05 & -53 & 5 & \\
\hline 6529 & 2.85 & 0.03 & 5.48 & 0.05 & -42 & 5 & \\
\hline 6534 & 2.80 & 0.03 & 5.42 & 0.05 & -53 & 5 & \\
\hline 6538 & 2.82 & 0.03 & 5.45 & 0.05 & -55 & 5 & \\
\hline 6545 & 2.83 & 0.03 & 5.47 & 0.05 & -53 & 5 & \\
\hline 6548 & 2.81 & 0.03 & 5.44 & 0.05 & -58 & 5 & \\
\hline 6555 & 2.82 & 0.03 & 5.43 & 0.05 & -47 & 5 & \\
\hline 6570 & 2.77 & 0.03 & 5.35 & 0.05 & -50 & 5 & \\
\hline 6580 & 2.88 & 0.03 & 5.56 & 0.05 & -52 & 5 & \\
\hline 6900 & 2.79 & 0.03 & 5.40 & 0.05 & -54 & 5 & \\
\hline 6901 & 2.77 & 0.03 & 5.34 & 0.05 & -45 & 5 & \\
\hline 6907 & 2.76 & 0.03 & 5.34 & 0.05 & -58 & 5 & \\
\hline 6908 & 2.79 & 0.03 & 5.40 & 0.05 & -52 & 5 & \\
\hline 6912 & 2.79 & 0.03 & 5.39 & 0.05 & -47 & 5 & \\
\hline 6920 & 2.75 & 0.04 & 5.33 & 0.07 & -56 & 4 & \\
\hline 6922 & 2.82 & 0.04 & 5.45 & 0.07 & -52 & 4 & \\
\hline 6924 & 2.77 & 0.04 & 5.35 & 0.07 & -52 & 4 & \\
\hline 6926 & 2.85 & 0.04 & 5.49 & 0.07 & -48 & 4 & \\
\hline 6928 & 2.79 & 0.04 & 5.39 & 0.07 & -52 & 4 & \\
\hline 6931 & 2.80 & 0.04 & 5.40 & 0.07 & -49 & 4 & \\
\hline 6933 & 2.75 & 0.04 & 5.30 & 0.07 & -52 & 4 & \\
\hline 6942 & 2.76 & 0.04 & 5.32 & 0.07 & -44 & 4 & \\
\hline 6944 & 2.74 & 0.04 & 5.32 & 0.07 & -61 & 4 & \\
\hline 6945 & 2.76 & 0.04 & 5.35 & 0.07 & -55 & 4 & \\
\hline 6947 & 2.68 & 0.04 & 5.19 & 0.07 & -53 & 4 & \\
\hline 6949 & 2.76 & 0.04 & 5.33 & 0.07 & -46 & 4 & \\
\hline 6951 & 2.74 & 0.04 & 5.30 & 0.07 & -50 & 4 & \\
\hline 6953 & 2.80 & 0.04 & 5.41 & 0.07 & -54 & 4 & \\
\hline 6954 & 2.79 & 0.04 & 5.37 & 0.07 & -47 & 4 & \\
\hline 6996 & 2.75 & 0.04 & 5.33 & 0.07 & -61 & 4 & \\
\hline 6997 & 2.73 & 0.04 & 5.27 & 0.07 & -49 & 4 & \\
\hline 6999 & 2.76 & 0.04 & 5.33 & 0.07 & -51 & 4 & \\
\hline 7001 & 2.70 & 0.04 & 5.20 & 0.07 & -43 & 4 & \\
\hline 7003 & 2.75 & 0.04 & 5.33 & 0.07 & -55 & 4 & \\
\hline 7007 & 2.80 & 0.04 & 5.42 & 0.07 & -57 & 4 & \\
\hline 7009 & 2.81 & 0.04 & 5.42 & 0.07 & -49 & 4 & \\
\hline 7010 & 2.67 & 0.04 & 5.16 & 0.07 & -48 & 4 & \\
\hline 7018 & 2.69 & 0.04 & 5.21 & 0.07 & -54 & 4 & \\
\hline 7019 & 2.75 & 0.04 & 5.30 & 0.07 & -49 & 4 & \\
\hline 7024 & 2.75 & 0.04 & 5.30 & 0.07 & -50 & 4 & \\
\hline 7027 & 2.78 & 0.04 & 5.36 & 0.07 & -49 & 4 & \\
\hline 7030 & 2.70 & 0.04 & 5.22 & 0.07 & -53 & 4 & \\
\hline 7034 & 2.79 & 0.04 & 5.39 & 0.07 & -53 & 4 & \\
\hline 7036 & 2.73 & 0.04 & 5.28 & 0.07 & -54 & 4 & \\
\hline 7132 & 2.81 & 0.04 & 5.42 & 0.07 & -48 & 4 & \\
\hline 7133 & 2.76 & 0.04 & 5.33 & 0.07 & -54 & 4 & \\
\hline 7135 & 2.74 & 0.04 & 5.29 & 0.07 & -48 & 4 & \\
\hline 7138 & 2.81 & 0.04 & 5.44 & 0.07 & -60 & 4 & \\
\hline 7140 & 2.77 & 0.04 & 5.35 & 0.07 & -48 & 4 & \\
\hline 7142 & 2.84 & 0.04 & 5.48 & 0.07 & -51 & 4 & \\
\hline 7144 & 2.81 & 0.04 & 5.43 & 0.07 & -51 & 4 & \\
\hline 7179 & 2.78 & 0.04 & 5.37 & 0.07 & -48 & 4 & \\
\hline 7180 & 2.78 & 0.04 & 5.35 & 0.07 & -46 & 4 & \\
\hline 7184 & 2.77 & 0.04 & 5.35 & 0.07 & -54 & 4 & \\
\hline 7187 & 2.72 & 0.04 & 5.26 & 0.07 & -54 & 4 & \\
\hline 7189 & 2.75 & 0.04 & 5.31 & 0.07 & -46 & 4 & \\
\hline
\end{tabular}




\begin{tabular}{lllllll}
7191 & 2.82 & 0.04 & 5.45 & 0.07 & -53 & 4 \\
7192 & 2.76 & 0.04 & 5.35 & 0.07 & -60 & 4 \\
7200 & 2.72 & 0.04 & 5.24 & 0.07 & -50 & 4 \\
7201 & 2.78 & 0.04 & 5.36 & 0.07 & -48 & 4 \\
7203 & 2.77 & 0.04 & 5.36 & 0.07 & -54 & 4 \\
7205 & 2.78 & 0.04 & 5.38 & 0.07 & -53 & 4 \\
7207 & 2.70 & 0.04 & 5.23 & 0.07 & -55 & 4 \\
7209 & 2.77 & 0.04 & 5.34 & 0.07 & -51 & 4 \\
7211 & 2.82 & 0.04 & 5.43 & 0.07 & -44 & 4 \\
7212 & 2.76 & 0.04 & 5.34 & 0.07 & -57 & 4 \\
7242 & 2.74 & 0.04 & 5.30 & 0.07 & -52 & 4 \\
7243 & 2.74 & 0.04 & 5.30 & 0.07 & -49 & 4 \\
7245 & 2.75 & 0.04 & 5.31 & 0.07 & -49 & 4 \\
7247 & 2.74 & 0.04 & 5.29 & 0.07 & -48 & 4 \\
7249 & 2.70 & 0.04 & 5.22 & 0.07 & -57 & 4 \\
7252 & 2.71 & 0.04 & 5.24 & 0.07 & -49 & 4 \\
7253 & 2.80 & 0.04 & 5.41 & 0.07 & -55 & 4 \\
7254 & 2.76 & 0.04 & 5.33 & 0.07 & -52 & 4 \\
7279 & 2.72 & 0.04 & 5.26 & 0.07 & -54 & 4 \\
7281 & 2.73 & 0.04 & 5.28 & 0.07 & -51 & 4 \\
7284 & 2.72 & 0.04 & 5.26 & 0.07 & -49 & 4 \\
7286 & 2.74 & 0.04 & 5.30 & 0.07 & -53 & 4 \\
7288 & 2.69 & 0.04 & 5.21 & 0.07 & -52 & 4 \\
7290 & 2.75 & 0.04 & 5.32 & 0.07 & -52 & 4 \\
7292 & 2.78 & 0.04 & 5.37 & 0.07 & -50 & 4 \\
7293 & 2.74 & 0.04 & 5.30 & 0.07 & -50 & 4 \\
Average & $\mathbf{2 . 7 7}$ & $\mathbf{0 . 0 0}$ & $\mathbf{5 . 3 4}$ & $\mathbf{0 . 0 1}$ & $\mathbf{- 5 1}$ & $\mathbf{0}$ \\
\hline
\end{tabular}


A Supplementary information: High-precision triple oxygen isotope measurements of silicates

Table A.3: Oxygen isotope data of UWG-2 garnet fraction \#180 $(N=15)$ measured in sessions together with San Carlos olivine.

\begin{tabular}{cccccccc}
\hline ID & $\begin{array}{l}\delta^{17} \mathrm{O} \\
(\% o)\end{array}$ & $\pm 1 \sigma$ & $\begin{array}{l}\delta^{18} \mathrm{O} \\
(\% \circ)\end{array}$ & $\pm 1 \sigma$ & $\begin{array}{l}\Delta^{\prime 17} \mathrm{O} \\
(\mathrm{ppm})\end{array}$ & $\pm 1 \sigma$ & Outlier \\
\hline 5308 & 2.98 & 0.02 & 5.77 & 0.03 & -66 & 8 & \\
5315 & 3.00 & 0.02 & 5.79 & 0.03 & -51 & 8 & \\
5321 & 2.94 & 0.02 & 5.70 & 0.03 & -62 & 8 & \\
5324 & 2.96 & 0.02 & 5.74 & 0.03 & -63 & 8 & \\
5329 & 2.98 & 0.02 & 5.75 & 0.03 & -50 & 8 & \\
5333 & 2.96 & 0.02 & 5.76 & 0.03 & -75 & 8 & \\
5335 & 2.97 & 0.02 & 5.74 & 0.03 & -56 & 8 & \\
5418 & 3.02 & 0.11 & 5.84 & 0.09 & -61 & 6 & \\
5443 & 2.93 & 0.11 & 5.66 & 0.09 & -54 & 6 & \\
5466 & 2.97 & 0.11 & 5.75 & 0.09 & -60 & 6 & \\
5575 & 2.96 & 0.11 & 5.75 & 0.09 & -67 & 6 & \\
5613 & 2.97 & 0.11 & 5.75 & 0.09 & -62 & 6 & \\
5681 & 2.97 & 0.11 & 5.75 & 0.09 & -58 & 6 & \\
5809 & 2.97 & 0.11 & 5.75 & 0.09 & -64 & 6 & \\
5885 & 2.98 & 0.11 & 5.75 & 0.09 & -48 & 6 & \\
Average & $\mathbf{2 . 9 7}$ & $\mathbf{0 . 0 1}$ & $\mathbf{5 . 7 5}$ & $\mathbf{0 . 0 1}$ & $\mathbf{- 6 0}$ & $\mathbf{2}$ & $\mathbf{1}$ \\
\hline
\end{tabular}

Table A.4: Oxygen isotope data of UWG-2 garnet fraction \#200 $(N=36)$ measured in sessions together with San Carlos olivine.

\begin{tabular}{|c|c|c|c|c|c|c|c|}
\hline ID & $\begin{array}{l}\delta^{17} \mathrm{O} \\
(\% \circ)\end{array}$ & $\pm 1 \sigma$ & $\begin{array}{l}\delta^{18} \mathrm{O} \\
(\% o)\end{array}$ & $\pm 1 \sigma$ & $\begin{array}{l}\Delta^{\prime 17} \mathrm{O} \\
(\mathrm{ppm})\end{array}$ & $\pm 1 \sigma$ & Outlier \\
\hline 6490 & 2.99 & 0.03 & 5.80 & 0.05 & -68 & 9 & \\
\hline 6492 & 3.02 & 0.03 & 5.84 & 0.05 & -59 & 9 & \\
\hline 6496 & 2.98 & 0.03 & 5.76 & 0.05 & -59 & 9 & \\
\hline 6512 & 2.96 & 0.03 & 5.72 & 0.05 & -61 & 9 & \\
\hline 6513 & 2.95 & 0.03 & 5.71 & 0.05 & -60 & 9 & \\
\hline 6514 & 2.95 & 0.03 & 5.67 & 0.05 & -38 & 9 & \\
\hline 6535 & 2.99 & 0.03 & 5.77 & 0.05 & -53 & 9 & \\
\hline 6539 & 3.00 & 0.03 & 5.79 & 0.05 & -52 & 9 & \\
\hline 6546 & 2.95 & 0.03 & 5.72 & 0.05 & -70 & 9 & \\
\hline 6549 & 2.97 & 0.03 & 5.75 & 0.05 & -59 & 9 & \\
\hline 6564 & 2.97 & 0.03 & 5.72 & 0.05 & -51 & 9 & \\
\hline 6618 & 2.91 & 0.04 & 5.64 & 0.07 & -58 & 5 & \\
\hline 6623 & 3.03 & 0.04 & 5.86 & 0.07 & -63 & 5 & \\
\hline 6634 & 3.01 & 0.04 & 5.84 & 0.07 & -69 & 5 & \\
\hline 6638 & 2.91 & 0.04 & 5.66 & 0.07 & -69 & 5 & \\
\hline 6647 & 2.97 & 0.04 & 5.73 & 0.07 & -54 & 5 & \\
\hline 6651 & 2.98 & 0.04 & 5.77 & 0.07 & -66 & 5 & \\
\hline 6685 & 3.01 & 0.04 & 5.82 & 0.07 & -57 & 5 & \\
\hline 6689 & 2.95 & 0.04 & 5.70 & 0.07 & -60 & 5 & \\
\hline 6693 & 2.96 & 0.04 & 5.73 & 0.07 & -64 & 5 & \\
\hline 6725 & 3.00 & 0.04 & 5.80 & 0.07 & -61 & 5 & \\
\hline 6728 & 2.96 & 0.04 & 5.72 & 0.07 & -55 & 5 & \\
\hline 6736 & 2.96 & 0.04 & 5.74 & 0.07 & -65 & 5 & \\
\hline 6904 & 2.98 & 0.03 & 5.77 & 0.05 & -60 & 9 & \\
\hline 6906 & 2.94 & 0.03 & 5.69 & 0.05 & -62 & 9 & \\
\hline 6911 & 2.99 & 0.03 & 5.79 & 0.05 & -68 & 9 & \\
\hline 6919 & 2.98 & 0.04 & 5.78 & 0.07 & -65 & 4 & \\
\hline 6925 & 2.96 & 0.04 & 5.72 & 0.07 & -57 & 4 & \\
\hline 6941 & 2.98 & 0.04 & 5.75 & 0.07 & -55 & 4 & \\
\hline 6992 & 2.98 & 0.04 & 5.75 & 0.07 & -48 & 4 & \\
\hline 7017 & 2.97 & 0.04 & 5.75 & 0.07 & -62 & 4 & \\
\hline 7131 & 2.97 & 0.04 & 5.75 & 0.07 & -59 & 4 & \\
\hline 7178 & 2.97 & 0.04 & 5.75 & 0.07 & -66 & 4 & \\
\hline 7199 & 2.97 & 0.04 & 5.75 & 0.07 & -57 & 4 & \\
\hline 7241 & 2.97 & 0.04 & 5.75 & 0.07 & -57 & 4 & \\
\hline 7278 & 2.97 & 0.04 & 5.75 & 0.07 & -66 & 4 & \\
\hline Average & 2.97 & 0.00 & 5.75 & 0.01 & -60 & 1 & 5 \\
\hline
\end{tabular}




\section{B Supplementary information: Triple oxygen isotope fractionation in feldspar-rich rocks}

\section{B.1 Analytical methods}

We conducted oxygen isotope measurements on mineral separates by means of laser fluorination in combination with a dual-inlet gas source isotope ratio mass spectrometry (IRMS; Sharp 1990). The rocks were crushed using a steel mortar and material was sieved in different grain size fractions. The mineral separates were prepared from the $0.5-0.25 \mathrm{~mm}$ or the $0.25-0.125 \mathrm{~mm}$ fraction. The grains were all inspected by microscopy to make sure only clear, unweathered grains were analysed. The masses of the analysed grains was adjusted so that $30 \mu \mathrm{mol} \mathrm{O}_{2}$ was released for samples and standards. This corresponds to sample masses in the range of $2 \mathrm{mg}$. Samples were fluorinated at $\mathrm{BrF}_{5}$ pressures of 100 mbar. The sample $\mathrm{O}_{2}$ was purified using cold traps $\left(-196^{\circ} \mathrm{C}\right)$, heated $\mathrm{NaCl}\left(190^{\circ} \mathrm{C}\right)$ for $\mathrm{F}_{2}$ removal, and gas chromatography $\left(10 \mathrm{~m}, 5 \AA 1 / 8^{\prime}\right.$ " packed molecular sieve column, $10 \mathrm{ml} \mathrm{min}^{-1} \mathrm{He}$ flow) for further cleaning. We routinely scanned the sample gas composition between the masses 11-100 amu to check for gas contamination. An in-line thermal conductivity detector was used for the yield determination. An air lock system was connected to the $\mathrm{BrF}_{5}$ line to use small 2-pit sample holders. Using this analytical setup we can avoid the contact between feldspar samples and $\mathrm{BrF}_{5}$ during an analytical session until the fluorination of these samples is intended. The air lock system was used for most of the measurements. For the other measurements an equivalently precise and accurate alternative was used, the conventional system in combination with pre-melting (see chapter 4.5).

The triple oxygen isotope ratios $\left({ }^{17} \mathrm{O} /{ }^{16} \mathrm{O},{ }^{18} \mathrm{O} /{ }^{16} \mathrm{O}\right)$ were determined using a Thermo Scientific ${ }^{T M}$ MAT $253^{T M}$ and a Thermo Scientific ${ }^{T M} 253$ Plus $^{T M}$ 10kV IRMS. 20-60 cycles were analysed for each measurement with an integration time of $26 \mathrm{~s}$ and an idle time of $15 \mathrm{~s}$. The target signal intensity on mass 32 was adjusted to $5000-5500 \mathrm{mV}$. The calculation of $\Delta^{\prime 17} \mathrm{O}$ is based on $\delta^{17} \mathrm{O}$ and $\delta^{18} \mathrm{O}$ values reported relative to VSMOW scale (see also Sharp and Wostbrock 2021). The $\delta^{18} \mathrm{O}_{\text {raw }}$ and the $\Delta^{17} \mathrm{O}_{\text {raw }}$ of the samples were normalised to the measured values of the standards of each analytical session. We analysed the following standards: San Carlos olivine and UWG-2 garnet (Valley et al. 1995). Two different fractions of San Carlos olivine were used as standard materials for this study (SC 0215M: table B.10 and SC 0919: table B.11) with different $\delta^{18} \mathrm{O}$ values $(5.18 \%$ o and $5.34 \%$ ) and an identical $\Delta^{\prime 17} \mathrm{O}$ of $-52 \mathrm{ppm}$ (mean value of Pack et al. 2016, Sharp 
B Supplementary information: Triple oxygen isotope fractionation in feldspar-rich rocks

et al. 2016, Wostbrock et al. 2020). UWG-2 garnet (\#180 and \#200: table B.12) was also analysed with a $\delta^{18} \mathrm{O}=5.75 \%$ and a $\Delta^{\prime 17} \mathrm{O}=-60 \mathrm{ppm}$.

The external reproducibility $( \pm 1 \sigma)$ for a single oxygen isotope measurement was estimated based on the San Carlos olivine fractions $(N=34), 0.09 \%$ for $\delta^{18} \mathrm{O}$ and $7 \mathrm{ppm}$ for $\Delta^{\prime 17} \mathrm{O}$. Every mineral specimen was analysed 3-10 times, resulting in an uncertainty for the samples of typically $0.03-0.04 \%$ in $\delta^{18} \mathrm{O}$ and $2-4 \mathrm{ppm}$ in $\Delta^{\prime 17} \mathrm{O}$. We discarded measurements with gas extraction yields $<80 \%$. The uncertainty of the yield calculation is $\pm 3 \%$. 


\section{B.2 Additional figures}

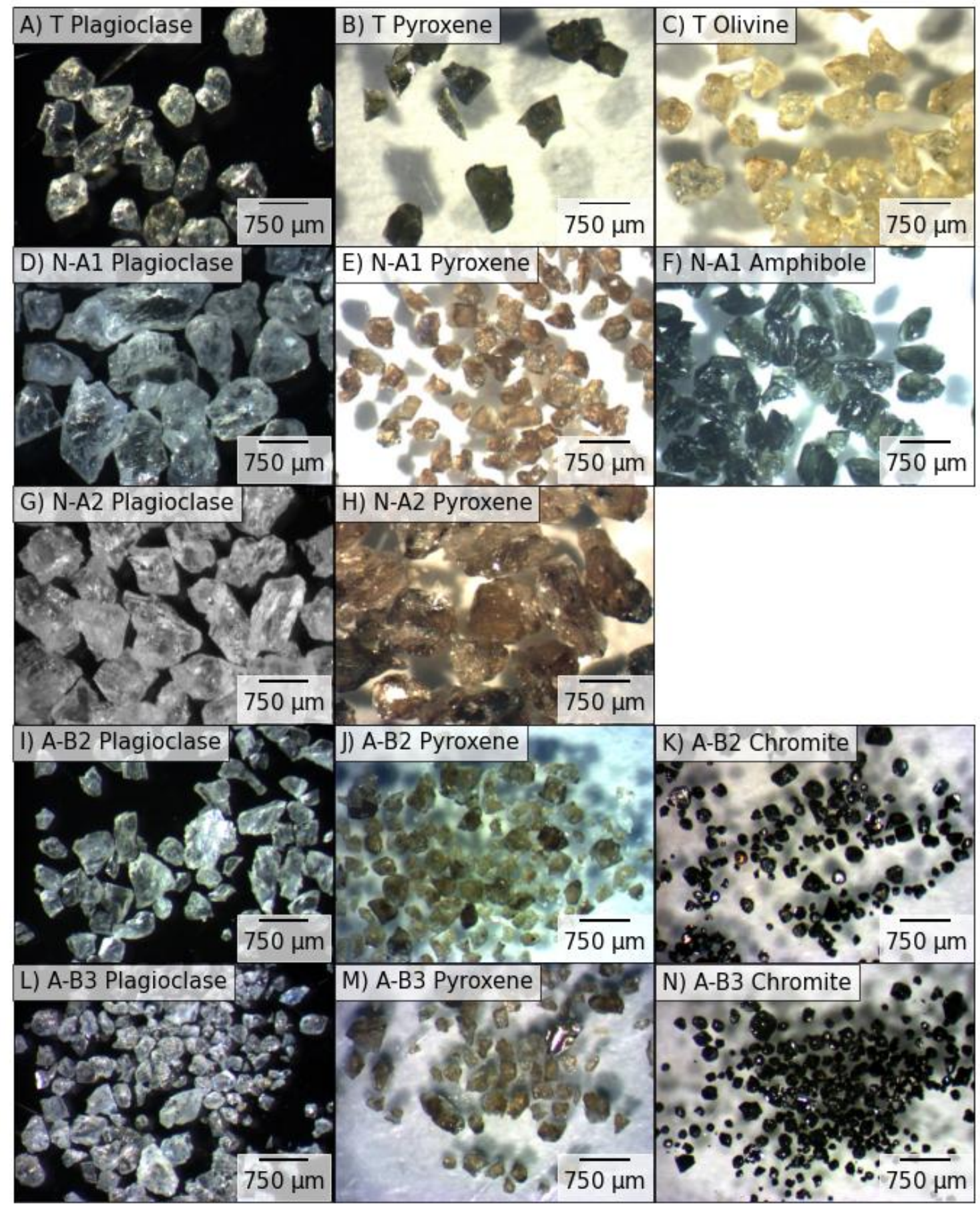

Figure B.1: Images of the mineral separates of the troctolite (T; A-C), norite A1 (N-A1; D-F), norite A2 (N-A2; G-H), anorthosite B2 (A-B2; I-K) and anorthosite B3 (A-B3; L-N). 
B Supplementary information: Triple oxygen isotope fractionation in feldspar-rich rocks

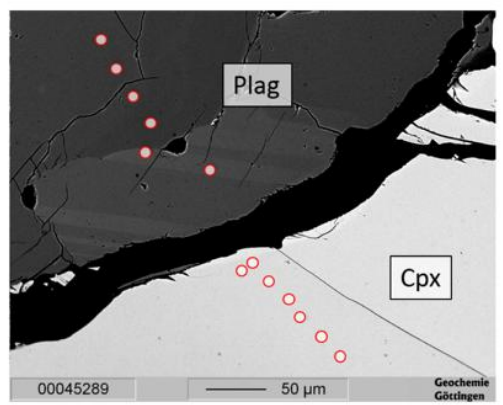

A) Line profile: Clinopyroxene-Plagioclase (1)

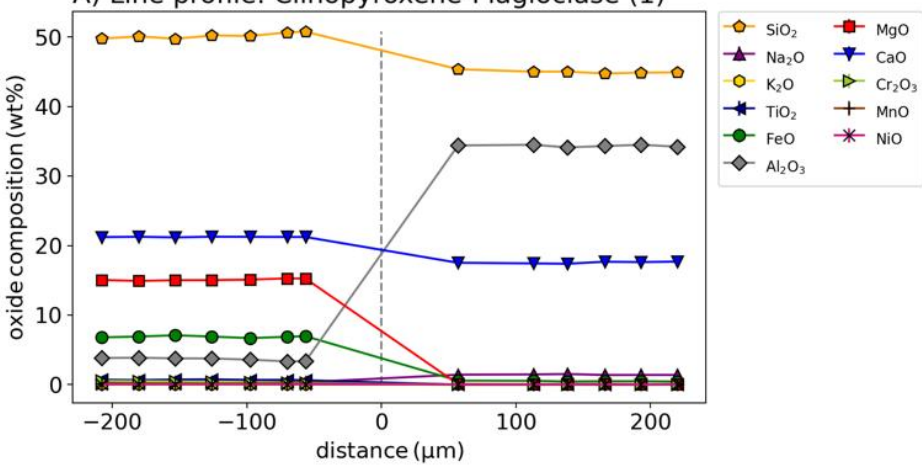

B) Line profile: Plagioclase-Clinopyroxene (2)
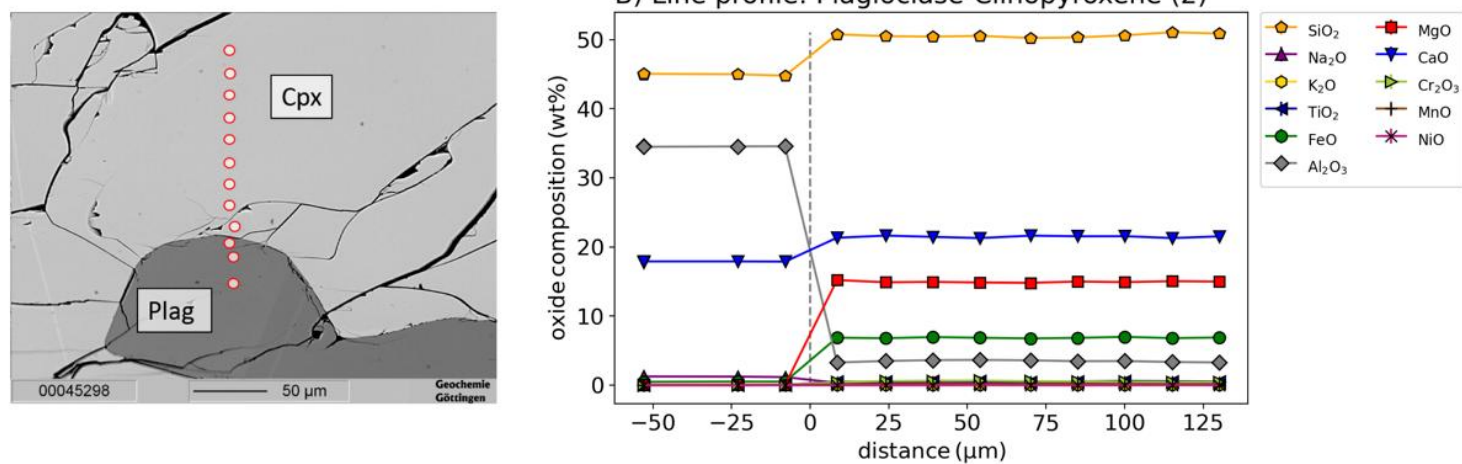

C) Line profile: Plagioclase-Olivine (1)
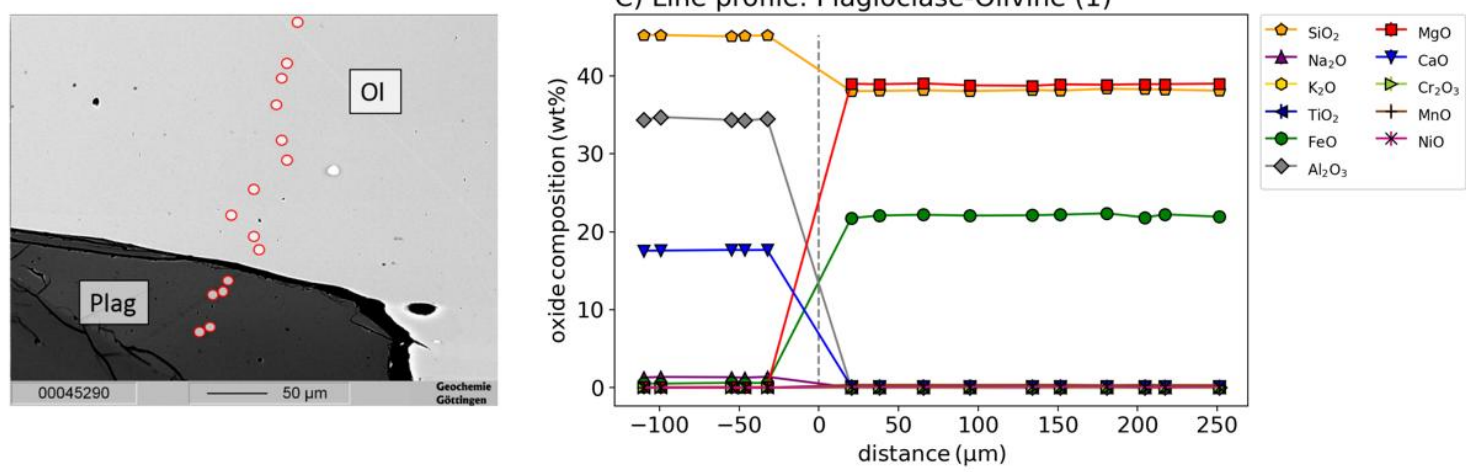

D) Line profile: Olivine-Plagioclase (2)
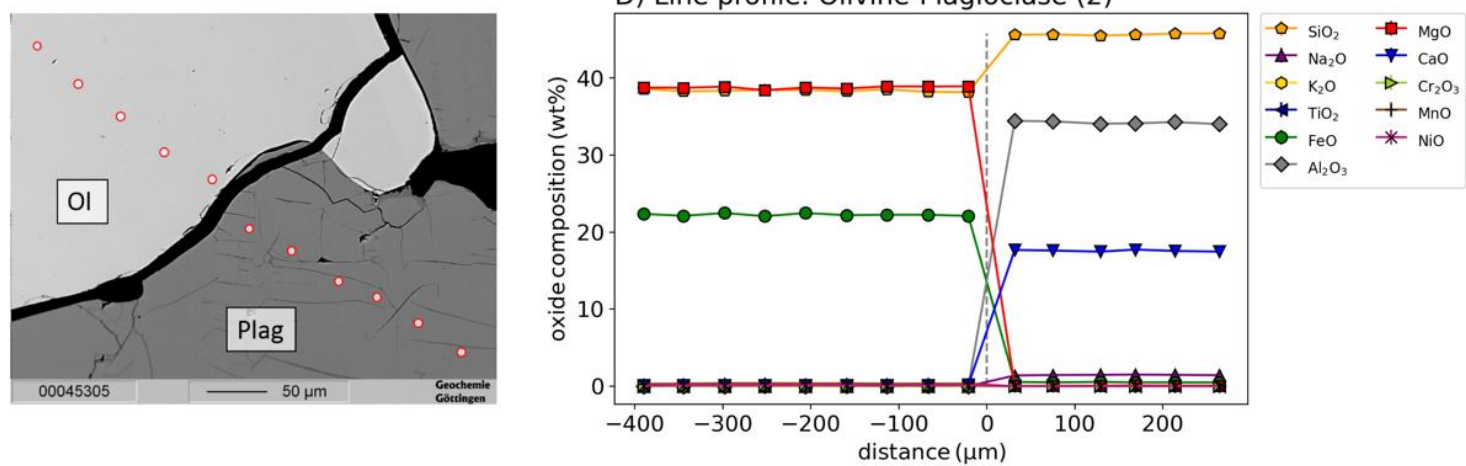


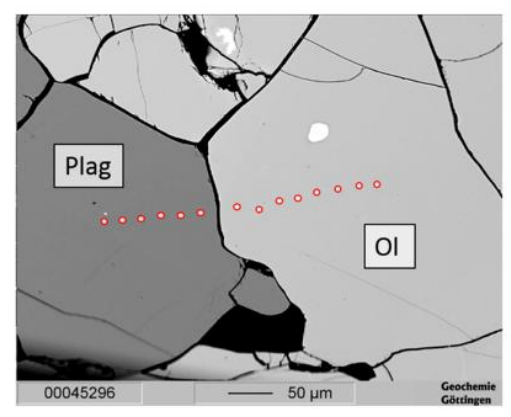

E) Line profile: Plagioclase-Olivine (3)
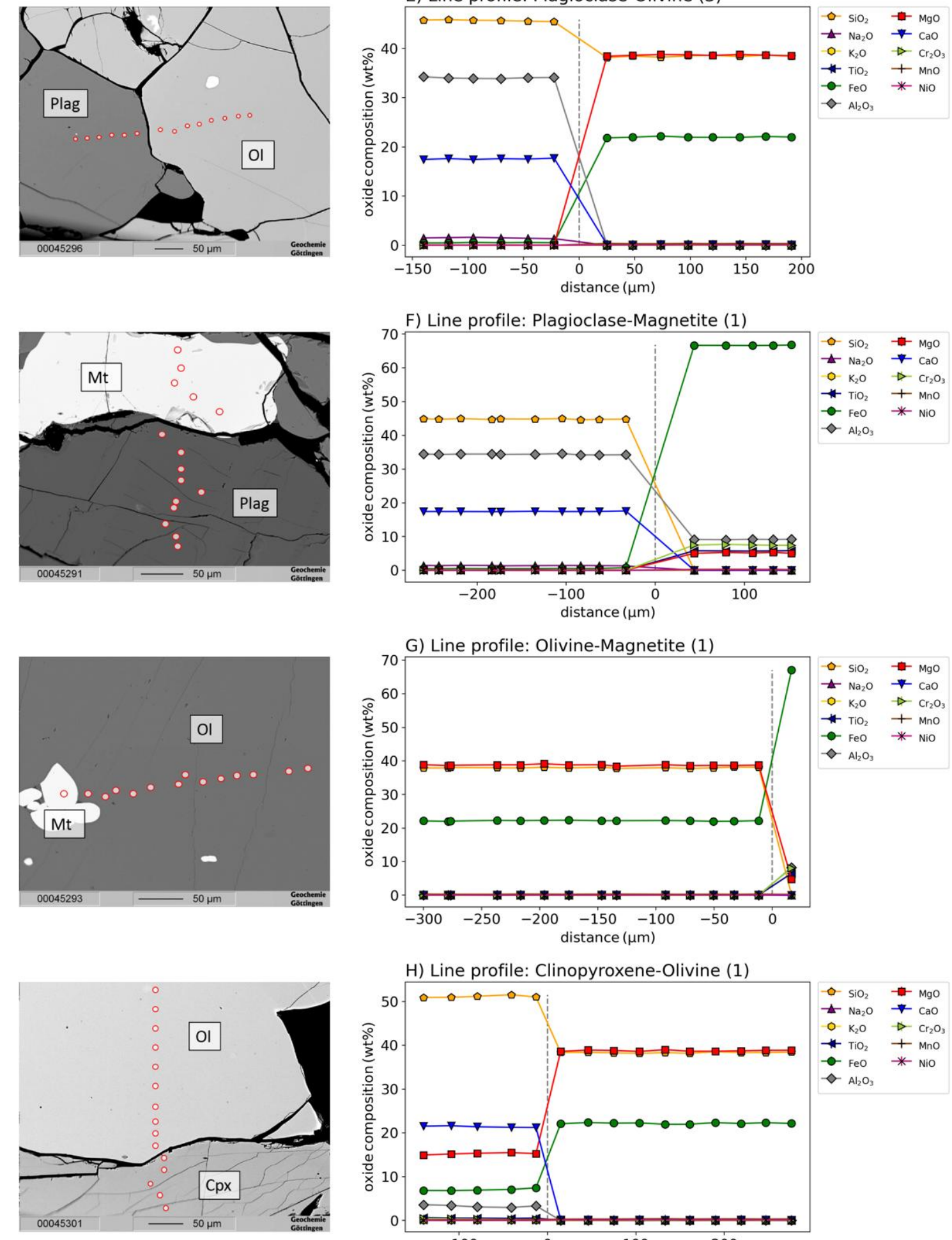

H) Line profile: Clinopyroxene-Olivine (1)

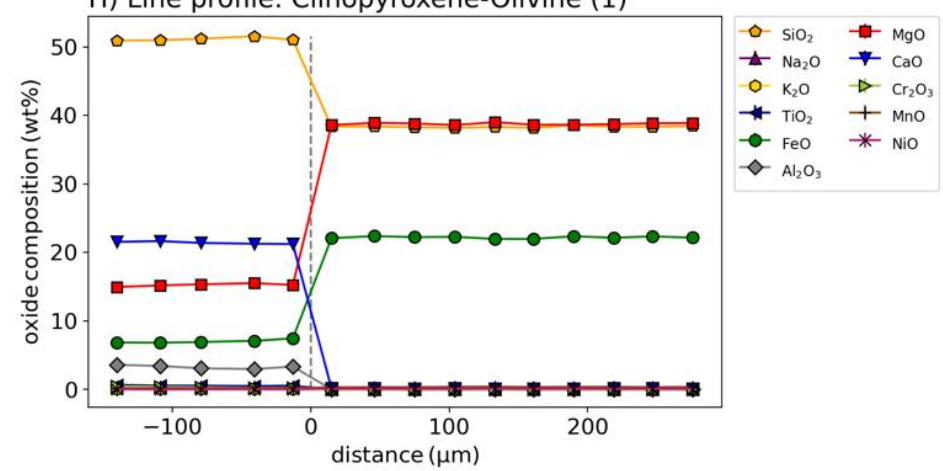




\section{B Supplementary information: Triple oxygen isotope fractionation in feldspar-rich}

rocks
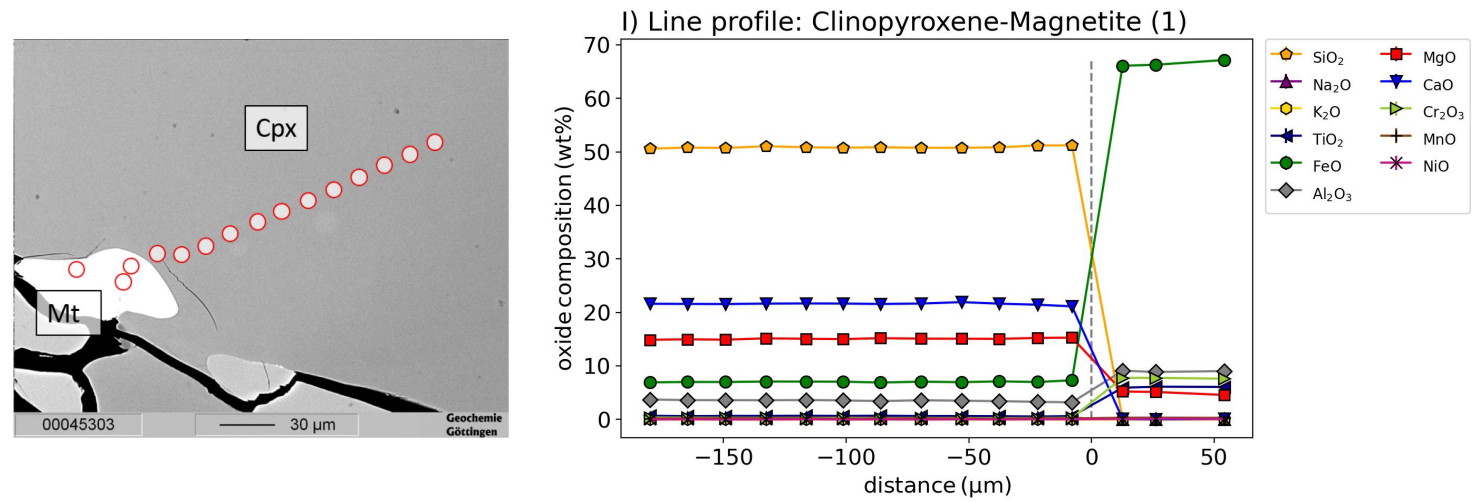

Figure B.2: Individual EMP line profiles (A-I) of the troctolite thin section. The position of each line profile is shown in a BSE image (left) and the oxide composition is plotted vs. the distance in a line plot (right). The following abbreviations were used: plagioclase (Plag), clinopyroxene ( $\mathrm{Cpx})$, olivine $(\mathrm{Ol})$, magnetite $(\mathrm{Mt})$. The corresponding data can be found in the digital appendix: EMPA-LineProfile-Data.xlsx.
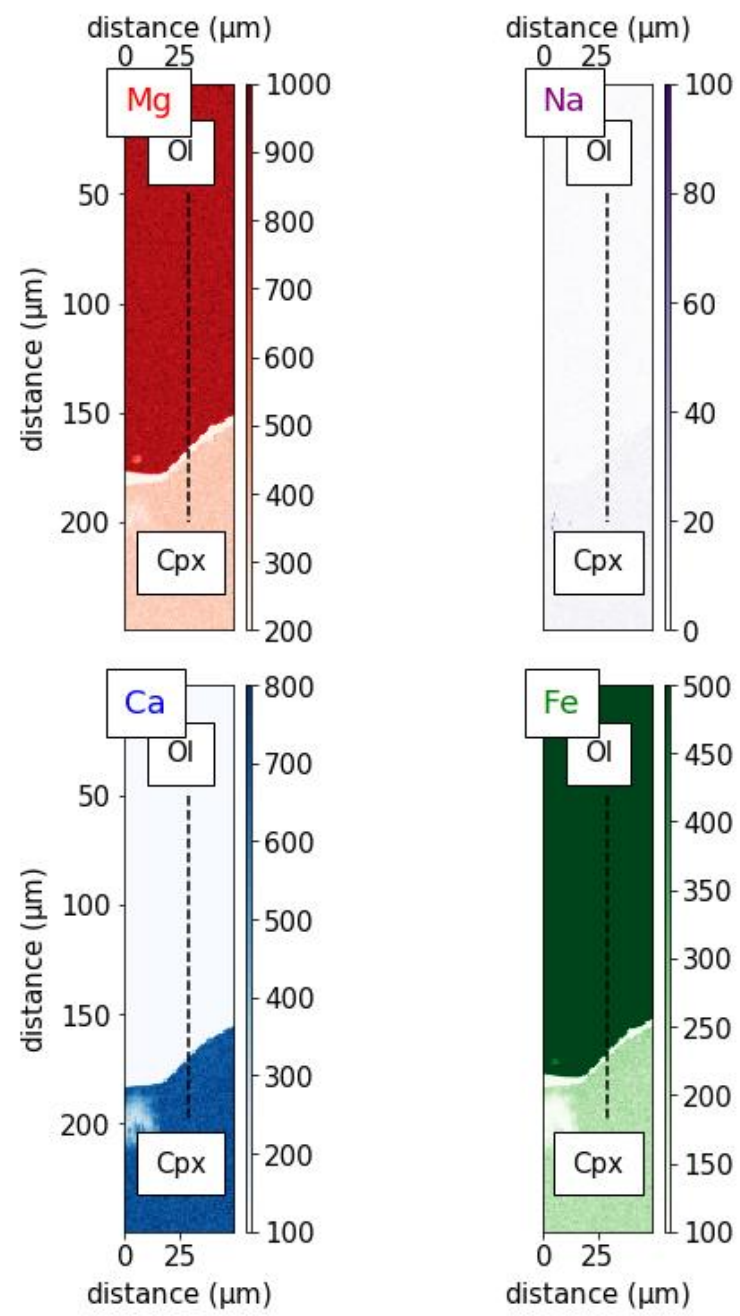

Figure B.3: Set of EMP element mappings covering an area of the troctolite thin section. The mappings show the $\mathrm{Mg}, \mathrm{Na}, \mathrm{Ca}$ and Fe levels in this area. The position of a corresponding line profile is illustrated as dotted line (profile B.2H). The following abbreviations were used: plagioclase (Plag), olivine (Ol). The corresponding ascii data can be found in the digital appendix: folder EMPA-ElementMaps. 

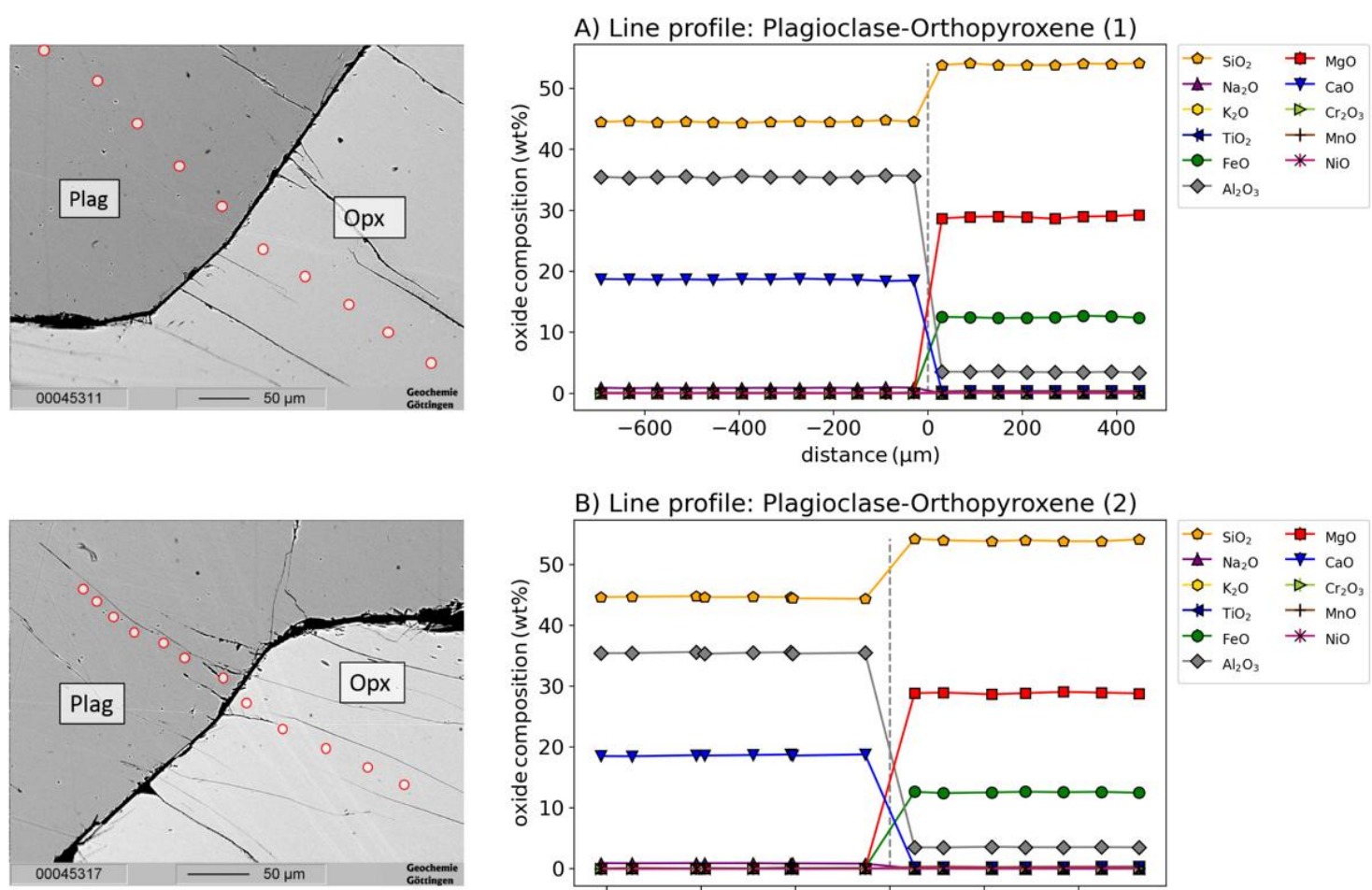

B) Line profile: Plagioclase-Orthopyroxene (2)

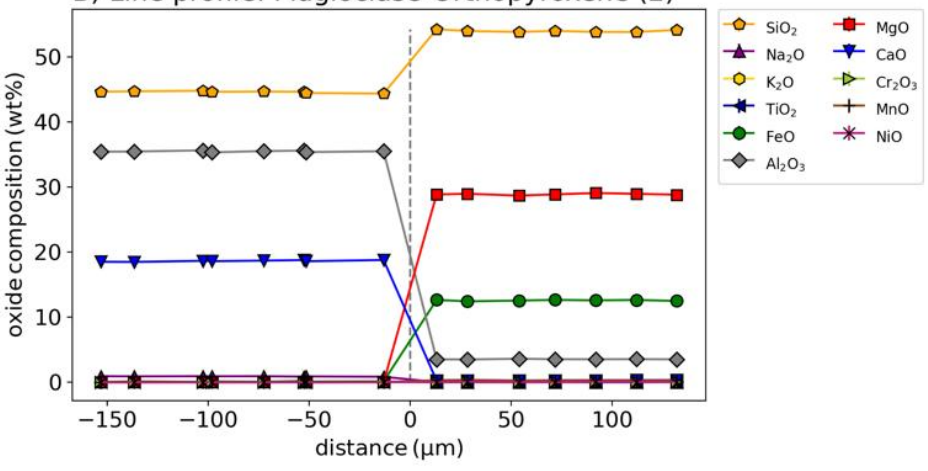

C) Line profile: Plagioclase-Orthopyroxene (3)
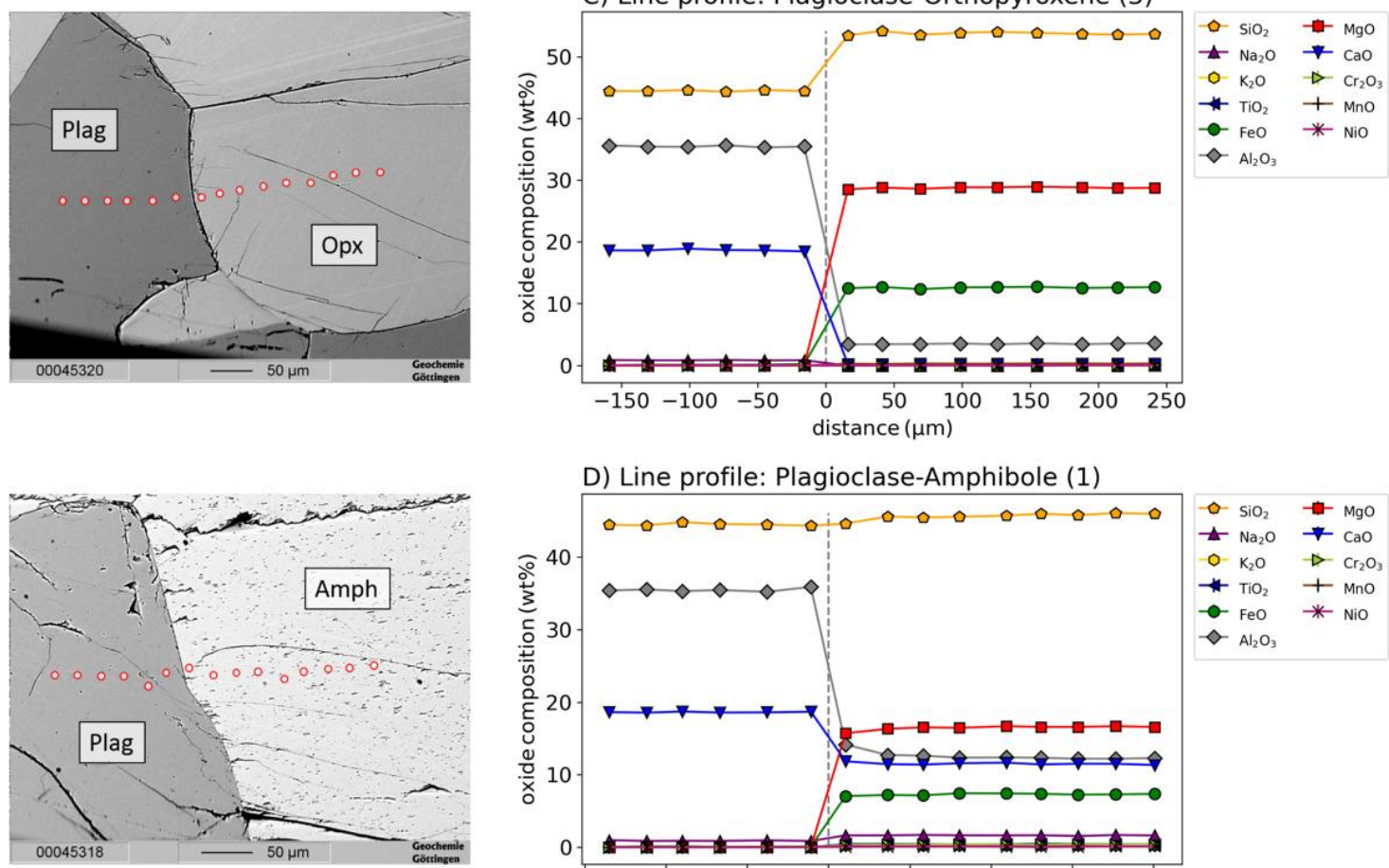

D) Line profile: Plagioclase-Amphibole (1)

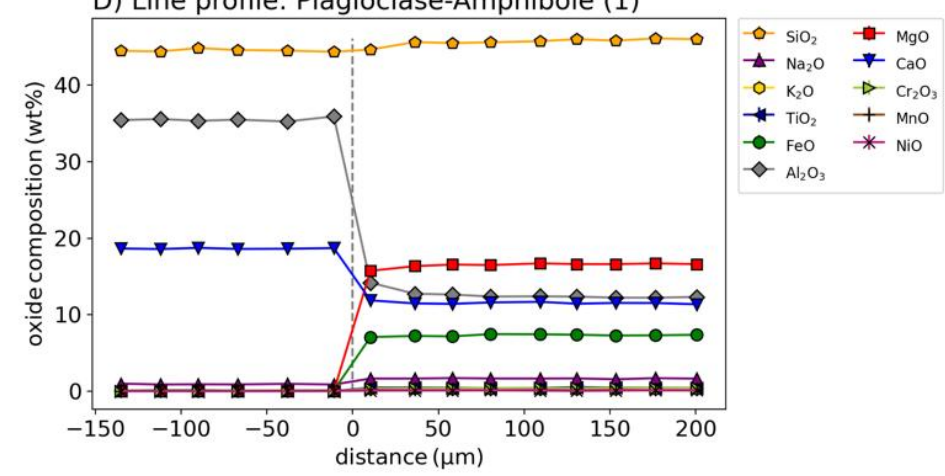


B Supplementary information: Triple oxygen isotope fractionation in feldspar-rich rocks

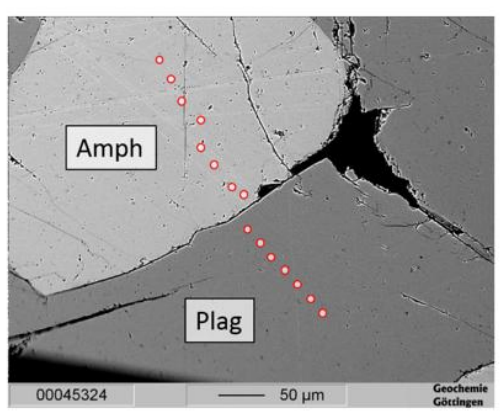

E) Line profile: Plagioclase-Amphibole (2)
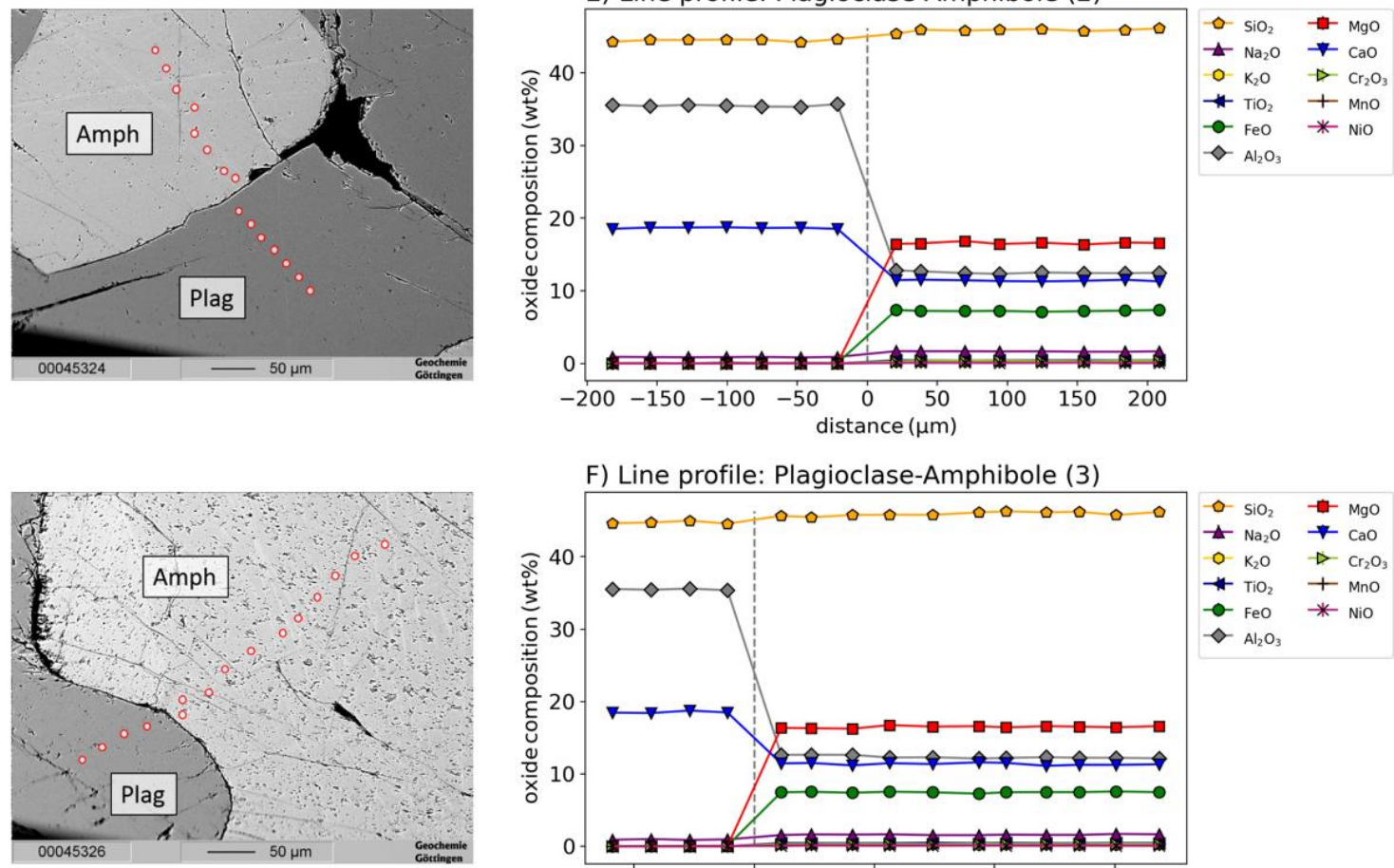

F) Line profile: Plagioclase-Amphibole (3)
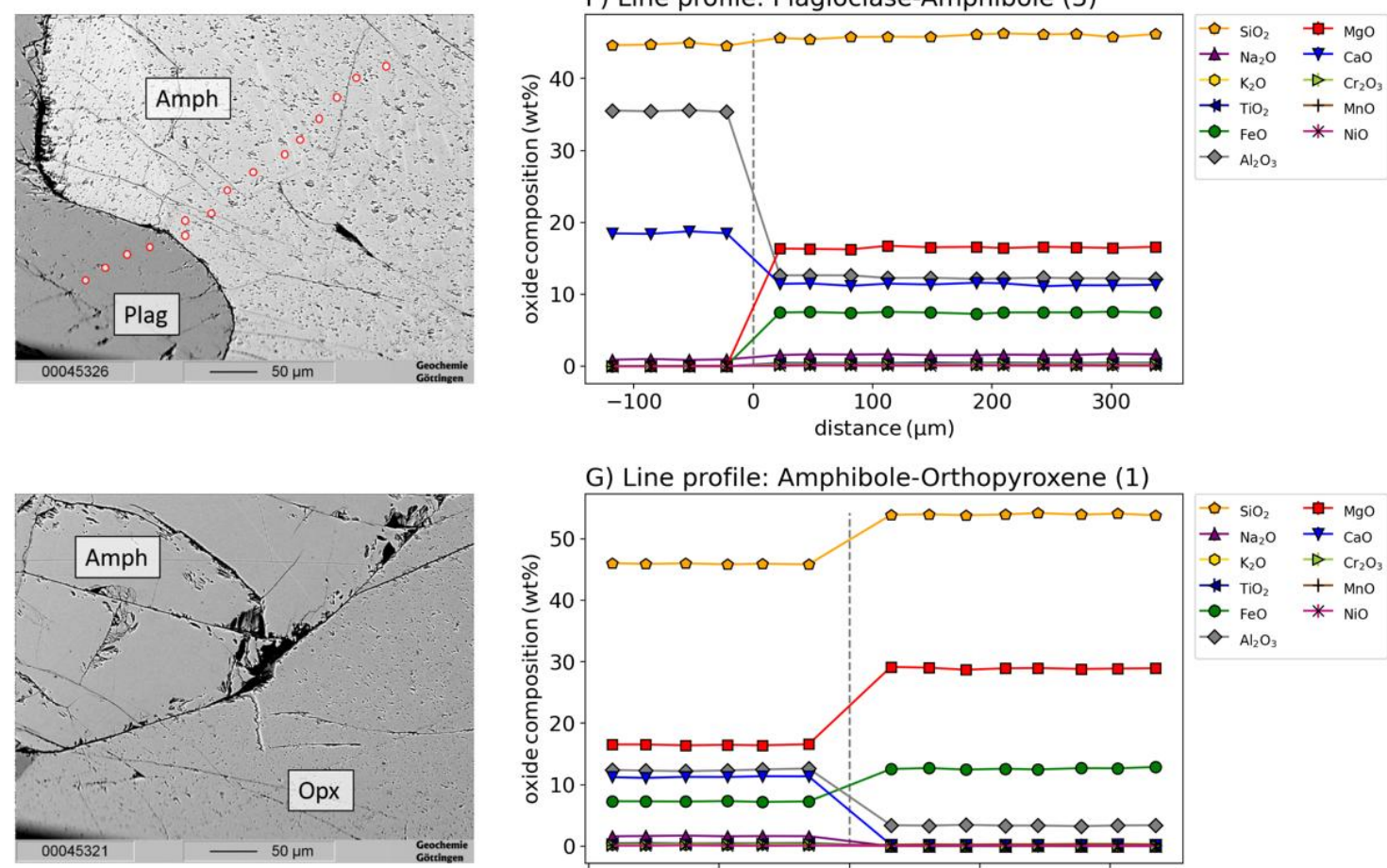

G) Line profile: Amphibole-Orthopyroxene (1)

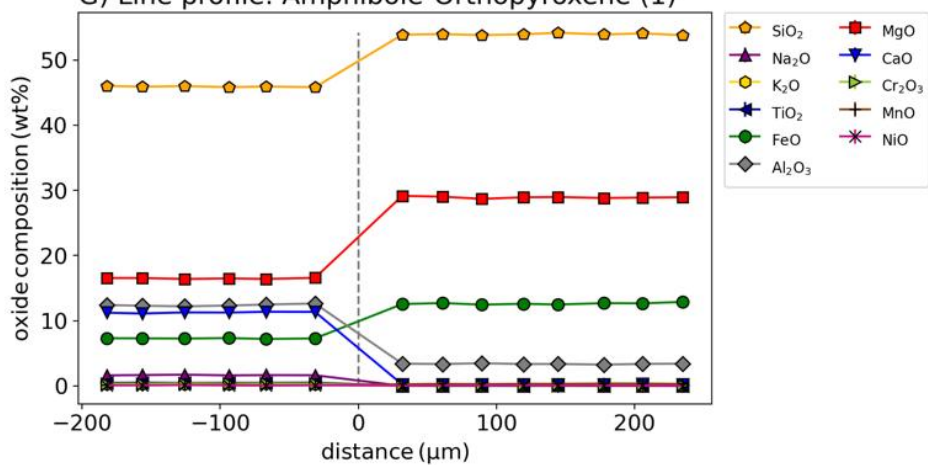

H) Line profile: Orthopyroxene-Amphibole (2)
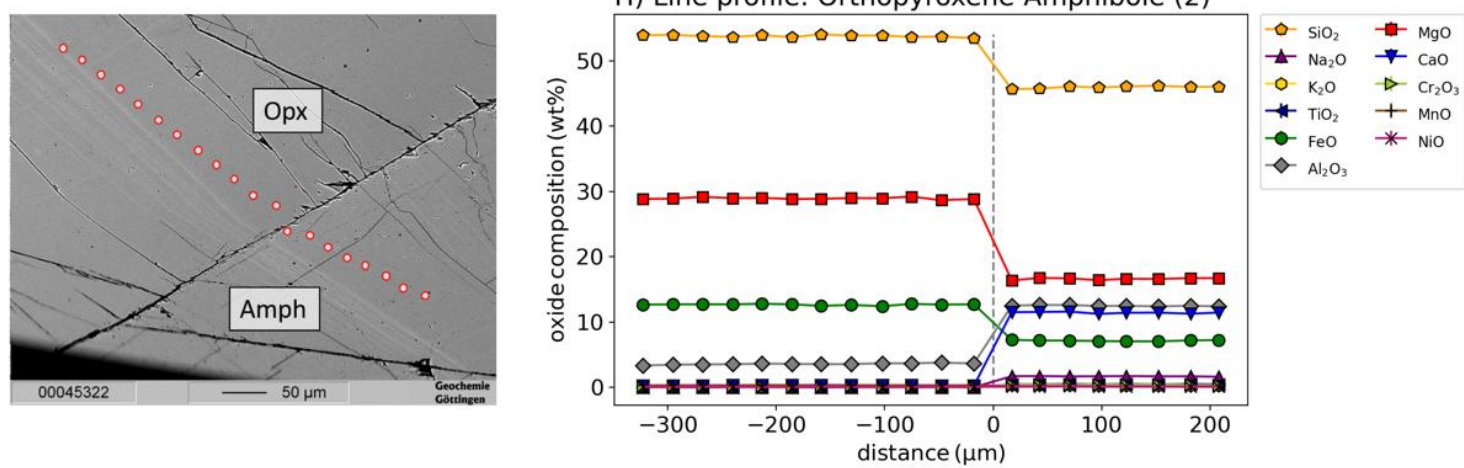

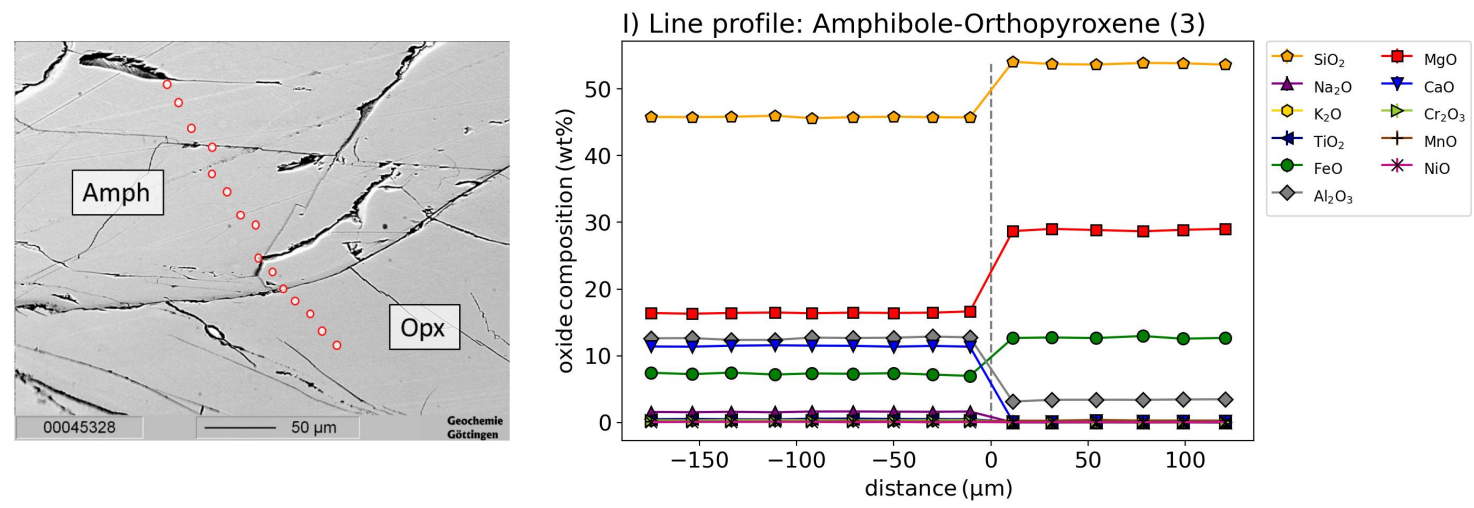

Figure B.4: Individual EMP line profiles (A-I) of the norite A1 thin section. The position of each line profile is shown in a BSE image (left) and the oxide composition is plotted vs. the distance in a line plot (right). The following abbreviations were used: plagioclase (Plag), orthopyroxene (Opx), amphibole (Amph). The corresponding data can be found in the digital appendix: EMPA-LineProfileData.xlsx.
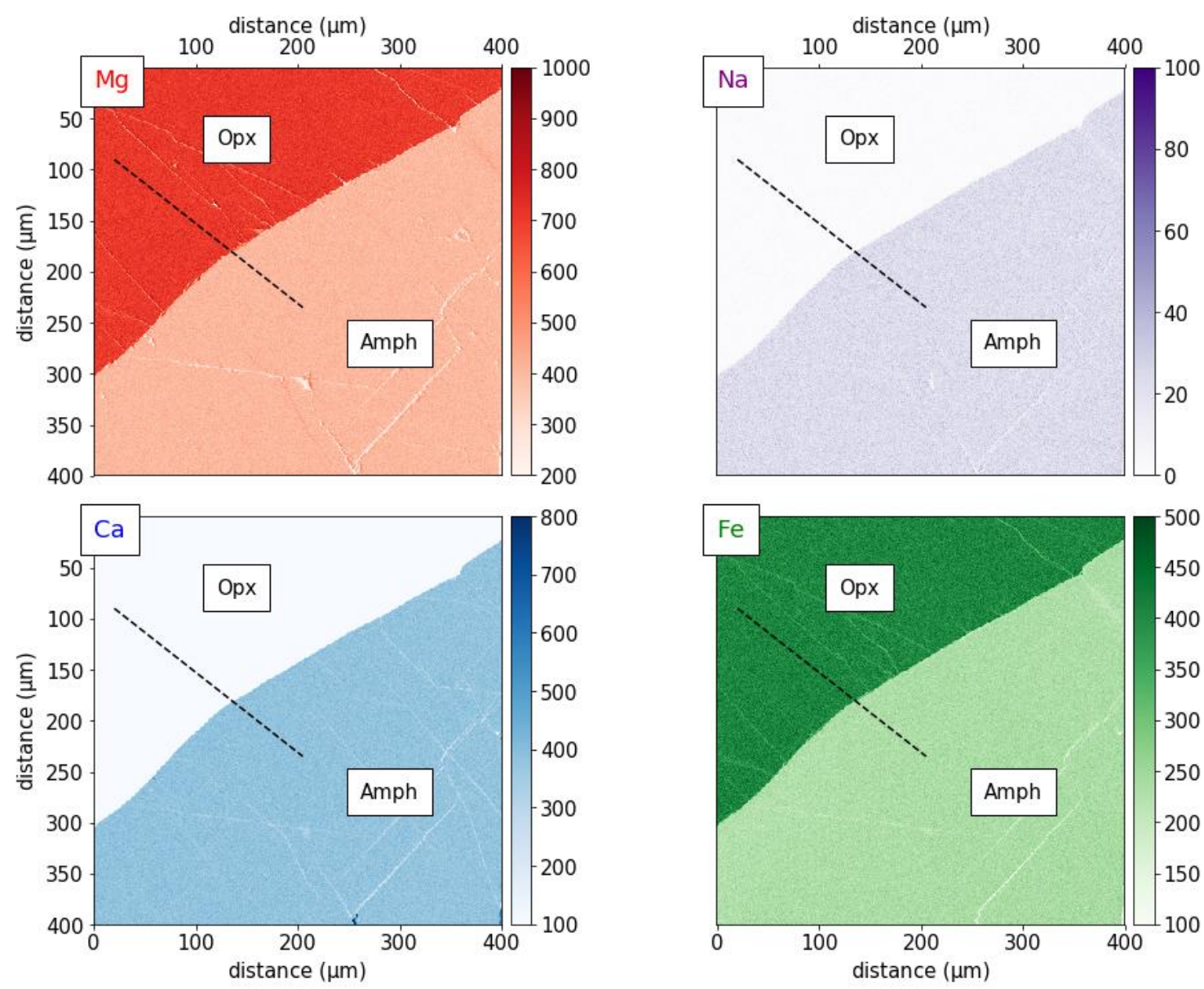

Figure B.5: Set of EMP element mappings covering an area of the norite A1 thin section. The mappings show the Mg, $\mathrm{Na}, \mathrm{Ca}$ and Fe levels in this area. The position of a corresponding line profile is illustrated as dotted line (profile B.4H). The following abbreviations were used: orthopyroxene (Opx), amphibole (Amph). The corresponding ascii data can be found in the digital appendix: folder EMPA-ElementMaps. 


\section{B Supplementary information: Triple oxygen isotope fractionation in feldspar-rich}

rocks
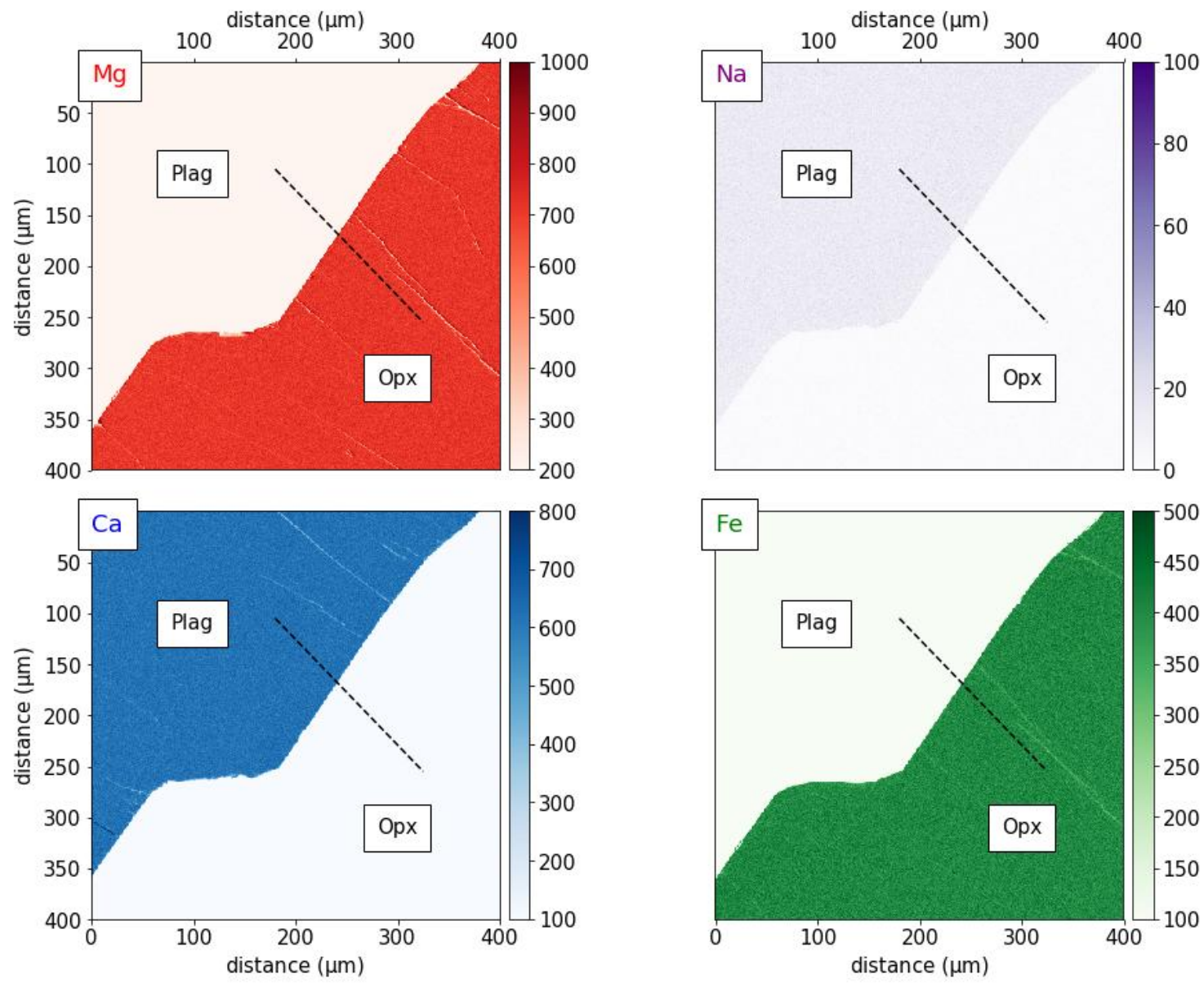

Figure B.6: Set of EMP element mappings covering an area of the norite A1 thin section. The mappings show the $\mathrm{Mg}, \mathrm{Na}, \mathrm{Ca}$ and Fe levels in this area. The position of a corresponding line profile is illustrated as dotted line (profile B.4A). The following abbreviations were used: plagioclase (Plag), orthopyroxene (Opx). The corresponding ascii data can be found in the digital appendix: folder EMPA-ElementMaps. 

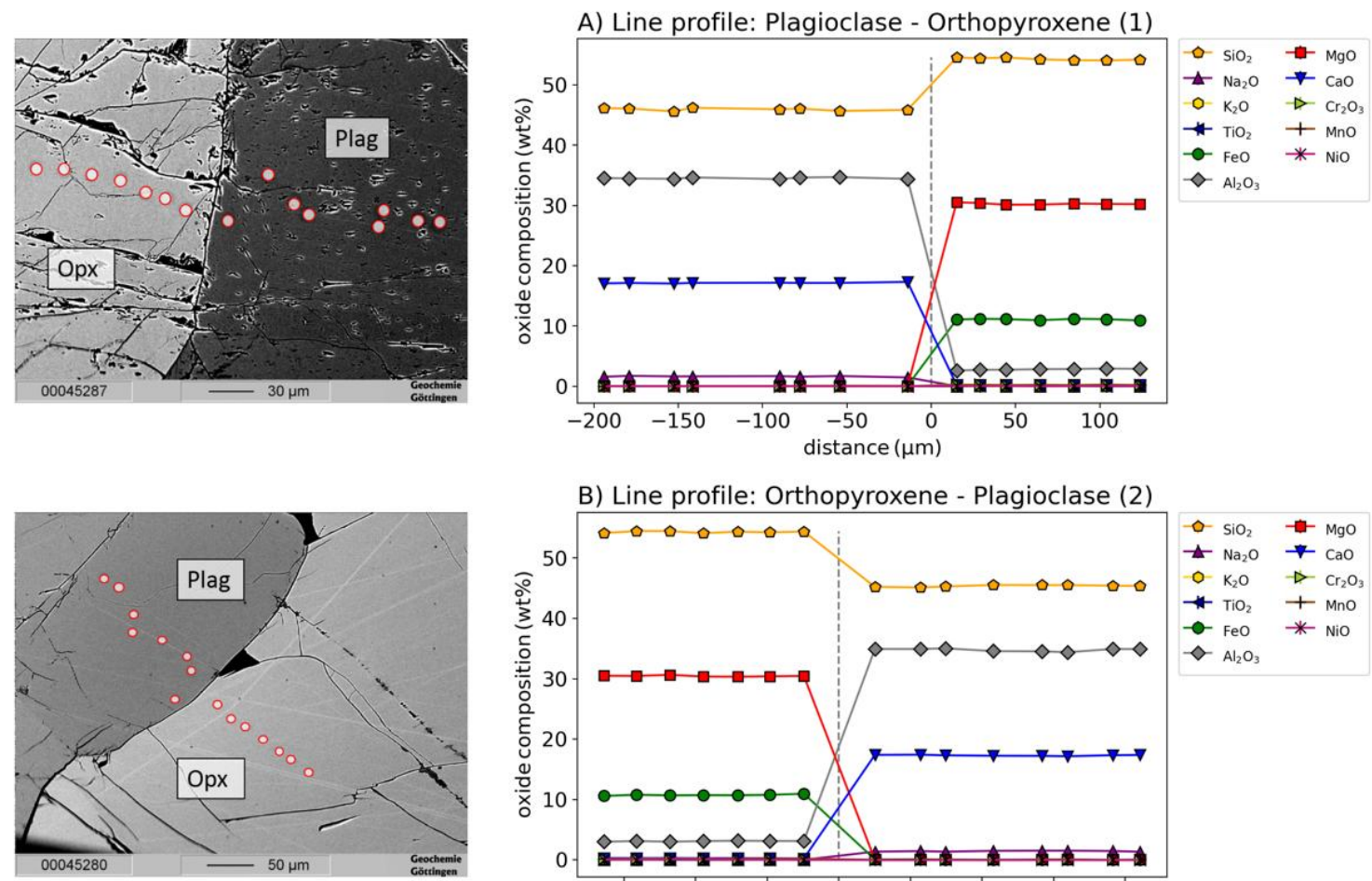

B) Line profile: Orthopyroxene - Plagioclase (2)

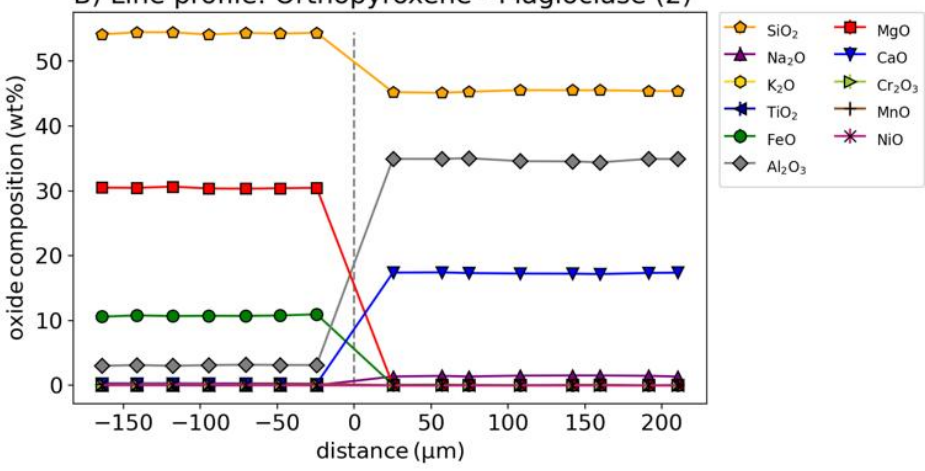

C) Line profile: Orthopyroxene - Plagioclase (3)
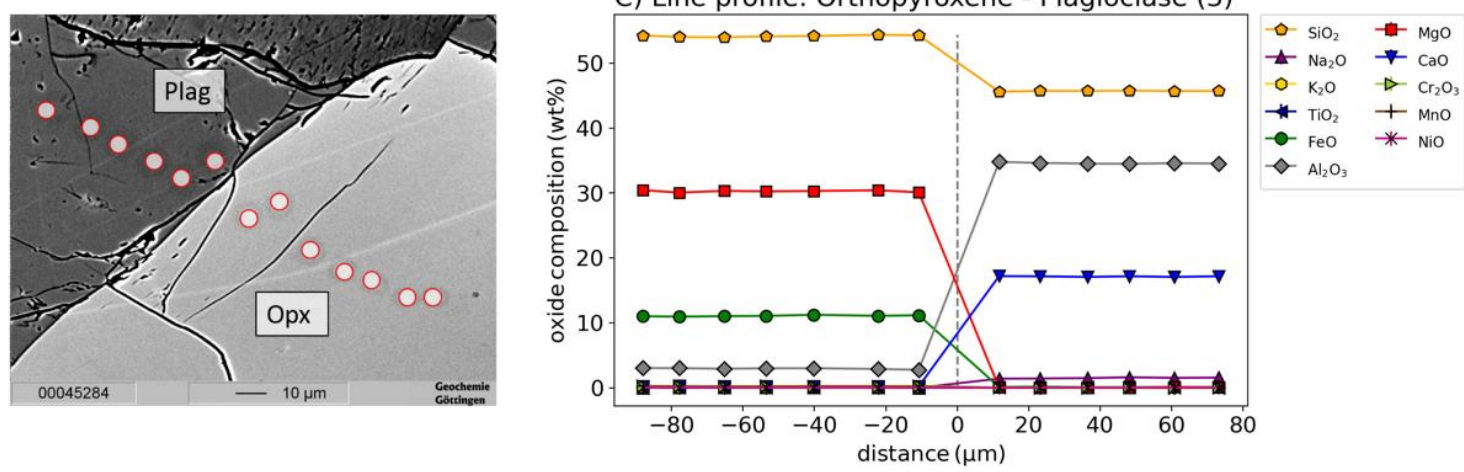

D) Line profile: Plagioclase - Biotite (1)
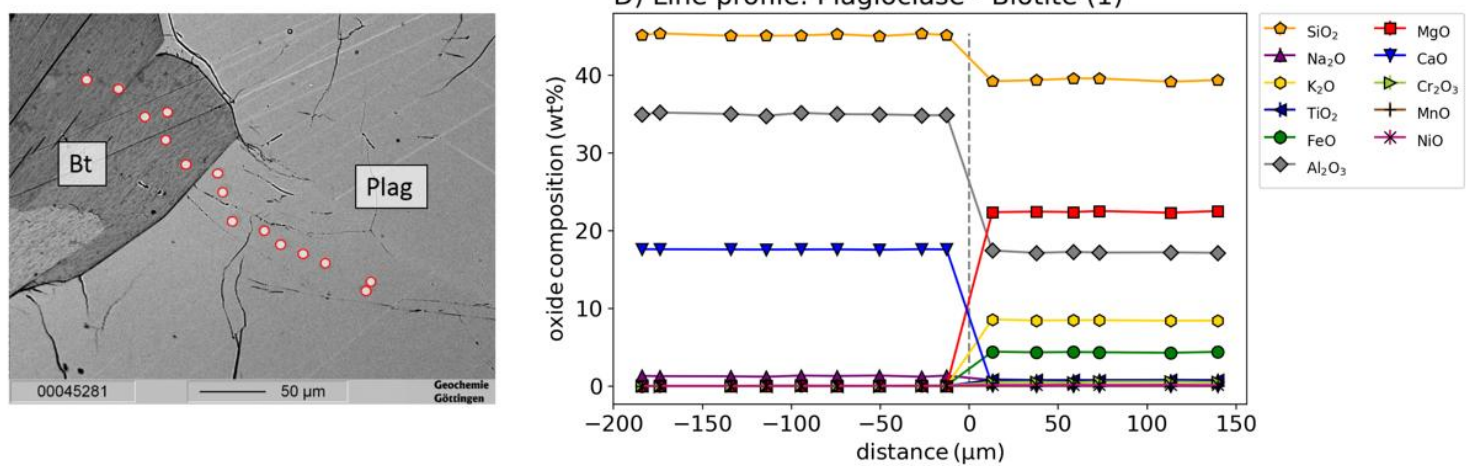
B Supplementary information: Triple oxygen isotope fractionation in feldspar-rich rocks

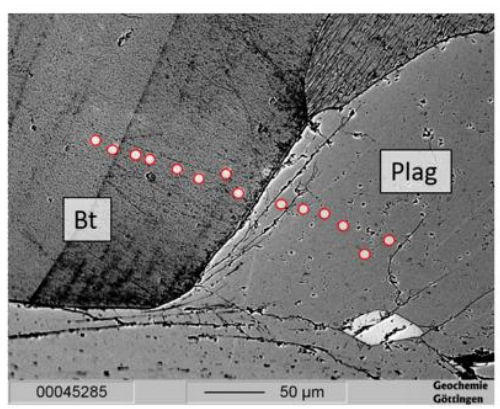

E) Line profile: Plagioclase - Biotite (2)

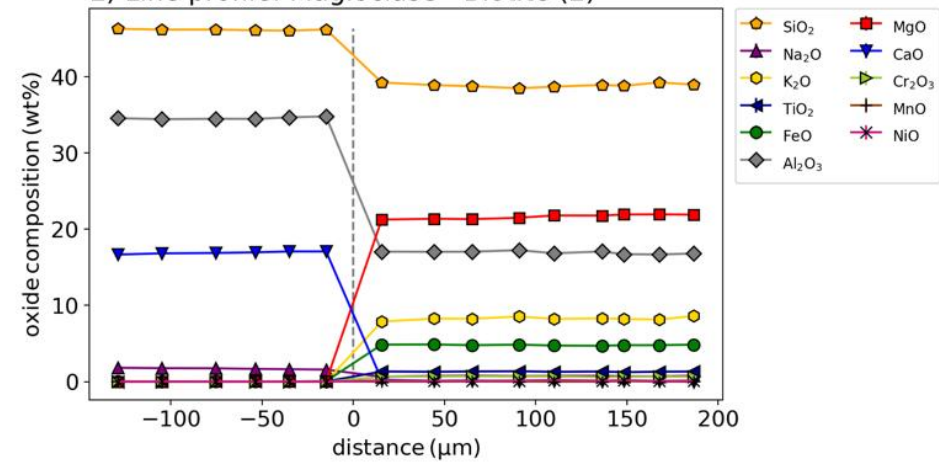

F) Line profile: Plagioclase - Biotite (3)
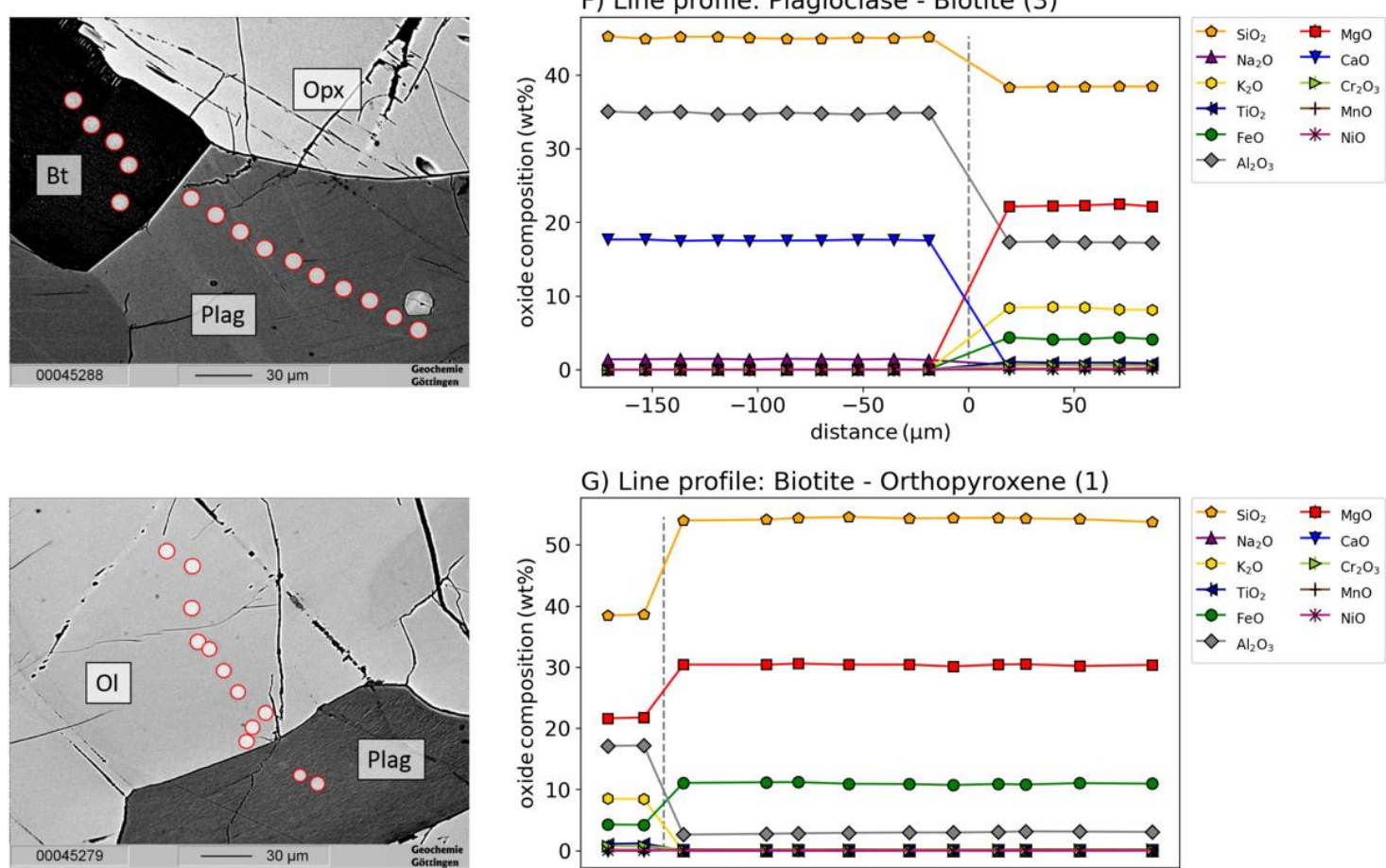

G) Line profile: Biotite - Orthopyroxene (1)

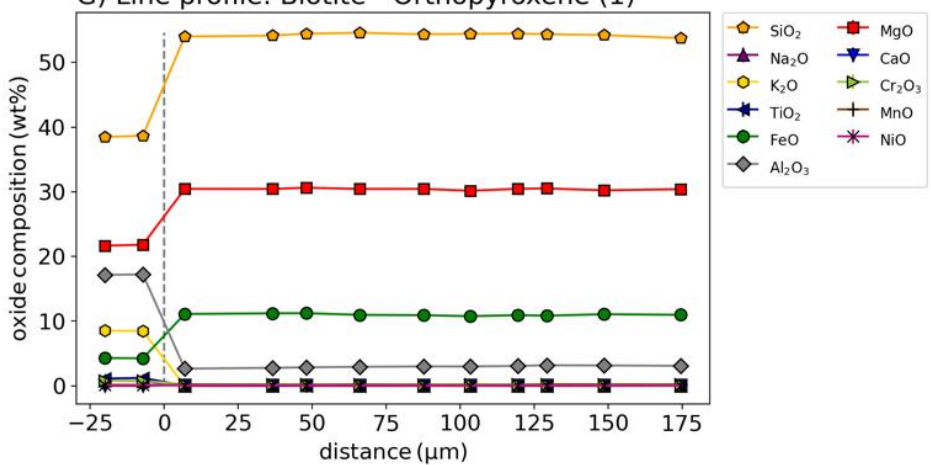

H) Line profile: Orthopyroxene - Biotite (2)
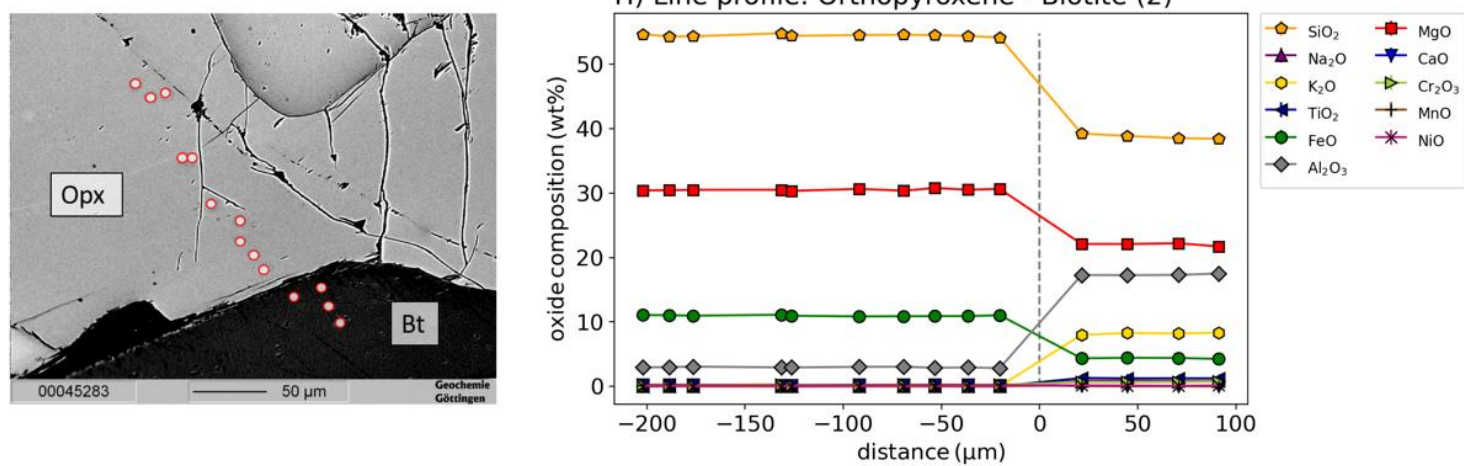

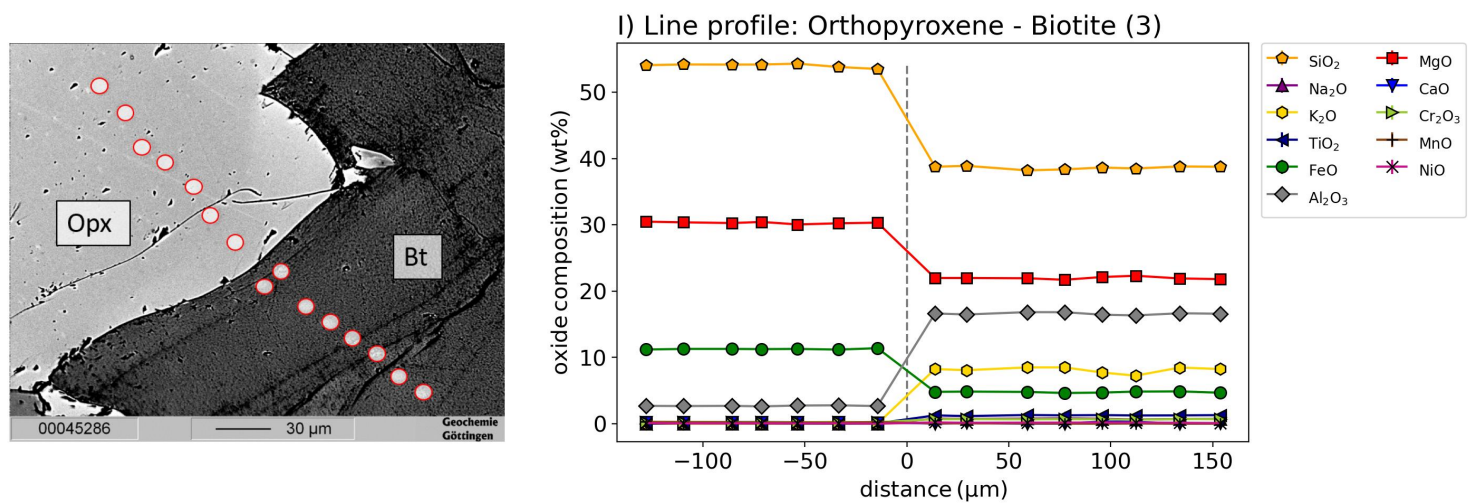

Figure B.7: Individual EMP line profiles (A-I) of the norite A2 thin section. The position of each line profile is shown in a BSE image (left) and the oxide composition is plotted vs. the distance in a line plot (right). The following abbreviations were used: plagioclase (Plag), orthopyroxene (Opx), biotite (Bt). The corresponding data can be found in the digital appendix: EMPA-LineProfile-Data.xlsx.
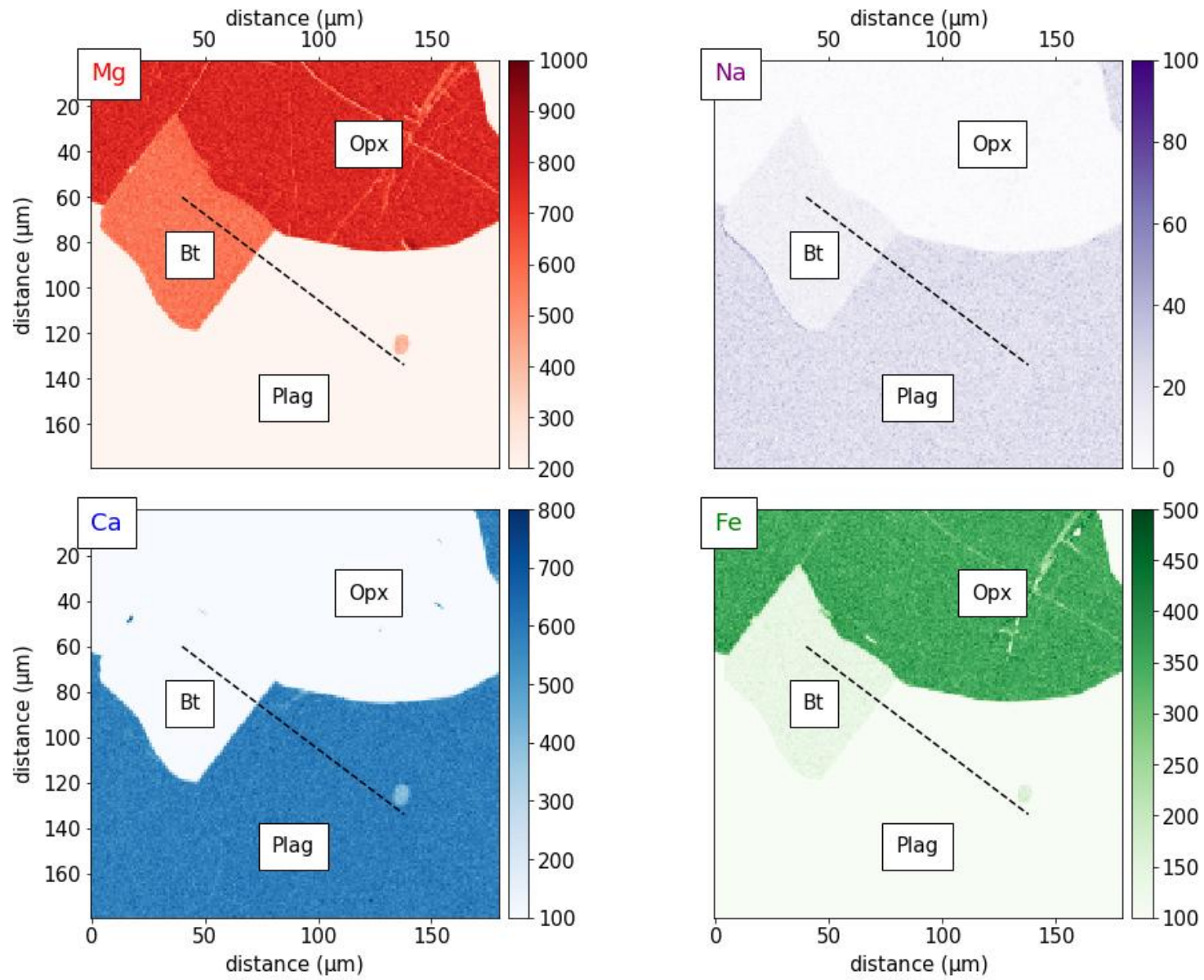

Figure B.8: Set of EMP element mappings covering an area of the norite A2 thin section. The mappings show the $\mathrm{Mg}, \mathrm{Na}, \mathrm{Ca}$ and $\mathrm{Fe}$ levels in this area. The position of a corresponding line profile is illustrated as dotted line (profile B.7F). The following abbreviations were used: plagioclase (Plag), orthopyroxene (Opx), biotite (Bt). The corresponding ascii data can be found in the digital appendix: folder EMPA-ElementMaps. 
B Supplementary information: Triple oxygen isotope fractionation in feldspar-rich rocks

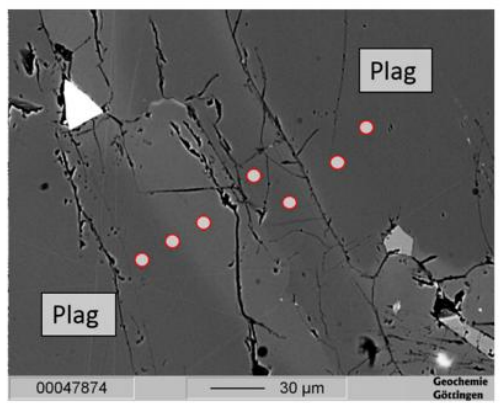

A) Line profile: Plagioclase - Plagioclase (1)

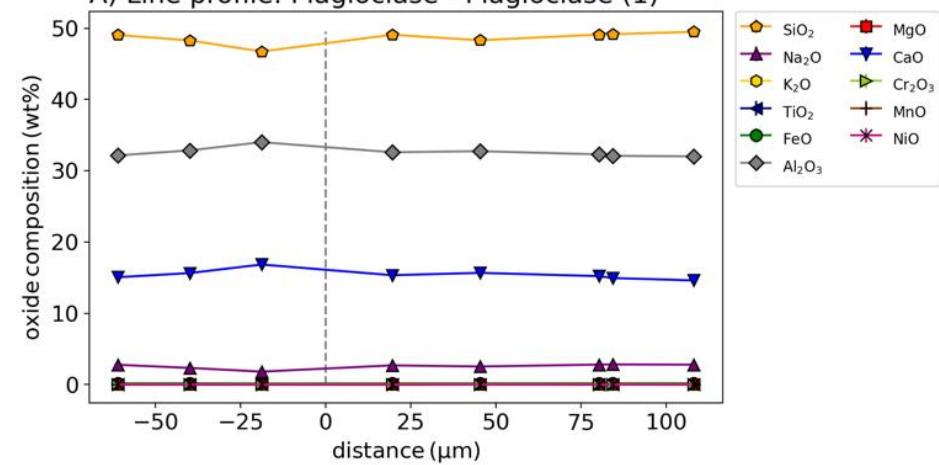

B) Line profile: Plagioclase - Orthopyroxene (1)
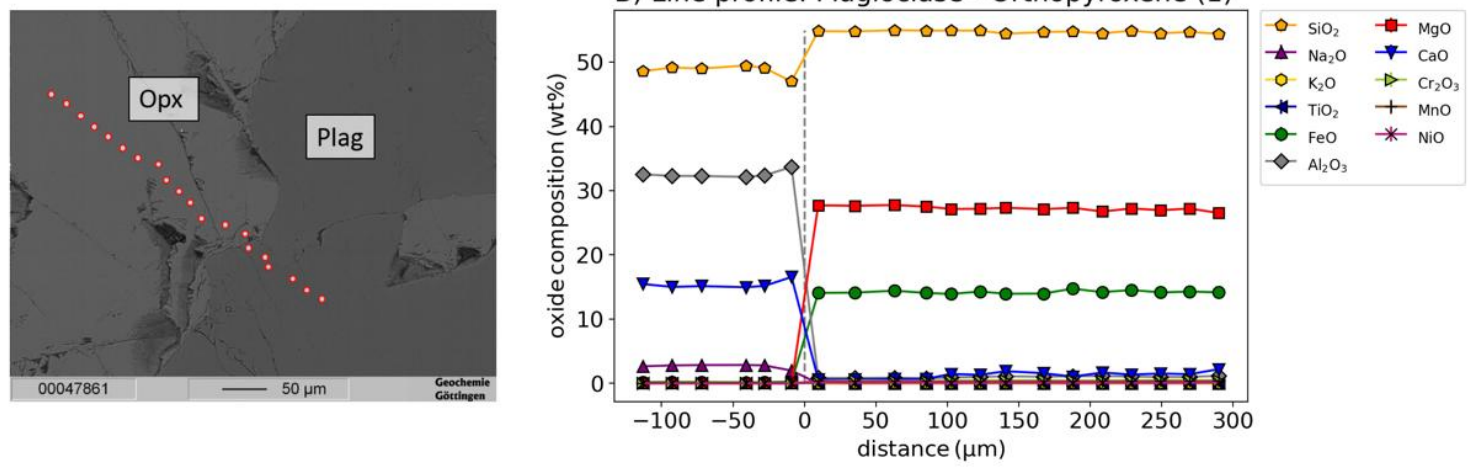

C) Line profile: Plagioclase - Orthopyroxene (2)
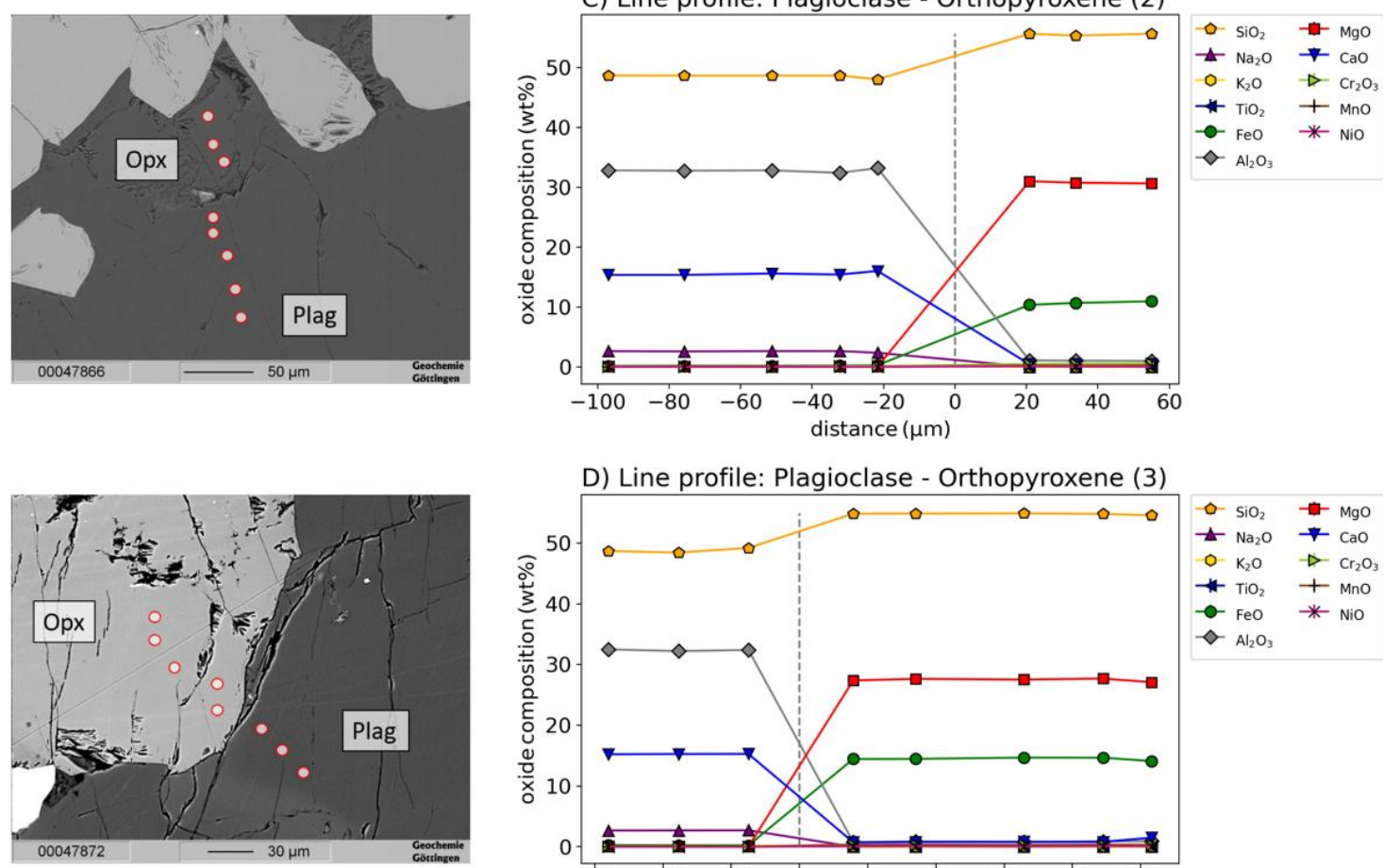

D) Line profile: Plagioclase - Orthopyroxene (3)

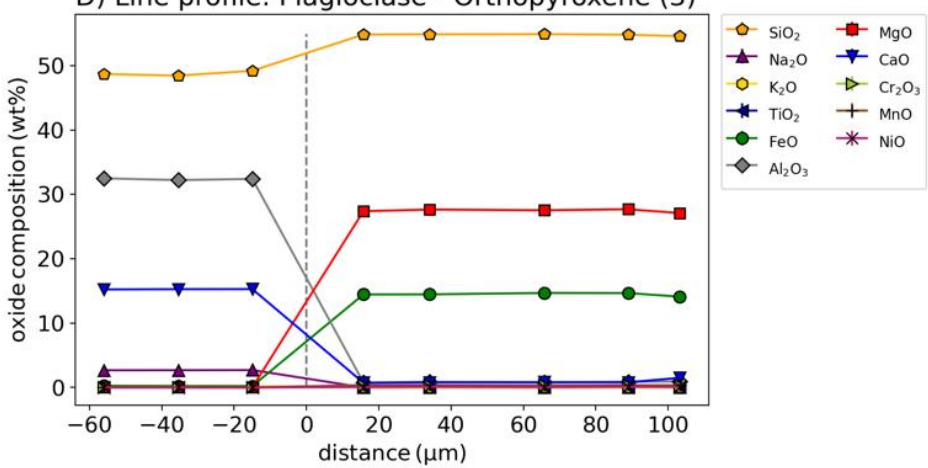




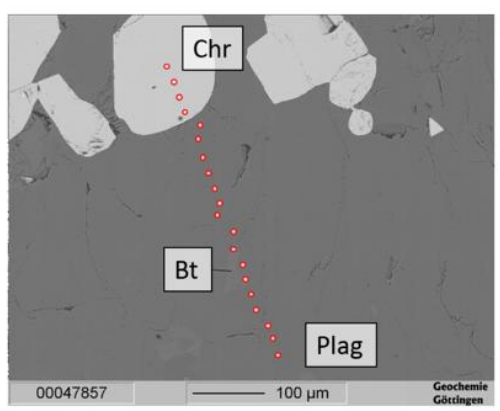

E) Line profile: Plagioclase - Chromite (1)

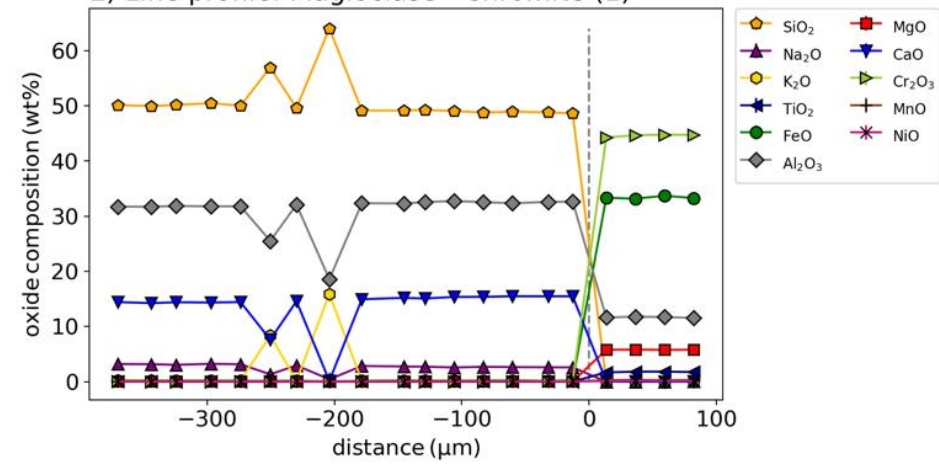

F) Line profile: Plagioclase - Chromite (2)
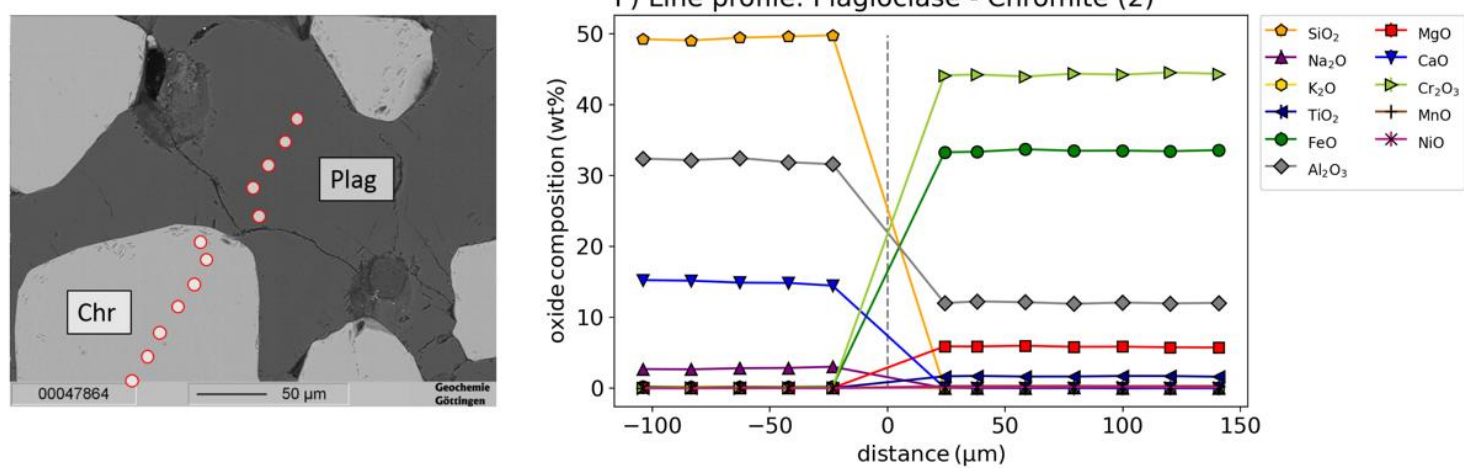

G) Line profile: Plagioclase - Chromite (3)
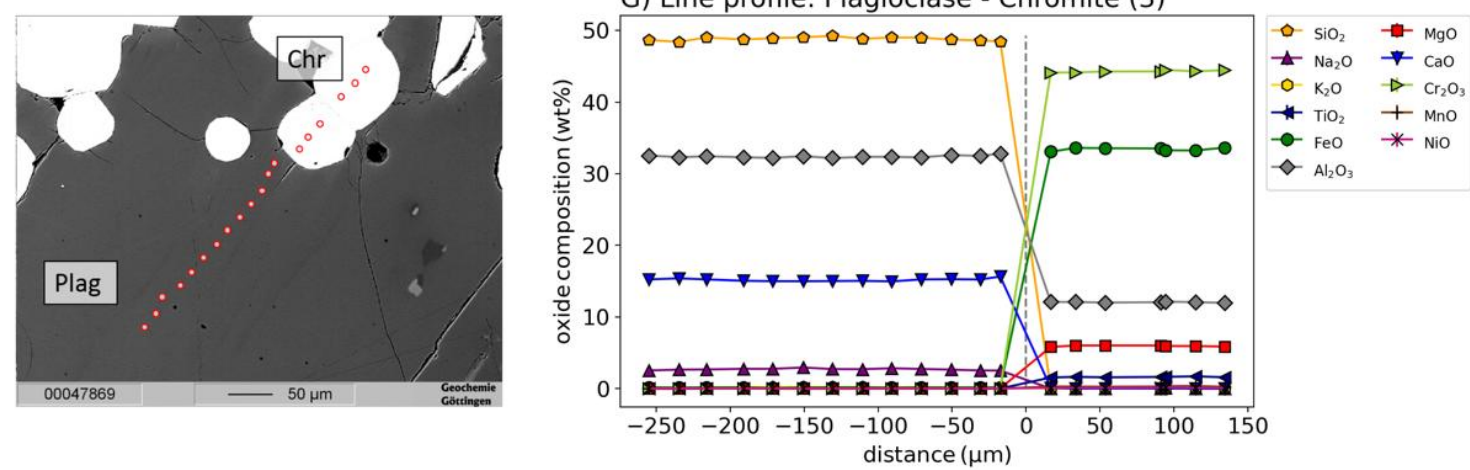

H) Line profile: Orthopyroxene (1)
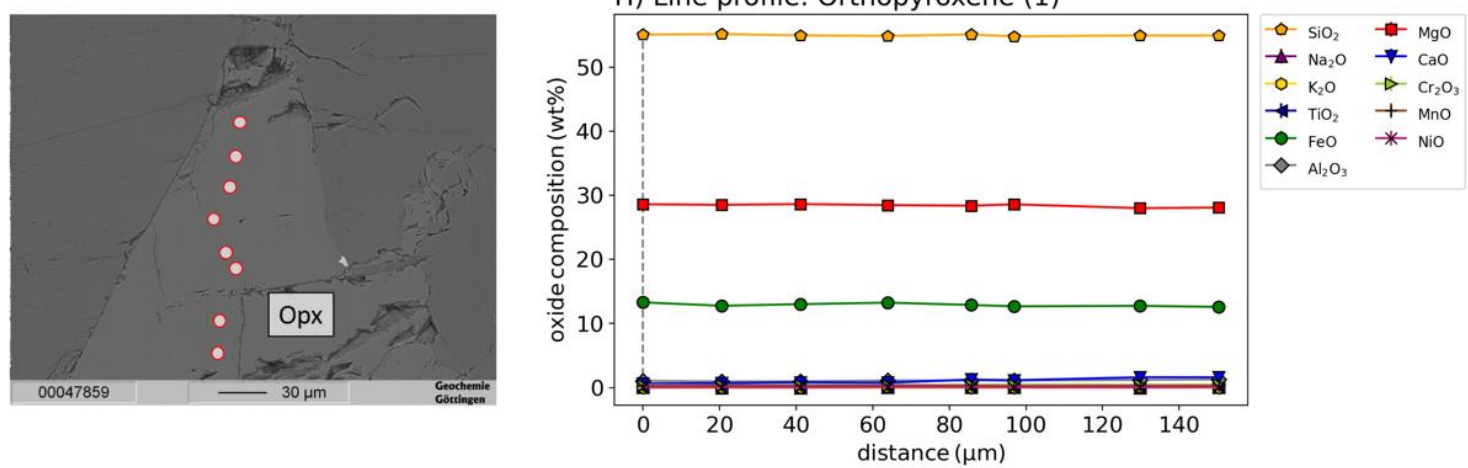

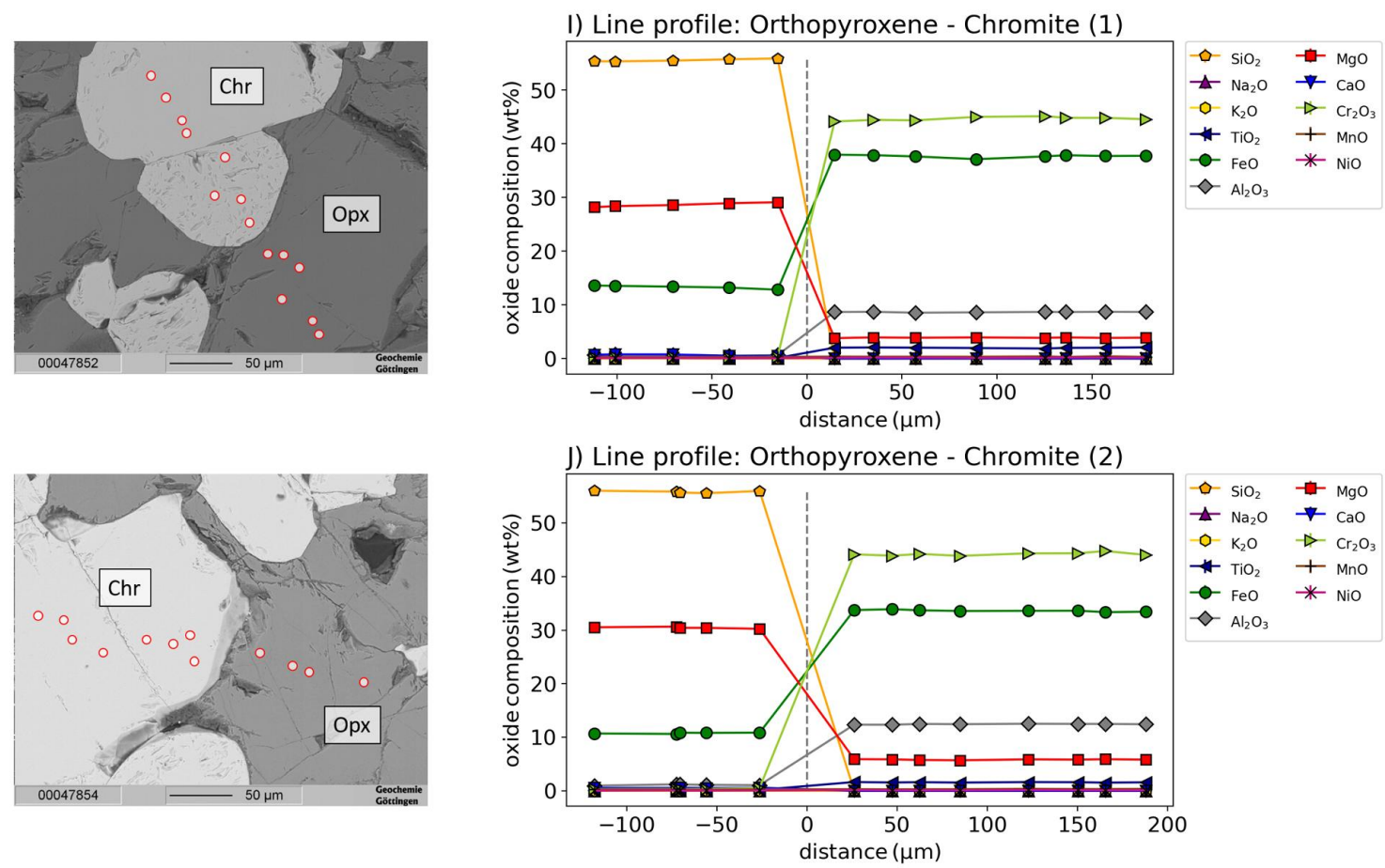

Figure B.9: Individual EMP line profiles (A-J) of the anorthosite B2 thin section. The position of each line profile is shown in a BSE image (left) and the oxide composition is plotted vs. the distance in a line plot (right). The following abbreviations were used: plagioclase (Plag), orthopyroxene (Opx), biotite (Bt), chromite (Chr). The corresponding data can be found in the digital appendix: EMPA-LineProfile-Data.xlsx. 

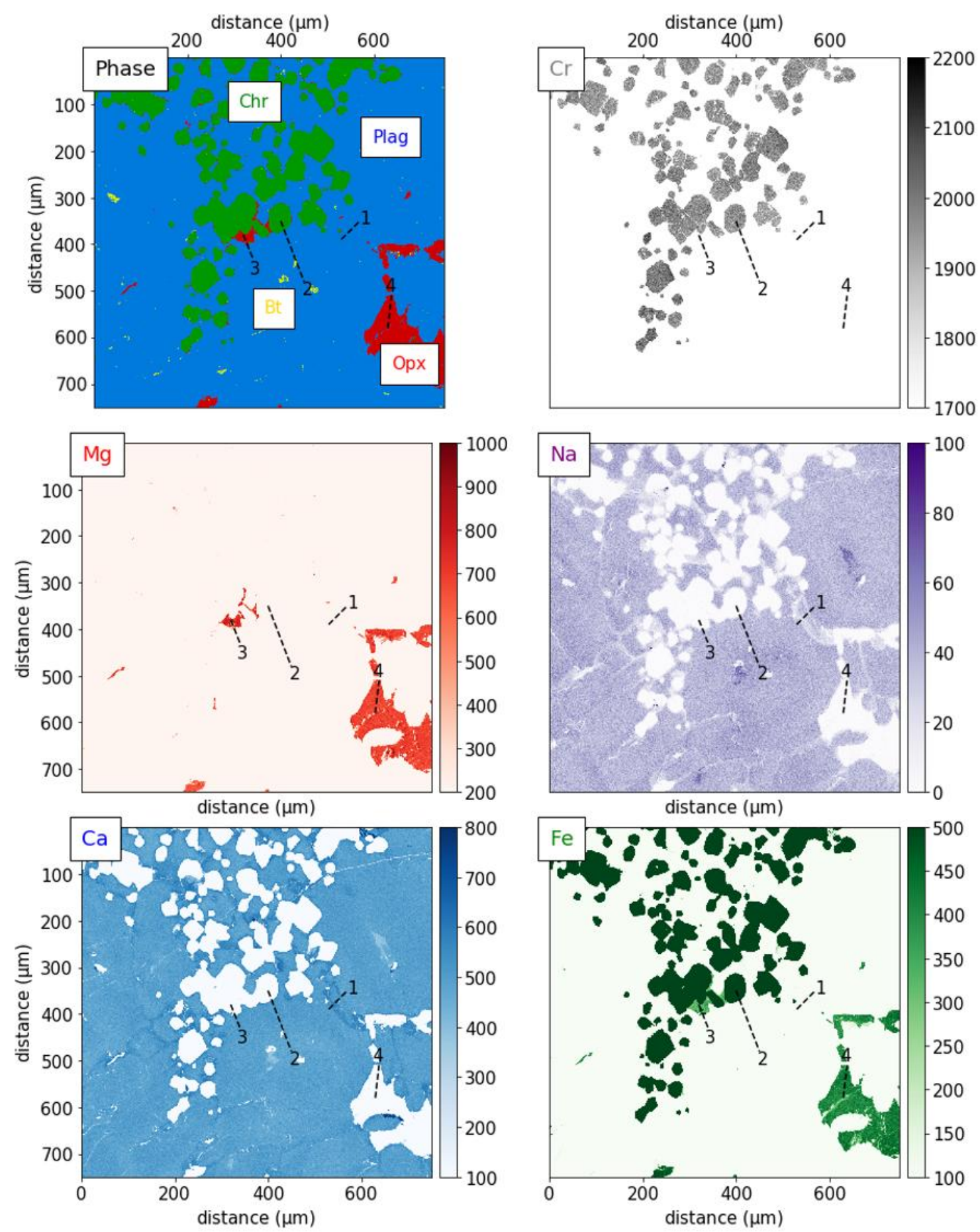

Figure B.10: Set of EMP element mappings covering an area of the anorthosite B2 thin section. The mappings show the mineral phases, $\mathrm{Cr}, \mathrm{Mg}, \mathrm{Na}, \mathrm{Ca}$ and $\mathrm{Fe}$ levels in this area. The position of the additional line profiles are illustrated as dotted lines and labelled with the numbers 1 (profile B.9A), 2 (profile B.9E), 3 (profile B.9C) and 4 (profile B.9H). The following abbreviations were used: plagioclase (Plag), orthopyroxene (Opx), biotite (Bt), chromite (Chr). The corresponding ascii data can be found in the digital appendix: folder EMPA-ElementMaps. 
B Supplementary information: Triple oxygen isotope fractionation in feldspar-rich rocks
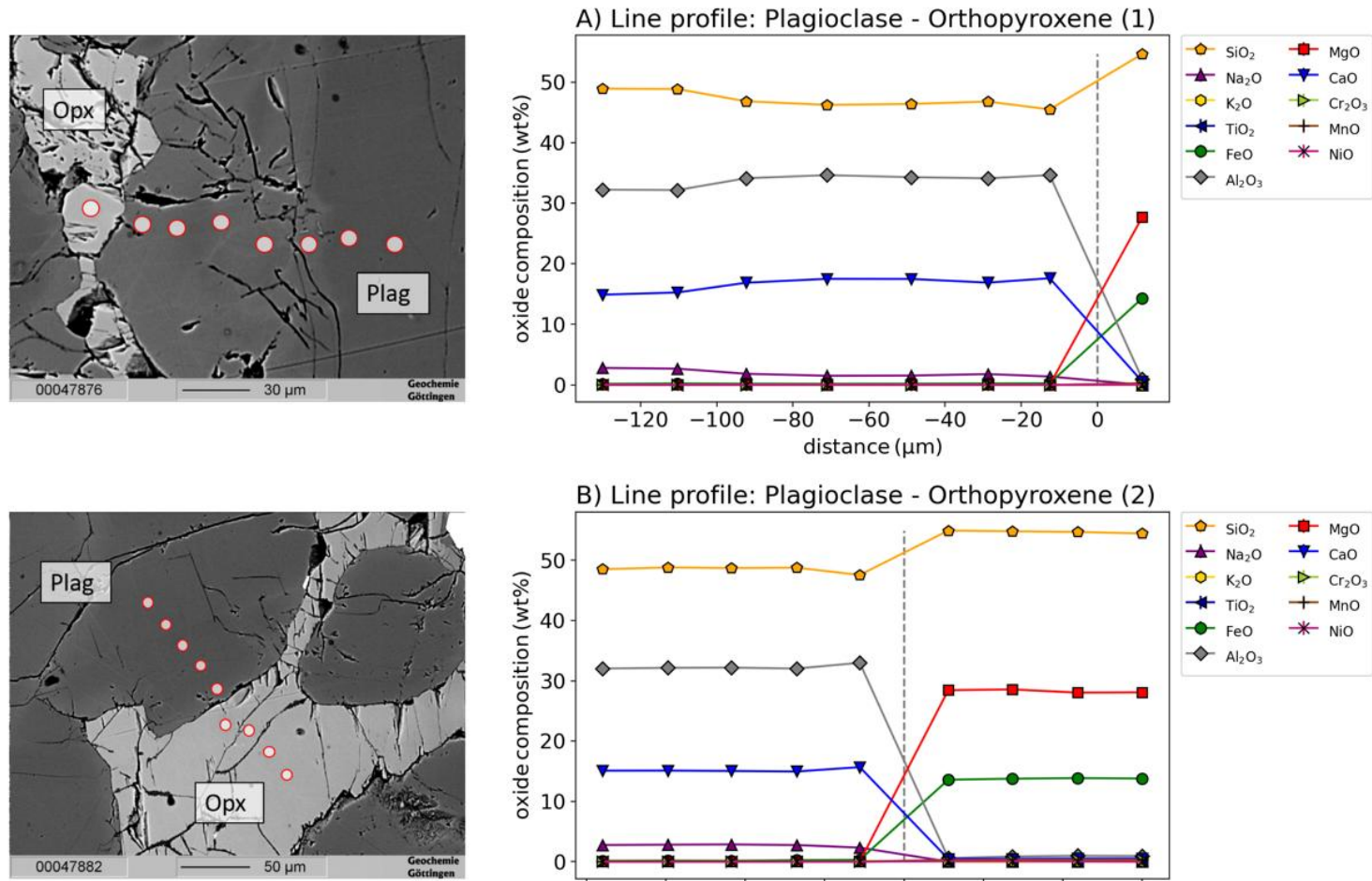

B) Line profile: Plagioclase - Orthopyroxene (2)
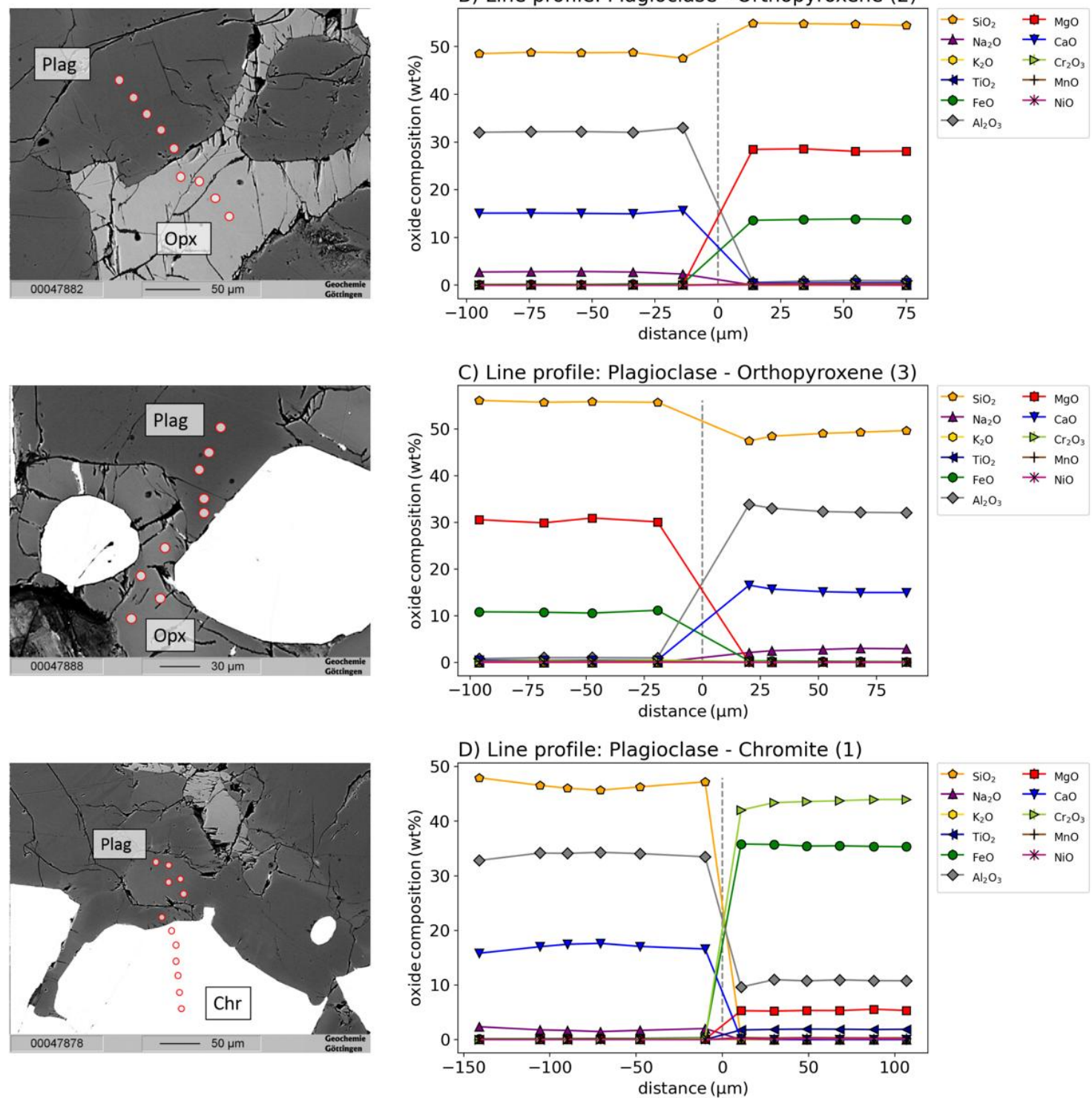


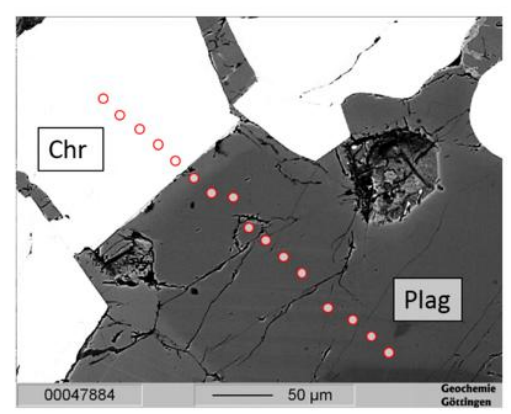

E) Line profile: Plagioclase - Chromite (2)

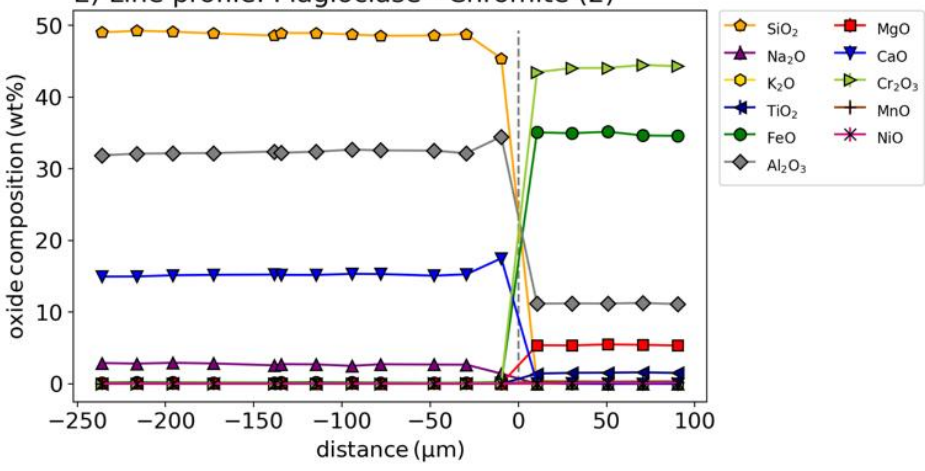

F) Line profile: Plagioclase - Chromite (3)
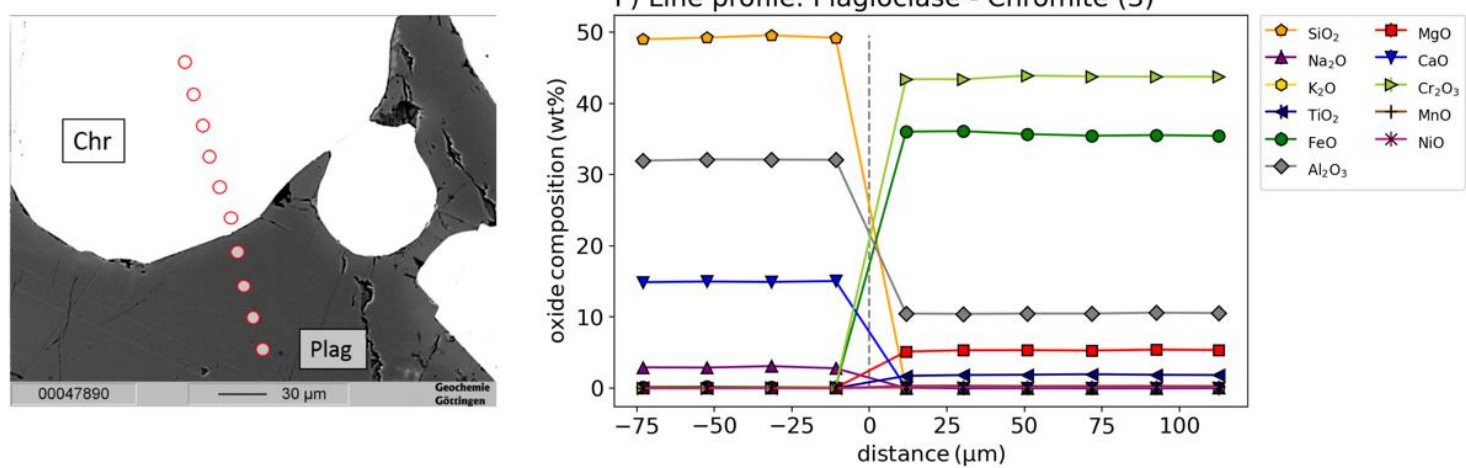

G) Line profile: Orthopyroxene - Chromite (1)
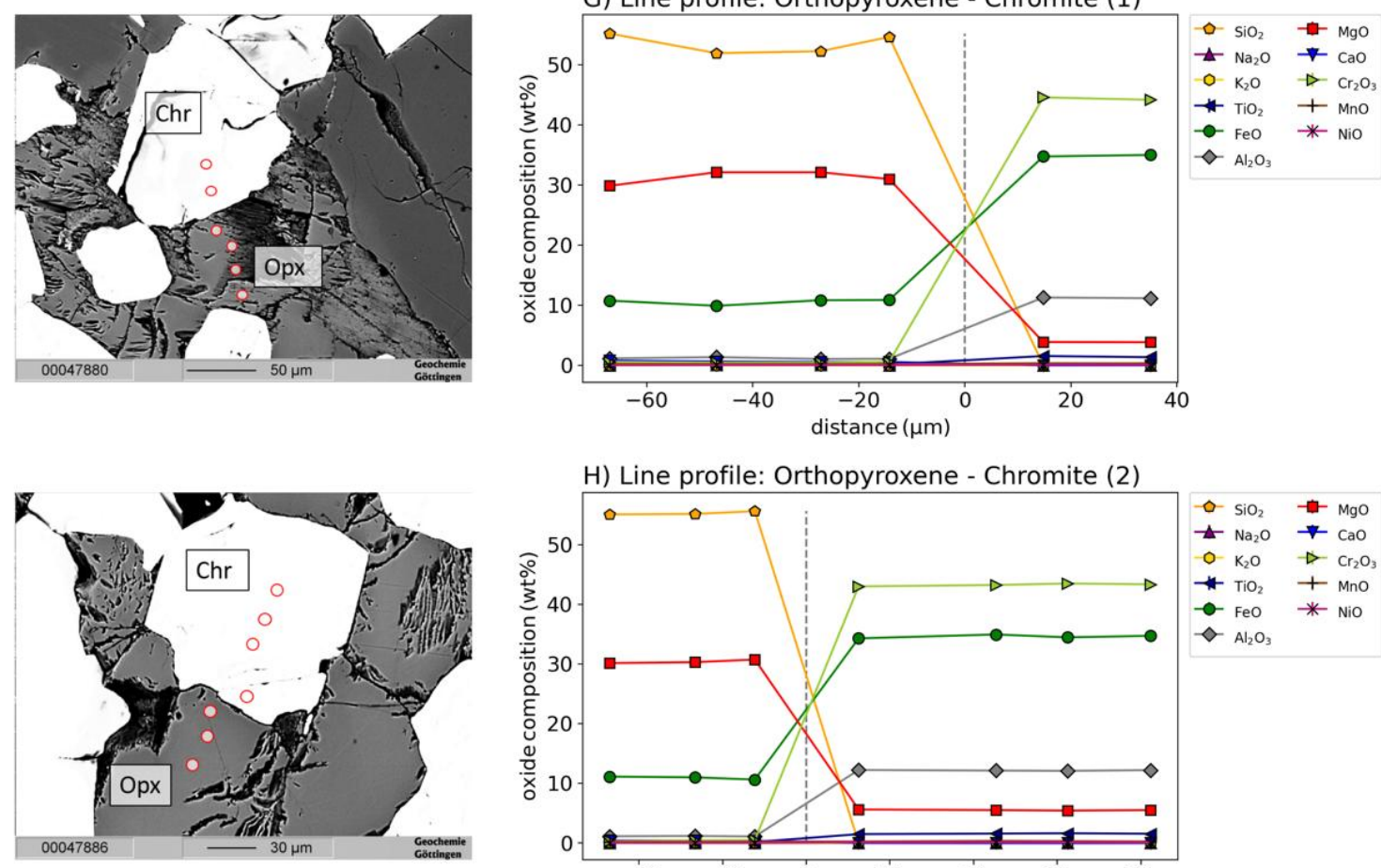

H) Line profile: Orthopyroxene - Chromite (2)

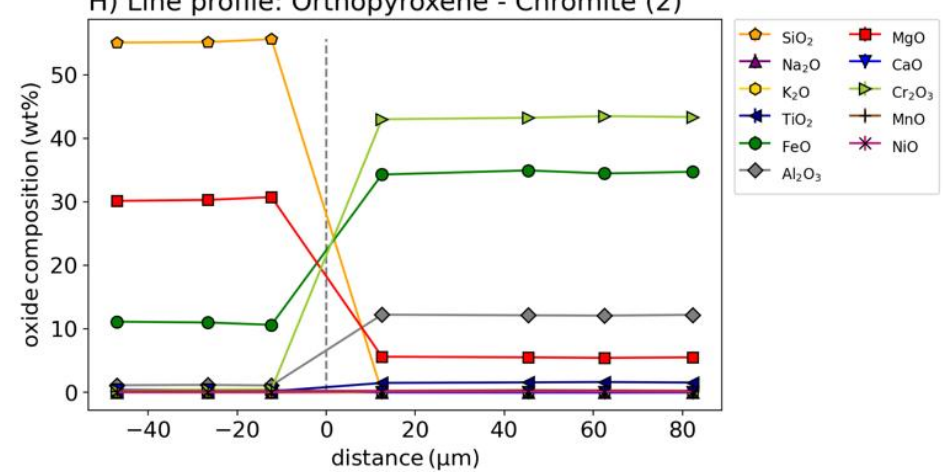




\section{B Supplementary information: Triple oxygen isotope fractionation in feldspar-rich}

rocks
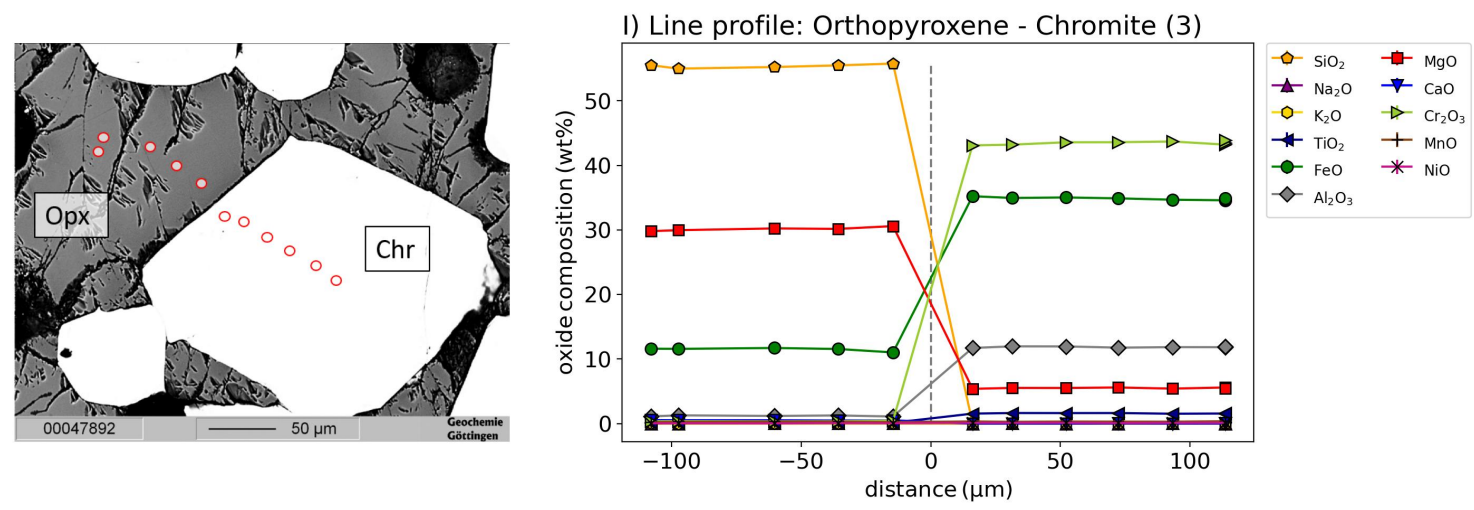

Figure B.11: Individual EMP line profiles (A-I) of the anorthosite B3 thin section. The position of each line profile is shown in a BSE image (left) and the oxide composition is plotted vs. the distance in a line plot (right). The following abbreviations were used: plagioclase (Plag), orthopyroxene (Opx), biotite (Bt), chromite ( $\mathrm{Chr})$. The corresponding data can be found in the digital appendix: EMPA-LineProfile-Data.xlsx. 

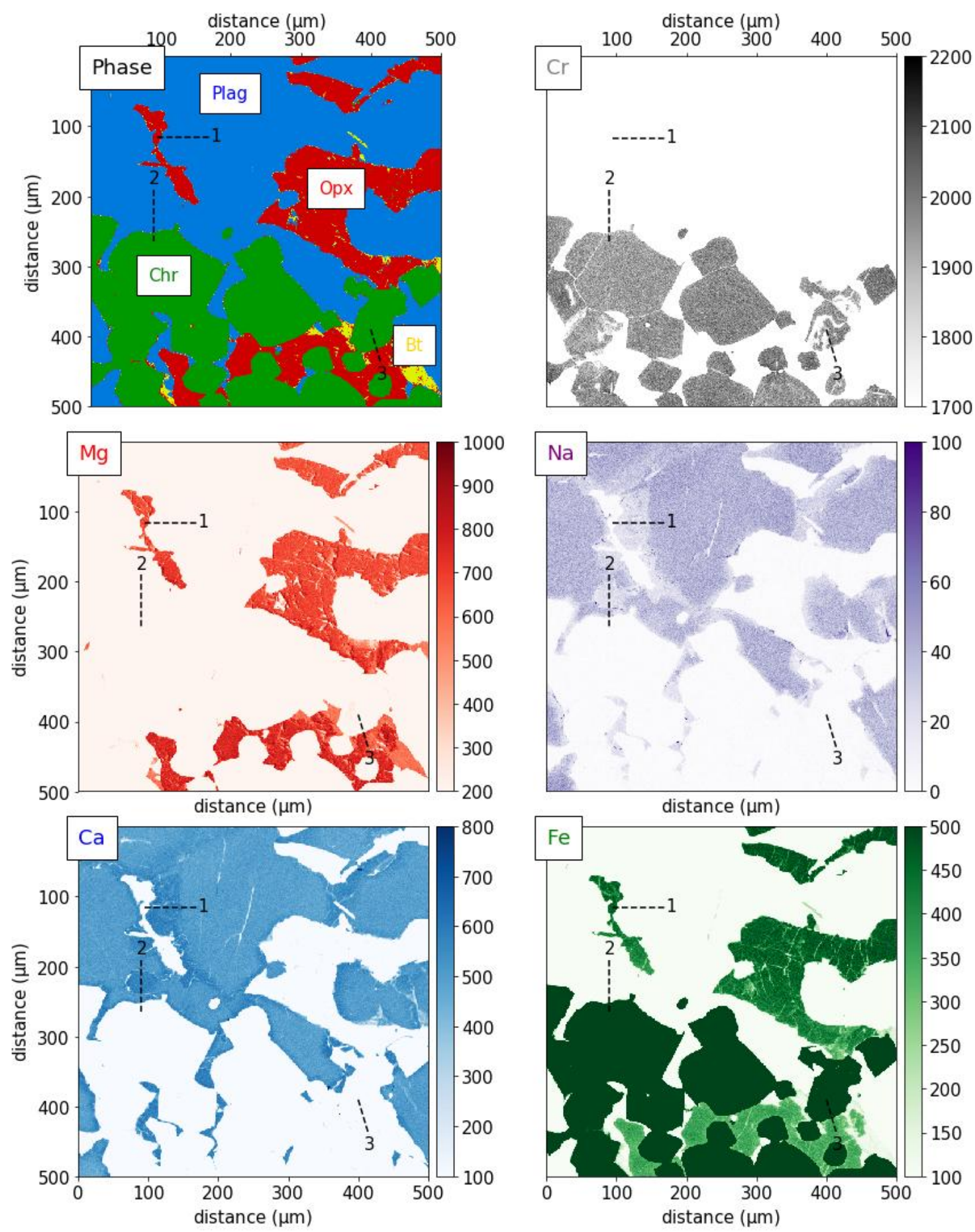

Figure B.12: Set of EMP element mappings covering an area of the anorthosite B3 thin section. The mappings show the mineral phases, $\mathrm{Cr}, \mathrm{Mg}, \mathrm{Na}, \mathrm{Ca}$ and $\mathrm{Fe}$ levels in this area. The position of the additional line profiles are illustrated as dotted lines and labelled with the numbers 1 (profile B.11A), 2 (profile B.11D) and 3 (profile B.11G). The following abbreviations were used: plagioclase (Plag), orthopyroxene (Opx), biotite (Bt), chromite (Chr). The corresponding ascii data can be found in the digital appendix: folder EMPA-ElementMaps. 
B Supplementary information: Triple oxygen isotope fractionation in feldspar-rich rocks

\section{B.3 Additional tables}

Table B.1: Oxide composition of the plagioclases based on the EMP measurements. The $\pm 1 \sigma$ SEM is given.

\begin{tabular}{|c|c|c|c|c|c|c|}
\hline Oxide & $\begin{array}{l}\text { Troctolite } \\
\text { Mean } \\
(N=25) \\
(\mathrm{wt} \%)\end{array}$ & $\pm 1 \sigma$ & $\begin{array}{l}\text { Norite A1 } \\
\text { Mean } \\
(N=6) \\
(\mathrm{wt} \%)\end{array}$ & $\pm 1 \sigma$ & $\begin{array}{l}\text { Norite A2 } \\
\text { Mean } \\
(N=28) \\
(\mathrm{wt} \%)\end{array}$ & $\pm 1 \sigma$ \\
\hline $\mathrm{SiO}_{2}$ & 45.86 & 0.08 & 44.5 & 0.05 & 46.06 & 0.09 \\
\hline $\mathrm{Al}_{2} \mathrm{O}_{3}$ & 34.32 & 0.03 & 35.52 & 0.03 & 34.77 & 0.06 \\
\hline $\mathrm{FeO}(\mathrm{t})$ & 0.51 & 0.1 & 0.06 & 0.01 & 0.04 & 0.01 \\
\hline $\mathrm{CaO}$ & 17.59 & 0.03 & 18.6 & 0.04 & 17.57 & 0.07 \\
\hline $\mathrm{Na}_{2} \mathrm{O}$ & 1.41 & 0.01 & 0.92 & 0.01 & 1.46 & 0.03 \\
\hline $\mathrm{K}_{2} \mathrm{O}$ & 0.021 & 0.002 & 0.925 & 0 & 0.006 & 0.002 \\
\hline $\mathrm{BaO}$ & 0.014 & 0.003 & 0.007 & - & 0.015 & 0.004 \\
\hline An $(\%)$ & 87.21 & & 91.71 & & 86.93 & \\
\hline $\mathrm{Ab}(\%)$ & 12.66 & & 8.25 & & 13.03 & \\
\hline \multirow[t]{2}{*}{ Or $(\%)$} & 0.13 & & 0.04 & & 0.04 & \\
\hline & Bytownite & & Anorthite & & Bytownite & \\
\hline
\end{tabular}

\begin{tabular}{|c|c|c|c|c|}
\hline Oxide & $\begin{array}{l}\text { Anorthosite B2 } \\
\text { Mean } \\
(N=16) \\
(\mathrm{wt} \%)\end{array}$ & $\pm 1 \sigma$ & $\begin{array}{l}\text { Anorthosite B3 } \\
\text { Mean } \\
(N=12) \\
(\mathrm{wt} \%)\end{array}$ & $\pm 1 \sigma$ \\
\hline $\mathrm{SiO}_{2}$ & 49.15 & 0.18 & 48.29 & 0.11 \\
\hline $\mathrm{Al}_{2} \mathrm{O}_{3}$ & 32.21 & 0.12 & 32.65 & 0.08 \\
\hline $\mathrm{FeO}(\mathrm{t})$ & 0.20 & 0.01 & 0.18 & 0.00 \\
\hline $\mathrm{CaO}$ & 15.03 & 0.12 & 15.60 & 0.08 \\
\hline $\mathrm{Na}_{2} \mathrm{O}$ & 2.81 & 0.06 & 2.51 & 0.05 \\
\hline $\mathrm{K}_{2} \mathrm{O}$ & 0.20 & 0.01 & 0.14 & 0.00 \\
\hline $\mathrm{BaO}$ & - & - & - & - \\
\hline An $(\%)$ & 73.84 & & 76.79 & \\
\hline $\mathrm{Ab}(\%)$ & 25.00 & & 22.40 & \\
\hline \multirow[t]{2}{*}{ Or $(\%)$} & 1.16 & & 0.81 & \\
\hline & Bytownite & & Bytownite & \\
\hline
\end{tabular}




\section{B.3 Additional tables}

Table B.2: Oxide composition of the pyroxenes based on the EMP measurements. The $\pm 1 \sigma$ SEM is given.

\begin{tabular}{|c|c|c|c|c|c|c|}
\hline Oxide & $\begin{array}{l}\text { Troctolite } \\
\text { Mean } \\
(N=9) \\
(\mathrm{wt} \%)\end{array}$ & $\pm 1 \sigma$ & $\begin{array}{l}\text { Norite A1 } \\
\text { Mean } \\
(N=6) \\
(\mathrm{wt} \%)\end{array}$ & $\pm 1 \sigma$ & $\begin{array}{l}\text { Norite A2 } \\
\text { Mean } \\
(N=21) \\
(\mathrm{wt} \%)\end{array}$ & $\pm 1 \sigma$ \\
\hline $\mathrm{SiO}_{2}$ & 50.72 & 0.15 & 53.89 & 0.08 & 54.46 & 0.07 \\
\hline $\mathrm{TiO}_{2}$ & 0.64 & 0.02 & 0.02 & 0.01 & 0.04 & 0 \\
\hline $\mathrm{Al}_{2} \mathrm{O}_{3}$ & 3.57 & 0.07 & 3.46 & 0.04 & 3 & 0.06 \\
\hline $\mathrm{Cr}_{2} \mathrm{O}_{3}$ & 0.37 & 0.03 & 0.11 & 0.01 & 0.21 & 0.01 \\
\hline $\mathrm{FeO}(\mathrm{t})$ & 6.92 & 0.03 & 12.63 & 0.07 & 10.81 & 0.04 \\
\hline $\mathrm{MnO}$ & 0.17 & 0.01 & 0.3 & 0.01 & 0.21 & 0.01 \\
\hline $\mathrm{MgO}$ & 14.95 & 0.04 & 28.95 & 0.07 & 30.23 & 0.04 \\
\hline $\mathrm{CaO}$ & 21.53 & 0.06 & 0.28 & 0.02 & 0.21 & 0.01 \\
\hline $\mathrm{Na}_{2} \mathrm{O}$ & 0.321 & 0.01 & 0.018 & 0.01 & 0.008 & 0.002 \\
\hline $\mathrm{K}_{2} \mathrm{O}$ & 0.004 & 0.002 & 0.012 & 0.004 & 0.01 & 0.002 \\
\hline Wo (\%) & 44.45 & & 0.56 & & 0.41 & \\
\hline En $(\%)$ & 42.97 & & 79.49 & & 82.66 & \\
\hline Fs $(\%)$ & 11.38 & & 19.89 & & 16.89 & \\
\hline \multirow[t]{2}{*}{ Ac $(\%)$} & 1.2 & & 0.06 & & 0.03 & \\
\hline & Diopside & & Enstatite & & Enstatite & \\
\hline
\end{tabular}

\begin{tabular}{|c|c|c|c|c|}
\hline Oxide & $\begin{array}{l}\text { Anorthosite B2 } \\
\text { Mean } \\
(N=16) \\
(\text { wt } \%)\end{array}$ & $\pm 1 \sigma$ & $\begin{array}{l}\text { Anorthosite B3 } \\
\text { Mean } \\
(N=14) \\
(\mathrm{wt} \%)\end{array}$ & $\pm 1 \sigma$ \\
\hline $\mathrm{SiO}_{2}$ & 55.08 & 0.15 & 55.18 & 0.04 \\
\hline $\mathrm{TiO}_{2}$ & 0.16 & 0.01 & 0.16 & 0.003 \\
\hline $\mathrm{Al}_{2} \mathrm{O}_{3}$ & 1.03 & 0.04 & 0.96 & 0.01 \\
\hline $\mathrm{Cr}_{2} \mathrm{O}_{3}$ & 0.42 & 0.02 & 0.38 & 0.01 \\
\hline $\mathrm{FeO}(\mathrm{t})$ & 12.74 & 0.40 & 12.34 & 0.12 \\
\hline $\mathrm{MnO}$ & 0.29 & 0.01 & 0.27 & 0.003 \\
\hline $\mathrm{MgO}$ & 28.54 & 0.37 & 29.25 & 0.09 \\
\hline $\mathrm{CaO}$ & 1.01 & 0.12 & 0.56 & 0.01 \\
\hline $\mathrm{Na}_{2} \mathrm{O}$ & 0.01 & 0.003 & 0.01 & 0.0009 \\
\hline $\mathrm{K}_{2} \mathrm{O}$ & 0.01 & 0.002 & 0.01 & 0.0007 \\
\hline Wo $(\%)$ & 1.99 & & 1.10 & \\
\hline En $(\%)$ & 77.97 & & 79.58 & \\
\hline Fs $(\%)$ & 20.01 & & 19.27 & \\
\hline \multirow[t]{2}{*}{ Ac $(\%)$} & 0.04 & & 0.04 & \\
\hline & Enstatite & & Enstatite & \\
\hline
\end{tabular}




\section{B Supplementary information: Triple oxygen isotope fractionation in feldspar-rich}

rocks

Table B.3: Oxide composition of the olivine in the troctolite based on the EMP measurements. The $\pm 1 \sigma$ SEM is given

\begin{tabular}{ccc}
\hline Oxide & $\begin{array}{l}\text { Troctolite } \\
\text { Mean } \\
(N=16) \\
(\text { wt } \%)\end{array}$ & $\pm 1 \sigma$ \\
\hline $\mathrm{SiO}_{2}$ & 38.14 & 0.05 \\
$\mathrm{TiO}_{2}$ & 0.013 & 0.004 \\
$\mathrm{Al}_{2} \mathrm{O}_{3}$ & 0.018 & 0.003 \\
$\mathrm{Cr}_{2} \mathrm{O}_{3}$ & 0.006 & 0.003 \\
$\mathrm{FeO}$ & 22.09 & 0.05 \\
$\mathrm{MnO}$ & 0.35 & 0.01 \\
$\mathrm{MgO}$ & 38.59 & 0.05 \\
$\mathrm{NiO}$ & 0.11 & 0.01 \\
$\mathrm{CaO}$ & 0.14 & 0.01 \\
& 75.4 & \\
$\mathrm{Fo}(\%)$ & 24.21 & \\
$\mathrm{Fa}(\%)$ & 0.39 \\
$\mathrm{Tp}(\%)$ & Forsterite \\
& \\
\hline
\end{tabular}

Table B.4: Oxide composition of the magnetite in the troctolite based on the EMP measurements. The $\pm 1 \sigma$ SEM is given.

\begin{tabular}{ccc}
\hline Oxide & $\begin{array}{l}\text { Troctolite } \\
\text { Mean } \\
(N=3) \\
(\mathrm{wt} \%)\end{array}$ & $\pm 1 \sigma$ \\
\hline $\mathrm{SiO}_{2}$ & 0.065 & 0.004 \\
$\mathrm{TiO}_{2}$ & 6.15 & 0.16 \\
$\mathrm{Al}_{2} \mathrm{O}_{3}$ & 8.85 & 0.23 \\
$\mathrm{Cr}_{2} \mathrm{O}_{3}$ & 7.72 & 0.17 \\
$\mathrm{FeO}$ & 67.01 & 0.09 \\
$\mathrm{MnO}$ & 0.27 & 0.02 \\
$\mathrm{MgO}$ & 4.81 & 0.11 \\
$\mathrm{CaO}$ & 0.03 & 0.03 \\
\multicolumn{3}{c}{ Magnetite } \\
\hline
\end{tabular}

Table B.5: Oxide composition of the chromite in anorthosite B2/B3 based on the EMP measurements. The $\pm 1 \sigma$ SEM is given.

\begin{tabular}{|c|c|c|c|c|}
\hline Oxide & $\begin{array}{l}\text { Anorthosite B2 } \\
\text { Mean } \\
(N=13) \\
(\mathrm{wt} \%)\end{array}$ & $\pm 1 \sigma$ & $\begin{array}{l}\text { Anorthosite B3 } \\
\text { Mean } \\
(N=7) \\
(\mathrm{wt} \%)\end{array}$ & $\pm 1 \sigma$ \\
\hline $\mathrm{SiO}_{2}$ & 0.01 & 0.003 & 0.07 & 0.01 \\
\hline $\mathrm{TiO}_{2}$ & 1.79 & 0.06 & 1.56 & 0.02 \\
\hline $\mathrm{Al}_{2} \mathrm{O}_{3}$ & 11.22 & 0.39 & 11.01 & 0.07 \\
\hline $\mathrm{Cr}_{2} \mathrm{O}_{3}$ & 44.45 & 0.14 & 44.10 & 0.05 \\
\hline $\mathrm{FeO}$ & 34.46 & 0.42 & 35.53 & 0.11 \\
\hline $\mathrm{MnO}$ & 0.32 & 0.01 & 0.32 & 0.002 \\
\hline $\mathrm{MgO}$ & 5.40 & 0.21 & 4.88 & 0.07 \\
\hline \multirow[t]{2}{*}{$\mathrm{CaO}$} & 0.01 & 0.003 & 0.02 & 0.001 \\
\hline & Chromite & & Chromite & \\
\hline
\end{tabular}




\section{B.3 Additional tables}

Table B.6: Oxide composition of the amphibole in norite A1 based on the EMP measurements. The $\pm 1 \sigma$ SEM is given.

\begin{tabular}{ccc}
\hline Oxide & $\begin{array}{l}\text { Norite } \mathrm{A} 1 \\
\text { Mean } \\
(N=6) \\
(\mathrm{wt} \%)\end{array}$ & $\pm 1 \sigma$ \\
\hline $\mathrm{SiO}_{2}$ & 46.03 & 0.05 \\
$\mathrm{TiO}_{2}$ & 0.45 & 0.01 \\
$\mathrm{Al}_{2} \mathrm{O}_{3}$ & 12.4 & 0.06 \\
$\mathrm{Cr}_{2} \mathrm{O}_{3}$ & 0.35 & 0.01 \\
$\mathrm{FeO}$ & 7.37 & 0.03 \\
$\mathrm{MnO}$ & 0.13 & 0.01 \\
$\mathrm{MgO}$ & 16.58 & 0.04 \\
$\mathrm{CaO}$ & 11.35 & 0.03 \\
$\mathrm{Na}{ }_{2} \mathrm{O}$ & 1.63 & 0.01 \\
$\mathrm{~K}_{2} \mathrm{O}$ & 0.27 & 0.01 \\
\multicolumn{3}{c}{} \\
$\mathrm{Calcic}$
\end{tabular}

Table B.7: Oxide composition of the mica in norite A2 and anorthosite B2/B3 based on the EMP measurements. The $\pm 1 \sigma$ SEM is given.

\begin{tabular}{|c|c|c|c|c|c|c|}
\hline Oxide & $\begin{array}{l}\text { Norite A2 } \\
\text { Mean } \\
(N=6) \\
(\mathrm{wt} \%)\end{array}$ & $\pm 1 \sigma$ & $\begin{array}{l}\text { Anorthosite B2 } \\
\text { Mean } \\
(N=1) \\
(\mathrm{wt} \%)\end{array}$ & $\pm 1 \sigma$ & $\begin{array}{l}\text { Anorthosite B3 } \\
\text { Mean } \\
(N=2) \\
(\mathrm{wt} \%)\end{array}$ & $\pm 1 \sigma$ \\
\hline $\mathrm{SiO}_{2}$ & 38.78 & 0.27 & 44.83 & - & 38.61 & 0.07 \\
\hline $\mathrm{TiO}_{2}$ & 1.12 & 0.18 & 1.93 & - & 4.09 & 0.05 \\
\hline $\mathrm{Al}_{2} \mathrm{O}_{3}$ & 17.14 & 0.28 & 12.66 & - & 13.82 & 0.04 \\
\hline $\mathrm{Cr}_{2} \mathrm{O}_{3}$ & 0.66 & 0.08 & 0.77 & - & 1.16 & 0.03 \\
\hline $\mathrm{FeO}$ & 4.46 & 0.2 & 5.20 & - & 3.55 & 0.05 \\
\hline $\mathrm{MnO}$ & 0.01 & 0.01 & 0.01 & - & 0.01 & 0.002 \\
\hline $\mathrm{MgO}$ & 17.14 & 0.28 & 20.24 & - & 22.44 & 0.01 \\
\hline $\mathrm{CaO}$ & 0.05 & 0.06 & 0.10 & - & 0.11 & 0.003 \\
\hline $\mathrm{Na}_{2} \mathrm{O}$ & 0.76 & 0.04 & 0.05 & - & 0.15 & 0.002 \\
\hline \multirow[t]{2}{*}{$\mathrm{K}_{2} \mathrm{O}$} & 8.38 & 0.13 & 9.23 & - & 9.10 & 0.02 \\
\hline & Biotite & & Biotite & & Biotite & \\
\hline
\end{tabular}




\section{B Supplementary information: Triple oxygen isotope fractionation in feldspar-rich}

rocks

Table B.8: Oxygen isotope composition of the mineral separates (single measurements). We used the following abbreviations: Plag = plagioclase, $\mathrm{Opx}=$ orthopyroxene $\mathrm{Cpx}=$ clinopyroxene, $\mathrm{Ol}=$ olivine, $\mathrm{Amph}=$ amphibole, $\mathrm{Chr}=$ chromite.

\begin{tabular}{|c|c|c|c|c|c|c|c|c|c|}
\hline ID & Sample ID & Mineral & $\begin{array}{l}\delta^{17} \mathrm{O} \\
(\% o)\end{array}$ & SD & $\begin{array}{l}\delta^{18} \mathrm{O} \\
(\% o)\end{array}$ & SD & $\begin{array}{l}\Delta^{\prime 17} \mathrm{O} \\
(\mathrm{ppm})\end{array}$ & SD & Outlier \\
\hline 4252 & Troctolite & Plag & 2.84 & 0.12 & 5.47 & 0.21 & -45 & 10 & 0 \\
\hline 4287 & Troctolite & Plag & 3.00 & 0.12 & 5.76 & 0.21 & -34 & 10 & \\
\hline 4297 & Troctolite & Plag & 2.87 & 0.12 & 5.56 & 0.21 & -59 & 10 & \\
\hline 4395 & Troctolite & Plag & 2.87 & 0.12 & 5.56 & 0.21 & -60 & 10 & \\
\hline 4409 & Troctolite & Plag & 2.69 & 0.12 & 5.20 & 0.21 & -59 & 10 & \\
\hline 4242 & Troctolite & Cpx & 2.38 & 0.10 & 4.63 & 0.20 & -64 & 5 & \\
\hline 4250 & Troctolite & Cpx & 2.42 & 0.10 & 4.69 & 0.20 & -58 & 5 & \\
\hline 4291 & Troctolite & Cpx & 2.55 & 0.10 & 4.94 & 0.20 & -53 & 5 & \\
\hline 4388 & Troctolite & Cpx & 2.56 & 0.10 & 4.95 & 0.20 & -54 & 5 & \\
\hline 4407 & Troctolite & $\mathrm{Cpx}$ & 2.29 & 0.10 & 4.44 & 0.20 & -49 & 5 & \\
\hline 4243 & Troctolite & $\mathrm{Ol}$ & 2.44 & 0.05 & 4.75 & 0.09 & -67 & 9 & 2 \\
\hline 4251 & Troctolite & $\mathrm{Ol}$ & 2.52 & 0.05 & 4.88 & 0.09 & -46 & 9 & \\
\hline 4260 & Troctolite & $\mathrm{Ol}$ & 2.50 & 0.05 & 4.82 & 0.09 & -44 & 9 & \\
\hline 4298 & Troctolite & $\mathrm{Ol}$ & 2.52 & 0.05 & 4.90 & 0.09 & -60 & 9 & \\
\hline 4400 & Troctolite & $\mathrm{Ol}$ & 2.59 & 0.05 & 5.01 & 0.09 & -47 & 9 & \\
\hline 4245 & Norite A1 & Plag & 3.01 & 0.09 & 5.81 & 0.16 & -48 & 7 & 0 \\
\hline 4270 & Norite A1 & Plag & 3.03 & 0.09 & 5.86 & 0.16 & -60 & 7 & \\
\hline 4290 & Norite A1 & Plag & 3.11 & 0.09 & 5.98 & 0.16 & -40 & 7 & \\
\hline 4292 & Norite A1 & Plag & 3.11 & 0.09 & 6.00 & 0.16 & -57 & 7 & \\
\hline 4390 & Norite A1 & Plag & 3.10 & 0.09 & 5.98 & 0.16 & -55 & 7 & \\
\hline 8756 & Norite A1 & Plag & 3.07 & 0.09 & 5.95 & 0.16 & -61 & 7 & \\
\hline 8757 & Norite A1 & Plag & 3.08 & 0.09 & 5.96 & 0.16 & -65 & 7 & \\
\hline 8761 & Norite A1 & Plag & 3.08 & 0.09 & 5.93 & 0.16 & -51 & 7 & \\
\hline 8763 & Norite A1 & Plag & 3.11 & 0.09 & 6.00 & 0.16 & -60 & 7 & \\
\hline 4262 & Norite A1 & Opx & 2.79 & 0.07 & 5.41 & 0.14 & -65 & 9 & 2 \\
\hline 4288 & Norite A1 & Opx & 2.85 & 0.07 & 5.48 & 0.14 & -38 & 9 & \\
\hline 4402 & Norite A1 & Opx & 2.94 & 0.07 & 5.70 & 0.14 & -65 & 9 & \\
\hline 5046 & Norite A1 & Opx & 2.87 & 0.07 & 5.53 & 0.14 & -47 & 9 & \\
\hline 5055 & Norite A1 & Opx & 2.77 & 0.07 & 5.35 & 0.14 & -54 & 9 & \\
\hline 5059 & Norite A1 & Opx & 2.76 & 0.07 & 5.36 & 0.14 & -65 & 9 & \\
\hline 5060 & Norite A1 & Opx & 2.81 & 0.07 & 5.45 & 0.14 & -68 & 9 & \\
\hline 8754 & Norite A1 & Opx & 2.94 & 0.07 & 5.70 & 0.14 & -62 & 9 & \\
\hline 8764 & Norite A1 & Opx & 2.96 & 0.07 & 5.73 & 0.14 & -63 & 9 & \\
\hline 4296 & Norite A1 & Amph & 2.48 & 0.14 & 4.82 & 0.26 & -56 & 9 & 0 \\
\hline 4399 & Norite A1 & Amph & 2.36 & 0.14 & 4.59 & 0.26 & -59 & 9 & \\
\hline 4401 & Norite A1 & Amph & 2.41 & 0.14 & 4.73 & 0.26 & -80 & 9 & \\
\hline 4408 & Norite A1 & Amph & 2.18 & 0.14 & 4.26 & 0.26 & -66 & 9 & \\
\hline 4412 & Norite A1 & Amph & 2.29 & 0.14 & 4.48 & 0.26 & -72 & 9 & \\
\hline 4457 & Norite A1 & Amph & 2.32 & 0.14 & 4.54 & 0.26 & -72 & 9 & \\
\hline 4455 & Norite A1 & Amph & 2.24 & 0.14 & 4.36 & 0.26 & -62 & 9 & \\
\hline 8753 & Norite A1 & Amph & 2.61 & 0.14 & 5.04 & 0.26 & -49 & 9 & \\
\hline 8760 & Norite A1 & Amph & 2.59 & 0.14 & 5.03 & 0.26 & -60 & 9 & \\
\hline 3350 & Norite A2 & Plag & 2.96 & 0.13 & 5.70 & 0.25 & -48 & 8 & \\
\hline 3352 & Norite A2 & Plag & 2.99 & 0.13 & 5.79 & 0.25 & -60 & 8 & \\
\hline 3353 & Norite A2 & Plag & 3.05 & 0.13 & 5.90 & 0.25 & -66 & 8 & \\
\hline 3355 & Norite A2 & Plag & 2.80 & 0.13 & 5.42 & 0.25 & -56 & 8 & \\
\hline 3434 & Norite A2 & Plag & 2.96 & 0.13 & 5.71 & 0.25 & -51 & 8 & \\
\hline 3435 & Norite A2 & Plag & 3.19 & 0.13 & 6.15 & 0.25 & -54 & 8 & \\
\hline 3446 & Norite A2 & Plag & 3.05 & 0.13 & 5.92 & 0.25 & -73 & 8 & \\
\hline 3779 & Norite A2 & Plag & 2.75 & 0.13 & 5.32 & 0.25 & -52 & 8 & \\
\hline 3786 & Norite A2 & Plag & 2.85 & 0.13 & 5.52 & 0.25 & -61 & 8 & \\
\hline 3496 & Norite A2 & Opx & 2.76 & 0.05 & 5.36 & 0.08 & -67 & 9 & 0 \\
\hline 3501 & Norite A2 & Opx & 2.78 & 0.05 & 5.42 & 0.08 & -76 & 9 & \\
\hline 3502 & Norite A2 & Opx & 2.74 & 0.05 & 5.28 & 0.08 & -48 & 9 & \\
\hline 3598 & Norite A2 & Opx & 2.83 & 0.05 & 5.45 & 0.08 & -44 & 9 & \\
\hline 3599 & Norite A2 & Opx & 2.88 & 0.05 & 5.58 & 0.08 & -61 & 9 & \\
\hline 5045 & Norite A2 & Opx & 2.84 & 0.05 & 5.50 & 0.08 & -56 & 9 & \\
\hline 5049 & Norite A2 & Opx & 2.84 & 0.05 & 5.49 & 0.08 & -55 & 9 & \\
\hline 5052 & Norite A2 & Opx & 2.88 & 0.05 & 5.57 & 0.08 & -52 & 9 & \\
\hline 5054 & Norite A2 & Opx & 2.80 & 0.05 & 5.42 & 0.08 & -59 & 9 & \\
\hline 5057 & Norite A2 & Opx & 2.80 & 0.05 & 5.40 & 0.08 & -49 & 9 & \\
\hline 8289 & Anorthosite B2 & Plag & 3.46 & 0.07 & 6.69 & 0.12 & -65 & 13 & 0 \\
\hline 8298 & Anorthosite B2 & Plag & 3.31 & 0.07 & 6.42 & 0.12 & -71 & 13 & \\
\hline 8340 & Anorthosite B2 & Plag & 3.38 & 0.07 & 6.55 & 0.12 & -71 & 13 & \\
\hline
\end{tabular}




\begin{tabular}{llllllllll}
8731 & Anorthosite B2 & Plag & 3.47 & 0.07 & 6.66 & 0.12 & -35 & 13 & \\
8743 & Anorthosite B2 & Plag & 3.51 & 0.07 & 6.78 & 0.12 & -62 & 13 & \\
8733 & Anorthosite B2 & Opx & 3.28 & 0.06 & 6.31 & 0.12 & -50 & 4 & \\
8299 & Anorthosite B2 & Chr & 1.22 & 0.07 & 2.41 & 0.14 & -52 & 6 & 0 \\
8338 & Anorthosite B2 & Chr & 1.32 & 0.07 & 2.58 & 0.14 & -48 & 6 & \\
8730 & Anorthosite B2 & Chr & 1.14 & 0.07 & 2.23 & 0.14 & -38 & 6 & \\
8281 & Anorthosite B3 & Plag & 3.52 & 0.07 & 6.78 & 0.13 & -59 & 5 & 0 \\
8297 & Anorthosite B3 & Plag & 3.34 & 0.07 & 6.45 & 0.13 & -63 & 5 & \\
8341 & Anorthosite B3 & Plag & 3.47 & 0.07 & 6.68 & 0.13 & -51 & 5 & \\
8734 & Anorthosite B3 & Plag & 3.50 & 0.07 & 6.75 & 0.13 & -53 & 5 & \\
8745 & Anorthosite B3 & Plag & 3.53 & 0.07 & 6.80 & 0.13 & -53 & 5 & \\
8736 & Anorthosite B3 & Opx & 3.28 & 0.06 & 6.33 & 0.12 & -59 & 4 & \\
8282 & Anorthosite B3 & Chr & 1.22 & 0.11 & 2.42 & 0.22 & -53 & 5 & 0 \\
8296 & Anorthosite B3 & Chr & 1.10 & 0.11 & 2.18 & 0.22 & -46 & 5 & \\
8342 & Anorthosite B3 & Chr & 1.20 & 0.11 & 2.36 & 0.22 & -46 & 5 & \\
8739 & Anorthosite B3 & Chr & 0.94 & 0.11 & 1.85 & 0.22 & -38 & 5 & \\
\hline
\end{tabular}

Table B.9: Results of the additional measurements of the norite A1 plagioclase separate to test the effect of different laser fluorination protocols (single measurements). We used the following abbreviations: conv. = conventional, prem. $=$ pre-melted., $\mathrm{G}=$ grains, $\mathrm{P}=$ powder.

\begin{tabular}{|c|c|c|c|c|c|c|c|c|c|}
\hline ID & Technique & Treatment & Material & $\begin{array}{l}\delta^{17} \mathrm{O} \\
(\%)\end{array}$ & SD & $\begin{array}{l}\delta^{18} \mathrm{O} \\
(\% o)\end{array}$ & SD & $\begin{array}{l}\Delta^{\prime 17} \mathrm{O} \\
(\mathrm{ppm})\end{array}$ & SD \\
\hline 5311 & conv. & non & $\mathrm{G}$ & 2.89 & 0.09 & 5.58 & 0.16 & -50 & 7 \\
\hline 5312 & conv. & non & $\mathrm{G}$ & 2.82 & 0.09 & 5.45 & 0.16 & -60 & 7 \\
\hline 5314 & conv. & non & G & 2.95 & 0.09 & 5.73 & 0.16 & -69 & 7 \\
\hline 5316 & conv. & non & $\mathrm{G}$ & 2.96 & 0.09 & 5.74 & 0.16 & -65 & 7 \\
\hline Average & conv. & non & G & 2.91 & 0.04 & 5.63 & 0.08 & -61 & 3 \\
\hline 6620 & conv. & non & $\mathrm{P}$ & 2.94 & 0.09 & 5.68 & 0.16 & -60 & 7 \\
\hline 6621 & conv. & non & $\mathrm{P}$ & 3.13 & 0.09 & 6.04 & 0.16 & -54 & 7 \\
\hline 6622 & conv. & non & $\mathrm{P}$ & 3.12 & 0.09 & 6.03 & 0.16 & -61 & 7 \\
\hline 6686 & conv. & non & $\mathrm{P}$ & 3.09 & 0.09 & 5.98 & 0.16 & -58 & 7 \\
\hline 6687 & conv. & non & $\mathrm{P}$ & 3.10 & 0.09 & 5.98 & 0.16 & -55 & 7 \\
\hline 6690 & conv. & non & $\mathrm{P}$ & 2.98 & 0.09 & 5.76 & 0.16 & -60 & 7 \\
\hline 6691 & conv. & non & $\mathrm{P}$ & 3.06 & 0.09 & 5.91 & 0.16 & -56 & 7 \\
\hline 6692 & conv. & non & $\mathrm{P}$ & 3.10 & 0.09 & 5.96 & 0.16 & -45 & 7 \\
\hline Average & conv. & non & $\mathbf{P}$ & 3.06 & 0.03 & 5.92 & 0.06 & -56 & 2 \\
\hline 5319 & conv. & prem. & $\mathrm{G}$ & 2.92 & 0.09 & 5.66 & 0.16 & -64 & 7 \\
\hline 5320 & conv. & prem. & $\mathrm{G}$ & 2.99 & 0.09 & 5.78 & 0.16 & -62 & 7 \\
\hline 5322 & conv. & prem. & $\mathrm{G}$ & 3.00 & 0.09 & 5.79 & 0.16 & -58 & 7 \\
\hline 5323 & conv. & prem. & $\mathrm{G}$ & 2.98 & 0.09 & 5.77 & 0.16 & -59 & 7 \\
\hline Average & conv. & prem. & $\mathbf{G}$ & 2.97 & 0.04 & 5.75 & 0.08 & -60 & 3 \\
\hline 6726 & conv. & prem. & $\mathrm{P}$ & 3.08 & 0.09 & 5.95 & 0.16 & -60 & 7 \\
\hline 6727 & conv. & prem. & $\mathrm{P}$ & 3.08 & 0.09 & 5.96 & 0.16 & -64 & 7 \\
\hline 6730 & conv. & prem. & $\mathrm{P}$ & 3.06 & 0.09 & 5.91 & 0.16 & -61 & 7 \\
\hline 6731 & conv. & prem. & $\mathrm{P}$ & 3.09 & 0.09 & 6.00 & 0.16 & -72 & 7 \\
\hline 6735 & conv. & prem. & $\mathrm{P}$ & 3.14 & 0.09 & 6.06 & 0.16 & -60 & 7 \\
\hline Average & conv. & prem. & $\mathbf{P}$ & 3.09 & 0.04 & 5.98 & 0.07 & -63 & 3 \\
\hline 5330 & air lock & non & $\mathrm{G}$ & 2.97 & 0.09 & 5.75 & 0.16 & -63 & 7 \\
\hline 5331 & air lock & non & $\mathrm{G}$ & 2.92 & 0.09 & 5.65 & 0.16 & -59 & 7 \\
\hline 5334 & air lock & non & $\mathrm{G}$ & 2.88 & 0.09 & 5.57 & 0.16 & -63 & 7 \\
\hline 5344 & air lock & non & G & 2.97 & 0.09 & 5.77 & 0.16 & -71 & 7 \\
\hline Average & air lock & non & G & 2.93 & 0.04 & 5.69 & 0.08 & -64 & 3 \\
\hline 6635 & air lock & non & $\mathrm{P}$ & 3.15 & 0.09 & 6.11 & 0.16 & -68 & 7 \\
\hline 6636 & air lock & non & $\mathrm{P}$ & 3.06 & 0.09 & 5.94 & 0.16 & -72 & 7 \\
\hline 6650 & air lock & non & $\mathrm{P}$ & 3.03 & 0.09 & 5.86 & 0.16 & -60 & 7 \\
\hline Average & air lock & non & $\mathbf{P}$ & 3.08 & 0.05 & 5.97 & 0.09 & -67 & 4 \\
\hline 5332 & air lock & prem. & $\mathbf{G}$ & 2.96 & 0.09 & 5.74 & 0.16 & -67 & \\
\hline 6637 & air lock & prem. & $\mathrm{P}$ & 3.19 & 0.09 & 6.16 & 0.16 & -59 & 7 \\
\hline 6648 & air lock & prem. & $\mathrm{P}$ & 3.13 & 0.09 & 6.06 & 0.16 & -65 & 7 \\
\hline 6649 & air lock & prem. & $\mathrm{P}$ & 3.18 & 0.09 & 6.15 & 0.16 & -64 & 7 \\
\hline Average & air lock & prem. & $\mathbf{P}$ & 3.17 & 0.05 & 6.12 & 0.09 & -63 & 4 \\
\hline
\end{tabular}


B Supplementary information: Triple oxygen isotope fractionation in feldspar-rich rocks

Table B.10: Results of the oxygen isotope measurements of the San Carlos olivine fraction 0215M (single measurements).

\begin{tabular}{|c|c|c|c|c|c|c|c|}
\hline ID & $\begin{array}{l}\delta^{17} \mathrm{O} \\
(\% \circ)\end{array}$ & SD & $\begin{array}{l}\delta^{18} \mathrm{O} \\
(\% o)\end{array}$ & SD & $\begin{array}{l}\Delta^{\prime 17} \mathrm{O} \\
(\mathrm{ppm})\end{array}$ & SD & Outlier \\
\hline 3299 & 2.66 & 0.05 & 5.12 & 0.09 & -43 & 8 & 0 \\
\hline 3302 & 2.70 & 0.05 & 5.24 & 0.09 & -61 & 8 & \\
\hline 3313 & 2.75 & 0.05 & 5.29 & 0.09 & -42 & 8 & \\
\hline 3320 & 2.61 & 0.05 & 5.07 & 0.09 & -61 & 8 & \\
\hline 3348 & 2.80 & 0.05 & 5.40 & 0.09 & -45 & 8 & \\
\hline 3351 & 2.56 & 0.05 & 4.96 & 0.09 & -59 & 8 & \\
\hline 3356 & 2.68 & 0.05 & 5.18 & 0.09 & -52 & 8 & \\
\hline 3358 & 2.69 & 0.05 & 5.22 & 0.09 & -59 & 8 & \\
\hline 3361 & 2.66 & 0.05 & 5.14 & 0.09 & -45 & 8 & \\
\hline 3366 & 2.66 & 0.05 & 5.14 & 0.09 & -50 & 8 & \\
\hline 3375 & 2.70 & 0.05 & 5.23 & 0.09 & -53 & 8 & \\
\hline 3430 & 2.68 & 0.05 & 5.18 & 0.09 & -52 & 8 & \\
\hline 3445 & 2.69 & 0.05 & 5.18 & 0.09 & -45 & 8 & \\
\hline 3447 & 2.67 & 0.05 & 5.18 & 0.09 & -58 & 8 & \\
\hline 3468 & 2.68 & 0.05 & 5.18 & 0.09 & -52 & 8 & \\
\hline 3471 & 2.68 & 0.05 & 5.18 & 0.09 & -52 & 8 & \\
\hline 3495 & 2.68 & 0.05 & 5.18 & 0.09 & -52 & 8 & \\
\hline 3503 & 2.68 & 0.05 & 5.18 & 0.09 & -52 & 8 & \\
\hline 3597 & 2.68 & 0.05 & 5.18 & 0.09 & -52 & 8 & \\
\hline 3605 & 2.71 & 0.05 & 5.23 & 0.09 & -48 & 8 & \\
\hline 3609 & 2.65 & 0.05 & 5.13 & 0.09 & -55 & 8 & \\
\hline 3724 & 2.66 & 0.05 & 5.10 & 0.09 & -33 & 8 & \\
\hline 3727 & 2.75 & 0.05 & 5.30 & 0.09 & -48 & 8 & \\
\hline 3730 & 2.64 & 0.05 & 5.14 & 0.09 & -74 & 8 & \\
\hline 3770 & 2.77 & 0.05 & 5.35 & 0.09 & -51 & 8 & \\
\hline 3778 & 2.70 & 0.05 & 5.20 & 0.09 & -43 & 8 & \\
\hline 3785 & 2.75 & 0.05 & 5.33 & 0.09 & -55 & 8 & \\
\hline 4241 & 2.66 & 0.04 & 5.17 & 0.07 & -61 & 6 & \\
\hline 4246 & 2.70 & 0.04 & 5.19 & 0.07 & -43 & 6 & \\
\hline 4256 & 2.74 & 0.04 & 5.30 & 0.07 & -56 & 6 & \\
\hline 4259 & 2.69 & 0.04 & 5.20 & 0.07 & -49 & 6 & \\
\hline 4271 & 2.71 & 0.04 & 5.25 & 0.07 & -53 & 6 & \\
\hline 4285 & 2.63 & 0.04 & 5.10 & 0.07 & -58 & 6 & \\
\hline 4295 & 2.75 & 0.04 & 5.31 & 0.07 & -48 & 6 & \\
\hline 4394 & 2.75 & 0.04 & 5.31 & 0.07 & -54 & 6 & \\
\hline 4387 & 2.68 & 0.04 & 5.16 & 0.07 & -45 & 6 & \\
\hline 4413 & 2.75 & 0.04 & 5.33 & 0.07 & -59 & 6 & \\
\hline 4461 & 2.71 & 0.04 & 5.24 & 0.07 & -55 & 6 & \\
\hline Average & 2.69 & 0.01 & 5.20 & 0.01 & -52 & 1 & \\
\hline
\end{tabular}

Table B.11: Results of the oxygen isotope measurements of the San Carlos olivine fraction 0919 (single measurements).

\begin{tabular}{cccccccc}
\hline ID & $\begin{array}{l}\delta^{17} \mathrm{O} \\
(\%)\end{array}$ & $\mathrm{SD}$ & $\begin{array}{l}\delta^{18} \mathrm{O} \\
(\%)\end{array}$ & $\mathrm{SD}$ & $\begin{array}{l}{\Delta^{\prime 17} \mathrm{O}}^{17} \\
(\mathrm{ppm})\end{array}$ & SD & Outlier \\
\hline 8280 & 2.70 & 0.06 & 5.22 & 0.12 & -49 & 4 & 0 \\
8294 & 2.83 & 0.06 & 5.46 & 0.12 & -55 & 4 & \\
8336 & 2.78 & 0.06 & 5.38 & 0.12 & -51 & 4 & \\
8337 & 2.79 & 0.06 & 5.40 & 0.12 & -52 & 4 & \\
8343 & 2.71 & 0.06 & 5.24 & 0.12 & -52 & 4 & \\
8729 & 2.85 & 0.06 & 5.50 & 0.12 & -53 & 4 & \\
8732 & 2.70 & 0.06 & 5.23 & 0.12 & -55 & 4 & \\
8735 & 2.79 & 0.06 & 5.39 & 0.12 & -54 & 4 & \\
8741 & 2.65 & 0.06 & 5.11 & 0.12 & -45 & 4 & \\
8747 & 2.83 & 0.06 & 5.47 & 0.12 & -52 & 4 & \\
Average & $\mathbf{2 . 7 6}$ & $\mathbf{0 . 0 2}$ & $\mathbf{5 . 3 4}$ & $\mathbf{0 . 0 4}$ & $\mathbf{- 5 2}$ & $\mathbf{1}$ & \\
\hline
\end{tabular}


Table B.12: Results of the oxygen isotope measurements of UWG-2 (fraction \#180 and \#200; single measurements).

\begin{tabular}{|c|c|c|c|c|c|c|c|}
\hline ID & $\begin{array}{l}\delta^{17} \mathrm{O} \\
(\% o)\end{array}$ & SD & $\begin{array}{l}\delta^{18} \mathrm{O} \\
(\% o)\end{array}$ & SD & $\begin{array}{l}\Delta^{\prime 17} \mathrm{O} \\
(\mathrm{ppm})\end{array}$ & SD & Outlier \\
\hline 3602 & 2.96 & 0.05 & 5.69 & 0.04 & -43 & 10 & 3 \\
\hline 3773 & 2.88 & 0.05 & 5.58 & 0.04 & -60 & 10 & \\
\hline 3784 & 2.88 & 0.05 & 5.58 & 0.04 & -65 & 10 & \\
\hline 4249 & 2.94 & 0.08 & 5.67 & 0.04 & -46 & 6 & \\
\hline 4254 & 2.94 & 0.08 & 5.72 & 0.04 & -69 & 6 & \\
\hline 4263 & 2.93 & 0.08 & 5.67 & 0.04 & -61 & 6 & \\
\hline 4293 & 2.95 & 0.08 & 5.71 & 0.04 & -57 & 6 & \\
\hline 4391 & 2.91 & 0.08 & 5.63 & 0.04 & -65 & 6 & \\
\hline 4398 & 2.97 & 0.08 & 5.75 & 0.04 & -60 & 6 & \\
\hline 4406 & 2.93 & 0.08 & 5.66 & 0.04 & -51 & 6 & \\
\hline 4411 & 2.94 & 0.08 & 5.69 & 0.04 & -62 & 6 & \\
\hline 4453 & 2.94 & 0.08 & 5.69 & 0.04 & -57 & 6 & \\
\hline 5047 & 3.00 & 0.08 & 5.80 & 0.04 & -55 & 6 & \\
\hline 5053 & 2.99 & 0.08 & 5.77 & 0.04 & -55 & 6 & \\
\hline 5056 & 2.94 & 0.08 & 5.69 & 0.04 & -58 & 6 & \\
\hline 5061 & 2.95 & 0.08 & 5.74 & 0.04 & -72 & 6 & \\
\hline 5308 & 2.97 & 0.02 & 5.76 & 0.03 & -65 & 8 & \\
\hline 5315 & 3.00 & 0.02 & 5.77 & 0.03 & -50 & 8 & \\
\hline 5321 & 2.94 & 0.02 & 5.68 & 0.03 & -62 & 8 & \\
\hline 5324 & 2.96 & 0.02 & 5.72 & 0.03 & -62 & 8 & \\
\hline 5329 & 2.98 & 0.02 & 5.74 & 0.03 & -48 & 8 & \\
\hline 5333 & 2.96 & 0.02 & 5.74 & 0.03 & -75 & 8 & \\
\hline 5335 & 2.97 & 0.02 & 5.72 & 0.03 & -56 & 8 & \\
\hline 6618 & 2.91 & 0.04 & 5.62 & 0.07 & -57 & 5 & \\
\hline 6623 & 3.02 & 0.04 & 5.84 & 0.07 & -62 & 5 & \\
\hline 6634 & 3.01 & 0.04 & 5.82 & 0.07 & -67 & 5 & \\
\hline 6638 & 2.91 & 0.04 & 5.64 & 0.07 & -68 & 5 & \\
\hline 6647 & 2.96 & 0.04 & 5.71 & 0.07 & -54 & 5 & \\
\hline 6651 & 2.97 & 0.04 & 5.76 & 0.07 & -66 & 5 & \\
\hline 6685 & 3.00 & 0.04 & 5.80 & 0.07 & -57 & 5 & \\
\hline 6689 & 2.94 & 0.04 & 5.69 & 0.07 & -60 & 5 & \\
\hline 6693 & 2.95 & 0.04 & 5.72 & 0.07 & -63 & 5 & \\
\hline 6725 & 2.99 & 0.04 & 5.78 & 0.07 & -61 & 5 & \\
\hline 6728 & 2.96 & 0.04 & 5.70 & 0.07 & -54 & 5 & \\
\hline 6736 & 2.96 & 0.04 & 5.72 & 0.07 & -65 & 5 & \\
\hline 8752 & 2.86 & 0.08 & 5.52 & 0.04 & -56 & 6 & \\
\hline 8755 & 2.96 & 0.08 & 5.72 & 0.04 & -58 & 6 & \\
\hline 8759 & 3.02 & 0.08 & 5.84 & 0.04 & -57 & 6 & \\
\hline 8762 & 3.06 & 0.08 & 5.93 & 0.04 & -67 & 6 & \\
\hline 8766 & 2.96 & 0.08 & 5.73 & 0.04 & -61 & 6 & \\
\hline Average & 2.96 & 0.01 & 5.72 & 0.01 & -60 & 1 & \\
\hline
\end{tabular}




\section{B Supplementary information: Triple oxygen isotope fractionation in feldspar-rich}

rocks

Table B.13: Crystallisation temperatures based on oxygen isotope data. Numbers in grey print are exceeding or falling below the temperature range of the respective calibration. More details concerning the calculation of the oxygen isotope temperatures are reported in table B.14. Crystallisation temperatures based on chemical data were calculated for the following mineral pairs: cpxol: $1100^{\circ} \mathrm{C}$ (Loucks 1996); plag-amph: $940^{\circ} \mathrm{C}$ (Blundy and Holland 1990), $860^{\circ} \mathrm{C}$ (Holland and Blundy 1994). The following abbreviations were used: $\mathrm{T}=$ troctolite, $\mathrm{N}-\mathrm{A} 1=$ norite $\mathrm{A} 1, \mathrm{~N}-\mathrm{A} 2=$ norite $\mathrm{A} 2, \mathrm{~A}-\mathrm{B} 2=$ anorthosite $\mathrm{B} 2, \mathrm{~A}-\mathrm{B} 2=$ anorthosite $\mathrm{B} 3$, plagioclase (plag), orthopyroxene (opx), clinopyroxene (cpx), olivine (ol), amphibole (amph), chromite (chr).

\begin{tabular}{|c|c|c|c|c|c|}
\hline Sample & Mineral pair & Zheng (1991, 1993a,b) & $\begin{array}{c}\text { Oxygen isotope } \boldsymbol{T}\left({ }^{\circ} \mathbf{C}\right) \\
\text { Chiba et al. }(1989)\end{array}$ & Matthews et al. (1983) & Bottinga and Javoy (1975) \\
\hline $\mathrm{T}$ & plag-cpx & 750 & 760 & 660 & 780 \\
\hline $\mathrm{T}$ & plag-ol & 1400 & 1400 & - & 1600 \\
\hline $\mathrm{T}$ & cpx-ol & - & - & - & - \\
\hline $\mathrm{N}-\mathrm{A} 1$ & plag-opx & 1000 & 1200 & 1000 & 1180 \\
\hline $\mathrm{N}-\mathrm{A} 1$ & plag-amph & 540 & - & - & 620 \\
\hline $\mathrm{N}-\mathrm{A} 1$ & opx-amph & 230 & - & - & 370 \\
\hline $\mathrm{N}-\mathrm{A} 2$ & plag-opx & 1170 & 1400 & 1260 & 1450 \\
\hline A-B2 & plag-opx & 1080 & 1290 & 1150 & 1320 \\
\hline A-B2 & plag-chr & 700 & - & - & 630 \\
\hline A-B2 & opx-chr & 670 & - & - & 560 \\
\hline A-B3 & plag-opx & 990 & 1180 & 1050 & 1200 \\
\hline A-B3 & plag-chr & 680 & - & - & 600 \\
\hline A-B3 & opx-chr & 650 & - & - & 540 \\
\hline
\end{tabular}

Table B.14: Details concerning the match between the studied mineral assemblages and the assumed mineral pairs of the respective thermometry studies. The following abbreviations were used: $\mathrm{T}=$ troctolite, $\mathrm{N}-\mathrm{A} 1=$ norite $\mathrm{A} 1, \mathrm{~N}-\mathrm{A} 2=$ norite $\mathrm{A} 2, \mathrm{~A}-\mathrm{B} 2=$ anorthosite $\mathrm{B} 2, \mathrm{~A}-\mathrm{B} 2$ = anorthosite B3, An = anorthite content.

\begin{tabular}{cccccc} 
Sample & Mineral pair & Zheng (1991, 1993a,b) & Chiba et al. (1989) & Matthews et al. (1983) & Bottinga and Javoy (1975) \\
\hline $\mathrm{T}$ & An87-diopside & An100-diopside & An100-diopside & An87-diopside & An87-pyroxene \\
$\mathrm{T}$ & An87-forsterite & An100-forsterite & An100-forsterite & - & An87-olivine \\
$\mathrm{T}$ & diopside-forsterite & diopside-forsterite & diopside-forsterite & - & pyroxene-olivine \\
N-A1 & An92-enstatite & An100-enstatite & An100-diopside & An92-diopside & An92-pyroxene \\
N-A1 & An92-hornblende & An100-hornblende & - & - & An92-amphibole \\
N-A1 & enstatite-hornblende & enstatite-hornblende & - & pyroxene-amphibole \\
N-A2 & An87-enstatite & An100-enstatite & An100-diopside & An87-diopside & An87-pyroxene \\
A-B2 & An74-enstatite & An100-enstatite & An100-diopside & An87-diopside & An87-pyroxene \\
A-B2 & An74-chromite & An100-chromite & - & - & An87-chromite \\
A-B2 & enstatite-chromite & enstatite-chromite & - & - & pyroxene-chromite \\
A-B3 & An77-enstatite & An100-enstatite & An100-diopside & An87-diopside & An87-pyroxene \\
A-B3 & An77-chromite & An100-chromite & - & - & An87-chromite \\
A-B3 & enstatite-chromite & enstatite-chromite & - & pyroxene-chromite & \\
\hline
\end{tabular}

Table B.15: Individual $\theta$ values $\pm \mathrm{SD}_{\mathrm{MS}}$ of the studied mineral pairs. $\mathrm{SD}_{\mathrm{MS}}$ was determined using Monte Carlo simulations $(N=5000)$. The following abbreviations were used: plagioclase (plag), orthopyroxene (opx), clinopyroxene (cpx), olivine (ol), amphibole (amph), chromite (chr).

\begin{tabular}{|c|c|c|c|c|c|}
\hline & Troctolite & Norite A1 & Norite A2 & Anorthosite B2 & Anorthosite B3 \\
\hline$\theta_{\text {plag-px }}$ & 0.528 & 0.521 & 0.525 & 0.492 & 0.536 \\
\hline $\pm 1 \sigma$ & 0.145 & 0.100 & 3.825 & 0.300 & 0.262 \\
\hline $\begin{array}{c}\theta_{\text {plag-ol }} \\
\pm 1 \sigma\end{array}$ & $\begin{array}{l}0.546 \\
0.180\end{array}$ & - & - & - & - \\
\hline $\begin{array}{c}\theta_{\text {plag-amph }} \\
\pm 1 \sigma\end{array}$ & - & $\begin{array}{l}0.536 \\
0.004\end{array}$ & - & - & - \\
\hline $\begin{array}{l}\theta_{\text {plag-chr }} \\
\quad \pm 1 \sigma\end{array}$ & - & - & - & $\begin{array}{l}0.527 \\
0.016\end{array}$ & $\begin{array}{l}0.525 \\
0.017\end{array}$ \\
\hline $\begin{array}{c}\theta_{p x-o l} \\
\pm 1 \sigma\end{array}$ & $\begin{array}{l}0.532 \\
2.864\end{array}$ & - & - & - & - \\
\hline $\begin{array}{l}\theta_{p x-a m p h} \\
\quad \pm 1 \sigma\end{array}$ & - & $\begin{array}{l}0.531 \\
0.075\end{array}$ & - & - & - \\
\hline $\begin{array}{c}\theta_{p x-c h r} \\
\pm 1 \sigma\end{array}$ & - & - & - & $\begin{array}{l}0.524 \\
0.031\end{array}$ & $\begin{array}{l}0.526 \\
0.030\end{array}$ \\
\hline
\end{tabular}




\section{Supplementary information: Tight bounds on missing late veneer in early Archean peridotite from triple oxygen isotopes}

\section{C.1 Sample suite}

We determined the triple oxygen isotope compositions of olivine from a suite of postArchean, off-cratonic spinel lherzolite xenoliths, with the exceptions of samples from Hawaii and Beni Boussera, which are dunites. The majority of samples were erupted in continental intraplate magmas, with some samples having erupted in continental rift settings. We studied xenoliths from the East-African Rift system (Great Rift Valley, Ethiopia), the European Cenozoic Rift System (French Massif Central, West Eifel, Hessian Graben, Vogelsberg volcanic field, Ohře/Eger Graben), the Rio Grande Rift (Potrillo Volcanic Field, USA), the Middle Atlas mountains, (Tafraout maar, Morocco), the West Antarctic Rift (Mt. Melbourne volcanic field), and the Eastern block of the North China craton (Changle volcano). In order to investigate whether $\Delta^{\prime 17} \mathrm{O}$ values of subcontinental lithospheric mantle peridotite could potentially have been affected by metasomatic processes or processes of re-fertilisation, we also determined the triple oxygen isotope composition of a peridotite xenolith from the Dariganga volcanic plateau, Mongolia (sample $8520-12$ ), that was previously reported to have a $\delta^{18} \mathrm{O}_{\mathrm{ol}}$ value of $5.50 \pm 0.09 \%$ (Wiechert et al. 1997), i.e., a higher $\delta^{18} \mathrm{O}_{\mathrm{ol}}$ value than typical mantle peridotite $\left(\delta^{18} \mathrm{O}_{\mathrm{ol}} \sim 5.2 \%\right.$ o $)$. We did not reproduce the elevated $\delta^{18} \mathrm{O}_{\mathrm{ol}}$ value for this sample, and measured a $\delta^{18} \mathrm{O}_{\mathrm{ol}}$ of $5.15 \pm 0.06 \%$ (table C.1). A sample of orogenic peridotite from the Beni Boussera lherzolite massif in Morocco (14BB2) was included in the sample suite as well. Samples from the suboceanic lithospheric mantle were also measured, and include peridotite xenoliths that were erupted in ocean island basalts (OIBs) from Hawaii (Hualālai volcano), Lanzarote, and Tenerife.

We then determined the triple oxygen isotope compositions of olivine in Archean peridotite, predominantly of dunite composition, from the ultramafic enclaves in the Itsaq Gneiss Complex (IGC) and Fiskefjord region of southwest Greenland. We studied peridotite samples from two localities in the $>3.7 \mathrm{Ga}$ Isua supracrustal belt (ISB) (Dymek et al. 1988, Friend et al. 2002, Friend and Nutman 2011), one locality south of the Isua supracrustal belt (SOISB; Bennett et al. 2002, Friend et al. 2002, van de Löcht et al. 2020), the $\sim 3.8 \mathrm{Ga}$ Narssaq ultramafic body (NUB; Nutman et al. 2007, van de Löcht et al. 
2020), and the $~ 3.8$ Ga Ujaragssuit Nunât ultramafic body (Lowry et al. 2003, Rollinson et al. 2002). Each of these ultramafic enclaves carries an s-process Ru excess compared to the BSE (Fischer-Gödde et al. 2020). The samples from SOISB (10-27, 10-28) and one sample from NUB (10-09) that were analysed in the present study are aliquots of the same samples for which (Fischer-Gödde et al. 2020) also reported s-process excess Ru. The petrogenesis of these particular samples is discussed in detail by van de Löcht et al. (2020). We also determined the triple oxygen isotope compositions of olivine from ultramafic enclaves in the Mesoarchean Fiskefjord region that are geologically related to the Seqi peridotite body (Szilas et al. 2015a), for which excess s-process Ru compared to the bulk silicate Earth was also reported (Fischer-Gödde et al. 2020). Most of the ultramafic enclaves that were studied have been interpreted as slivers of residual mantle peridotite that were entrained in the Archean crust (Nutman et al. 1996, Bennett et al. 2002, Friend et al. 2002, Rollinson 2007, van de Löcht et al. 2018, 2020) or, alternatively, as cumulates from (ultra)mafic magmas (e.g., Dymek et al. 1988, Frei et al. 2004, Szilas et al. 2015a,b). The Ujaragssuit Nunât ultramafic body was interpreted as a layered intrusion with intact magmatic layering (Rollinson et al. 2002).

A common feature of the ultramafic enclaves from the IGC and Fiskefjord region is that forsterite contents in olivine can range up to comparatively high values, with forsterite contents up to $98 \mathrm{~mol} \%$ reported in samples from the ultramafic lenses of Isua (Friend and Nutman 2011). Magnetite is often present in the peridotite samples as well, and in some cases the presence of Ti-clinohumite has been reported (Dymek et al. 1988, Friend and Nutman 2011). These features are in notable agreement with our interpretation that some olivine in the ultramafic enclaves possibly formed by the dehydration of serpentinite minerals (Nishio et al. 2019, Peters et al. 2020b). For 3 samples from SOIB and NUB this interpretation is also in line with disturbed internal ${ }^{87} \mathrm{Rb}_{-}{ }^{87} \mathrm{Sr}$ and ${ }^{147} \mathrm{Sm}_{-}{ }^{143} \mathrm{Nd}$ isochrons, which suggest multiple overprints by fluids for these particular samples (van de Löcht 2019).

\section{C.2 Analytical methods}

Hand specimens of rock samples were crushed and sieved in different grain size fractions, such that inclusion-free, alteration-free olivine grains could be hand-picked under a binocular microscope for analysis. The samples were reacted with excess $\mathrm{BrF}_{5}$ in a stainless-steel sample chamber at a pressure of ca. 120 mbar, using a laser for heating of the samples. The equivalent sample mass of $\sim 30 \mu \mathrm{mol} \mathrm{O} \mathrm{O}_{2}$ (i.e., $2.0-2.2 \mathrm{mg}$ olivine) was reacted, meaning that a single extraction of $\mathrm{O}_{2}$ typically comprised 1-4 olivine grains for samples of mantle peridotite xenoliths and 5-10 olivine grains for samples of the Archean ultramafic enclaves in southwest Greenland. The $\mathrm{O}_{2}$ that was released from the samples was cleaned from contaminant gases in a vacuum line using liquid nitrogen-based cooling techniques, $\mathrm{NaCl}$ and a Hewlett Packard 5890 Series II gas chromatograph at $50{ }^{\circ} \mathrm{C}$ (Pack et al. 2016, Peters et al. 2020b). Most of this cleaning procedure had been automated and was pc-operated using LabView $^{T M}$. After cleaning the sample gas, it was transferred into a cold trap with $5 \AA$ molecular sieve beads, using a He stream at a flowrate of $10 \mathrm{ml} \mathrm{min}^{-1}$. After He was evacuated from this trap, the sample was expanded into a bellow of a Thermo Scientific ${ }^{T M}$ MAT $253^{T M}$ gas source mass spectrometer by heating the trap in a water bath 
at $50{ }^{\circ} \mathrm{C}$. The $\delta^{17} \mathrm{O}$ and $\delta^{18} \mathrm{O}$ values of the samples were then determined by measuring $\mathrm{O}_{2}^{+}$ion beams with $m / z=32,33,34$, for $\sim 40$ minutes, relative to a reference gas that was calibrated against the VSMOW2 and SLAP2 water standards (Pack et al. 2016).

The triple oxygen isotope compositions of the samples are reported here relative to the composition of San Carlos olivine. Analytical sessions typically comprised measurements of 8 samples that were bracketed by in total 6 measurements of San Carlos olivine, for each individual session. Two different fractions of San Carlos olivine were used for bracketing throughout the course of this study. These two fractions have identical $\Delta^{\prime 17} \mathrm{O}$ values at the level of $<1 \mathrm{ppm}$, but have apparently different $\delta^{18} \mathrm{O}$ values: One fraction $(\mathrm{SC} 0215 \mathrm{M})$ has a long-term $\delta^{18} \mathrm{O}=5.18 \pm 0.01 \%$ o $(N=52)$, whereas the other fraction (SC 0919) has a long-term $\delta^{18} \mathrm{O}=5.34 \pm 0.01 \%$ o $(N=91)$, relative to the composition of UWG-2 garnet $=5.74 \%$ (Valley et al. 1995). The samples were normalised to a $\Delta^{\prime 17} \mathrm{O}$ value of San Carlos olivine of $-51.8 \mathrm{ppm}$, which is the average $\Delta^{\prime 17} \mathrm{O}$ value for San Carlos olivine from the studies by Pack et al. (2016), Sharp et al. (2016), Wostbrock et al. (2020).

\section{C.3 Determining the bulk silicate Earth $\Delta^{\prime 17} \mathrm{O}$ value}

The $\Delta^{\prime 17} \mathrm{O}$ of the bulk silicate Earth (BSE) was determined in previous studies with precisions of up to ca. 2-3 ppm (1 SD) relative to the composition of San Carlos olivine (Cano et al. 2020; Greenwood et al. 2018 with data from Starkey et al. 2016; Herwartz et al. 2014 with data from Pack and Herwartz 2014). Some of the samples that were included in these previous studies, however, possibly do not have representative $\Delta^{\prime 17} \mathrm{O}$ values for the BSE. Greenwood et al. (2018) and Cano et al. (2020) included in their studies a number of glasses and phenocrysts from mid-ocean ridge basalts. However, mid-ocean ridge basalts contain on average $2 \%$ oxygen from subducted, altered oceanic crust and sediments with a $\delta^{18} \mathrm{O}$ of $\sim 10.5 \%$ o (Eiler 2001). The $\Delta^{\prime 17} \mathrm{O}$ values of high- $\delta^{18} \mathrm{O}$ altered oceanic crust and sediments are several tens of ppm lower than fertile mantle peridotite (Sengupta and Pack 2018), implying that the $\Delta^{\prime 17} \mathrm{O}$ values of MORB can potentially be lower than fertile mantle peridotite at the level $<5 \mathrm{ppm}$. Greenwood et al. (2018) also included samples from ocean island basalts (OIBs) in their study that were later interpreted to possibly reflect a component of subducted, altered oceanic crust in the mantle sources of the OIB samples (Cao et al. 2019). We propose here that olivine in fertile mantle peridotite is possibly a more representative sample type to determine the $\Delta^{\prime 17} \mathrm{O}$ of the BSE than mantle melts. Whereas olivine in mantle peridotite can potentially have exchanged oxygen isotopes with fluids and/or melts in the mantle, the oxygen isotope compositions of those fluids and/or melts would have been buffered by the oxygen isotope composition of mantle olivine (Chazot et al. 1997, Mattey et al. 1994). Indeed, there seems little variation in $\delta^{18} \mathrm{O}_{\mathrm{ol}}$ values of mantle peridotite, even if mantle peridotite samples are considered that experienced pervasive metasomatism (Chazot et al. 1997, Mattey et al. 1994, Regier et al. 2018).

We focused in our study on the analysis of olivine for multiple reasons. First, in mantle peridotite samples, the oxygen isotope composition of olivine is expected to be less affected by possible processes of mantle metasomatism compared to ortho- and clinopyroxene (Perkins et al. 2006), if any of such effects are present in mantle peridotite at all. In the Archean peridotite samples, we additionally focused on the analysis of hand-picked 
olivine grains to avoid incipient serpentinisation of the samples from obscuring the measured oxygen isotope compositions. Focusing on the triple oxygen isotopes compositions of olivine had the additional advantage that possible mineral-dependent effects during the analytical procedure (e.g. Young et al. 2016) or hypothesised mineral-specific crystalchemical effects in $\Delta^{\prime 17} \mathrm{O}$ (Kohl et al. 2017) do not affect the conclusions presented here.

\section{C.4 Mass balance calculations for missing late veneer}

Whereas the precise $\delta^{\mathrm{i}} \mathrm{O}$ values of the pre-late veneer mantle are unknown, they can be calculated from the suggested $\Delta^{\prime 17} \mathrm{O}$ value of the pre-late veneer mantle for an assumed composition of the late veneer. In $\delta^{17} \mathrm{O}$ versus $\delta^{18} \mathrm{O}$ space, the compositions of the prelate veneer mantle, the bulk silicate Earth and late veneer plot, by definition, on a mixing line (fig. C.1A). The slope $m$ and intercept $i$ of the mixing line can be calculated from the $\delta^{17} \mathrm{O}$ and $\delta^{18} \mathrm{O}$ values of the bulk silicate Earth (BSE) and late veneer (LV):

$$
\delta^{17} \mathrm{O}=m \cdot \delta^{18} \mathrm{O}+i
$$

with:

$$
m=\frac{\delta^{17} \mathrm{O}_{L V}-\delta^{17} \mathrm{O}_{B S E}}{\delta^{18} \mathrm{O}_{L V}-\delta^{18} \mathrm{O}_{B S E}}
$$

and

$$
i=\delta^{17} \mathrm{O}_{L V}-m \cdot \delta^{18} \mathrm{O}_{L V}
$$

In linearised triple oxygen isotope space, the pre-late veneer mantle also plots on a line with slope 0.528 and intercept that equals the $\Delta^{\prime 17} \mathrm{O}$ of the pre-late veneer mantle (PLVM), in per mill (fig. C.1B):

$$
10^{3} \ln \left(\frac{\delta^{17} \mathrm{O}}{10^{3}}+1\right)=0.528 \cdot 10^{3} \ln \left(\frac{\delta^{18} \mathrm{O}}{10^{3}}+1\right)+\frac{\Delta^{\prime 17} \mathrm{O}_{P L V M}}{10^{3}}
$$

The $\delta$-values of the pre-late veneer mantle correspond to the point of intersection of these two relations (fig. C.1), i.e.:

$$
0.528 \cdot \delta^{\prime 18} \mathrm{O}_{P L V M}+\frac{\Delta^{\prime 17} \mathrm{O}_{P L V M}}{10^{3}}=10^{3} \ln \left(m e^{\frac{\delta^{\prime 18} \mathrm{O}_{P L V M}}{10^{3}}}-m+\frac{i}{10^{3}}+1\right)
$$

Eq. C.5 cannot be solved algebraically, as it has a linear term on the left versus a logarithmic term on the right side, respectively. Instead, the $\delta^{\prime 18} \mathrm{O}$-values of the PLVM can be approximated from eq. C.5 with the Newton-Raphson method:

$$
\delta^{\prime 18} \mathrm{O}_{n+1}=\delta^{\prime 18} \mathrm{O}_{n}-\frac{{ }^{f}\left(\delta^{\prime 18} \mathrm{O}_{n}\right)}{f^{\prime}\left(\delta^{\prime 18} \mathrm{O}_{n}\right)}
$$

The $\delta^{\prime 18} \mathrm{O}_{P L V M}$ value can be used to determine $\delta^{18} \mathrm{O}_{P L V M}$, which in turn allows to calculate the missing oxygen atom fraction from the pre-late veneer mantle for an assumed composition of the late veneer. The missing oxygen atom fraction is given by:

$$
f_{M L V}=\frac{\delta^{18} \mathrm{O}_{B S E}-\delta^{18} \mathrm{O}_{P L V M}}{\delta^{18} \mathrm{O}_{L V}-\delta^{18} \mathrm{O}_{P L V M}} \cdot \frac{[\mathrm{O}]_{B S E}}{[\mathrm{O}]_{L V}}
$$



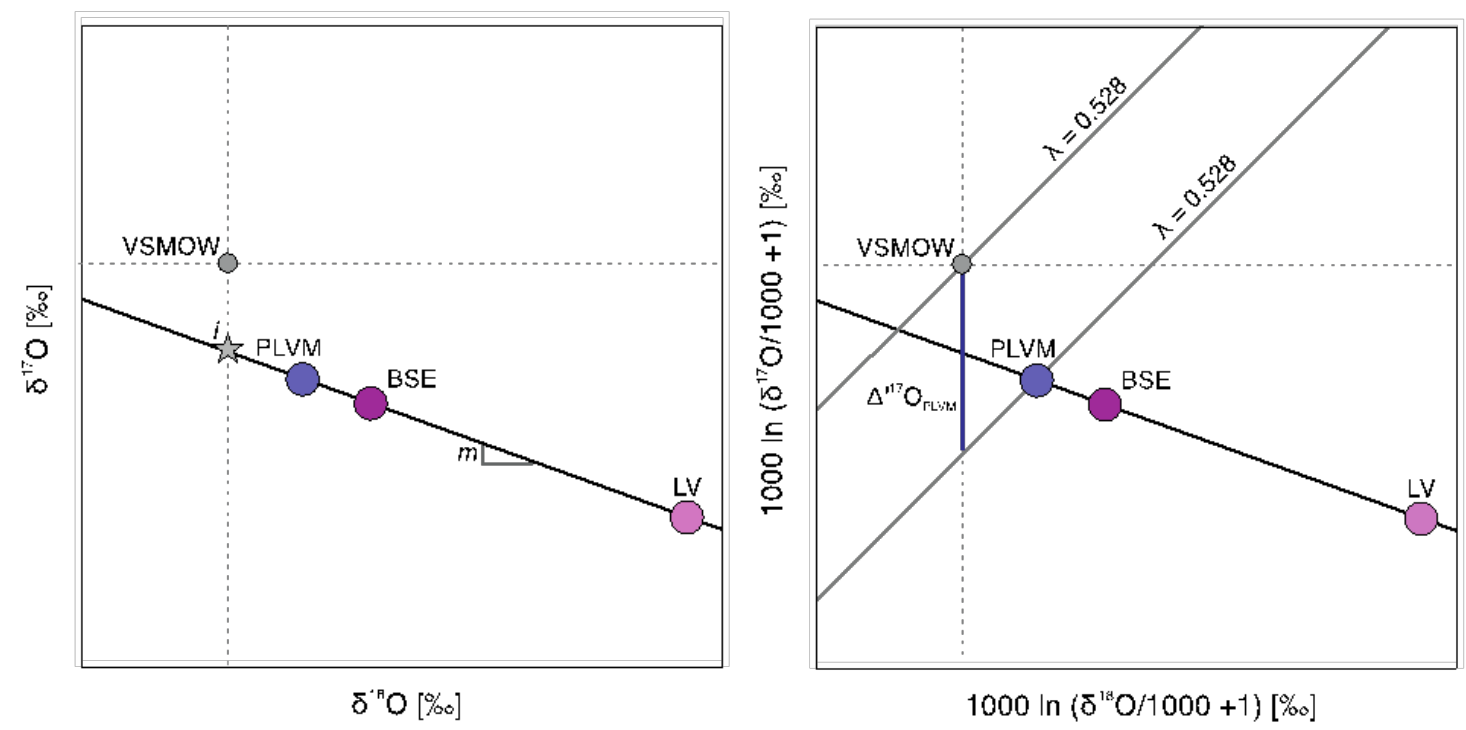

Figure C.1: A) The triple oxygen isotope composition of the pre-late veneer mantle (PLVM) plots in $\delta^{17} \mathrm{O}$ versus $\delta^{18} \mathrm{O}$ space, by definition, on a mixing line together with the compositions of the bulk silicate Earth (BSE) and late veneer (LV). The slope $m$ and intercept $i$ of the mixing line can be calculated from the triple oxygen isotope compositions of the bulk silicate Earth and an assumed composition for the late veneer (eq. C.1-C.3). B) The triple oxygen isotope composition of the pre-late veneer mantle plots by definition also on a line in $\delta^{\prime 17} \mathrm{O}$ versus $\delta^{\prime 18} \mathrm{O}$ space with slope $\lambda=0.528$ and an intercept that equals the $\Delta^{\prime 17} \mathrm{O}$ of the pre-late veneer mantle (eq. C.4). The point of intersection of eq. C. 1 and eq. C. 4 gives the $\delta^{17} \mathrm{O}$ and $\delta^{18} \mathrm{O}$ values of the pre-late veneer mantle for an assumed composition of the late veneer.

The concentration of oxygen in late accreted materials was assumed in this study to be similar to CI chondrites (46.5 wt\%), with the bulk silicate Earth having $44.33 \mathrm{wt} \%$ oxygen (Palme and O'Neill 2003). Missing late veneer is expressed in this study relative to the Earth's mass of $5.97210^{24} \mathrm{~kg}$, assuming a core mass fraction of $32.5 \%$.

Using eq. C.1-C.7, we determined in a Monte Carlo simulation the possible mass of late veneer that can be missing from the early Archean mantle if the missing component had similar compositions to carbonaceous chondrite groups. All carbonaceous chondrite meteorites for which triple oxygen isotope data are available were considered as possible end members for the composition of the late veneer, i.e., $f_{M L V}$ was calculated using the oxygen isotope composition of each single meteorite specimen for which data are available (C.7). The $\delta^{\mathrm{i} O}$ values of the BSE were sampled from a normally distributed data with $\delta^{18} \mathrm{O}=5.41 \%$ and $\Delta^{\prime 17} \mathrm{O}=-51.6 \pm 2.1 \mathrm{ppm}(1 \mathrm{SD})$. The $\Delta^{\prime 17} \mathrm{O}$ of the pre-late veneer mantle was sampled from a normally distributed data population as well, using the mean value and standard deviation from this study $\left(\Delta^{\prime 17} \mathrm{O}=-52.3 \pm 1.7 \mathrm{ppm} ; 1 \mathrm{SD}\right)$. The $97.72^{\text {nd }}$ percentiles of the outcomes of the simulations are considered as the uppermost likely values for missing late veneer.

\section{C.5 Additional tables}




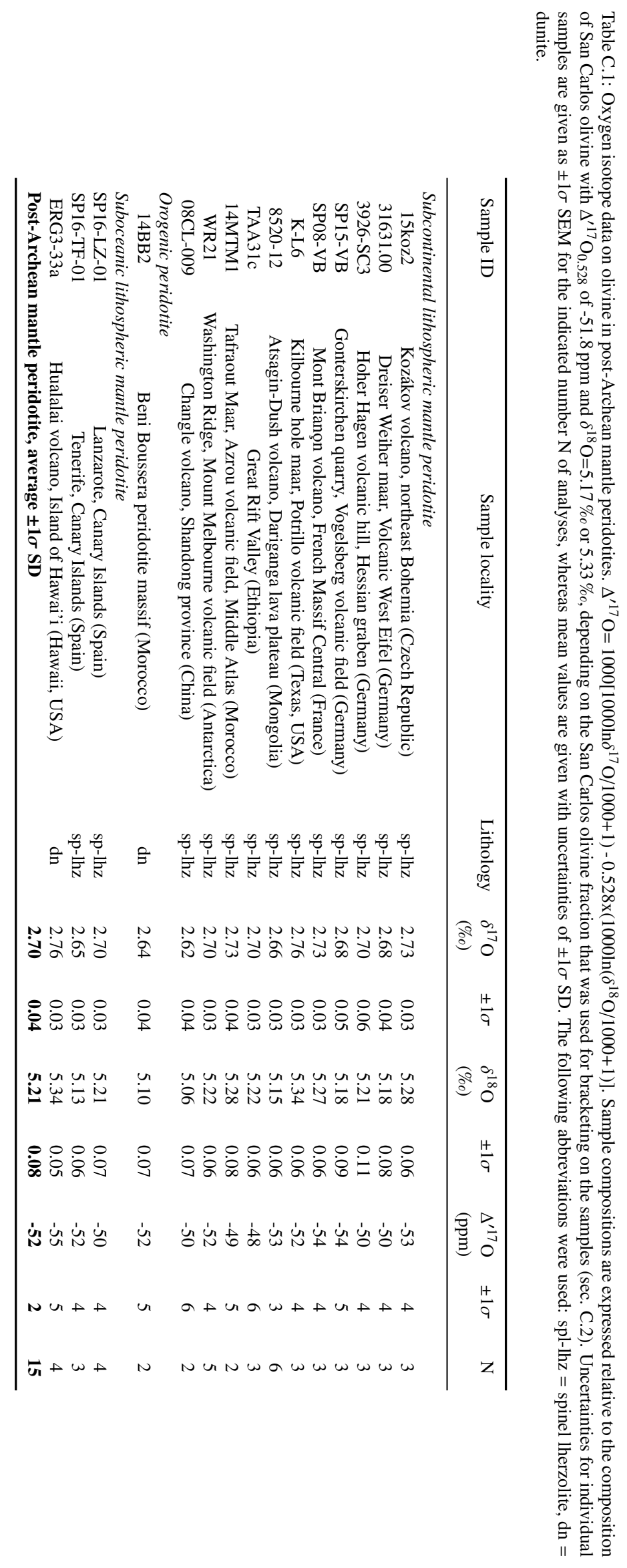




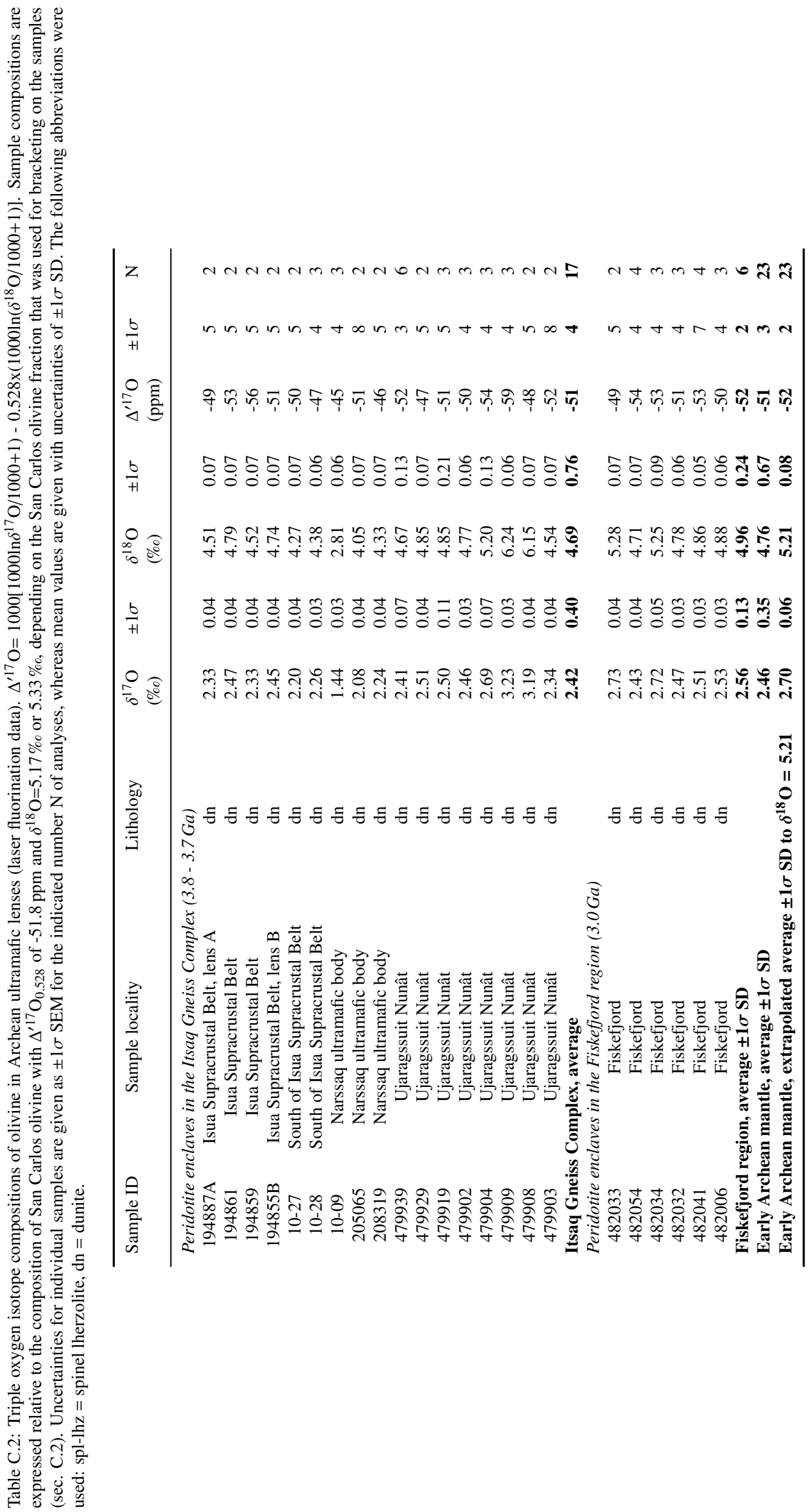





\section{Supplementary information: Tracing impactor signatures in lunar rocks using triple oxygen isotopes}

\section{D.1 Sample suite}

Our sample set comprises lunar rocks from 5 different Apollo missions and all important lunar lithologies $(N=27)$. It includes pristine lunar rocks and impact-influenced lunar rocks (table D.1).

Our pristine lunar sample set is composed of highland rocks $(N=4)$ representing the primordial lunar crust, mare basalts (high-Ti, $N=3$; low-Ti, $N=5$ ) and pyroclastic glasses $(N=2)$ representing the lunar mantle (fig. D.1). The other lunar samples are impact-influenced KREEP-rich breccias $(N=2)$, soils $(N=3)$ and impact rocks $(N=8$; fig. D.2). They have elevated HSE concentrations compared to pristine rocks proving the addition of meteoritic impact material (table D.1). Thorsten Kleine from the University of Münster kindly provided a few aliquots of sample material, Zachary Sharp from the University of New Mexico provided sample 15426UNMmix and Harry Becker from the FU Berlin supported us with four impact rock samples $(60035,61015,65055,77017)$. Some of the samples were given to us as powders, but we received most of the samples as rock chips. The rock chips were crushed to a fine grain size. The majority of the samples were analysed as WR samples. Some samples were separated into different mineral or glass fractions to study them in more detail. This concerns the green glass samples (15426, 15421: fig. D.1M-Q), the soil 15421R (fig. D.2C) and the impact rocks with a sufficient sample mass (60335, 67935, 72395, 73215: fig. D.2J-S).

We measured the primary standard San Carlos olivine $(0215 \mathrm{M} / 0919)$ together with the lunar rocks, because its triple oxygen isotope composition is representative for the bulk silicate Earth (see chapter 5). 
D Supplementary information: Tracing impactor signatures in lunar rocks using triple oxygen isotopes

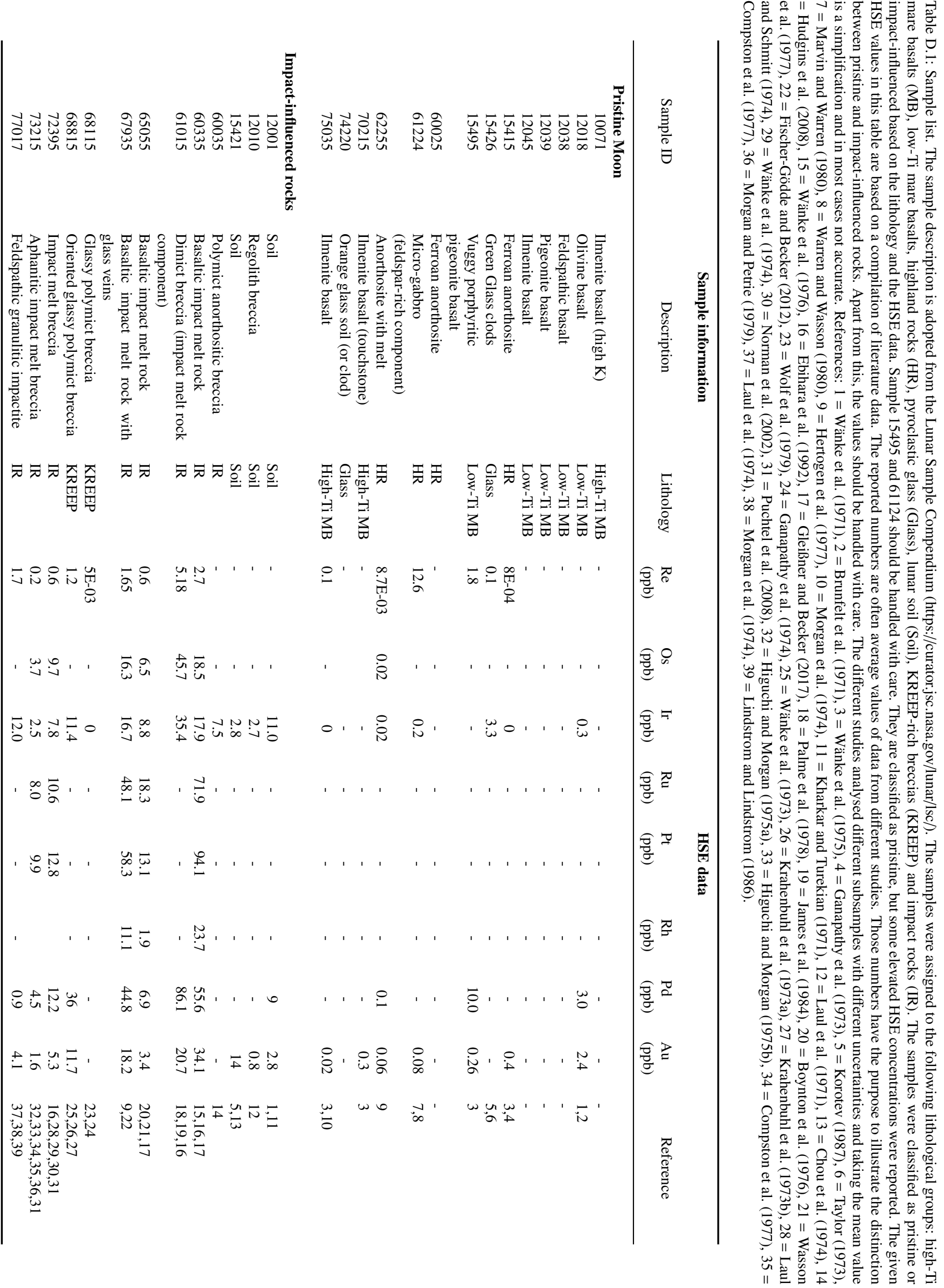



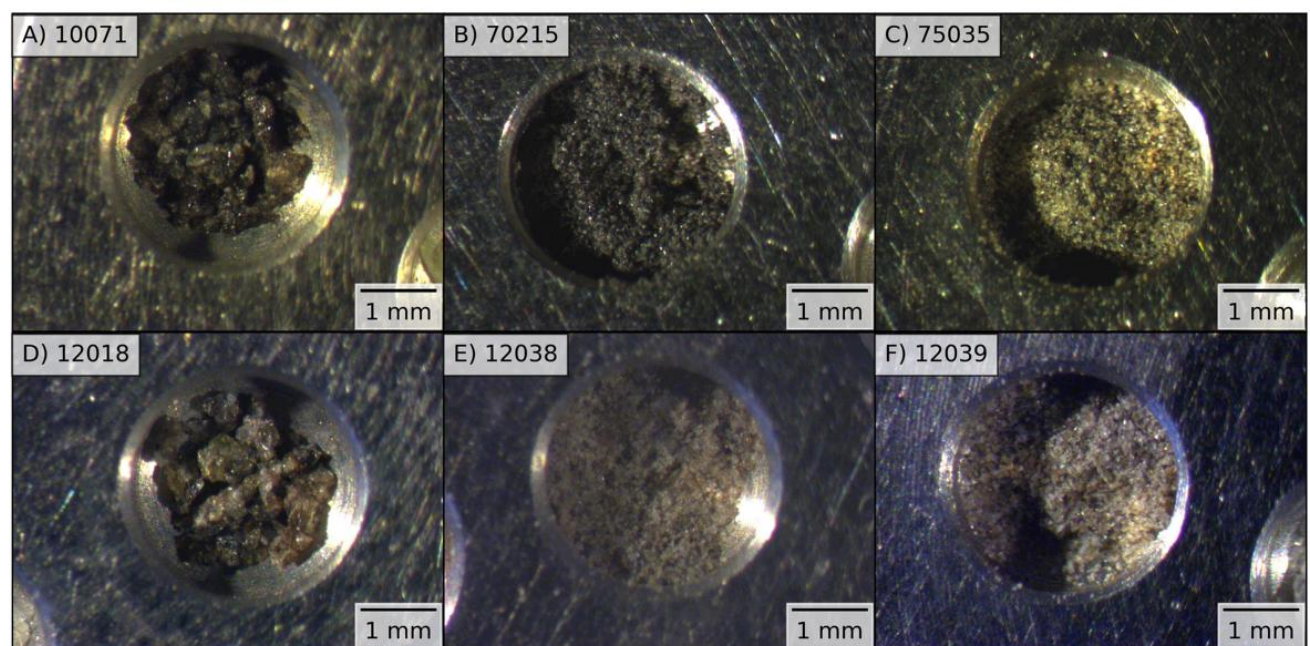

E) 12038

F) 12039

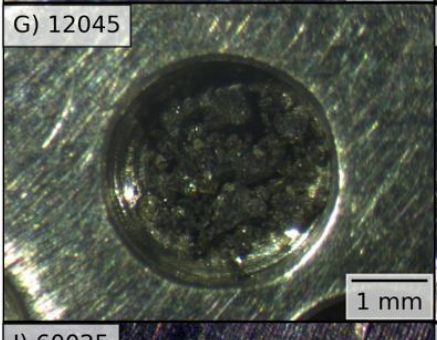

H) 15495

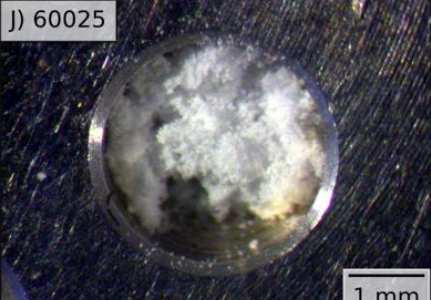

K) 62255

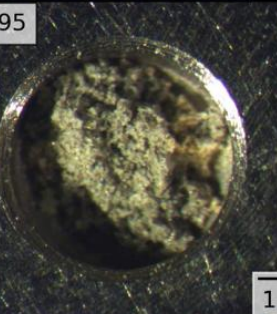

$1 \mathrm{~mm}$
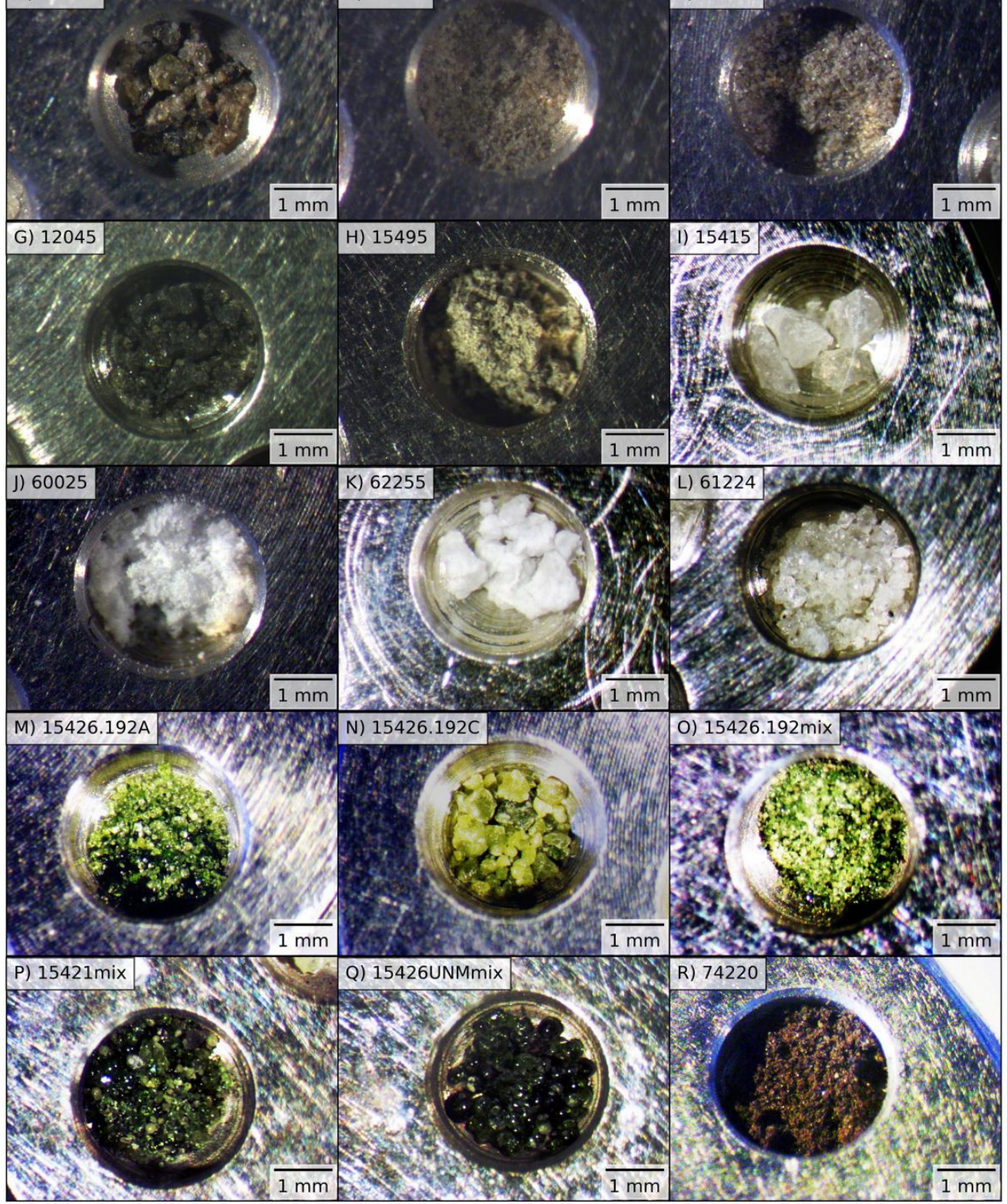

Figure D.1: The pristine lunar sample set: high-Ti mare basalts (A-C), low-Ti mare basalts (D-H), highland rocks (I-L) and pyroclastic glasses (M-R). Most of the samples were analysed as WR samples (A-L, R). The green glass sample 15426.192 was further separated. 15426.192A (M) represents the fraction of transparent, bottle-green glass. 15426.192C $(\mathrm{N})$ represents the fraction of opaque, light green glass. 15426.192mix (O) is the residual sample from which 15426.192A and 15426.192AC were separated. It can contain small amounts of impact glass and regolith. 15421.70 is a regolith with a certain amount of green glass. 15421.70mix (P) is handpicked green glass fraction containing all green glass types. Regolith and impact glass were separated. 15426UNMmix (Q) was prepared by Eric Cano from the original 15426 subsample assigned to the working group of the University of New Mexico. The sample comprises handpicked green glass of all green glass types. Regolith and impact glass were separated. 
D Supplementary information: Tracing impactor signatures in lunar rocks using triple oxygen isotopes

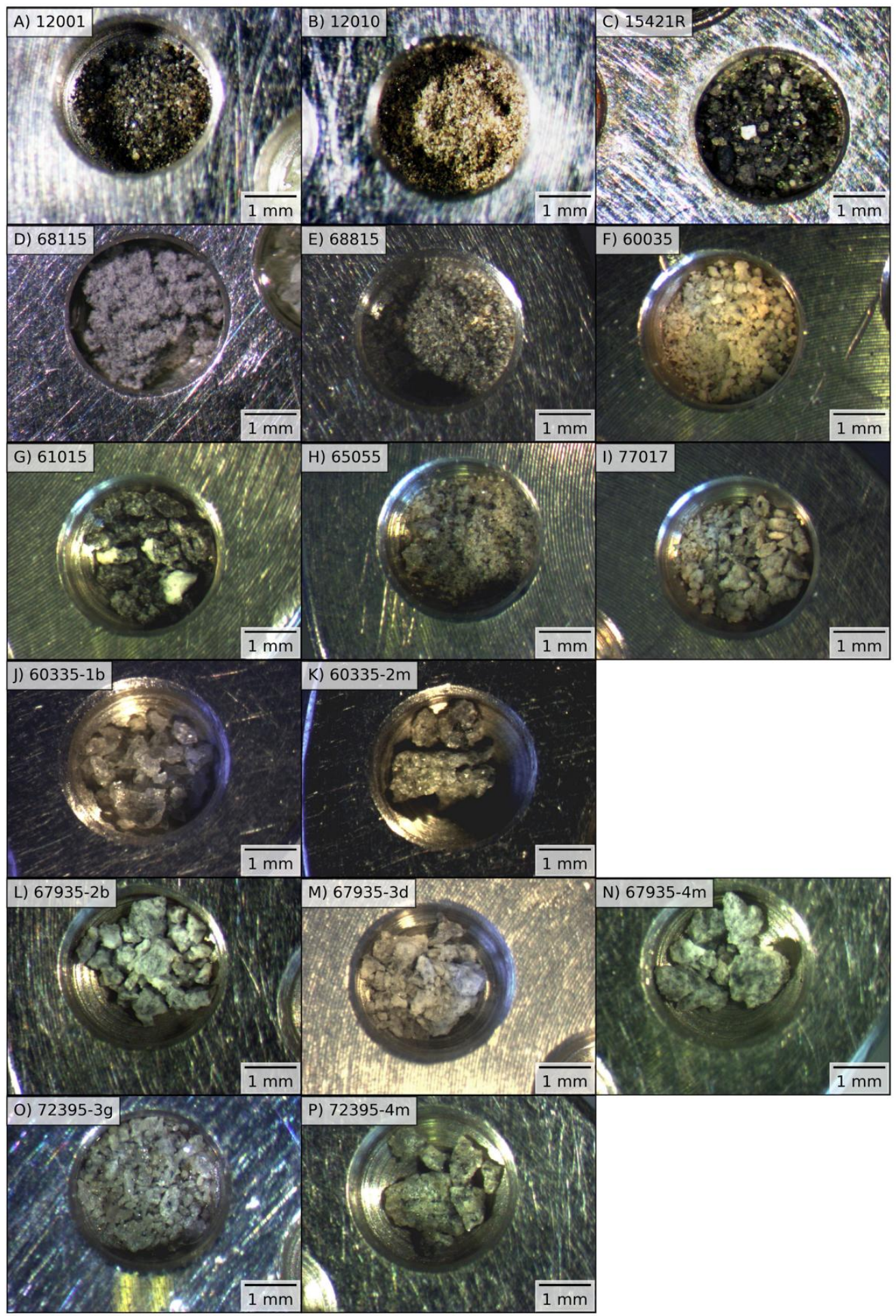




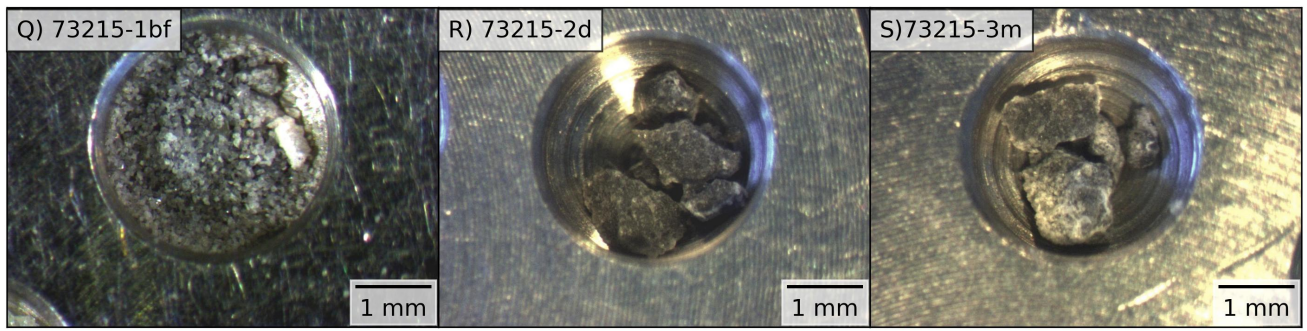

Figure D.2: The impact-influenced lunar sample set: soils (A-C), KREEP-rich breccias (D-E) and impact rocks (F-S). Most of the samples were analysed as WR samples (A-I). 15421R is the regolith component of sample 15421.70 (without green glass). 60335, 67935, 72395 and 73215 were also separated into different fractions. 60335.159 is the original sample. 60335-1b represents the feldspar fraction of the sample. 60335-2m represents the crushed and mixed sample. 67935.40 is the original sample. $67935-2 \mathrm{~b}$ represents the fraction, which is dominated by light-coloured minerals. 67935-3d represents the fraction, which is dominated by dark minerals. $67935.159-4 \mathrm{~m}$ represents a mixed fraction. 72395.109 is the original sample. $72395.109-3 \mathrm{~g}$ represents the fraction, which is containing less black minerals. $72395.109-4 \mathrm{~m}$ represents a mixed fraction. 73215.19 is the original sample. $73215.19-1 \mathrm{bf}$ represents the fraction, which is dominated by light-coloured minerals. 73215.19-2d represents the fraction, which is dominated by dark minerals. 73215.19-3m represents a mixed fraction.

\section{D.2 Analytical methods}

Oxygen was extracted from the samples by $\mathrm{BrF}_{5}$ laser fluorination (Sharp 1990) and measured using a IRMS (Thermo Scientific ${ }^{T M} M A T 253^{T M}$ ). A new laser fluorination line was constructed. The gas extraction, the purification procedure and the isotope measurements were fully automated using LabView ${ }^{T M}$ enhancing the reproducibility.

We analysed the lunar samples either as powder or as fine-grained material to have homogeneous samples. The sample mass was adapted to match $\sim 30 \mu \mathrm{mol}$ released $\mathrm{O}_{2}$ (1.8-2.1 mg lunar rock depending on the sample composition). The samples were premelted to improve the performance of the laser fluorination. The sample holder and the samples were 4 times pre-fluorinated to eliminate moisture ( $\left.\sim 50 \mathrm{mbar} \mathrm{BrF}_{5}, 10 \mathrm{~min}\right)$. $\mathrm{A}$ blank measurement was performed before the beginning of each session. We analysed for each lunar rock sample 2-3 standards on average. We applied standard bracketing to monitor the performance of the session effectively. The main standard was San Carlos olivine, but we analysed also $\sim 2$-times UWG-2 garnet per session to cross-check the San Carlos olivine. The samples were reacted with excess $\mathrm{BrF}_{5}$ in a stainless-steel sample chamber at a pressure of $\sim 100$ mbar. The laser fluorination was fully automated for these measurements and therefore very reproducible. The extracted oxygen was purified via a liquid nitrogen trap eliminating residual $\mathrm{BrF}_{5}$ and other condensable gases. The remaining gas was further cleaned by a heated $\mathrm{NaCl}$ trap $\left(T=180^{\circ} \mathrm{C}\right)$ combined with a liquid nitrogen trap separating fluorine compounds $\left(\mathrm{F}_{2}, \mathrm{HF}\right.$ etc.). The gas was collected on a $5 \AA$ molecular sieve using liquid nitrogen and passed through a gas chromatograph (Hewlett Packard 5890 Series II gas chromatograph, carrier gas: helium, $T=50^{\circ} \mathrm{C}$, flow rate of $10 \mathrm{ml} \mathrm{min}^{-1}$ ) to remove potential $\mathrm{N}_{2}, \mathrm{NF}_{3}$ or $\mathrm{CF}_{4}$. The purified oxygen was transported via capillaries to another cold molecular sieve trap. From there the gas was introduced into the IRMS.

The $\delta^{17} \mathrm{O}$ and $\delta^{18} \mathrm{O}$ values of the samples were then determined by measuring $\mathrm{O}_{2}^{+}$ion beams with $m / z=32,33,34$ for 60 cycles (for 40 cycles up to sample ID: 5633), relative to a reference gas that was calibrated against the VSMOW2 and SLAP2 water standards (Pack et al. 2016, dual-inlet technique). The reference oxygen (grade: 6.0) has an isotopic composition of $\delta^{18} \mathrm{O}=15.7 \%$ and $\Delta^{\prime 17} \mathrm{O}=-450 \mathrm{ppm}$. An integration time of $26 \mathrm{~s}$ and an 
D Supplementary information: Tracing impactor signatures in lunar rocks using triple oxygen isotopes

idle time of $15 \mathrm{~s}$ was applied for the measurements. The target signal intensity on mass 32 was adjusted to $5 \mathrm{~V}$. No filtering of the data for outliers was applied. We routinely monitored the gas matrix of each sample. We checked the gas matrix match between the standards and samples to verify that the standards are representative for the samples (fig. D.3). We aimed at preventing any material-specific or instrumental drift related variations in the gas matrices, which might lead to biased results.

All triple oxygen isotope data is reported relative the primary standard San Carlos olivine. San Carlos olivine has a $\Delta^{\prime 17} \mathrm{O}$ value of $-51.8 \mathrm{ppm}$ (mean value of the following studies: Pack et al. 2016, Sharp et al. 2016, Wostbrock et al. 2020). Two different San Carlos olivine fractions were used for this study (0215M and 0919), which have different $\delta^{18} \mathrm{O}$ values (5.18\%o and $5.34 \%$ ). The San Carlos olivine $0215 \mathrm{M}$ was used for all sessions with sample IDs smaller than 5900, the San Carlos olivine 0919 was used for sessions with larger sample IDs. A second standard, UWG-2 from Valley et al. (1995), was measured in the beginning of every measurement session (table D.6). We use a reference line with a slope of $\lambda_{R L}=0.528$ and a y-axis intercept $\gamma_{R L}=0$ for the calculation of the $\Delta^{\prime 17} \mathrm{O}$ values.

The external reproducibility according to the San Carlos olivine standard was $\delta^{18} \mathrm{O}$ : $0.1 \%$ and $\Delta^{\prime 17} \mathrm{O}: 6 / 4 \mathrm{ppm}$ (6 ppm San Carlos olivine 0215M, 4 ppm San Carlos olivine 0919). This results in a $4 / 3 \mathrm{ppm}$ uncertainty for doubled measured lunar samples.

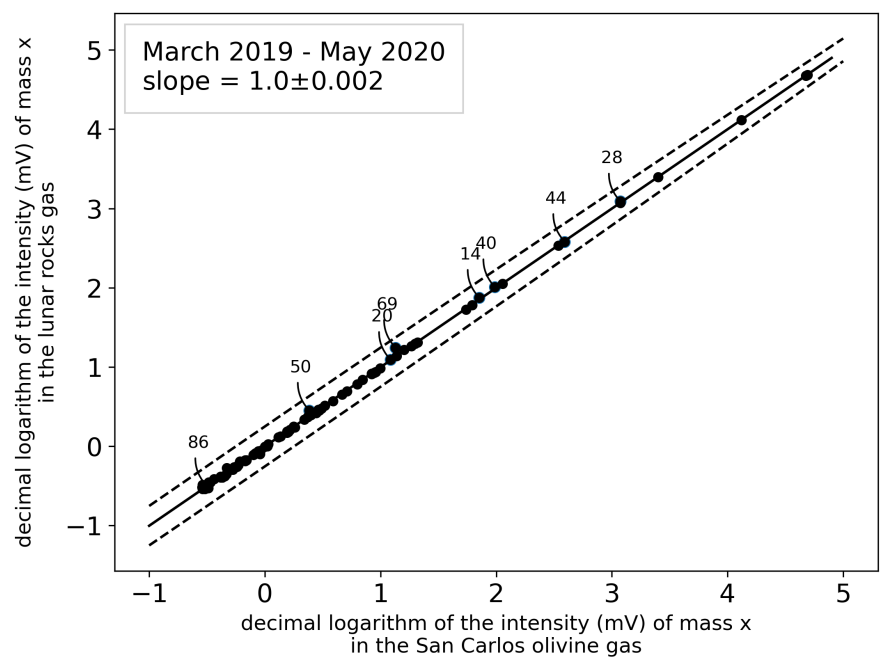

Figure D.3: Gas matrix match between the lunar samples (y-axis) and the terrestrial San Carlos olivine standard (x-axis). Absolute values are plotted. The individual gas compositions of both sample types have been averaged. A perfect match yields a slope of 1 . Standard error of the slope was calculated with the python package stats.linregress.

\section{D.3 Analysis of rock fractions}

\section{D.3.1 Pyroclastic green glass}

We analysed different subsamples (15426.192, 15426UNM, 15421.70mix) and different fractions (15426.192A, 15426.192C) of Apollo 15 green glass. We found little variation in $\Delta^{\prime 17} \mathrm{O}$ (SD: $3 \mathrm{ppm}$ ) and $\delta^{18} \mathrm{O}$ (SD: $0.05 \%$ ) (fig. D.4, table D.2). We did not observe significant differences between the subsamples or different glass fractions (transparent 
green glass 15426.192A vs. opaque light green glass 15426.192C). The green glass seems to be homogeneous, and its triple oxygen isotope composition is $\Delta^{\prime 17} \mathrm{O}=-52 \pm 1 \mathrm{ppm}$ and $\delta^{18} \mathrm{O}=5.43 \pm 0.02 \%$ o. 15426.192mix and 15421.70mix are not as 'pure' in green glass as the other aliquots (15426.192A, 15426.192C, 15426UNM). 15426.192mix was not further separated and includes traces of regolith and impact glass. 15421.70mix was hand-picked, but from a regolith dominated sample. Regolith has a higher $\delta^{18} \mathrm{O}$ value and this might explain the slightly higher $\delta^{18} \mathrm{O}$ values and the small-scale $\Delta^{\prime 17} \mathrm{O}$ deviation of these samples.

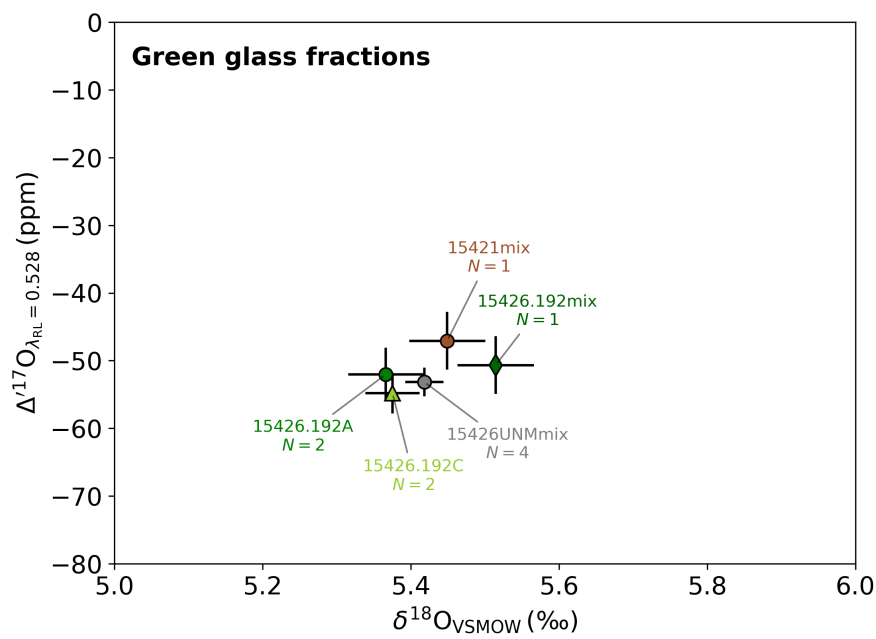

Figure D.4: Triple oxygen isotope plot of different green glass subsamples and fractions (mean values). 15426.192 is shown in shades of green, 15426UNM in grey and 15421.70 in a brown colour. Different fractions of 15426.192 were analysed: $15426.192 \mathrm{~A}$ is illustrated as dot, 15426.192C is illustrated as triangle and $15426.192 \mathrm{mix}$ as diamond.

Table D.2: Results of the different lunar green glass subsamples (15426.192, 15426UNMmix, 15421.70mix) and fractions (15426.192A, 15426.192C).

\begin{tabular}{cllllllll}
\hline Sample ID & Lithology & $\begin{array}{l}\delta^{17} \mathrm{O} \\
(\%)\end{array}$ & $\pm 1 \sigma$ & $\begin{array}{l}\delta^{18} \mathrm{O} \\
(\%)\end{array}$ & $\pm 1 \sigma$ & $\begin{array}{l}\Delta^{\prime 17} \mathrm{O} \\
(\mathrm{ppm})\end{array}$ & $\pm 1 \sigma$ & $\mathrm{N}$ \\
\hline 15426.192A & Green glass & 2.79 & 0.03 & 5.38 & 0.05 & -52 & 4 & 2 \\
15426.192C & Green glass & 2.79 & 0.02 & 5.39 & 0.04 & -54 & 3 & 2 \\
15426.192mix & Green glass & 2.87 & 0.02 & 5.53 & 0.05 & -50 & 4 & 1 \\
15426UNMmix & Green glass & 2.81 & 0.01 & 5.43 & 0.03 & -53 & 2 & 4 \\
15421.70mix & Green glass & 2.84 & 0.02 & 5.46 & 0.05 & -46 & 4 & 1 \\
Average & & 2.81 & 0.01 & 5.44 & 0.02 & -51 & 1 & \\
\hline
\end{tabular}

\section{D.3.2 Impact rocks}

We measured different fractions of several impact rocks (fig. D.5, table D.3). We tried to separate light-coloured, feldspar-dominated fractions, dark fractions dominated by mafic minerals and mixed fractions. Most of the rocks were very fine-grained and the separation was difficult. We aimed at investigating if the addition of meteoritic material is located in a specific phase. We tried to trace this with oxygen isotope measurements. The fractions of 60335.159 and 72395.109 give an unobtrusive result. No difference in the $\Delta^{\prime 17} \mathrm{O}$ is observed and the $\delta^{18} \mathrm{O}$ of the light-coloured fraction is higher compared to the value of the dark fraction. However, the pure plagioclase separate of sample 60335.159 has a low 
D Supplementary information: Tracing impactor signatures in lunar rocks using triple oxygen isotopes

$\delta^{18} \mathrm{O}$ with $5.51 \%$. The results of sample 67935.40 are inconclusive, the triple oxygen isotope compositions of the different fractions are within the error identical. This is most likely a consequence of the difficulties during the separation of the fine-grained sample material. Sample 73215 is the coarsest studied impact rock and the data indicates that the meteoritic signature might be located in the more light-coloured, feldspar-rich phase. The $\Delta^{\prime 17} \mathrm{O}$ and $\delta^{18} \mathrm{O}$ of the light-coloured and the mixed fraction is lower and further away from the pristine lunar value in contrast to value of the dark fraction.
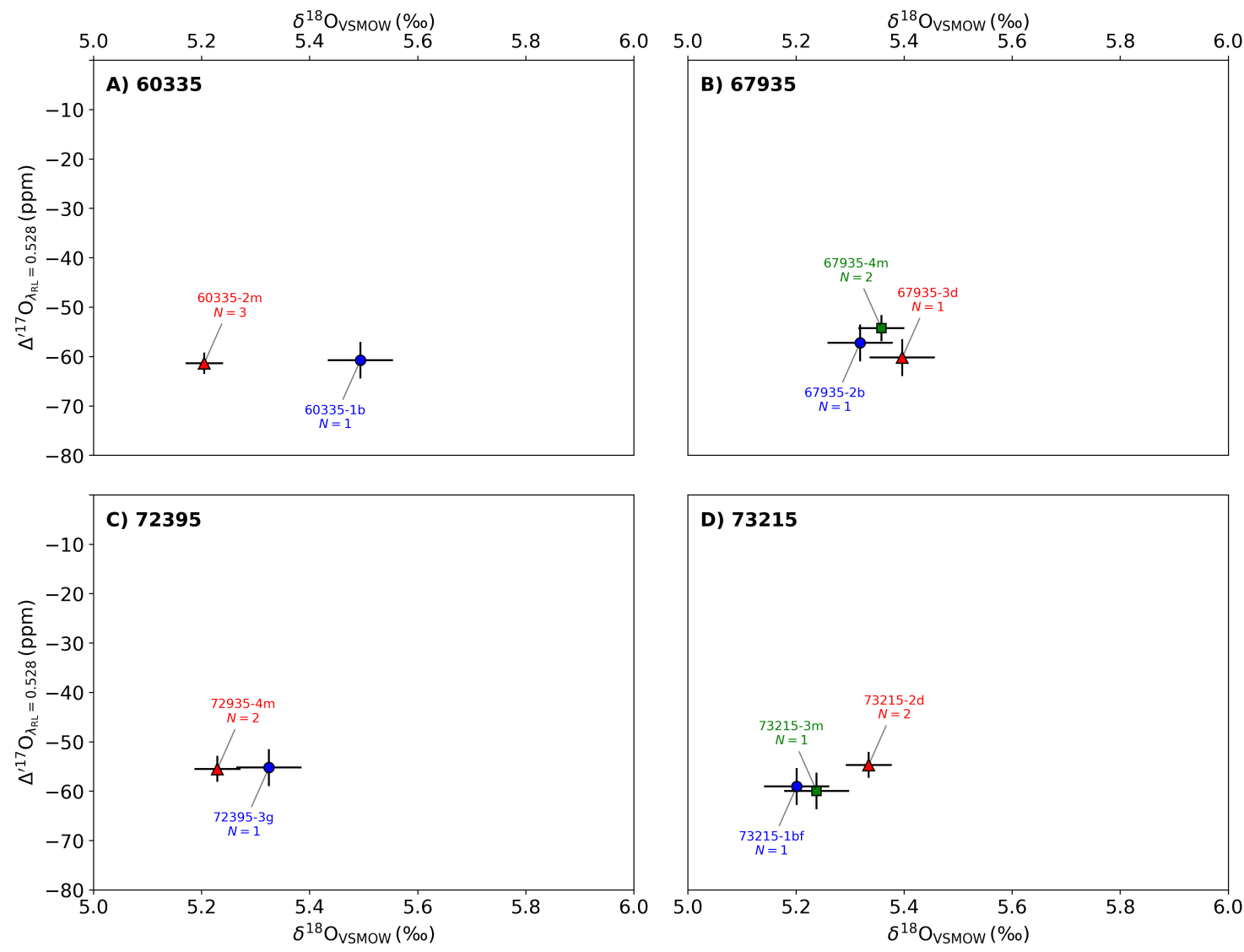

Figure D.5: Triple oxygen isotope plot of different impact rock fractions: A) 60335.159, B) 67935.40, C) 72395.109 and D) 73215.19 (mean values). Blue dots represent the fraction, which is dominated by light-coloured minerals ( $1 \mathrm{~b} / 2 \mathrm{~b} / 3 \mathrm{~g} / 2-4 \mathrm{bf})$, red triangles represent the fraction, which is dominated by dark minerals (3d), green squares illustrate the results of the mixed fractions (4m).

Table D.3: Results of the different impact rock fractions (mean and single values).

\begin{tabular}{ccccccccc}
\hline Sample ID & Lithology & $\begin{array}{l}\delta^{17} \mathrm{O} \\
(\%)\end{array}$ & $\pm 1 \sigma$ & $\begin{array}{l}\delta^{18} \mathrm{O} \\
(\% \circ)\end{array}$ & $\pm 1 \sigma$ & $\begin{array}{l}\Delta^{17} \mathrm{O} \\
(\mathrm{ppm})\end{array}$ & $\pm 1 \sigma$ & $\mathrm{N}$ \\
\hline 60335.159-1b & Impact rock & 2.85 & 0.03 & 5.53 & 0.06 & -60 & 4 & 1 \\
$60335.159-2 \mathrm{~m}$ & Impact rock & 2.70 & 0.02 & 5.23 & 0.04 & -61 & 2 & 3 \\
$67935.40-2 \mathrm{~b}$ & Impact rock & 2.76 & 0.03 & 5.35 & 0.06 & -57 & 4 & 1 \\
$67935.40-3 \mathrm{~d}$ & Impact rock & 2.80 & 0.03 & 5.43 & 0.06 & -60 & 4 & 1 \\
$67935.40-4 \mathrm{~m}$ & Impact rock & 2.79 & 0.02 & 5.39 & 0.04 & -54 & 3 & 2 \\
$72395.109-3 \mathrm{~g}$ & Impact rock & 2.77 & 0.03 & 5.35 & 0.06 & -55 & 4 & 1 \\
$72935.109-4 \mathrm{~m}$ & Impact rock & 2.72 & 0.02 & 5.26 & 0.04 & -55 & 3 & 2 \\
$73215.19-2-4 b f$ & Impact rock & 2.70 & 0.03 & 5.23 & 0.06 & -59 & 4 & 1 \\
$73215.19-2 \mathrm{~d}$ & Impact rock & 2.77 & 0.02 & 5.36 & 0.04 & -54 & 3 & 2 \\
$73215.19-3 \mathrm{~m}$ & Impact rock & 2.72 & 0.03 & 5.27 & 0.06 & -60 & 4 & 1 \\
& Average & $\mathbf{2 . 7 5}$ & $\mathbf{0 . 0 2}$ & $\mathbf{5 . 3 3}$ & $\mathbf{0 . 0 3}$ & $\mathbf{- 5 8}$ & $\mathbf{1}$ & \\
\hline
\end{tabular}




\section{D.4 Determining the $\Delta^{\prime 17} \mathrm{O}$ of the bulk silicate Moon}

Lunar lithology-dependent $\Delta^{\prime 17} \mathrm{O}$ variations would complicate the Earth-Moon comparison. In this case, averaging the $\Delta^{\prime 17} \mathrm{O}$ of pristine lithologies from the lunar surface would be inadequate to assess the $\Delta^{\prime 17} \mathrm{O}$ of the bulk silicate Moon (BSM; traditional approach).

\section{D.4.1 Lithology-dependent $\Delta^{\prime 17} \mathrm{O}$ variations}

We did not detect $\Delta^{\prime 17} \mathrm{O}$ variations between different pristine lithologies of the Moon $(N=14)$. This is in agreement with the work of Wiechert et al. (2001) and Greenwood et al. (2018), who also studied comprehensive sample sets $(N=31, N=17$; fig. D.6). Our study and Greenwood et al. (2018) found no increased variation in the lunar sample set (SD: $2 \mathrm{ppm} / 6 \mathrm{ppm}$ ) compared to the terrestrial sample set (SD: $2 \mathrm{ppm}$, see chapter 5/ SD: $6 \mathrm{ppm})$, in contrast to the study of Cano et al. (2020) $\left(N=24 ; \mathrm{SD}_{\mathrm{Mon}}: 10 \mathrm{ppm}\right.$ vs. $\left.\mathrm{SD}_{\text {Earth }}: 4 \mathrm{ppm}\right)$.

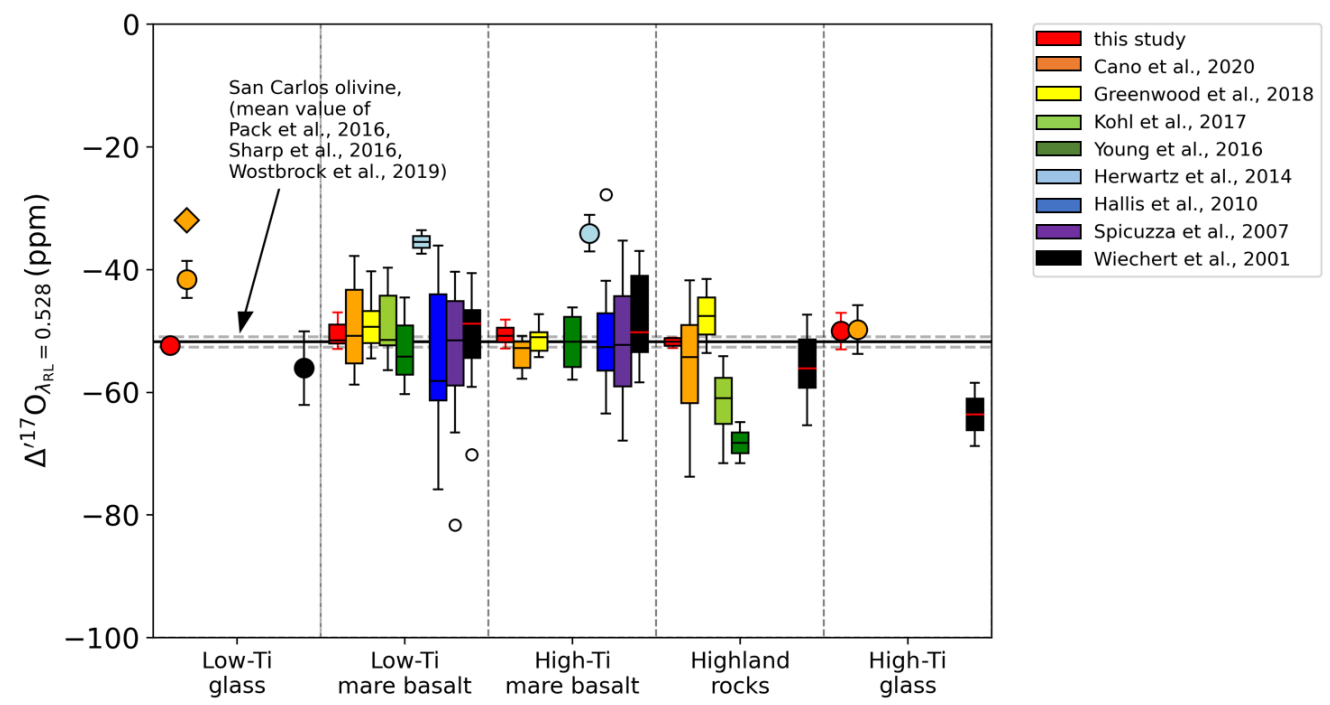

Figure D.6: Boxplot $-\Delta^{\prime 17} \mathrm{O}$ vs. lithology. Comparison between the results of this study and the literature data of the last 20 years (Wiechert et al. 2001, Spicuzza et al. 2007, Hallis et al. 2010, Herwartz et al. 2014, Young et al. 2016, Kohl et al. 2017, Greenwood et al. 2018, Cano et al. 2020). The input data of the box plots are mean values of whole rock measurements of various samples from the same lithology. The only exception is that the highland rock boxplot of Cano et al. (2020) comprises also mineral separate data in accordance to their own data presentation approach. Low-Ti glass includes lunar green glass (15426), high-Ti glass includes lunar orange glass $(74220,74241)$. Single dots \pm SEM $(1 \sigma)$ are plotted for mean values of single samples. The orange diamond illustrates at which value Cano et al. (2020) suggests the pristine $\Delta^{\prime 17} \mathrm{O}$ of green glass considering only specific green glass fractions. The precision of the green glass data point $(N=1)$ from Wiechert et al. (2001) is unknown, 6 ppm were assumed. The empty dots represent outliers.

$\Delta \Delta^{17} \mathbf{O}$ trend Cano et al. (2020) describes a trend towards lower $\Delta^{\prime 17} \mathrm{O}$ values from low-Ti glass over low-Ti mare basalts and high-Ti mare basalts to highland rocks (fig. D.6). They suggest that this variation is caused by various degrees of mixing between the primary material of the respective lithology with a vapour phase component of anomalous $\Delta^{\prime 17} \mathrm{O}$ created during the Moon-forming impact. The most important sample in this study is the low-Ti green glass (15426), the variations between the other lithologies are comparable small. The green glass shows the highest $\Delta^{\prime 17} \mathrm{O}$ values and is interpreted as most pristine 
D Supplementary information: Tracing impactor signatures in lunar rocks using triple oxygen isotopes

(unaffected by vapour contamination) by Cano et al. (2020). They assess the $\Delta^{\prime 17} \mathrm{O}$ of the bulk silicate Moon based on the green glass fraction with the highest $\Delta^{\prime 17} \mathrm{O},-32 \mathrm{ppm}$.

Our data is not showing any variation in $\Delta^{\prime 17} \mathrm{O}$ between the highland rocks, mare basalts and pyroclastic materials including the low-Ti green glass (fig. D.6). We found the $\Delta^{\prime 17} \mathrm{O}$ of different green glass subsamples and fractions to be very reproducible indicating homogeneity. We analysed three different green glass subsamples (15426.192, 15426 $\mathrm{UNM}$ and 15421.70) and the $\Delta^{\prime 17} \mathrm{O}$ variation is still smaller than the variation reported by Cano et al. (2020) for one portion (15426UNM; fig. D.7A). We also analysed an identical subsample (15426UNMmix), yielding a more precise result (fig. D.7B). The mean value of all green glass measurements of Cano et al. (2020) is within the error of our value. Our measurement results are only lacking the sporadic high $\Delta^{\prime 17} \mathrm{O}$ values of Cano et al. (2020), which are interpreted by them as the true, pristine value.
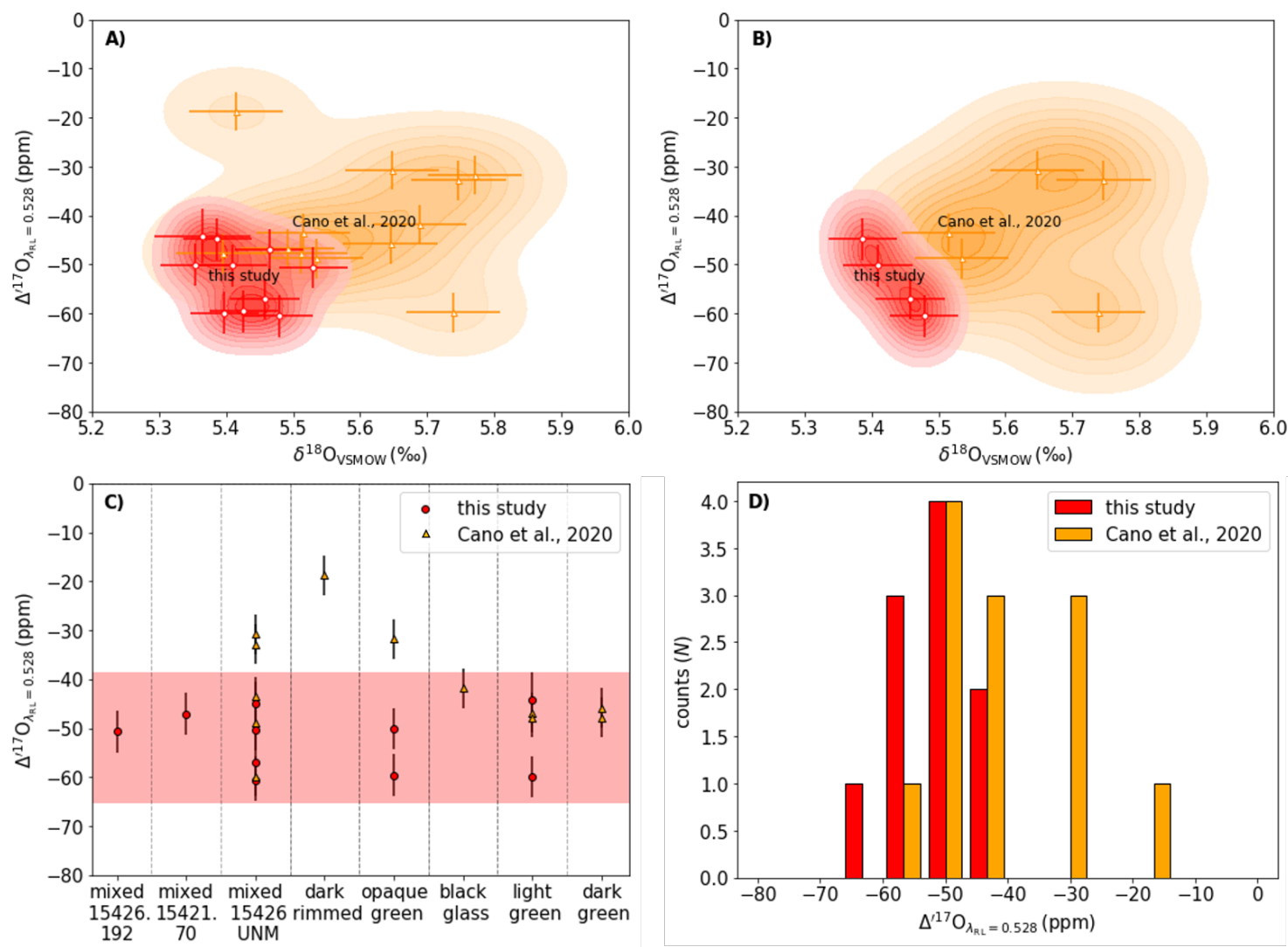

Figure D.7: Comparison between different triple oxygen isotope results of lunar green glass. A) and B) Three oxygen isotope plots, which compare the green glass data of this study with the data of Cano et al. (2020). The data of this study is shown in red and dots, the data of Cano et al. (2020) is displayed in orange and triangles. A) Single measurement results are plotted of all analysed subsamples and glass type fractions. B) Single measurement results are plotted of one particular subsample 15426UNMmix, which has been analysed during both studies (mixUMGö vs. mixUNM). C) The plot illustrates the $\Delta^{\prime 17} \mathrm{O}$ for the different green glass subsamples and glass fractions of this study and the study of Cano et al. (2020). D) Histogram illustrating the distribution of the $\Delta^{\prime 17} \mathrm{O}$ data of this study and the study of Cano et al. (2020).

Cano et al. (2020) studied different green glass fractions. They report that the $\Delta^{\prime 17} \mathrm{O}$ heterogeneity in their mixed portion (15426UNMmix) originates from different proportions of certain glass fractions. We were able to study also some of the different green glass fractions from sample 15426.192 (fig. D.7C). The results of the classical, light and dark green glass spherules of Cano et al. (2020) are in agreement with our data. Though, 
Cano et al. (2020) reported higher $\Delta^{\prime 17} \mathrm{O}$ values for the picked fractions: 'dark rimmed', 'opaque' and 'black glass'. We analysed the 'opaque' fraction significantly lower in $\Delta^{\prime 17} \mathrm{O}$ $-54 \mathrm{ppm}(N=2)$ instead of $-32 \mathrm{ppm}(N=1$, Cano et al. 2020). Unfortunately, there was not enough material available to study the 'dark rimmed' and 'black' fraction. Though, we think it is important for the interpretation of the 'black glass' and 'dark rimmed' fraction to question their pristinity. Sample 15426 was transported in a bag along with regolith to Earth. Regolith contains impact glass, which is often orange or black. $\Delta^{\prime 17} \mathrm{O}$ variation in the 'black glass' fraction can also be created by the inefficient separation of impact glass. The 'dark rimmed' fraction should also be treated with care, because the study of Walker et al. (2004) found elevated HSE values in the rims of green glass spherules. Hence, impact contamination cannot be ruled out as explanation of the anomalous high $\Delta^{\prime 17} \mathrm{O}$ values reported for these glass fractions.

We suggest that the systematic-appearing $\Delta^{\prime 17} \mathrm{O}$ trend in the data set of Cano et al. (2020) is based on a wrong assumption concerning the $\Delta^{\prime 17} \mathrm{O}$ of pristine lunar green glass and is not related to lithology-dependent processes.

Feldspar effect Young et al. (2016) and Kohl et al. (2017) reported systematically lower $\Delta^{\prime 17} \mathrm{O}$ values for feldspar-rich highland rocks $(\sim 12 \mathrm{ppm})$. They discussed the possibility of a feldspar-specific isotope anomaly ('feldspar effect') related to the crystal lattice structure of tectosilicates. Our highland rock sample set does not support this hypothesis, neither do the studies on terrestrial analogous rocks (chapter 4 as well as Cano et al. 2020). Based on our studies, there is no indication of a feldspar-specific $\Delta^{\prime 17} \mathrm{O}$ anomaly.

\section{D.4.2 Earth-Moon comparison}

We are confident that our $\Delta^{\prime 17} \mathrm{O}$ Earth-Moon comparison is representative, because of the detected $\Delta^{\prime 17} \mathrm{O}$ homogeneity (absence of lithology-dependent $\Delta^{\prime 17} \mathrm{O}$ variations). We found the lunar rocks only affected by high- $T$ equilibrium fractionation and not by other petrological processes. We agree with Clayton et al. (1974a) and Mayeda et al. (1975) that oxygen isotopes are an excellent tool for answering whole-Moon questions.

Our data is in agreement with studies, who found the $\Delta^{\prime 17} \mathrm{O}$ of Earth and Moon identical within uncertainty (Wiechert et al. 2001, Spicuzza et al. 2007, Hallis et al. 2010, Young et al. 2016, Greenwood et al. 2018; fig. D.6). We extend the finding of Young et al. (2016) that Earth and Moon are identical in $\Delta^{\prime 17} \mathrm{O}$ within $5 \mathrm{ppm}$ (based on $N=8$; mainly lunar basalts). Earth and Moon are even identical in $\Delta^{\prime 17} \mathrm{O}$ within $1 \mathrm{ppm}$ (based on $N=14$; lunar basalts, pyroclastic deposits and highland rocks).

We disagree with studies, who have found a $\Delta^{\prime 17} \mathrm{O}$ difference between Earth and Moon (Herwartz et al. 2014, Greenwood et al. 2018, Cano et al. 2020; fig. D.6). Herwartz et al. (2014) analysed three lunar basalts and found an offset. Identical sample portions were remeasured and are included in this study showing no offset. Herwartz et al. (2014) were working with an old analytical setup. We assume their results were affected by analytical difficulties. Greenwood et al. (2018) created a comprehensive data set and claims to have found a small difference between bulk silicate Earth and Moon. We suggest that the significance of this $\Delta^{\prime 17} \mathrm{O}$ difference should be reconsidered, because it depends on the usage of mantle melts as representative terrestrial samples. Cano et al. (2020) have reported a $\Delta^{\prime 17} \mathrm{O}$ difference between Moon and Earth of $19 \mathrm{ppm}$. This value was obtained 
D Supplementary information: Tracing impactor signatures in lunar rocks using triple oxygen isotopes

differently from the previously mentioned studies, not by averaging lunar and terrestrial rock data. We disagree with this approach, which is based on the concept of lithologydependent $\Delta^{\prime 17} \mathrm{O}$ variations (discussed above).

\section{D.5 The late accretion to the lunar crust}

There are two rock types, which can be studied to constrain the late accretion onto the lunar crust: lunar impact rocks and soils. The advantage of impact rocks over soils is that impact rocks can be better dated and it is easier to assign them to a specific impact crater event (Joy et al. 2016). Many chemical signatures are better preserved in impact rocks, soils are more intensively exposed to space weathering than any other lithology. Though, soils can contain the most direct evidence of the late accretion: projectiles (e.g. Joy et al. 2012; for more informations on soils see Joy et al. 2016).

\section{D.5.1 Soils}

Speace weathering in form of 'impact gardening' is affecting the triple oxygen isotope composition of lunar soils. Epstein and Taylor Jr. (1971) found lunar soils enriched in the heavy oxygen isotope ${ }^{18} \mathrm{O}$ (i.e., higher $\delta^{18} \mathrm{O}$ values; ${ }^{17} \mathrm{O}$ was not studied), while the total oxygen amount is depleted. It was shown that this is not only valid for oxygen, but also for silicon, sulfur and potassium (Epstein and Taylor Jr. 1971, Clayton et al. 1974b). The phenomenon was linked to surface processes on the Moon. It is correlating with depth and soil maturity (features: content of solar wind, content of carbon, content of glassy agglutinates; Clayton et al. 1974a). Clayton et al. (1974b) interpreted the observation as the effect of kinetic fractionation during thermal volatilisation triggered by the micrometeorite bombardment.

This process might be important to understand the $\delta^{18} \mathrm{O}$ of the analysed soil samples 12001, 12010 and 15421R. Sample 12001 has a maturity index of 56 (Morris 1978) and a fraction of $40.1 \%$ agglutinates relative to the total modal mineralogy (Simon et al. 1981). Sample 12010 is less studied, but it contains only $1.3 \%$ agglutinates indicating that this soil is less mature (Simon et al. 1981). The soil maturity is unknown for the separated soil sample 15421R. The more mature sample 12001 has indeed a higher $\delta^{18} \mathrm{O}$ than sample 12010 (table D.11). The ${ }^{18} \mathrm{O}$ enrichment is not incorporated in the agglutinates, but the agglutinates are representative for the maturity of the soil (Clayton et al. 1974b). The oxygen isotope compositions of the pyroclastic glasses are not effected by those processes (Clayton et al. 1974b).

The effect on the triple oxygen isotope composition of soils by the described process is not yet well understood and difficult to reconstruct. Hence, we decided to use only impact rocks for constraining the composition of the late accretion.

\section{D.5.2 Impact rocks}

The late accreted material mixed into the lunar crust was assessed in the past by highly siderophile (Re, Os, Ir, Ru, Pt, Rh, Pd; e.g. Norman et al. 2002, Puchtel et al. 2008, Fischer-Gödde and Becker 2012, Sharp et al. 2014, Liu et al. 2015, Gleißner and Becker 
2017, 2019) or moderately siderophile element techniques (W; Kruijer et al. 2015, Thiemens et al. 2019). HSE studies analysed HSE concentrations, abundance patterns, and isotopic compositions of impact rocks from Apollo 14, 15, 16 and 17 with ages $>3.8 \mathrm{Ga}$ and detected several impactor signatures related to different impact events. We studied the triple oxygen isotope composition of ten impact rocks, which were also characterised and interpreted by HSE studies (Puchtel et al. 2008, Fischer-Gödde and Becker 2012, Gleißner and Becker 2017), to constrain the late accreted material from an oxygen isotope perspective.

Both approaches, HSE and $\Delta^{\prime 17} \mathrm{O}$, are sensitive to different impactor types and should therefore provide complementary results. The strongest HSE signal (highest concentration) is introduced by metal-bearing, differentiated bodies, hence the HSE approach is very sensitive to stony-iron and iron meteorite-like material. Though, it is more difficult to distinguish between different chondrite types applying this technique. The strongest $\Delta^{\prime 17} \mathrm{O}$ signal (largest isotopic anomaly) is introduced by primitive bodies, hence the $\Delta^{\prime 17} \mathrm{O}$ approach is very sensitive to most chondrites and achondrites. Shortcomings of this approach are: (I) It is impossible or very difficult to trace iron and stony-iron meteoritelike material, because this material contains no or little oxygen. (II) It is difficult to resolve material-types, whose triple oxygen isotope composition is very similar to the Earth-Moon material (e.g. enstatite chondrites or terrestrial meteorites). (III) There are several possible impactor types, which we cannot assess because too little triple oxygen isotope data is available (e.g. comets, $\mathrm{K}$ chondrites) or the uncertainty concerning this data is too large (e.g. aubrites, angrites).

Several impact rock sample sets were interpreted by HSE studies to reflect the addition of chondritic impactor material or unknown primitive material. The relative HSE abundances in many rocks were too high for any known meteoritic materials (suprachondritic values; Norman et al. 2002, Puchtel et al. 2008, Sharp et al. 2014, Liu et al. 2015). The addition of (non-chondritic) differentiated metal impactors e.g. fragments of planetary cores were discussed as explanation of this phenomenon (Morgan et al. 1972, 1974 and Fischer-Gödde and Becker 2012: IVA iron meteorite). It is still debated if the HSE signatures represent the composition of one impactor (Sharp et al. 2014) or the mixed composition of several impactors (Fischer-Gödde and Becker 2012, Gleißner and Becker 2017, 2019). It was also argued that the signatures are affected by large-scale fractional crystallisation of metal within impact melt pools (Vaughan et al. 2013), though Gleißner and Becker (2017) refuted this hypothesis. Gleißner and Becker $(2017,2019)$ found that the HSE data from all analysed impact rocks form a gradual trend and that two ancient samples with a similar age (67935: 4.21 Ga, non-chondritic signature, Nectaris basin; 65055: $4.20 \mathrm{Ga}$, chondritic signature, Serenitas basin) and opposing signatures define this trend (see fig. D.8A). Gleißner and Becker (2017) suggest that two ancient impact events influenced most of the lunar nearside and that all impact rock signatures represent varying degrees of mixing between those two impactor components with the target Moon (three-component mixing model).

Several late accretion studies on terrestrial materials imply carbonaceous chondrite (CC)-like material (e.g. Wang and Becker 2013, Varas-Reus et al. 2019, Braukmüller et al. 2019, Fischer-Gödde et al. 2020). The oxygen isotope composition of the analysed Apollo 16 and 17 impact rocks could be indeed explained by the addition of CC-like material (except CI) or primitive achondrites. A chondritic HSE impactor signature was only traced for sample 65055 (Gleißner and Becker 2017) and 73215 (Puchtel et al. 2008) of 
D Supplementary information: Tracing impactor signatures in lunar rocks using triple oxygen isotopes

the studied sample set (fig. D.8A). HSE studies suggest the addition of ordinary chondrite $(\mathrm{OC})$ or enstatite chondrite (EC) impactor material for both impact rocks. Based on our oxygen isotope data a low $\Delta^{\prime 17} \mathrm{O}$ chondritic impactor $(\mathrm{CC})$ would explain the oxygen isotope composition of the impact rocks better. Primitive achondrites were discussed for feldspathic granulitic impact rocks like 60035 and 77017 (different samples were studied, Gleißner and Becker 2019), which could also explain the oxygen isotope data. HSE studies detected only non-chondritic metal impactor signatures in sample 60335, 61015, 67935 and 72395 (Puchtel et al. 2008, Fischer-Gödde and Becker 2012, Gleißner and Becker 2017). The oxygen isotope data indicates also a primitive chondritic signature in these samples, which might support the idea of Gleißner and Becker (2017) that impactor signatures in rocks from all Apollo sites result from a mixture of non-chondritic impactor as well as chondritic impactor component in varying degrees. With oxygen isotopes we can detect the small chondritic impactor component in the otherwise more non-chondritic influenced impact rocks. We also observed that the samples with the most impactor component show the lowest $\Delta^{\prime 17} \mathrm{O}$ values (fig. D.8B). From an oxygen isotope perspective alone the correlation seems to imply a two-component mixing (target, one impactor, Sharp et al. 2014), and not a three-component mixing (target, a chondritic impactor, a differentiated impactor, Gleißner and Becker 2017, 2019). Nevertheless, we cannot exclude a more-component mixing, because we can only determine the average effect created by the addition of extraterrestrial material with oxygen isotopes.
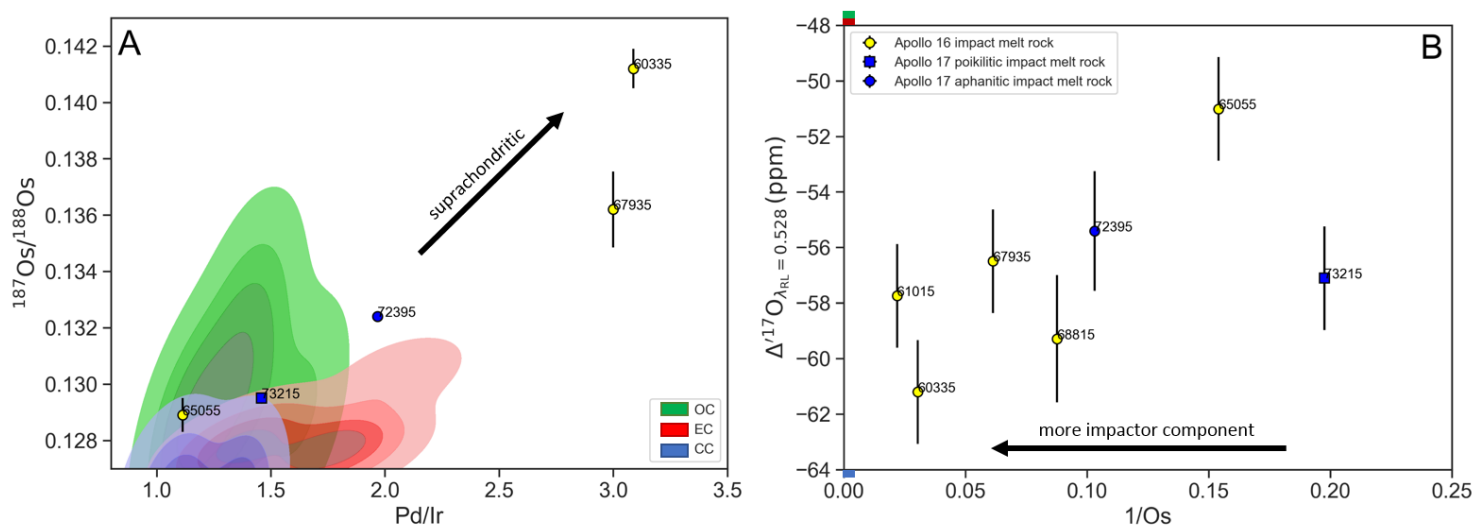

Figure D.8: The relation between the HSE and $\Delta^{\prime 17} \mathrm{O}$ signatures in lunar impact rocks. The HSE data was obtained from Puchtel et al. (2008), Fischer-Gödde and Becker (2012), Gleißner and Becker (2017) and by personal communication with P. Gleißner (not for all of the analysed impact rocks is HSE data available). A) Plot of ${ }^{187} \mathrm{Os} /{ }^{188} \mathrm{Os}$ vs. Pd/Ir. The HSE data of chondrites, ordinary (OC), enstatite (EC) and carbonaceous chondrites (CC), was obtained from Fischer-Gödde et al. (2011) and is displayed as kernel density contour plots (level $=10$ ). The HSE signature in sample 65055 and 73215 indicate a chondritic impactor, the other samples show suprachondritic values indicating a differentiated impactor (e.g. similar to an IVA iron meteorite, Fischer-Gödde and Becker 2012). B) $\Delta^{\prime 17} \mathrm{O}$ vs. $1 / \mathrm{Os}$, the lower $1 / \mathrm{Os}$ the higher the impactor component in the impact rock. The coloured blocks on top and below the subplot indicate the direction in which the respective chondrite would plot. The Apollo 16 impact melt rocks indicate a weak correlation between higher impactor component and lower $\Delta^{\prime 17} \mathrm{O}$. The aphanitic impact melt rock (73215) is not supporting this trend. Oxygen isotopes indicate that the differentiated impactor signatures in the HSE cannot be generated by an IVA iron meteorite (Fischer-Gödde and Becker 2012), because this material has a higher $\Delta^{\prime 17} \mathrm{O}$ value than the target and would not be able to generate lower $\Delta^{\prime 17} \mathrm{O}$ values (there is also evidence against IVA iron meteorites from a HSE perspective, see Gleißner and Becker 2017).

W studies found a difference between Earth and Moon, the BSM exhibits a positive $\varepsilon^{182} \mathrm{~W}$ anomaly compared to the BSE (Kruijer et al. 2015, Touboul et al. 2015, Kruijer and Kleine 2017). It is still debated if this excess in $\varepsilon^{182} \mathrm{~W}$ is the result of the different mass contribution of the late accretion to Earth and Moon (received less low ${ }^{182} \mathrm{~W}$ material; Kruijer et al. 2015, Touboul et al. 2015, Kruijer and Kleine 2017) or in-situ decay of the 
now extinct ${ }^{182} \mathrm{Hf}$ to ${ }^{182} \mathrm{~W}$ combined with an early Moon formation and is unrelated to the late accretion (Thiemens et al. 2019). Lunar KREEP-rich impact rocks were analysed in Kruijer et al. (2015) and Touboul et al. (2015) (e.g. 68115, 68815), which we also studied from an oxygen isotope perspective in chapter 6 . The $\mathrm{W}$ studies corrected these samples for their surface meteoritic component to receive representative values for the lunar mantle. We instead studied the surface meteoritic component. The findings concerning these samples can therefore not be compared. 
D Supplementary information: Tracing impactor signatures in lunar rocks using triple oxygen isotopes

\section{D.6 Additional figures}
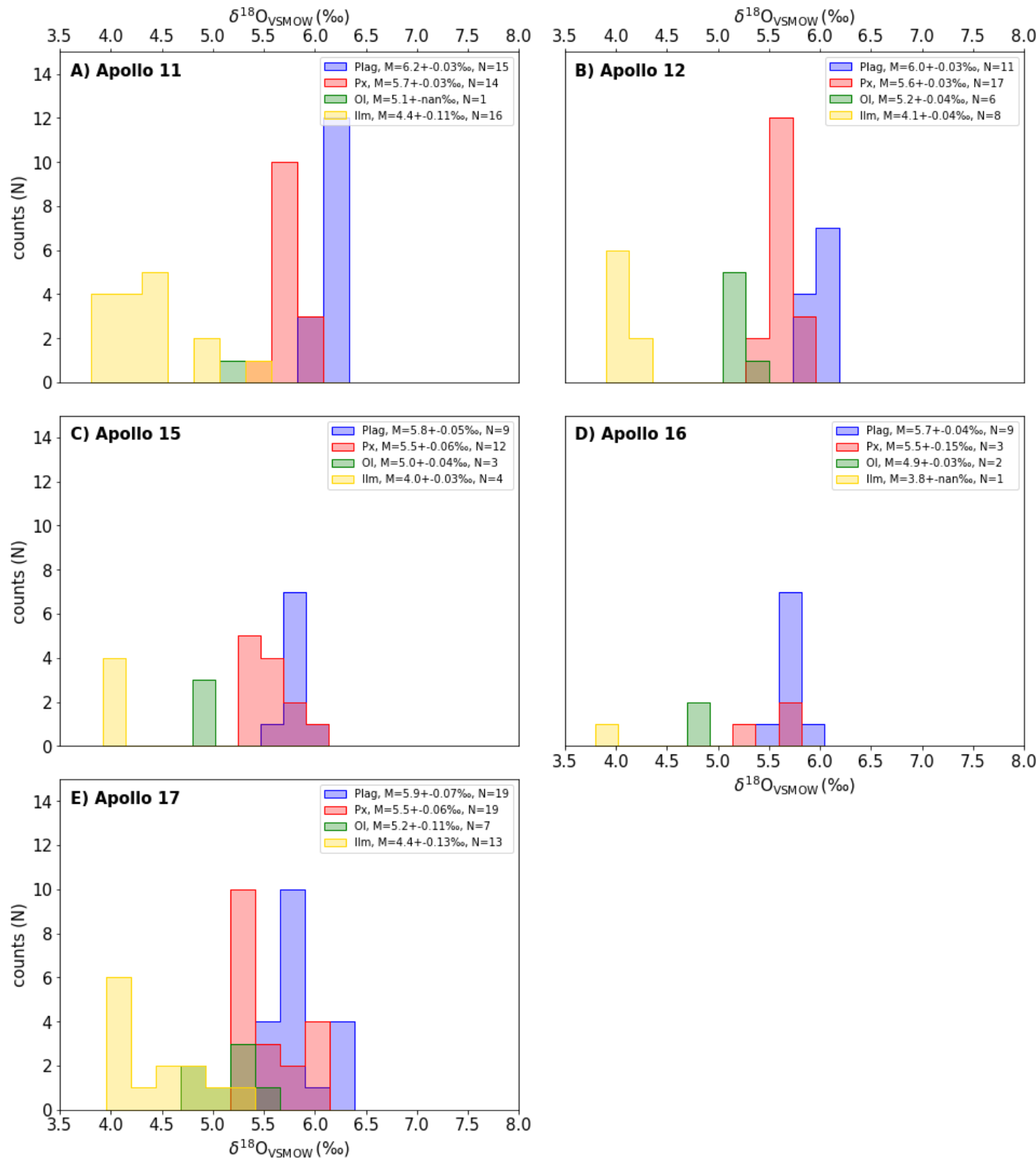

Figure D.9: Each histogram shows the distribution of the available $\delta^{18} \mathrm{O}$ data on the mineral separates plagioclase (Plag), pyroxene (Px; clinopyroxene, orthopyroxene, pigeonite), olivine (Ol) and ilmenite (Ilm) from different Apollo missions (11, 12, 15, 16, 17). Apollo 14 is not displayed, because the data is too scarce. The mean values $(M)$ of the individual mineral separates \pm SEM are reported in the legend including the sample size $(\mathrm{N})$. These plots are based on the data from: Apollo 11 (Onuma et al. 1970, O'Neil and Adami 1970, Taylor and Epstein 1970, Cano et al. 2020), Apollo 12 (Clayton et al. 1971, Epstein and Taylor Jr. 1971), Apollo 15 (Epstein and Taylor 1972, Clayton et al. 1974a, Greenwood et al. 2018, Cano et al. 2020), Apollo 16 (Taylor and Epstein 1973, Clayton et al. 1974a, Cano et al. 2020), Apollo 17 (Clayton and Mayeda 1975, Mayeda et al. 1975, Greenwood et al. 2018, Cano et al. 2020). 


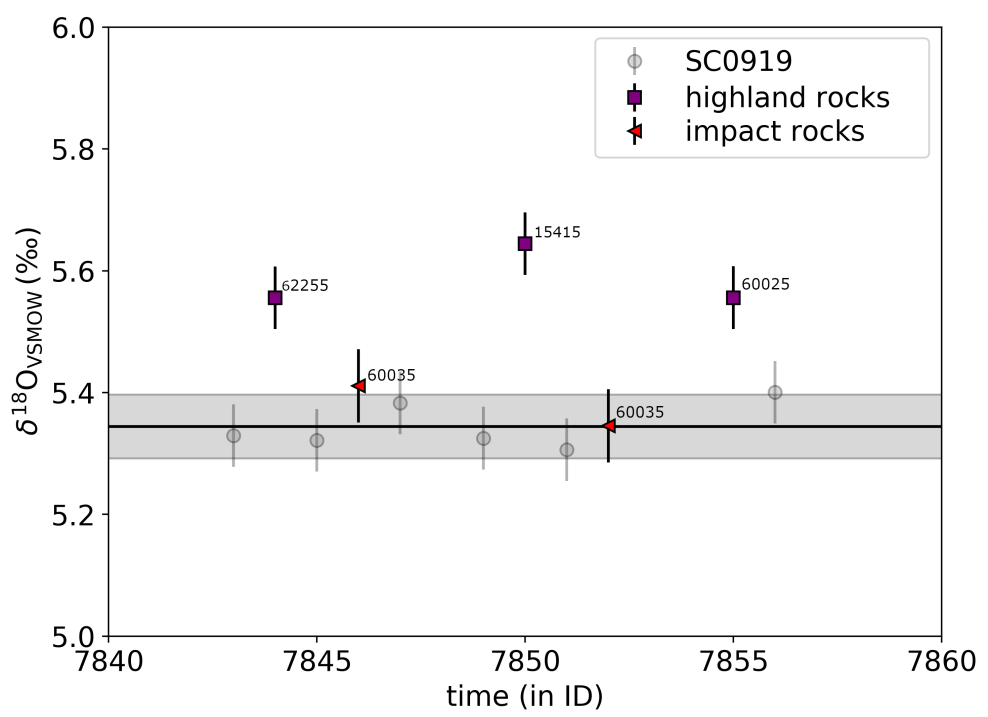

Figure D.10: $\delta^{18} \mathrm{O}$ data of the measurement session from the 28-30th of April in 2020. Pristine highland rocks were analysed along with a feldspar-rich impact rock. The samples were measured against the standard San Carlos olivine 0919 (SC0919). The horizontal lines represents the mean value $\pm \mathrm{SD}$ of the standard data. The impact rock 60035 is composed of pure plagioclase comparable to the highland rocks. There is an apparent $\delta^{18} \mathrm{O}$ offset of $\sim 0.2 \%$ o between the plagioclase of the impact rock and the plagioclase of the pristine highland rocks. 
D Supplementary information: Tracing impactor signatures in lunar rocks using triple oxygen isotopes

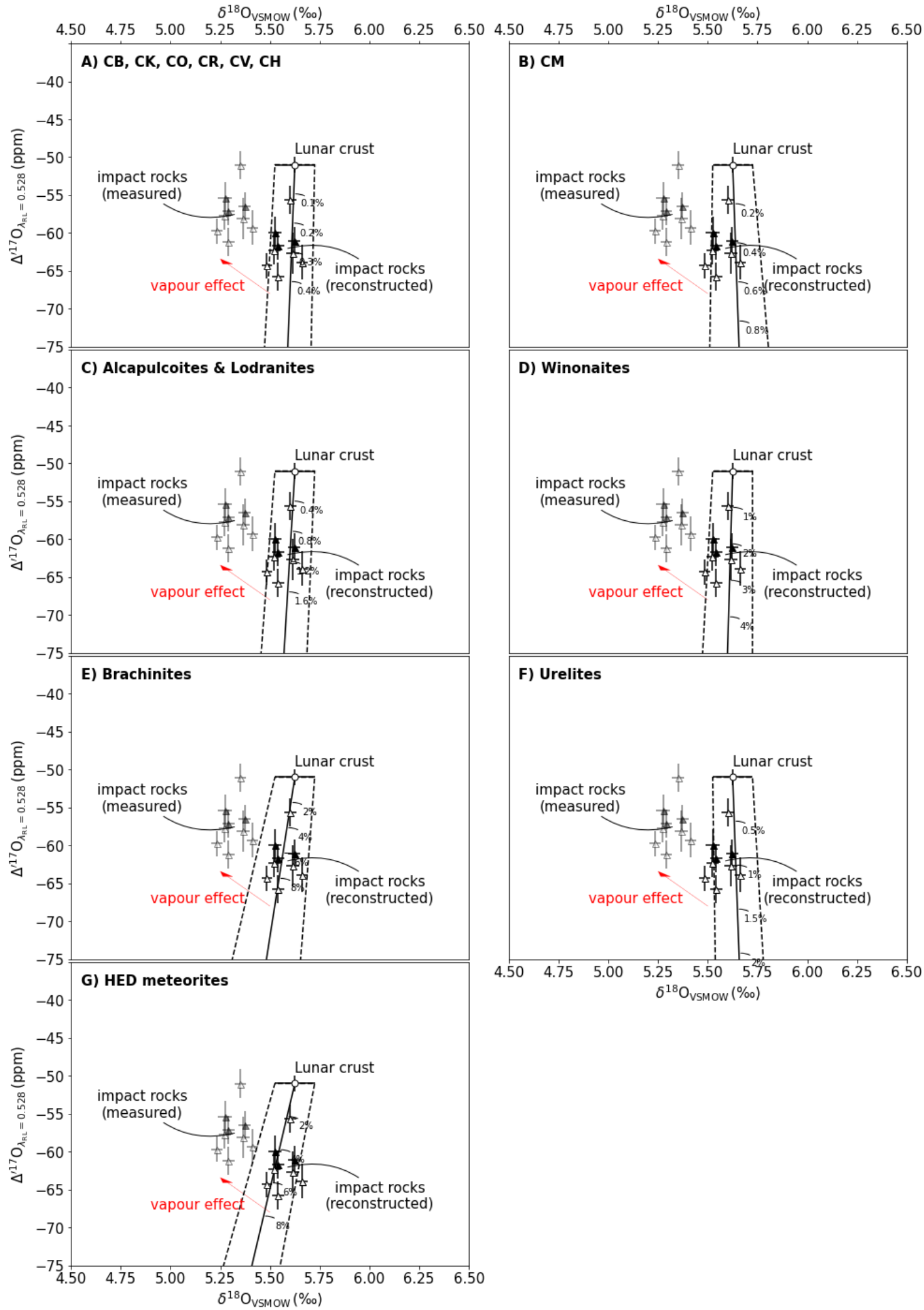

Figure D.11: Mixing model visualisation - triple oxygen isotope subplots. Individual subplots of possible impactor types (A-G) showing mixing curves with mixing degrees (impactor/target rock mixing ratios). The measured triple oxygen isotope compositions of the Apollo 16 impact rocks are plotted as transparent, white triangles, the composition of the Apollo 17 impact rocks are plotted as transparent, black triangles. The vaporisation corrected triple oxygen isotope composition of the impact rock data set is shown in solid symbols. The red arrow illustrates the effect of the condensation of an impact-induced light vapour. 


\section{D.7 Additional tables}

Table D.4: Oxygen isotope data on San Carlos olivine 0215M (single measurements, $N=57$ ).

\begin{tabular}{|c|c|c|c|c|c|c|}
\hline ID & $\begin{array}{l}\delta^{17} \mathrm{O} \\
(\% o)\end{array}$ & SD & $\begin{array}{l}\delta^{18} \mathrm{O} \\
(\% o)\end{array}$ & SD & $\begin{array}{l}\Delta^{\prime 17} \mathrm{O} \\
(\mathrm{ppm})\end{array}$ & SD \\
\hline 5419 & 2.66 & 0.04 & 5.13 & 0.07 & -50 & 6 \\
\hline 5421 & 2.72 & 0.04 & 5.24 & 0.07 & -49 & 6 \\
\hline 5423 & 2.69 & 0.04 & 5.19 & 0.07 & -50 & 6 \\
\hline 5425 & 2.71 & 0.04 & 5.24 & 0.07 & -50 & 6 \\
\hline 5426 & 2.66 & 0.04 & 5.14 & 0.07 & -49 & 6 \\
\hline 5428 & 2.68 & 0.04 & 5.19 & 0.07 & -56 & 6 \\
\hline 5430 & 2.66 & 0.04 & 5.13 & 0.07 & -42 & 6 \\
\hline 5432 & 2.64 & 0.04 & 5.12 & 0.07 & -57 & 6 \\
\hline 5444 & 2.68 & 0.04 & 5.18 & 0.07 & -52 & 6 \\
\hline 5449 & 2.64 & 0.04 & 5.09 & 0.07 & -46 & 6 \\
\hline 5456 & 2.68 & 0.04 & 5.18 & 0.07 & -56 & 6 \\
\hline 5458 & 2.68 & 0.04 & 5.19 & 0.07 & -58 & 6 \\
\hline 5459 & 2.74 & 0.04 & 5.31 & 0.07 & -59 & 6 \\
\hline 5468 & 2.71 & 0.04 & 5.23 & 0.07 & -43 & 6 \\
\hline 5471 & 2.73 & 0.04 & 5.26 & 0.07 & -47 & 6 \\
\hline 5472 & 2.68 & 0.04 & 5.18 & 0.07 & -46 & 6 \\
\hline 5475 & 2.62 & 0.04 & 5.09 & 0.07 & -60 & 6 \\
\hline 5476 & 2.69 & 0.04 & 5.21 & 0.07 & -61 & 6 \\
\hline 5478 & 2.58 & 0.04 & 5.00 & 0.07 & -60 & 6 \\
\hline 5482 & 2.75 & 0.04 & 5.30 & 0.07 & -45 & 6 \\
\hline 5576 & 2.71 & 0.04 & 5.25 & 0.07 & -57 & 6 \\
\hline 5578 & 2.68 & 0.04 & 5.20 & 0.07 & -58 & 6 \\
\hline 5580 & 2.72 & 0.04 & 5.26 & 0.07 & -48 & 6 \\
\hline 5583 & 2.67 & 0.04 & 5.17 & 0.07 & -53 & 6 \\
\hline 5585 & 2.65 & 0.04 & 5.13 & 0.07 & -53 & 6 \\
\hline 5587 & 2.63 & 0.04 & 5.07 & 0.07 & -48 & 6 \\
\hline 5589 & 2.67 & 0.04 & 5.15 & 0.07 & -49 & 6 \\
\hline 5590 & 2.70 & 0.04 & 5.22 & 0.07 & -49 & 6 \\
\hline 5614 & 2.66 & 0.04 & 5.15 & 0.07 & -57 & 6 \\
\hline 5617 & 2.66 & 0.04 & 5.15 & 0.07 & -56 & 6 \\
\hline 5619 & 2.70 & 0.04 & 5.20 & 0.07 & -37 & 6 \\
\hline 5621 & 2.73 & 0.04 & 5.27 & 0.07 & -49 & 6 \\
\hline 5622 & 2.70 & 0.04 & 5.22 & 0.07 & -53 & 6 \\
\hline 5626 & 2.66 & 0.04 & 5.16 & 0.07 & -57 & 6 \\
\hline 5628 & 2.66 & 0.04 & 5.13 & 0.07 & -48 & 6 \\
\hline 5633 & 2.67 & 0.04 & 5.17 & 0.07 & -57 & 6 \\
\hline 5682 & 2.74 & 0.04 & 5.29 & 0.07 & -48 & 6 \\
\hline 5684 & 2.72 & 0.04 & 5.25 & 0.07 & -47 & 6 \\
\hline 5686 & 2.74 & 0.04 & 5.28 & 0.07 & -47 & 6 \\
\hline 5688 & 2.73 & 0.04 & 5.27 & 0.07 & -51 & 6 \\
\hline 5689 & 2.67 & 0.04 & 5.15 & 0.07 & -50 & 6 \\
\hline 5691 & 2.65 & 0.04 & 5.12 & 0.07 & -53 & 6 \\
\hline 5693 & 2.56 & 0.04 & 4.97 & 0.07 & -60 & 6 \\
\hline 5694 & 2.63 & 0.04 & 5.11 & 0.07 & -58 & 6 \\
\hline 5810 & 2.70 & 0.04 & 5.21 & 0.07 & -46 & 6 \\
\hline 5819 & 2.74 & 0.04 & 5.29 & 0.07 & -53 & 6 \\
\hline 5820 & 2.65 & 0.04 & 5.12 & 0.07 & -50 & 6 \\
\hline 5821 & 2.67 & 0.04 & 5.16 & 0.07 & -53 & 6 \\
\hline 5822 & 2.64 & 0.04 & 5.11 & 0.07 & -57 & 6 \\
\hline 5886 & 2.69 & 0.04 & 5.19 & 0.07 & -49 & 6 \\
\hline 5887 & 2.66 & 0.04 & 5.14 & 0.07 & -49 & 6 \\
\hline 5889 & 2.62 & 0.04 & 5.07 & 0.07 & -53 & 6 \\
\hline 5891 & 2.71 & 0.04 & 5.22 & 0.07 & -44 & 6 \\
\hline 5893 & 2.67 & 0.04 & 5.15 & 0.07 & -45 & 6 \\
\hline 5896 & 2.68 & 0.04 & 5.19 & 0.07 & -57 & 6 \\
\hline 5898 & 2.68 & 0.04 & 5.21 & 0.07 & -65 & 6 \\
\hline 5900 & 2.73 & 0.04 & 5.28 & 0.07 & -53 & 6 \\
\hline Average & 2.68 & 0.01 & 5.18 & 0.01 & -52 & 1 \\
\hline
\end{tabular}


D Supplementary information: Tracing impactor signatures in lunar rocks using triple oxygen isotopes

Table D.5: Oxygen isotope data on San Carlos olivine 0919 (single measurements, $N=112$ ).

\begin{tabular}{|c|c|c|c|c|c|c|}
\hline ID & $\begin{array}{l}\delta^{17} \mathrm{O} \\
(\% \circ)\end{array}$ & SD & $\begin{array}{l}\delta^{18} \mathrm{O} \\
(\% o)\end{array}$ & SD & $\begin{array}{l}\Delta^{\prime 17} \mathrm{O} \\
(\mathrm{ppm})\end{array}$ & SD \\
\hline 6769 & 2.74 & 0.03 & 5.30 & 0.05 & -57 & 4 \\
\hline 6770 & 2.74 & 0.03 & 5.29 & 0.05 & -47 & 4 \\
\hline 6773 & 2.78 & 0.03 & 5.38 & 0.05 & -53 & 4 \\
\hline 6775 & 2.78 & 0.03 & 5.40 & 0.05 & -61 & 4 \\
\hline 6777 & 2.77 & 0.03 & 5.35 & 0.05 & -48 & 4 \\
\hline 6779 & 2.77 & 0.03 & 5.35 & 0.05 & -48 & 4 \\
\hline 6779 & 2.77 & 0.03 & 5.35 & 0.05 & -48 & 4 \\
\hline 6789 & 2.76 & 0.03 & 5.34 & 0.05 & -57 & 4 \\
\hline 6791 & 2.73 & 0.03 & 5.28 & 0.05 & -57 & 4 \\
\hline 6793 & 2.82 & 0.03 & 5.43 & 0.05 & -47 & 4 \\
\hline 6795 & 2.74 & 0.03 & 5.29 & 0.05 & -45 & 4 \\
\hline 6797 & 2.77 & 0.03 & 5.35 & 0.05 & -47 & 4 \\
\hline 6799 & 2.79 & 0.03 & 5.39 & 0.05 & -55 & 4 \\
\hline 6801 & 2.75 & 0.03 & 5.32 & 0.05 & -56 & 4 \\
\hline 6920 & 2.73 & 0.03 & 5.28 & 0.06 & -57 & 4 \\
\hline 6922 & 2.80 & 0.03 & 5.41 & 0.06 & -52 & 4 \\
\hline 6924 & 2.75 & 0.03 & 5.31 & 0.06 & -52 & 4 \\
\hline 6926 & 2.82 & 0.03 & 5.45 & 0.06 & -49 & 4 \\
\hline 6928 & 2.77 & 0.03 & 5.35 & 0.06 & -52 & 4 \\
\hline 6931 & 2.78 & 0.03 & 5.36 & 0.06 & -49 & 4 \\
\hline 6933 & 2.72 & 0.03 & 5.26 & 0.06 & -52 & 4 \\
\hline 6942 & 2.77 & 0.03 & 5.34 & 0.06 & -45 & 4 \\
\hline 6944 & 2.75 & 0.03 & 5.34 & 0.06 & -62 & 4 \\
\hline 6945 & 2.77 & 0.03 & 5.37 & 0.06 & -55 & 4 \\
\hline 6947 & 2.70 & 0.03 & 5.21 & 0.06 & -53 & 4 \\
\hline 6949 & 2.77 & 0.03 & 5.35 & 0.06 & -47 & 4 \\
\hline 6951 & 2.76 & 0.03 & 5.32 & 0.06 & -50 & 4 \\
\hline 6953 & 2.81 & 0.03 & 5.43 & 0.06 & -55 & 4 \\
\hline 6954 & 2.80 & 0.03 & 5.39 & 0.06 & -47 & 4 \\
\hline 6996 & 2.77 & 0.03 & 5.36 & 0.06 & -61 & 4 \\
\hline 6997 & 2.75 & 0.03 & 5.30 & 0.06 & -49 & 4 \\
\hline 6999 & 2.78 & 0.03 & 5.37 & 0.06 & -51 & 4 \\
\hline 7001 & 2.72 & 0.03 & 5.24 & 0.06 & -44 & 4 \\
\hline 7003 & 2.77 & 0.03 & 5.36 & 0.06 & -55 & 4 \\
\hline 7007 & 2.82 & 0.03 & 5.46 & 0.06 & -57 & 4 \\
\hline 7009 & 2.83 & 0.03 & 5.46 & 0.06 & -49 & 4 \\
\hline 7010 & 2.69 & 0.03 & 5.20 & 0.06 & -49 & 4 \\
\hline 7018 & 2.72 & 0.03 & 5.26 & 0.06 & -54 & 4 \\
\hline 7019 & 2.77 & 0.03 & 5.35 & 0.06 & -49 & 4 \\
\hline 7024 & 2.77 & 0.03 & 5.35 & 0.06 & -50 & 4 \\
\hline 7027 & 2.80 & 0.03 & 5.41 & 0.06 & -49 & 4 \\
\hline 7030 & 2.73 & 0.03 & 5.27 & 0.06 & -53 & 4 \\
\hline 7034 & 2.81 & 0.03 & 5.44 & 0.06 & -53 & 4 \\
\hline 7036 & 2.76 & 0.03 & 5.34 & 0.06 & -54 & 4 \\
\hline 7086 & 2.79 & 0.03 & 5.37 & 0.05 & -46 & 4 \\
\hline 7087 & 2.79 & 0.03 & 5.40 & 0.05 & -56 & 4 \\
\hline 7089 & 2.75 & 0.03 & 5.30 & 0.05 & -45 & 4 \\
\hline 7091 & 2.73 & 0.03 & 5.28 & 0.05 & -54 & 4 \\
\hline 7093 & 2.72 & 0.03 & 5.27 & 0.05 & -58 & 4 \\
\hline 7095 & 2.78 & 0.03 & 5.38 & 0.05 & -59 & 4 \\
\hline 7097 & 2.79 & 0.03 & 5.38 & 0.05 & -47 & 4 \\
\hline 7098 & 2.78 & 0.03 & 5.37 & 0.05 & -49 & 4 \\
\hline 7132 & 2.79 & 0.03 & 5.38 & 0.05 & -49 & 4 \\
\hline 7133 & 2.73 & 0.03 & 5.28 & 0.05 & -55 & 4 \\
\hline 7135 & 2.71 & 0.03 & 5.24 & 0.05 & -48 & 4 \\
\hline 7138 & 2.78 & 0.03 & 5.40 & 0.05 & -60 & 4 \\
\hline 7140 & 2.75 & 0.03 & 5.30 & 0.05 & -48 & 4 \\
\hline 7142 & 2.81 & 0.03 & 5.43 & 0.05 & -51 & 4 \\
\hline 7144 & 2.79 & 0.03 & 5.38 & 0.05 & -51 & 4 \\
\hline 7179 & 2.78 & 0.03 & 5.36 & 0.06 & -48 & 4 \\
\hline 7180 & 2.77 & 0.03 & 5.35 & 0.06 & -46 & 4 \\
\hline 7184 & 2.76 & 0.03 & 5.34 & 0.06 & -54 & 4 \\
\hline 7187 & 2.72 & 0.03 & 5.26 & 0.06 & -54 & 4 \\
\hline 7189 & 2.75 & 0.03 & 5.30 & 0.06 & -47 & 4 \\
\hline 7191 & 2.82 & 0.03 & 5.45 & 0.06 & -53 & 4 \\
\hline
\end{tabular}




\begin{tabular}{|c|c|c|c|c|c|c|}
\hline 7192 & 2.76 & 0.03 & 5.35 & 0.06 & -61 & 4 \\
\hline 7200 & 2.72 & 0.03 & 5.25 & 0.06 & -50 & 4 \\
\hline 7201 & 2.78 & 0.03 & 5.36 & 0.06 & -48 & 4 \\
\hline 7203 & 2.78 & 0.03 & 5.37 & 0.06 & -54 & 4 \\
\hline 7205 & 2.79 & 0.03 & 5.38 & 0.06 & -53 & 4 \\
\hline 7207 & 2.71 & 0.03 & 5.24 & 0.06 & -55 & 4 \\
\hline 7209 & 2.77 & 0.03 & 5.35 & 0.06 & -51 & 4 \\
\hline 7211 & 2.82 & 0.03 & 5.44 & 0.06 & -45 & 4 \\
\hline 7212 & 2.77 & 0.03 & 5.35 & 0.06 & -57 & 4 \\
\hline 7242 & 2.77 & 0.03 & 5.34 & 0.06 & -52 & 4 \\
\hline 7243 & 2.77 & 0.03 & 5.34 & 0.06 & -50 & 4 \\
\hline 7245 & 2.77 & 0.03 & 5.35 & 0.06 & -50 & 4 \\
\hline 7247 & 2.76 & 0.03 & 5.33 & 0.06 & -49 & 4 \\
\hline 7249 & 2.72 & 0.03 & 5.27 & 0.06 & -57 & 4 \\
\hline 7252 & 2.74 & 0.03 & 5.28 & 0.06 & -49 & 4 \\
\hline 7253 & 2.82 & 0.03 & 5.45 & 0.06 & -56 & 4 \\
\hline 7254 & 2.78 & 0.03 & 5.37 & 0.06 & -53 & 4 \\
\hline 7279 & 2.75 & 0.03 & 5.31 & 0.06 & -55 & 4 \\
\hline 7281 & 2.76 & 0.03 & 5.34 & 0.06 & -51 & 4 \\
\hline 7284 & 2.76 & 0.03 & 5.32 & 0.06 & -49 & 4 \\
\hline 7286 & 2.77 & 0.03 & 5.35 & 0.06 & -53 & 4 \\
\hline 7288 & 2.72 & 0.03 & 5.26 & 0.06 & -52 & 4 \\
\hline 7290 & 2.78 & 0.03 & 5.38 & 0.06 & -53 & 4 \\
\hline 7292 & 2.81 & 0.03 & 5.42 & 0.06 & -50 & 4 \\
\hline 7293 & 2.78 & 0.03 & 5.36 & 0.06 & -50 & 4 \\
\hline 7843 & 2.76 & 0.03 & 5.33 & 0.05 & -53 & 4 \\
\hline 7845 & 2.76 & 0.03 & 5.32 & 0.05 & -50 & 4 \\
\hline 7847 & 2.79 & 0.03 & 5.38 & 0.05 & -50 & 4 \\
\hline 7849 & 2.75 & 0.03 & 5.33 & 0.05 & -56 & 4 \\
\hline 7851 & 2.75 & 0.03 & 5.31 & 0.05 & -48 & 4 \\
\hline 7856 & 2.79 & 0.03 & 5.40 & 0.05 & -54 & 4 \\
\hline 7864 & 2.81 & 0.03 & 5.42 & 0.05 & -50 & 4 \\
\hline 7865 & 2.77 & 0.03 & 5.35 & 0.05 & -52 & 4 \\
\hline 7867 & 2.78 & 0.03 & 5.36 & 0.05 & -49 & 4 \\
\hline 7870 & 2.78 & 0.03 & 5.37 & 0.05 & -46 & 4 \\
\hline 7872 & 2.76 & 0.03 & 5.34 & 0.05 & -57 & 4 \\
\hline 7874 & 2.75 & 0.03 & 5.30 & 0.05 & -51 & 4 \\
\hline 7876 & 2.77 & 0.03 & 5.36 & 0.05 & -57 & 4 \\
\hline 7877 & 2.71 & 0.03 & 5.24 & 0.05 & -52 & 4 \\
\hline 7886 & 2.69 & 0.03 & 5.21 & 0.05 & -57 & 4 \\
\hline 7887 & 2.80 & 0.03 & 5.42 & 0.05 & -53 & 4 \\
\hline 7889 & 2.81 & 0.03 & 5.42 & 0.05 & -48 & 4 \\
\hline 7891 & 2.78 & 0.03 & 5.37 & 0.05 & -53 & 4 \\
\hline 7893 & 2.78 & 0.03 & 5.38 & 0.05 & -54 & 4 \\
\hline 7895 & 2.73 & 0.03 & 5.27 & 0.05 & -49 & 4 \\
\hline 7897 & 2.76 & 0.03 & 5.33 & 0.05 & -47 & 4 \\
\hline 7898 & 2.77 & 0.03 & 5.36 & 0.05 & -53 & 4 \\
\hline Average & 2.77 & 0.00 & 5.34 & 0.01 & -52 & 0 \\
\hline
\end{tabular}


D Supplementary information: Tracing impactor signatures in lunar rocks using triple oxygen isotopes

Table D.6: Oxygen isotope data on UWG-2 garnet (single measurements, $N=23$ ). Fraction \#180 was analysed from ID 5418 to 5885. Fraction \#200 was measured from ID 6788 to ID 7885.

\begin{tabular}{ccccccc}
\hline ID & $\begin{array}{l}\delta^{17} \mathrm{O} \\
(\%)\end{array}$ & $\mathrm{SD}$ & $\begin{array}{l}\delta^{18} \mathrm{O} \\
(\% o)\end{array}$ & $\mathrm{SD}$ & $\begin{array}{l}\Delta^{17} \mathrm{O} \\
(\mathrm{ppm})\end{array}$ & $\mathrm{SD}$ \\
\hline 5418 & 3.01 & 0.04 & 5.82 & 0.07 & -57 & 6 \\
5443 & 2.92 & 0.04 & 5.64 & 0.07 & -50 & 6 \\
5466 & 2.98 & 0.04 & 5.79 & 0.07 & -63 & 6 \\
5575 & 2.98 & 0.04 & 5.79 & 0.07 & -67 & 6 \\
5613 & 2.99 & 0.04 & 5.81 & 0.07 & -62 & 6 \\
5681 & 2.93 & 0.04 & 5.68 & 0.07 & -58 & 6 \\
5809 & 3.00 & 0.04 & 5.81 & 0.07 & -63 & 6 \\
5885 & 2.94 & 0.04 & 5.68 & 0.07 & -48 & 6 \\
6788 & 2.96 & 0.02 & 5.73 & 0.05 & -56 & 4 \\
6919 & 2.96 & 0.03 & 5.73 & 0.06 & -65 & 4 \\
6925 & 2.94 & 0.03 & 5.68 & 0.06 & -57 & 4 \\
6941 & 2.99 & 0.03 & 5.77 & 0.06 & -55 & 4 \\
6992 & 3.00 & 0.03 & 5.78 & 0.06 & -49 & 4 \\
7017 & 3.00 & 0.03 & 5.80 & 0.06 & -61 & 4 \\
7085 & 3.00 & 0.02 & 5.81 & 0.05 & -65 & 4 \\
7131 & 2.94 & 0.02 & 5.70 & 0.05 & -60 & 4 \\
7178 & 2.96 & 0.03 & 5.74 & 0.06 & -67 & 4 \\
7199 & 2.98 & 0.03 & 5.76 & 0.06 & -57 & 4 \\
7241 & 3.00 & 0.03 & 5.80 & 0.06 & -57 & 4 \\
7278 & 3.00 & 0.03 & 5.81 & 0.06 & -66 & 4 \\
7842 & 2.97 & 0.02 & 5.77 & 0.05 & -64 & 4 \\
7863 & 3.06 & 0.02 & 5.92 & 0.05 & -60 & 4 \\
7885 & 3.03 & 0.02 & 5.86 & 0.05 & -57 & 4 \\
Average & $\mathbf{2 . 9 8}$ & $\mathbf{0 . 0 1}$ & $\mathbf{5 . 7 7}$ & $\mathbf{0}$ & $\mathbf{- 5 9}$ & $\mathbf{1}$ \\
\hline & & & & & & \\
\hline
\end{tabular}

Table D.7: Oxygen isotope data on lunar mare basalts (single measurements, $N=16$ ). Sample 10071,70215 and 75035 are high-Ti mare basalts, the other samples are low-Ti mare basalts.

\begin{tabular}{cccccccc}
\hline ID & Sample ID & $\begin{array}{l}\delta^{17} \mathrm{O} \\
(\%)\end{array}$ & $\mathrm{SD}$ & $\begin{array}{l}\delta^{18} \mathrm{O} \\
(\% \mathrm{o})\end{array}$ & $\mathrm{SD}$ & $\begin{array}{l}\Delta^{\prime 17} \mathrm{O} \\
(\mathrm{ppm})\end{array}$ & $\mathrm{SD}$ \\
\hline 5457 & 10071.122 & 2.92 & 0.04 & 5.62 & 0.07 & -47 & 6 \\
5577 & 10071.122 & 2.92 & 0.04 & 5.65 & 0.07 & -55 & 6 \\
5481 & 12018.267 & 2.92 & 0.04 & 5.64 & 0.07 & -55 & 6 \\
5624 & 12018.267 & 2.81 & 0.04 & 5.42 & 0.07 & -48 & 6 \\
5427 & 12038.264 & 2.92 & 0.04 & 5.62 & 0.07 & -45 & 6 \\
5586 & 12038.264 & 2.89 & 0.04 & 5.59 & 0.07 & -53 & 6 \\
5420 & 12039.47 & 2.92 & 0.04 & 5.63 & 0.07 & -53 & 6 \\
5692 & 12039.65 & 2.80 & 0.04 & 5.41 & 0.07 & -52 & 6 \\
5455 & 12045.26 & 2.87 & 0.04 & 5.52 & 0.07 & -44 & 6 \\
5629 & 12045.26 & 2.81 & 0.04 & 5.42 & 0.07 & -50 & 6 \\
5683 & 15495.202 & 2.76 & 0.04 & 5.35 & 0.07 & -54 & 6 \\
6800 & 15495.202 & 2.89 & 0.02 & 5.58 & 0.05 & -51 & 4 \\
5469 & 70215.324 & 2.93 & 0.04 & 5.65 & 0.07 & -50 & 6 \\
6796 & 70215.324 & 2.91 & 0.02 & 5.62 & 0.05 & -56 & 4 \\
5479 & 75035.226 & 2.94 & 0.04 & 5.65 & 0.07 & -43 & 6 \\
6790 & 75035.226 & 3.02 & 0.02 & 5.83 & 0.05 & -54 & 4 \\
& Average & $\mathbf{2 . 8 9}$ & $\mathbf{0 . 0 2}$ & $\mathbf{5 . 5 8}$ & $\mathbf{0 . 0 3}$ & $\mathbf{- 5 1}$ & $\mathbf{1}$ \\
\hline
\end{tabular}


Table D.8: Oxygen isotope data on highland rocks (single measurements, $N=11$ ).

\begin{tabular}{cccccccc}
\hline ID & Sample ID & $\begin{array}{l}\delta^{17} \mathrm{O} \\
(\% \circ)\end{array}$ & $\mathrm{SD}$ & $\begin{array}{l}\delta^{18} \mathrm{O} \\
(\% \circ)\end{array}$ & $\mathrm{SD}$ & $\begin{array}{l}\Delta^{\prime 17} \mathrm{O} \\
(\mathrm{ppm})\end{array}$ & $\mathrm{SD}$ \\
\hline 5429 & 15415.171 & 3.00 & 0.04 & 5.78 & 0.07 & -49 & 6 \\
5584 & 15415.171 & 3.05 & 0.04 & 5.89 & 0.07 & -56 & 6 \\
7850 & 15415.171 & 2.92 & 0.02 & 5.64 & 0.05 & -52 & 4 \\
5422 & 60025.842 & 2.99 & 0.04 & 5.78 & 0.07 & -54 & 6 \\
5690 & 60025.173 & 3.02 & 0.04 & 5.83 & 0.07 & -50 & 6 \\
7844 & 60025.173 & 2.87 & 0.02 & 5.56 & 0.05 & -55 & 4 \\
5470 & 61224.52 & 2.91 & 0.04 & 5.62 & 0.07 & -54 & 6 \\
5618 & 61224.52 & 3.00 & 0.04 & 5.79 & 0.07 & -48 & 6 \\
5588 & 62255.311 & 2.97 & 0.04 & 5.72 & 0.07 & -44 & 6 \\
5627 & 62255.311 & 2.98 & 0.04 & 5.75 & 0.07 & -52 & 6 \\
7855 & 62255.311 & 2.87 & 0.02 & 5.56 & 0.05 & -58 & 4 \\
& Average & $\mathbf{2 . 9 6}$ & $\mathbf{0 . 0 2}$ & $\mathbf{5 . 7 2}$ & $\mathbf{0 . 0 3}$ & $\mathbf{- 5 2}$ & $\mathbf{1}$ \\
\hline
\end{tabular}

Table D.9: Oxygen isotope data on lunar pyroclastic glass (single measurements, $N=13$ ).

\begin{tabular}{cccccccc}
\hline ID & Sample ID & $\begin{array}{l}\delta^{17} \mathrm{O} \\
(\%)\end{array}$ & $\mathrm{SD}$ & $\begin{array}{l}\delta^{18} \mathrm{O} \\
(\% o)\end{array}$ & $\mathrm{SD}$ & $\begin{array}{l}\Delta^{\prime 17} \mathrm{O} \\
(\mathrm{ppm})\end{array}$ & $\mathrm{SD}$ \\
\hline 5890 & $15426.192 \mathrm{~A}$ & 2.78 & 0.04 & 5.36 & 0.07 & -44 & 6 \\
6771 & $15426.192 \mathrm{~A}$ & 2.79 & 0.02 & 5.40 & 0.05 & -60 & 4 \\
6774 & $15426.192 \mathrm{C}$ & 2.80 & 0.02 & 5.43 & 0.05 & -60 & 4 \\
7873 & $15426.192 \mathrm{C}$ & 2.77 & 0.02 & 5.35 & 0.05 & -50 & 4 \\
7875 & $15426.192 \mathrm{mix}$ & 2.87 & 0.02 & 5.53 & 0.05 & -51 & 4 \\
6778 & $15426 \mathrm{UNMmix}$ & 2.82 & 0.02 & 5.46 & 0.05 & -57 & 4 \\
7869 & $15426 \mathrm{UNMmix}$ & 2.83 & 0.02 & 5.48 & 0.05 & -61 & 4 \\
7894 & $15426 \mathrm{UNMmix}$ & 2.80 & 0.02 & 5.39 & 0.05 & -45 & 4 \\
7896 & $15426 \mathrm{UNMmix}$ & 2.80 & 0.02 & 5.41 & 0.05 & -50 & 4 \\
7890 & $15421.70 \operatorname{mix}$ & 2.83 & 0.02 & 5.46 & 0.05 & -47 & 4 \\
5888 & 74220.94 & 2.86 & 0.04 & 5.53 & 0.07 & -58 & 6 \\
6780 & 74220.94 & 2.88 & 0.02 & 5.53 & 0.05 & -41 & 4 \\
7866 & 74220.94 & 2.88 & 0.02 & 5.56 & 0.05 & -51 & 4 \\
& Average & $\mathbf{2 . 8 2}$ & $\mathbf{0 . 0 1}$ & $\mathbf{5 . 4 5}$ & $\mathbf{0 . 0 2}$ & $\mathbf{- 5 2}$ & $\mathbf{2}$ \\
\hline
\end{tabular}

Table D.10: Oxygen isotope data on lunar KREEP-rich breccias (single measurements, $N=7$ ).

\begin{tabular}{cccccccc}
\hline ID & Sample ID & $\begin{array}{l}\delta^{17} \mathrm{O} \\
(\% o\end{array}$ & SD & $\begin{array}{l}\delta^{18} \mathrm{O} \\
(\% \circ)\end{array}$ & $\mathrm{SD}$ & $\begin{array}{l}\Delta^{\prime 17} \mathrm{O} \\
(\mathrm{ppm})\end{array}$ & $\mathrm{SD}$ \\
\hline 5615 & 68115.11 & 2.67 & 0.04 & 5.18 & 0.07 & -61 & 6 \\
6792 & 68115.11 & 2.81 & 0.02 & 5.45 & 0.05 & -61 & 4 \\
7094 & 68115.11 & 2.83 & 0.02 & 5.47 & 0.05 & -52 & 4 \\
5685 & 68815.40 & 2.89 & 0.04 & 5.58 & 0.07 & -54 & 6 \\
6798 & 68815.40 & 2.83 & 0.02 & 5.48 & 0.05 & -62 & 4 \\
7088 & 68815.40 & 2.75 & 0.02 & 5.34 & 0.05 & -59 & 4 \\
7134 & 68815.40 & 2.71 & 0.02 & 5.26 & 0.05 & -63 & 4 \\
& Average & $\mathbf{2 . 7 9}$ & $\mathbf{0 . 0 3}$ & $\mathbf{5 . 3 9}$ & $\mathbf{0 . 0 5}$ & $\mathbf{- 5 9}$ & $\mathbf{1}$ \\
\hline
\end{tabular}

Table D.11: Oxygen isotope data on lunar soil (single measurements, $N=9$ ).

\begin{tabular}{cccccccc}
\hline ID & Sample ID & $\begin{array}{l}\delta^{17} \mathrm{O} \\
(\%)\end{array}$ & $\mathrm{SD}$ & $\begin{array}{l}\delta^{18} \mathrm{O} \\
(\% o)\end{array}$ & $\mathrm{SD}$ & $\begin{array}{l}\Delta^{\prime 17} \mathrm{O} \\
(\mathrm{ppm})\end{array}$ & $\mathrm{SD}$ \\
\hline 5811 & 12001.22 & 2.90 & 0.04 & 5.62 & 0.07 & -66 & 6 \\
5899 & 12001.22 & 3.03 & 0.04 & 5.85 & 0.07 & -51 & 6 \\
7096 & 12001.22 & 2.99 & 0.02 & 5.79 & 0.05 & -61 & 4 \\
7141 & 12001.22 & 2.96 & 0.02 & 5.71 & 0.05 & -53 & 4 \\
5817 & 12010.78 & 2.90 & 0.04 & 5.60 & 0.07 & -51 & 6 \\
5897 & 12010.78 & 2.84 & 0.04 & 5.49 & 0.07 & -53 & 6 \\
7090 & 12010.78 & 2.92 & 0.02 & 5.63 & 0.05 & -46 & 4 \\
7143 & 12010.78 & 2.92 & 0.02 & 5.64 & 0.05 & -50 & 4 \\
7888 & $15421.70 \mathrm{R}$ & 2.94 & 0.02 & 5.69 & 0.05 & -57 & 4 \\
& Average & $\mathbf{2 . 9 3}$ & $\mathbf{0 . 0 2}$ & $\mathbf{5 . 6 7}$ & $\mathbf{0 . 0 3}$ & $\mathbf{- 5 4}$ & $\mathbf{2}$ \\
\hline
\end{tabular}




\section{Supplementary information: Tracing impactor signatures in lunar rocks using triple oxygen isotopes}

Table D.12: Oxygen isotope data on lunar impact rocks (single measurements, $N=32$ ). Sample 60035, 61015, 65055 and 77017 were analysed as WR. Different rock fractions were analysed for the other samples.

\begin{tabular}{cccccccc}
\hline ID & Sample ID & $\begin{array}{l}\delta^{17} \mathrm{O} \\
(\%)\end{array}$ & SD & $\begin{array}{l}\delta^{18} \mathrm{O} \\
(\%)\end{array}$ & SD & $\begin{array}{l}\Delta^{17} \mathrm{O} \\
(\mathrm{ppm})\end{array}$ & $\mathrm{SD}$ \\
\hline 7210 & 60035.64 & 2.61 & 0.03 & 5.05 & 0.06 & -57 & 4 \\
7250 & 60035.64 & 2.75 & 0.03 & 5.32 & 0.06 & -58 & 4 \\
7285 & 60035.64 & 2.59 & 0.03 & 5.04 & 0.06 & -65 & 4 \\
7846 & 60035.64 & 2.79 & 0.03 & 5.41 & 0.06 & -64 & 4 \\
7852 & 60035.64 & 2.76 & 0.03 & 5.35 & 0.06 & -55 & 4 \\
6927 & 60335.159 -sub1-1b & 2.84 & 0.03 & 5.51 & 0.06 & -61 & 4 \\
6921 & 60335.159 -sub1-2m & 2.67 & 0.03 & 5.17 & 0.06 & -59 & 4 \\
6930 & 60335.159 -sub1-2m & 2.69 & 0.03 & 5.23 & 0.06 & -61 & 4 \\
7020 & 60335.159 -sub1-2m & 2.71 & 0.03 & 5.26 & 0.06 & -64 & 4 \\
7188 & 61015.11 & 2.77 & 0.03 & 5.35 & 0.06 & -57 & 4 \\
7208 & 61015.11 & 2.66 & 0.03 & 5.17 & 0.06 & -66 & 4 \\
7244 & 61015.11 & 2.75 & 0.03 & 5.32 & 0.06 & -53 & 4 \\
7291 & 61015.11 & 2.71 & 0.03 & 5.24 & 0.06 & -54 & 4 \\
7183 & 65055.54 & 2.81 & 0.03 & 5.43 & 0.06 & -56 & 4 \\
7202 & 65055.54 & 2.74 & 0.03 & 5.28 & 0.06 & -42 & 4 \\
7251 & 65055.54 & 2.78 & 0.03 & 5.38 & 0.06 & -56 & 4 \\
7282 & 65055.54 & 2.75 & 0.03 & 5.30 & 0.06 & -50 & 4 \\
7000 & 67935.40 -sub1-2b & 2.75 & 0.03 & 5.33 & 0.06 & -57 & 4 \\
6952 & 67935.40 -sub1-3d & 2.79 & 0.03 & 5.41 & 0.06 & -60 & 4 \\
6998 & $67935.40-$ sub1-4m & 2.77 & 0.03 & 5.35 & 0.06 & -53 & 4 \\
7136 & 67935.40 -sub-1-4m & 2.79 & 0.03 & 5.39 & 0.06 & -55 & 4 \\
7025 & 72395.109 -sub1-3g & 2.76 & 0.03 & 5.34 & 0.06 & -55 & 4 \\
7004 & 72935.109 -sub1-4m & 2.64 & 0.03 & 5.11 & 0.06 & -54 & 4 \\
7031 & 72395.109 -sub1-4m & 2.78 & 0.03 & 5.37 & 0.06 & -57 & 4 \\
7008 & 73215.19 -sub1-2-4bf & 2.69 & 0.03 & 5.21 & 0.06 & -59 & 4 \\
6950 & 73215.19 -sub1-2d & 2.78 & 0.03 & 5.37 & 0.06 & -55 & 4 \\
7035 & 73215.19 -sub1-2d & 2.75 & 0.03 & 5.32 & 0.06 & -55 & 4 \\
6946 & 73215.19 -sub1-3m & 2.71 & 0.03 & 5.25 & 0.06 & -60 & 4 \\
7190 & 77017.20 & 2.76 & 0.03 & 5.36 & 0.06 & -64 & 4 \\
7204 & 77017.20 & 2.81 & 0.03 & 5.43 & 0.06 & -57 & 4 \\
7246 & 77017.20 & 2.88 & 0.03 & 5.58 & 0.06 & -60 & 4 \\
7289 & 77017.20 & 2.79 & 0.03 & 5.39 & 0.06 & -55 & 4 \\
& Average & $\mathbf{2 . 7 5}$ & $\mathbf{0 . 0 1}$ & $\mathbf{5 . 3 1}$ & $\mathbf{0 . 0 2}$ & $\mathbf{- 5 7}$ & $\mathbf{1}$ \\
\hline
\end{tabular}

Table D.13: $\delta^{18} \mathrm{O}$ estimates of the impacts rocks $60335,65055,72395$ and 77017 . The estimates are based on the mineral mode of the sample (literature data: 60335, Walker et al. 1973; 65055, Vaniman and Papike 1980; 72395, Dymek et al. 1976; 77017, McCallum et al. 1974) and the oxygen isotope data on mineral separates from the respective Apollo landing site (fig. D.9, see references therein). $\delta^{18} \mathrm{O}_{\text {calc }}$ values represent rough estimates, because the impact rocks are often complex breccias and very heterogeneous (exceptions are impact melt rocks: $60335,65055,67935,77017)$. The sample volumes analysed in this study are small, hence there might be little agreement with the mineral modes described in the literature. Additionally, the reported $\delta^{18} \mathrm{O}_{\text {meas }}$ of 60335 and 72395 are no mean values of WR measurements, but of different fractions. Nevertheless, the comparison between calculated and measured $\delta^{18} \mathrm{O}$ shows a systematic offset towards lower values $(0.2-0.3 \%$ ) .

$* \delta^{18} \mathrm{O}$ of a pure plagioclase separate from 60335

\begin{tabular}{|c|c|c|c|c|c|c|}
\hline & $\begin{array}{l}\delta^{18} \mathrm{O}(\%) \\
\text { Apollo } 16\end{array}$ & $\begin{array}{l}\text { Mineral mode }(\%) \\
\quad 60335\end{array}$ & $\begin{array}{l}\text { Mineral mode }(\%) \\
65055\end{array}$ & $\begin{array}{l}\delta^{18} \mathrm{O}(\%) \\
\text { Apollo } 17\end{array}$ & $\begin{array}{l}\text { Mineral mode }(\%) \\
72395\end{array}$ & $\begin{array}{c}\text { Mineral mode }(\%) \\
77017\end{array}$ \\
\hline Plagioclase & $5.75 /(5.51 *)$ & 70 & 70 & 5.86 & 56 & 75 \\
\hline Pyroxene & 5.52 & 11 & 28 & 5.53 & 31 & 20 \\
\hline Olivine & 4.89 & 17 & 0 & 5.19 & 9 & 5 \\
\hline Ilmenite & 3.8 & 2 & 2 & 4.4 & 1 & 0 \\
\hline$\delta^{18} \mathrm{O}_{\text {calc }}(\% o)$ & & $5.53 /(5.36 *)$ & 5.64 & & 5.54 & 5.76 \\
\hline$\delta^{18} \mathrm{O}_{\text {meas }}(\% o)$ & & 5.29 & 5.35 & & 5.28 & 5.44 \\
\hline
\end{tabular}


Table D.14: Mixing model input — impact rock data. More information on the Ir data can be found in table D.1.

\begin{tabular}{lccccccc}
\hline Sample ID & Description & Apollo & $\begin{array}{l}\mathrm{Ir} \\
(\mathrm{ppb})\end{array}$ & $\begin{array}{l}\delta^{18} \mathrm{O} \\
(\%)\end{array}$ & $\pm 1 \sigma$ & $\begin{array}{l}\Delta^{\prime 17} \mathrm{O} \\
(\mathrm{ppm})\end{array}$ & $\pm 1 \sigma$ \\
\hline 60035.64 & Polymict anorthositic breccia & 16 & 7.5 & 5.48 & 0.03 & -60 & 5 \\
60335.16 & Basaltic impact melt rock & 16 & 17.9 & 5.54 & 0.03 & -61 & 4 \\
61015.11 & Dimict breccia (impact melt rock component) & 16 & 35.4 & 5.52 & 0.03 & -58 & 4 \\
65055.54 & Basaltic impact melt rock & 16 & 8.8 & 5.60 & 0.03 & -51 & 4 \\
67935.40 & Basaltic impact melt rock with glass veins & 16 & 16.7 & 5.62 & 0.03 & -56 & 4 \\
68115.11 & Glassy polymict breccia & 16 & 0.0 & 5.62 & 0.03 & -58 & 3 \\
68815.40 & Oriented glassy polymict breccia & 16 & 11.4 & 5.66 & 0.03 & -59 & 4 \\
72395.11 & Impact melt breccia & 17 & 7.8 & 5.53 & 0.03 & -55 & 3 \\
73215.19 & Aphanitic impact melt breccia & 17 & 2.5 & 5.54 & 0.03 & -57 & 4 \\
77017.20 & Feldspathic granulitic impactite & 17 & 12.0 & 5.69 & 0.03 & -59 & 4 \\
\hline
\end{tabular}

Table D.15: Mixing model input - meteorite data. Given are mean values based on a data compilation, which comprised results reported in Clayton et al. (1976), Clayton and Mayeda (1983), Clayton et al. (1983b, 1991), Rowe et al. (1994), Clayton and Mayeda (1996, 1999), Herwartz et al. (2014) and data from the Meteoritical Bulletin Database (https://www.lpi.usra.edu/meteor/, February 2020 ). In order to take the intrinsic oxygen isotope variation in the composition of the meteorite types into account the $\pm 1 \sigma$ SD was used to assess the uncertainty. Abbreviations are explained in the list of abbreviations.

\begin{tabular}{cccccc}
\hline Meteorites & Class & $\begin{array}{c}\delta^{18} \mathrm{O} \\
(\%)\end{array}$ & SD & $\begin{array}{c}\Delta^{\prime 17} \mathrm{O} \\
(\mathrm{ppm})\end{array}$ & $\mathrm{SD}$ \\
\hline CI & Carbonaceous chondrites & 17.2 & 1.7 & 226 & 252 \\
CM & Carbonaceous chondrites & 9.1 & 5.2 & 2625 & 1152 \\
CB, CK, CO, CR, CV, CH & Carbonaceous chondrites & 0.1 & 2.8 & -3924 & 1267 \\
H, L, LL & Ordinary chondrites & 4.95 & 0.8 & 851 & 288 \\
EH, EL & Enstatite chondrites & 5.9 & 0.6 & -37 & 89 \\
R & Other chrondrites & 5.1 & 1 & 2730 & 328 \\
K & Other chrondrites & 4.9 & 1.7 & -1404 & 560 \\
Aca, Lod & Primitive achondrites & 3.4 & 0.7 & -1050 & 171 \\
Win & Primitive achondrites & 5.1 & 0.6 & -532 & 98 \\
Bra & Primitive achondrites & 4.6 & 0.6 & -218 & 83 \\
Ure & Primitive achondrites & 7.2 & 1.1 & -1211 & 627 \\
Aub & Asteroidal achondrites & 5.3 & 0.2 & -68 & 117 \\
Ang & Asteroidal achondrites & 3.9 & 0.4 & -91 & 100 \\
HED & Asteroidal achondrites & 3.66 & 0.5 & -270 & 82 \\
SNC & Asteroidal achondrites & 4.8 & 0.7 & 281 & 133 \\
Pal & Stony-iron meteorites & 3.2 & 0.4 & -310 & 182 \\
Pal PES & Stony-iron meteorites & -2.4 & 0.4 & -4650 & 496 \\
Mes & Stony-iron meteorites & 3.7 & 0.4 & -264 & 67 \\
IAB & Iron meteorites & 4.6 & 0.6 & -574 & 276 \\
IVA & Iron meteorites & 4.7 & 0.12 & 1154 & 76 \\
IIE & Iron meteorites & 4.3 & 0.5 & 559 & 98 \\
IIAB, IIID, IIICD & Iron meteorites & 5.7 & 1.1 & -488 & 49 \\
IIIAB & Iron meteorites & 2.3 & 0.3 & -212 & 47 \\
Recent mix & & 4.5 & - & 652 & - \\
\hline
\end{tabular}


D Supplementary information: Tracing impactor signatures in lunar rocks using triple oxygen isotopes

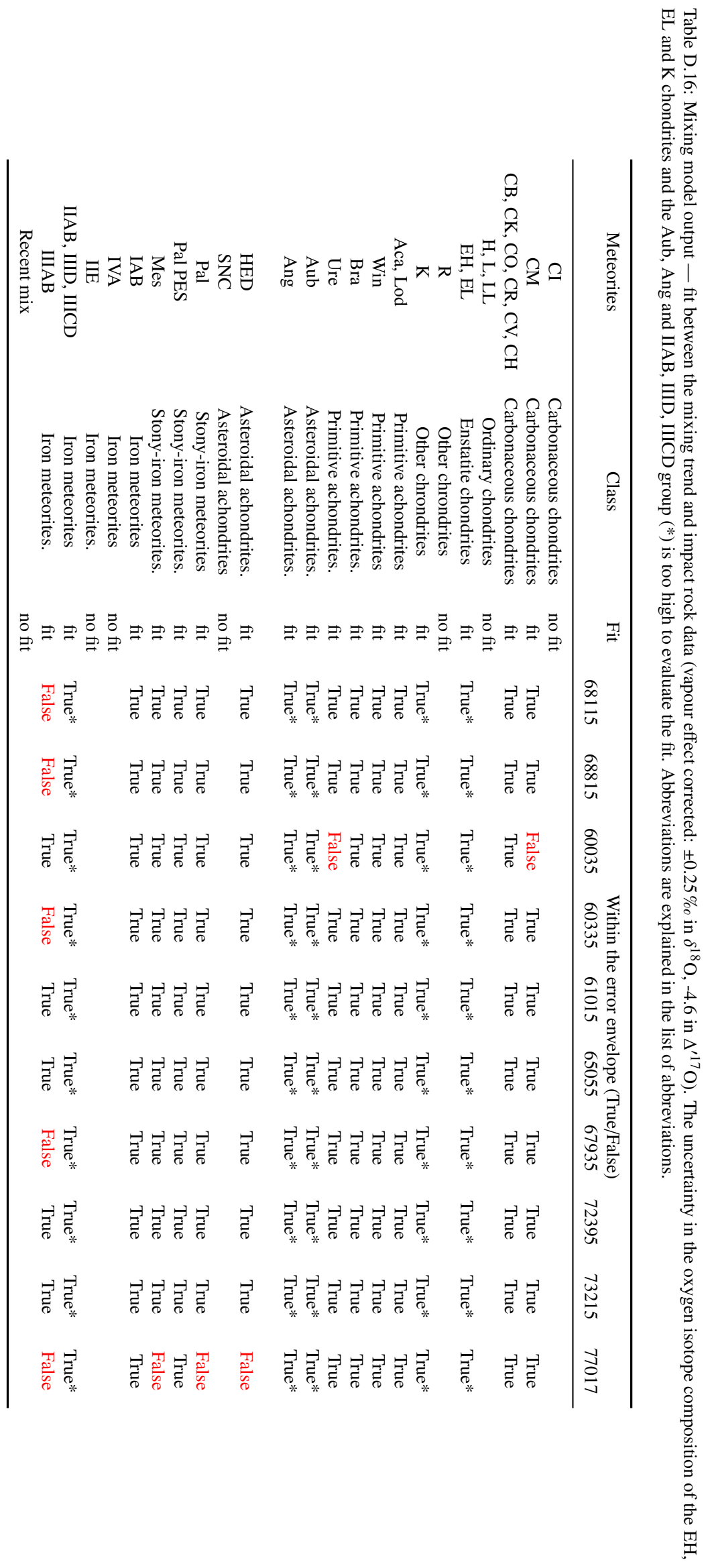


Table D.17: Mixing model output — average mixing ratios (\%) of the Apollo 16 and Apollo 17 impact rock samples. The values are derived from the mixing model. The errors were assessed by means of a Monte Carlo simulation $(N=1000)$. In red highlighted are errors which strongly exceed the value of the respective mixing ratio, hence those values are unreliable. Abbreviations are explained in the list of abbreviations.

\begin{tabular}{ccccc} 
Meteorites & Apollo 16 samples & SD $_{\text {MC }}$ & Apollo 17 samples & SD $_{\text {MC }}$ \\
\hline CB, CK, CO, CR, CV, CH & 0.3 & 0.5 & 0.3 & 1.2 \\
CM & 0.4 & 5.8 & 0.4 & 5.0 \\
Aca, Lod & 1.1 & 0.3 & 1.0 & 0.3 \\
Win & 2.3 & 0.8 & 2.1 & 0.7 \\
Bra & 7 & 58 & 6 & 82 \\
Ure & 1 & 99 & 0.9 & 40 \\
HED & 5 & 22 & 5 & 30 \\
\hline
\end{tabular}





\section{Acknowledgements}

First of all, I want to express my gratitude to my supervisors Andreas Pack, Paul Hartogh and Stefan Peters for their support and advice during my PhD project. You fostered my interest in isotope geology and cosmochemistry, you helped me to advance my skills and to make this project a success. Thank you. The supervision of a junior scientist can be challenging and I am truly grateful for your patience and time.

I thank the NASA Johnson Space Center for providing lunar samples from the Apollo missions. I also greatly appreciate that Thorsten Kleine from the University of Münster, Zachary Sharp from the University of New Mexico and Harry Becker and Philipp Gleißner from the FU Berlin shared lunar sample material with us to promote the scientific research on the Moon. I also want to thank Gerhard Wörner from the University of Göttingen, Kristoffer Szilas from the University of Kopenhagen and Jens Gutzmer from the Helmholtz Institute Freiberg for Research Technology for the provision of terrestrial feldspar-rich samples. The project would not have been possible without this comprehensive sample set of lunar and terrestrial rocks. Thank you.

I would like to thank Tommaso di Rocco, Dennis Kohl, Axel Dierschke, Benjamin Maksumic and Fabian Zahnow for their support in the stable isotope laboratories. I enjoyed a lot to work in this state-of-the art facilities. I also want to express my gratitude to my other colleagues from the isotope department of the University Göttingen: Jakub Surma, Dingsu Feng, Oliver Jäger, Nils Meßling and Rachel Bezard. You supported me with your company and advice during our laboratory and scientific meetings, the coffee and lunch breaks. Thank you. I am also grateful for the support I have received by Andreas Kronz and Jochen Gätjen during my electron microprobe studies.

I would like to thank all my past and present colleagues from the Geoscience Center and Max Planck Institute of Solar System Research. I felt always supported and home in both institutes. I also want to express my gratitude to the IMPRS and Sonja Schuh for the support and input. Special thanks go to Nina Albrecht and Jakub Surma, who read my dissertation drafts and gave me helpful comments. I appreciate your effort and hope I can repay it in time.

Finally, I wish to thank my family and all my friends who encouraged and supported me. 



\section{Curriculum vitae}





\section{Meike Fischer}

Date of birth

Place of birth
09.07.1991

Hann. Münden, Germany

\section{Academic career}

2017 - 2021 DOCTORATE Max Planck Institute for Solar System Research, Geoscience Center Göttingen

$2017-2014$

GEOSCIENCES Georg-August-University Göttingen

M.Sc.

$2014-2011$

GEOSCIENCES Georg-August-University Göttingen

B.Sc.

$2011-2004$

HIGH SCHOOL Grotefend Gymnasium Hann. Münden

Abitur

\section{Graduate theses}

DISSERTATION (2021)

"Triple oxygen isotope study on the Earth-Moon system"

MASTER THESIS (2017)

"Reconstruction of paleo-atmospheric $\mathrm{CO}_{2}$ levels using fossil cosmic spherules"

BACHELOR THESIS (2014)

"High-precision measurements of $\mathrm{CO}_{2}{ }^{17} \mathrm{O} /{ }^{16} \mathrm{O}$ ratios for carbonate analysis based on isotope equilibration of $\mathrm{CO}_{2}$ and $\mathrm{H}_{2} \mathrm{O}$ "

\section{Professional development}

2018

2018

2017

2017

2016

2016

$2015-2017$
Teaching: „Massenspektrometrie“, graduate level course, Geoscience Center Göttinen (1 week) TRR170 Summer School „Origin of the Earth-Moon-System“(DFG funded)

Teaching: Supervision of a Bachelor student (6 month)

TRR170 Summer School „Impact Processes in the Solar System“(DFG funded)

Course: "In-situ isotope and trace element analyses with (MC-) ICP-MS coupled to a femtosecond laser ablation system", Leibniz University Hannover

Internship: Alfred-Wegener-Institut Helmholtz Zentrum für Polar- und Meeresforschung, glaciology divison, Bremerhaven

Topic:

- Analysis of a snow profile from Greenland based on various physical and chemical parameters and the comparison between ion chromatography and mass spectrometry

Student assistant for the stable isotope geology division, Geoscience Center Göttingen

Topic:

- Assistance in the construction of a water reactor and the execution of triple oxygen isotope analyses

- Execution of triple oxygen isotope analyses of minerals and rock samples (laser fluorination technique) 


\section{Grants \& Awards}

2012

2016

2017

2018

2018

2019
Travel grant for the „Euroscience Open Forum“ (ESOF) in Dublin (Robert Bosch Stiftung)

Travel grant for the Barberton field workshop SPP1833 „Building a Habitable Earth“ in South Africa Travel grant for the Pilbara field workshop SPP1833 „Building a Habitable Earth“ in Australia Talk at the Annual meeting of the DMG-sections Geochemistry, Petrology and Petrophysics in Göttingen awarded with the DMG student award (2 ${ }^{\text {nd }}$ prize)

Travel grant for the Abitibi field workshop SPP1833 „Building a Habitable Earth“ in Canada Talk at the Annual meeting of the DMG-sections Geochemistry, Petrology and Petrophysics in Heidelberg awarded with the DMG student award (1 $1^{\text {st }}$ prize) 


\section{Publications}

\section{Refereed publications}

- Fischer M.B., Oeser M., Weyer S., Folco L., Peters S.T.M., Zahnow F., Pack A. (2021) I-type cosmic spherules as proxy for the $\Delta^{\prime 17} \mathrm{O}$ of the atmosphere - Calibration with Quaternary air. Paleoceanography and Paleoclimatology, 36, e2020PA004159.

- Fischer, M.B., Maksumic B., Peters, S.T.M., Hartogh, P., Pack, A. (in prep.) Triple oxygen isotope fractionation in feldspar-rich rocks. Contributions to Mineralogy and Petrology.

- Peters, S.T.M, Fischer, M.B, Pack, A., Szilas, K., Appel, P.W.U, Münker, C., Dallai, L., Marien, C.S. (2021) Tight bounds on missing late veneer in early Archean peridotite from triple oxygen isotopes. Geochemical Perspective Letters, 18, $27-31$.

- Fischer, M.B., Peters, S.T.M., Herwartz, D., Hartogh, P., Pack, A. (in prep.) A cannon ball impact model of Moon formation and the nature of the earliest meteorites. Proceedings of the National Academy of Sciences of the United States of America.

- Bischoff, A., O’D Alexander, C.M., Barrat, J.-A., Burkhardt, C., Busemann, H., Degering, D., Di Rocco, T., Fischer, M., Fockenberg, T., Foustoukos, D.I., Gattacceca, J., R. A. Godinho, J., Harries, D., Heinlein, D., Hellmann, J.L., Hertkorn, N., Holm, A., Timothy Jull, A.J., Kerraouch, I., King, A.J., Kleine, T., Koll, D., Lachner, J., Ludwig, T., Merchel, S., A. K. Mertens, C., Morino, P., Neumann, W., Pack, A., Patzek, M., Pavetich, S., Reitze, M.P., Rüfenacht, M., Rugel, G., Schmidt, C., Schmitt-kopplin, P., Schönbächler, M., Trieloff, M., Wallner, A., Wimmer, K., Wölfer, E. (2021) The old, unique C1 chondrite Flensburg - insight into the first processes of aqueous alteration, brecciation, and the diversity of water-bearing parent bodies and lithologies. Geochimica et Cosmochimica Acta, 293, 142-186.

\section{Conference proceedings}

(own contributions only)

- Fischer, M.B., Pack, A., Oeser, M., Weyer, S., Peters, S.T.M, Folco, L. (2017) Reconstructing the oxygen isotope composition of the upper atmosphere using cosmic spherules. Paneth Kolloquium. Nördlingen, Germany. [Talk] 
- Fischer, M.B., Pack, A., Oeser, M., Weyer, S., Peters, S.T.M, Folco, L. (2018) Reconstructing the oxygen isotope composition of the upper atmosphere using cosmic spherules. Annual meeting of the DMG-sections Geochemistry, Petrology and Petrophysics. Göttingen, Germany. [Talk, awarded with the DMG student award (2nd price)]

- Fischer, M.B., Maksumic, B., Peters, S.T.M, Sengupta, S., Hartogh, P., Pack, A. (2018) Oxygen isotope fractionation in equilibrated high-temperature feldspar-rich rocks. GeoBonn 2018, Bonn, Germany. [Poster]

- Fischer, M.B., Peters, S.T.M, Hartogh, P., Pack, A. (2019) Investigating the $\Delta^{\prime 17} \mathrm{O}$ variation of different lunar lithologies using high-precision oxygen isotope measurements. Annual meeting of the DMG-sections Geochemistry, Petrology and Petrophysics. Heidelberg, Germany. [Talk, awarded with the DMG student award (1st prize)]

- Fischer, M.B., Peters, S.T.M, Hartogh, P., Pack, A. (2019) New high-precision triple oxygen isotope measurements of lunar rocks. Goldschmidt Conference 2019, Barcelona, Spain. [Poster]

- Fischer, M.B., Peters, S.T.M, Hartogh, P., Pack, A. (2019) The triple oxygen isotope composition of lunar rocks. GeoMünster 2019. Münster, Germany. [Talk]

- Fischer, M.B., Peters, S., Hartogh, P., Pack, A. (2019) Triple oxygen isotope comparison between terrestrial and lunar rocks - implications for the lunar formation. Paneth Kolloquium. Nördlingen, Germany. [Poster]

- Fischer, M.B., Peters, S.T.M, Hartogh, P., Pack, A. (2020) Triple oxygen isotope comparison between Earth and Moon revisited. LPSC. Houston, Texas. [Abstract]

- Fischer, M.B., Peters, S.T.M, Hartogh, P., Pack, A. (2020) A triple oxygen isotope study on the Moon. GeoKolloquium. Göttingen, Germany. [Talk] 